Illinois State University

ISU ReD: Research and eData

Theses and Dissertations

$3-12-2020$

\title{
Reconsidering Undergraduate Anatomy and Physiology Curriculum
}

Eric Michael Walsh

Illinois State University, emwalsh333@gmail.com

Follow this and additional works at: https://ir.library.illinoisstate.edu/etd

Part of the Biology Commons, Physiology Commons, and the Science and Mathematics Education Commons

\section{Recommended Citation}

Walsh, Eric Michael, "Reconsidering Undergraduate Anatomy and Physiology Curriculum" (2020). Theses and Dissertations. 1217.

https://ir.library.illinoisstate.edu/etd/1217

This Thesis is brought to you for free and open access by ISU ReD: Research and eData. It has been accepted for inclusion in Theses and Dissertations by an authorized administrator of ISU ReD: Research and eData. For more information, please contact ISUReD@ilstu.edu. 
RECONSIDERING UNDERGRADUATE ANATOMY AND PHYSIOLOGY CURRICULUM

\section{ERIC M. WALSH}

\section{Pages}

In the past 50 years several convergent factors have spurred unprecedented change in anatomy and physiology (A\&P) instruction. An explosion of biomedical knowledge, an increased demand for students well-versed in A\&P, and decreased resources for the course has provoked a vast array of research. However, most studies employ one of three strategies to enact change: testing the effectiveness of new pedagogies, exploring the utility of new technologies, or documenting learning in new contexts. By comparison, a much smaller body of research focuses on changing the A\&P curriculum to improve student learning. To address this gap, the musculoskeletal laboratory curriculum for an undergraduate A\&P course was revised to align with evidenced-based pedagogical practices, ground it in learning theories, and promote learning in context. Students perceptions and values related to the course were measured via the Anatomy Learning Experiences Questionnaire (ALEQ) and interviews, while student learning was measured via concept maps. Students reported the value of understanding how structures work together as opposed to memorizing what structures are because they see it as relevant to their future careers. Introducing students to the concept of functionally bound structures in conjunction with the curricular changes, may be a fruitful way of fostering students' understanding of the how of A\&P, while still arriving at the same knowledge of vocabulary. Future research should assess the curricular changes utilized across different institutional contexts, student populations, and content to explore their viability. 
KEYWORDS: Anatomy, Physiology, Undergraduate, Curriculum, Functionally-bound structures, Education 
RECONSIDERING UNDERGRADUATE ANATOMY AND PHYSIOLOGY CURRICULUM

ERIC M. WALSH

A Thesis Submitted in Partial Fulfillment of the Requirements for the Degree of

MASTER OF SCIENCE

School of Biological Sciences

ILLINOIS STATE UNIVERSITY

2020 
(C) 2020 Eric M. Walsh 
RECONSIDERING UNDERGRADUATE ANATOMY AND PHYSIOLOGY CURRICULUM

ERIC M. WALSH

COMMITTEE MEMBERS:

Rebekka L. Darner, Chair

Rachel Bowden

Peter Smith

Betsy Wargo 


\section{ACKNOWLEDGMENTS}

I would like to thank everyone who I've had the opportunity to cross paths with in life, your words, wisdom, and warmth have not been lost on me and they've made me who I am today. Sincerely, I thank you. Although you may not read this, know that you made an influence in someone's life. I would particularly like to thank all the educators that have left lasting impressions on me, especially Chris, Janice, Steve, Chris, Pete, Anna, Karen, Betty, Tony, Dan, Kristen, Dave, Mike, Steve, Kevin, Victor, Diane, Paul, Alison, Gavin, Tony, Tom, Scott, Laura, Nate, and Dan. The most important acknowledgment goes out to the ones I love: my family, my friends, and all those I hold dear. Thank you, Mom, for teaching me empathy, patience, and love. Thank you, Dad, for teaching me values, hard-work, and love. Thank you to my sisters for always being there and allowing me to learn what it means to be a brother, uncle, and friend. Thank you to Taylor for the continued laughs, good times, love, and support, I look forward to many more in our future. Thank you to my lab for the everything throughout my journey with you these past three years. It is with great respect and a heavy heart that I leave the lab, as you've truly made these past years a joy and made me a better person. I can already feel the nostalgia creeping in as I begin to reflect on my time here and will miss you dearly. Thank you for everything once again and I look forward to seeing what all of you achieve in your futures:

Rachel, Kara, Iresha, Amanda, Tanya, and Bekky. "Thank you" is not strong enough a phrase to convey my gratitude towards Bekky, so just know that you have been a role-model, instrumentally shaped who a part of who I am today, and helped me grow far beyond what I could've ever expected. Last, but most definitely not least, I would like to thank Barb, Bryce, Amy, Jeff, Betsy, Patrick, Bethany, Anne, and Mina, as well as Kona, Ooga, and Roo.

E.M.W. 


\section{CONTENTS}

ACKNOWLEDGMENTS

$\begin{array}{lll}\text { CONTENTS } & \text { ii }\end{array}$

TABLES - vi

FIGURES vii

CHAPTER I: INTRODUCTION 1

Literature Review $\quad 1$

$\begin{array}{ll}\text { Study Rationale } & 7\end{array}$

CHAPTER II: CONCEPTUAL FRAMEWORK 99

$\begin{array}{ll}\text { Complex Systems Theory } & 9\end{array}$

$\begin{array}{ll}\text { Embodied Cognition } & 12\end{array}$

$\begin{array}{ll}\text { Learning In-context } & 14\end{array}$

$\begin{array}{ll}\text { Evidenced-based Pedagogical Practices } & 16\end{array}$

$\begin{array}{ll}\text { Guided Inquiry } & 17\end{array}$

$\begin{array}{ll}\text { Flipped Labs } & 17\end{array}$

$\begin{array}{ll}\text { Active Learning } & 18\end{array}$

$\begin{array}{ll}\text { Conceptual Framework Summary } & 18\end{array}$

$\begin{array}{ll}\text { CHAPTER III: METHODOLOGY } & 19\end{array}$

$\begin{array}{lr}\text { Curricular Change } & 19\end{array}$

Complex Systems Theory Applications 19

$\begin{array}{ll}\text { Embodied Cognition Applications } & 20\end{array}$

$\begin{array}{ll}\text { Learning In-context } & 22\end{array}$ 
$\begin{array}{ll}\text { Evidenced-based Pedagogical Practices } & 22\end{array}$

$\begin{array}{ll}\text { Active Learning } & 22\end{array}$

$\begin{array}{ll}\text { Guided Inquiry } & 23\end{array}$

$\begin{array}{ll}\text { Flipped Labs } & 24\end{array}$

$\begin{array}{ll}\text { Curricular Change Summary } & 24\end{array}$

$\begin{array}{ll}\text { Experimental Curriculum } & 24\end{array}$

$\begin{array}{ll}\text { Comparison Curriculum } & 25\end{array}$

Curriculum Prior to Both Treatments 25

$\begin{array}{ll}\text { Research Questions } & 26\end{array}$

$\begin{array}{ll}\text { Q1 } & 26\end{array}$

Q2 26

Q3 26

$\begin{array}{ll}\text { Experimental Design } & 27\end{array}$

$\begin{array}{ll}\text { Participants } & 27\end{array}$

$\begin{array}{ll}\text { Research Setting } & 28\end{array}$

Implementation of Instructional Treatments 28

$\begin{array}{ll}\text { Data Collection } & 29\end{array}$

Data Collection Summary $\quad 32$

$\begin{array}{ll}\text { Data Analysis } & 32\end{array}$

$\begin{array}{ll}\text { ALEQ } & 32\end{array}$

$\begin{array}{ll}\text { Interviews } & 36\end{array}$

$\begin{array}{ll}\text { Concept Maps } & 37\end{array}$

Summary of Methods $\quad 39$ 
CHAPTER IV: STUDENTS' DISPOSITIONAL SHIFTS IN RESPONSE TO

UNDERGRADUATE MUSCULUOSKELETAL LABORATORY CURRICULA 40

$\begin{array}{lr}\text { Abstract } & 40\end{array}$

$\begin{array}{ll}\text { Introduction } & 41\end{array}$

$\begin{array}{ll}\text { Material and Methods } & 45\end{array}$

$\begin{array}{ll}\text { Research Setting } & 46\end{array}$

$\begin{array}{ll}\text { Participants } & 47\end{array}$

$\begin{array}{ll}\text { Implementation of Instructional Treatments } & 47\end{array}$

$\begin{array}{ll}\text { Data Collection } & 47\end{array}$

$\begin{array}{ll}\text { Data Analysis } & 49\end{array}$

$\begin{array}{lr}\text { ALEQ } & 50\end{array}$

$\begin{array}{ll}\text { Interviews } & 50\end{array}$

$\begin{array}{ll}\text { Concept Maps } & 51\end{array}$

$\begin{array}{ll}\text { Results } & 52\end{array}$

$\begin{array}{ll}\text { ALEQ } & 52\end{array}$

$\begin{array}{ll}\text { Interviews } & 53\end{array}$

$\begin{array}{ll}\text { Career Goals } & 53\end{array}$

A Lot $\quad 53$

$\begin{array}{ll}\text { Overwhelmed/Frustrated } & 54\end{array}$

$\begin{array}{ll}\text { Memorization or Exclusion } & 54\end{array}$

How $\quad 55$

$\begin{array}{ll}\text { Student Architypes } & 55\end{array}$

$\begin{array}{ll}\text { Concept Maps } & 56\end{array}$ 
$\begin{array}{ll}\text { Discussion } & 58\end{array}$

Conclusions and Research Prospects $\quad 61$

$\begin{array}{ll}\text { Literature Cited } & 63\end{array}$

$\begin{array}{ll}\text { REFERENCES } & 70\end{array}$

APPENDIX A: INTERVIEW TRANSCRIPTS 77

APPENDIX B: INTERVIEW PROTOCOLS 362

APPENDIX C: ACTIVITY SHEETS

$\begin{array}{ll}\text { APPENDIX D: CODE BOOK } & 376\end{array}$ 


\section{TABLES}

Table

Page

1. Results of instructor effect testing means represent percent change in student ALEQ responses over time, in comparison treatment students, across two different instructors. Standard deviations, sample sizes, and pvalues are also included.

2. Means and standard deviations for statistically significantly different items from spring administration of the ALEQ, which informed the fall 2019 interview protocol.

3. Variances and p-values from homogeneity of variance tests on the four statistically significant items from spring 2019.

4. Means, standard deviations, sample sizes, and p-value from comparison of fall and spring pre-questionnaire data, conducted to validate poolability across semesters.

5. Means, standard deviations, sample sizes, and p-value from homogeneity of variances test, used to determine the type of $t$ test utilized to assess poolability.

6. Assumption of normality for MIXED ANOVA test results including test, statistic, degrees of freedom, and the p-value.

7. Variances and $p$-values from homogeneity of variance tests on individual factors within the matched and pooled ALEQ post questionnaire data, analyzed across treatments.

8. Summary of conceptual framework including: guiding theories, practices, and perspectives; the tenets of each concept; and the instructional implications of each concept.

9. Results of concept maps including treatment, student pseudonym, interview, classifying information, and classifications. 


\section{FIGURES}

Figure

Page

1. Breadth of physiology across levels of biological organization. 10

2. Demographics of students who completed the pre-questionnaire. 27

3. Results of MIXED ANOVA on matched and pooled overall average ALEQ scores with means and standard error bars.

4. Normality plots of matched and pooled ALEQ data. (a) shows the plot for the comparison treatment pre, (b) shows the experimental treatment pre, (c) shows the comparison treatment post, (d) shows the experimental treatment post.

5. Results of comparisons of average ALEQ scores within factors and across treatments, displaying means and standard error bars.

6. $\quad$ Proposed laboratory sequence 


\section{CHAPTER I: INTRODUCTION}

\section{Literature Review}

For nearly hundreds of years, if not thousands, anatomy and physiology (A\&P) instructors have been tasked with integrating new discoveries into the curriculum and unveiling the nuanced complexity of human form and function to their students. However, during the last 50 years, educators have had to grapple with unprecedented change brought on by several convergent factors. There has been an explosion of biomedical knowledge that has saturated the anatomical and physiological curriculum with content (Leaung et al., 2006). Simultaneously, there is an increasing demand for primary and allied healthcare providers well-versed in A\&P (Kuyatt \& Baker, 2014). This demand is taking place in the face of decreased resources such as scarce cadaveric dissections, fewer qualified instructors, decreasing funds, and less time being dedicated to the course (Kuyatt \& Baker, 2014; Mitchell \& Batty, 2009; Mitrousias et al., 2018; Drake et al., 2009). Together these factors have necessitated educational reform in A\&P and provided the impetus for an array of research. However, most research in this field employs one of three strategies to enact change: testing the effectiveness of new pedagogies, exploring the utility of new technologies, or documenting learning in new contexts. Studies that seek to test the effectiveness of novel pedagogical approaches have examined pedagogical tools such as body painting, clay models, and 3D printing (Finn \& McLachlan, 2010; Motoike et al., 2009, McMenamin et al., 2014). Research assessing the utility of integrating technological advances has examined virtual reality modeling, 3D software, online discussions, and online instructional videos (Codd \& Choudbury, 2011; Mitrousis et al., 2018; Green et al., 2013; Langfield et al., 2017). Lastly, investigators exploring the potential benefits of an altered learning contexts have examined learning in blended courses, when near-peer teaching is used, or in interdisciplinary 
learning (Green \& Whitburn, 2016; Evans \& Cuffe, 2009; Hamilton et al., 2008). While these three strategies to enact change are not mutually exclusive, they all share the same overarching goal of improving how students engage with an A\&P curriculum that is relatively similar across these lines of research. For this study curriculum refers to the sequence and organization of content covered in the course, while pedagogy refers to how that content is taught.

By comparison, a much smaller body of literature focuses on changing the A\&P curriculum to improve student learning. This less common approach is somewhat surprising, because in response to the explosion of biomedical knowledge over the past decades, numerous initiatives, studies, and national reports have outlined the shortcomings of the conventional instructional model that dominates the discipline (AAMC, 1984; GMC, 1991; GMC; 1993 ACME-TRI, 1993; AAMC-HHMI, 2009; AMSA, 2006; Drake, 1998; Gibbs, 1992; Casotti et al., 2008). The conventional model is teacher-centered and lecture-based; the instructor is positioned as the expert or gatekeeper of knowledge, while students are positioned as passive recipients of content. Content in this model is traditionally organized through a regional approach (e.g., limbs and thorax are explored as individual units) and necessitates an unwieldy amount of lecture hours to be delivered (Heylings, 2002; Ettarh, 2014). In this way, the conventional model demands memorization to cope with the large amount of information, provides few opportunities for students to relate information to their future careers or lives, and lacks integration across disciplines (Drake, 1998). Labs in the conventional model are typically procedure-driven with detailed step-by-step instructions through which students lack opportunity to experience discovery, become knowledge generators, and engage in scientific practices (Casotti et al., 2008). Additionally, this model is self-perpetuating, fueled by; a heavy workload, a large amount of material, little opportunity to pursue topics in depth, little choice over the topics or methods of 
study, and anxiety-provoking assessments that reward simple recall of facts. These five undesirable curricular aspects synthesize to compel surface-level memorization rather than meaningful understanding (Gibbs, 1992). Additionally, the conventional model often preserves the notion that if A\&P instructors are experts of the content, they then must be effective educators. However, there is much research supporting the conception that experts do not reliably employ teaching practices that are known to be effective in fostering student learning (Berman, 2015; Bain, 2004).

In response to the conventional model, some studies have put forth guidelines for instructional change. These guidelines call for student-centered, active learning that takes place through variety of multi-modal experiences (Drake, 2014; Lowry 1992; Darda, 2010; Sugand et al., 2010; Drake \& Pawlina, 2014). The guidelines stress learning in context and revisiting material more than once (Drake, 2014; Wilkerson et al., 2009). Creating integrated courses that facilitate interdisciplinary and community-based learning is highly recommended (Drake, 2014; Lowry 1992). These guidelines for change in A\&P education have manifested as two alternative curricular models: the problem-based curricular model and the systems-oriented curricular model. In the problem-based model, students are actively involved in identifying learning objectives, selecting learning resources, and setting boundaries for individual study, through a problem-solving lens (Drake, 1998). Additionally, students' learning in the problem-based model is compelled by their collaborative work to solve a problem that feels authentic to their future careers. The systems-oriented model primarily changes how material is organized, while instruction usually adheres to the conventional lecture-based approach and still positions students in a passive role. However, systems-based courses move through each system in the body, as opposed to regionally analyzing the human form and usually involve the integration of several 
disciplines (Drake, 1998). Today, the systems-based curricular model is common in A\&P courses. A 2002 survey of 28 departments across the UK and Ireland that teach A\&P found that 12 courses were systems-based, 5 were problem-based, and 4 operated under the conventional model (Heylings, 2002).

The systems-based approach may not be an improvement on the conventional model, as some research has even demonstrated it to harm student performance (McKeown et al., 2003). Recognizing this, several scholars claim that the ideal curriculum is likely a hybridization and modernization of all three approaches (Drake, 1998; Nayak et al., 2008) Moreover, the ideal curriculum would differ in every program, as it should be carefully constructed to meet the needs of the students, faculty, and institution (Drake, 1998).

Despite this call for course customization, a handful of studies have identified and verified curricular components that seem to be universally beneficial. First, educators agree that success hinges on learning concepts rather than memorizing facts, but A\&P students believe that the course requires incessant memorization (Miller et al., 2002). Therefore, there is a call to reduce the amount of factual material students must memorize and scaffold the connections they should make between new material and material they have already learned (Griff, 2016; Darda, 2010). Additionally, inquiry-based labs have reliably shown to improve students critical and analytical thinking skills and break them out of memorization habits, and this has been documented in A\&P labs (Casotti et al., 2008).

Even with guidelines providing a framework for curricular change and research identifying and validating pedagogical approaches, instructional change lags because lasting and substantial curricular change is very difficult to achieve (Silverthorn et al., 2006; Drake, 1998; Mattheis \& Jensen, 2014). In 2006, the Integrative Themes in Physiology (ITIP) project, funded 
by the National Science Foundation (NSF), was a collaboration between the American Physiological Society (APS) and the Human Anatomical and Physiological Society (HAPS). The goal of the project was to create active learning resources that undergraduate A\&P instructors could incorporate into their curricula. Throughout the course of the study 17 of the 36 volunteer instructors withdrew, and remaining instructors failed to use the modules created during the program. The remaining instructors reported "lack of support from academic leadership, unplanned class size increases and heavy teaching loads, a union strike, insufficient time to develop a mindset for change, inadequate technology/funding, an adverse human subjects ruling, incompatibility of module's with instructors' established content and expectations, and personal factors" prohibited their use of the modules (Silverthorn et al., 2006 pg. 204). As the findings from the ITIP demonstrate, understanding why curriculum stagnates is a dynamic and complex issue as there are factors operating on institutional, pedagogical, and personal levels.

Nonetheless, factors potentially contributing to the inert state of A\&P curricula deserve to be postulated. First, A\&P instruction is historically a-theoretical. As one of the oldest disciplines in the 'hard' sciences the very foundations of A\&P instruction are experiential. Educational and learning theory did not inform early A\&P instruction; rather, the experiences instructors had with A\&P informed their instruction. This was simply a product of the times in which A\&P was founded, as learning and educational theories were not robustly understood yet. Nevertheless, without being informed by educational literature, instruction in A\&P classrooms became direct and didactic. This instruction was likely effective when situated in the context of cadaveric or other dissections that were once commonplace, but as the opportunities for hands-on A\&P instruction have dwindled, didactic lecturing has remained and likely replaced hands-on instructional time. Although A\&P instructors try their best to explain things in a manner that 
students can grasp, direct and didactic lecture-based instruction, for which there is little evidence to support its effectiveness, dominates today. In this way, the roughly 2,000 years of experiential instruction in which this discipline was constructed may serve as historical inertia that generates contemporary barriers to instructional change. These barriers may also be compounded by the fact the A\&P scholars have only recently begun to inform their instruction with educational theory. Groundbreaking curricular change is unlikely to happen quickly as the ITIP shows and the enormous amount of complicated content that must be revamped only serves to make this a more daunting task. A second factor possibly contributing to the lack of curricular change is that those who have taken and then teach A\&P may sometimes harbor a "rite-of-passage-mentality." In other words, they believe that because they struggled to get through the course, they feel that future students must struggle also, so they work to preserve the conventional model. A third factor opposing curricular change in $\mathrm{A} \& \mathrm{P}$ is the presence of readily accessible resources (e.g. textbooks, exams, standards) that perpetuate the current manner of instruction. These "teacherproof" packages deskill and devalue the role of the instructor as a transformative intellectual by having educators simply implementing predetermined content and instructional procedures (Giroux, 2002). Lastly, as the ITIP findings began to elucidate, A\&P curriculum is deeply institutionalized. There is a status quo of content that decision-makers often feel must be covered in an undergraduate A\&P course. This likely stems from an altruistic motive of providing students with the content knowledge that they need to be successful in their future careers. However, research argues that reducing the amount of content and making what remains more meaningful will provide students with a more impactful educational experience and a better foundational understanding of A\&P (Griff, 2016). 


\section{Study Rationale}

There is a need to understand how curricular change in undergraduate A\&P laboratories may affect the student experience (Griff, 2016). There is also a need to implement and evaluate the active learning, inquiry-based, and student-centered approaches across different institutional contexts and student populations. Lastly, there is a call for students to come to understand the underlying anatomical and physiological principles in-context, so that their A\&P knowledge becomes more sophisticated than simple memorization (Wilkerson et al., 2009; Miller et al., 2002; Griff, 2016; Bergman et al., 2011).

To address these gaps this study examines an approach in which the laboratory musculoskeletal curriculum for a Human Anatomy \& Physiology I course was revised and then compared to a conventional approach. To do so, active learning opportunities were created through a guided inquiry approach that utilized flipped lab experiences. The curriculum was informed by complex systems theory and embodied cognition, to support learning in-context and develop students' understanding of the underlying anatomical and physiological principles. This curriculum was implemented during the spring and fall semesters of 2019, and student experiences were measured quantitatively via the 27-item Anatomy Learning Experiences Questionnaire (ALEQ; Choi-Lundberg et al., 2017). Additionally, students' perceptions of the course were qualitatively assessed via interviews and concept mapping tasks.

This study enters the A\&P educational arena at a pivotal time as we try to cope with an increased demand for our students in the face of decreasing resources. Less than $40 \%$ of A\&P medical students feel like they know enough anatomy to competently practice, while $73 \%$ of them feel the hours of anatomy teaching are too few (AMSA, 2006). To potentially assuage these burdens, this study served to concurrently assess bold curricular changes called for in the 
literature. Most importantly, this study served to advance our understanding of how we can improve the educational experiences of A\&P students, a population that will go on to directly impact the lives of many throughout their careers. 


\section{CHAPTER II: CONCEPTUAL FRAMEWORK}

A considerable amount of the A\&P education literature lacks theoretical grounding (Unge et al., 2018). A systematic literature review of this theoretical sparsity is absent from the A\&P education literature. However, Unge et al.'s 2018 review of studies about e-learning in the health sciences found that theoretical support was found in few studies and that "learning and teaching in the digital age is not fully served by the learning theories we have relied on up until now" (p. 59). Therefore, future research should provide a clearer theoretical rationale by relying upon research developed theories and models as this will promote system alignment and educational development (Unge et al., 2018). As such, the curricular changes in this study were grounded in complex systems theory, embodied cognition theory, contemporary theoretical perspectives of the human musculoskeletal system, and evidenced-based pedagogical practices.

\section{Complex Systems Theory}

Complex systems theory (CST) examines natural phenomena by accounting for their multiple causes and consequences that coexist at many different scales of time, space, and organization (Jacobson \& Wilensky, 2006). As natural phenomena, A\&P profoundly exemplifies this manner of existence. Self-organization, multi-scale hierarchies, interdependence, and emergent properties are the aspects of CST that have been selected as the most relevant for framing A\&P curricula in this study.

A\&P is self-organizing, which is difficult for students to appreciate. We do not have control over how our bodies develop, and as such deeply complex beings, it can be perplexing that 30-40 trillion cells have the capacity to arrange themselves into a singular sophisticated organism. At times, educators might anthropomorphize structures so that students can develop some understanding of their self-organizing nature. However, by introducing students to the 
biological principle of parsimony in evolution and development, students may come to understand self-organization in a more cross-cutting, generalizable way. Parsimony, in this respect, is the notion that life persists through time with the fewest amount of evolutionary and developmental changes possible. This gives rise to many common structures and patterns of development that can be seen across extremely diverse groups of organisms. Through enabling students to consider these common patterns of development across a diverse set of A\&P phenomena they may be able to abstract a more cross-cutting understanding of structures. Some A\&P educators already integrate evolution into their curricula which has proved to be a fruitful, yet untapped conceptual underpinning (NCSE, 2020).

A\&P also has many multi-scale hierarchies (Figure 1).

Figure 1. Breadth of physiology across levels of biological organization.

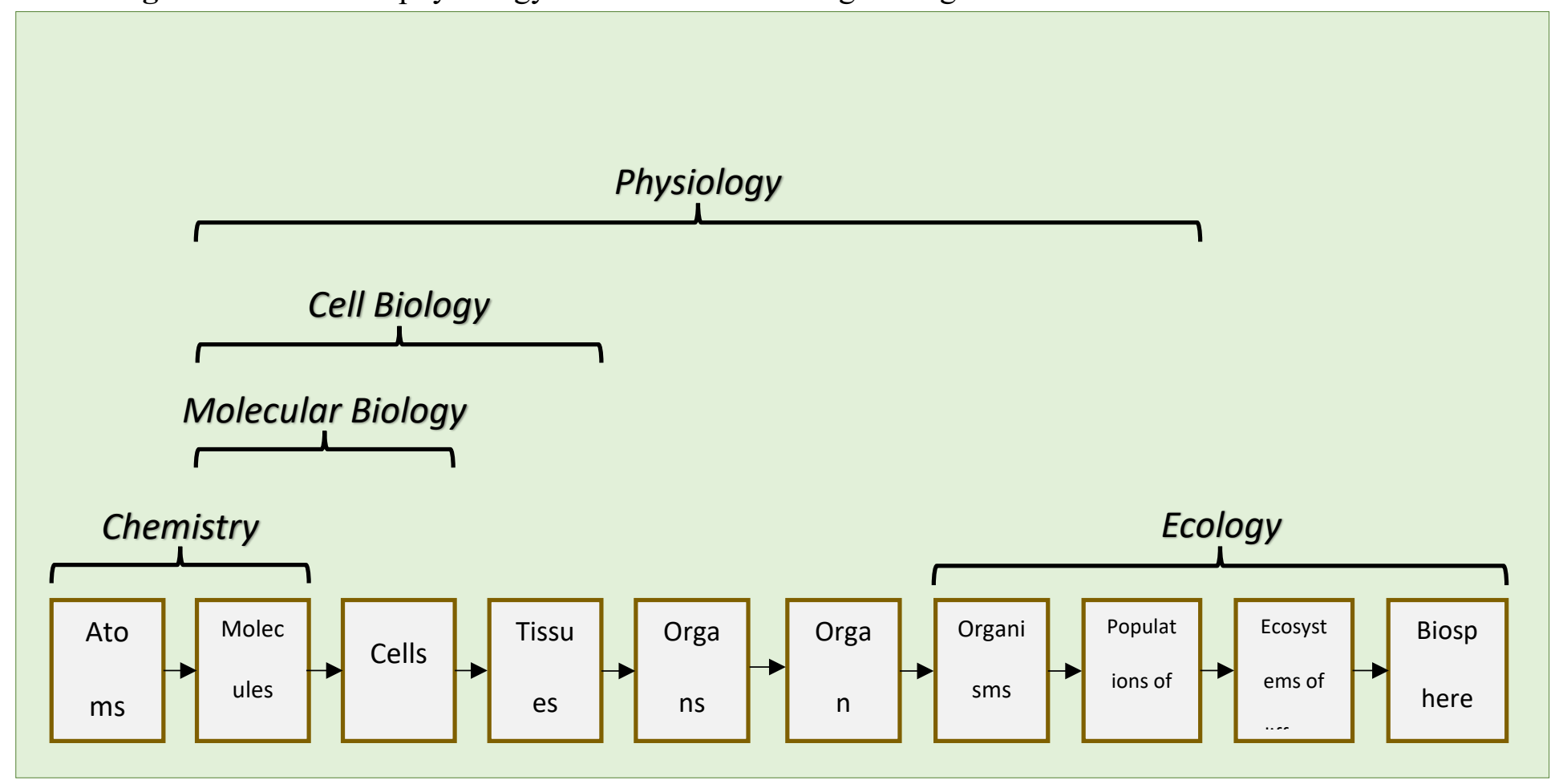

Anatomists and physiologists have an understanding that spans from atomic and molecular structures to the organismal and ecological level. As structures increase in their order of 
organization (e.g., cells constitute tissues, tissues constitute organs, etc.), there are a myriad of unique organizational arrangements within the same level of organization. Muscular tissues wonderfully illustrate the multi-scale hierarchies of the body. In skeletal muscle tissue, sarcomeres make up myofibrils, and myofibrils makeup muscle fibers, muscle fibers makeup fascicles, and fascicles makeup muscles; this unique organizational scale is all happening at the same organizational level of tissues. Being aware of these multi-scale hierarchies when developing the curriculum should be on the forefront of any A\&P educator's mind so that we can carefully construct learning opportunities that allow students to use these multi-scale hierarchies as scaffoldings as they develop a conceptual understanding, rather than as multi-layered terminology to memorize.

Interdependence is the idea that two or more things depend upon each other for their function. However, the very use of the name anatomy and physiology drives a wedge between this principle of interdependence. This sends the message to students that there are structures and then there are functions, but we know that there is no structure without function and no function without structure. Thus, in this study students were implicitly introduced to the concept of interdependence through functionally bound structures, which are distinct anatomical structures that require each other to achieve systems-level functioning, often in the form of an emergent property. In this way, the musculoskeletal system is essentially one large functionally bound structure because all the bones and all the muscles depend upon each other to achieve the systems-level function of movement. As such, building students' understanding of interdependence among functionally bound structures was a key component of the conceptual framework that informed curricular change in this study. 
Further, students were implicitly introduced to the principle of emergent properties. Emergent properties are properties of a system that the system parts do not individually possess. For example, one neuron does not remember what you had for lunch or enable you to compose a symphony, but the collection of neurons comprising the nervous system give rise to memory and creative thought. Another example is blood flow; one contractile myocardial cell does not create blood flow, nor does one blood vessel, the cardiovascular system as a whole enables the emergent property of blood flow. A final example is movement. Bones and muscles share an interdependence and thus require each other to achieve their greater function. However, one sarcomere does not provide movement nor does one muscle, osteon, or bone; rather, the whole musculoskeletal system provides movement to the human body.

In all, framing the curriculum through the conceptual framework of these four properties of complex systems emphasizes cross-cutting and generalizable properties of the human body. Moreover, a curriculum grounded in these four properties creates novel learning opportunities and enables students to develop an understanding of the underlying principles of A\&P.

\section{Embodied Cognition}

Embodied cognition also significantly contributed to the conceptual framework that directed the curricular changes in this study. For the purposes of this study, embodied cognition is the notion that states of the body modify states of the mind relative to the task at hand, the resources available to solve that task, and how those resources are arranged to reach a solution (Wilson \& Golonka, 2013). We know that there is a continual loop of feedback and response between the world and our bodies, which behave differentially relative to the task at hand, the resources available to solve that task, and how those resources are arranged. As such, embodied cognition has been drawn upon because it may allow this simple premise of feedback and 
response to be manipulated, creating innovative learning opportunities for students. I believe the most impactful way to manipulate this feedback and response loop is by conscientiously changing the way we word questions.

We know that understanding underlying concepts is important for developing a functional grasp of A\&P (Griff, 2016). Still, the primary form of questioning in conventional A\&P instruction puts forth surface-level what questions as opposed to how questions. Undergraduate A\&P courses repetitively ask students to recall names and locations of structures. However, we could be asking students to describe, using the same terminology, how these structures work to perform simple, familiar tasks. Students would arrive at the same knowledge of vocabulary but with a potentially more meaningful and generalizable understanding of the self-organization, interdependence, and emergent properties of functionally bound structures. So, for example, instead of asking students to identify which bones and muscles compose the leg, we should be asking students to describe how the musculoskeletal system performs a squat. This is an example of reframing the task to potentially enable students to cognitively engage in a way that is more grounded in the principles of A\&P. Taking the notion of embodied cognition further, we can ask students to, "Explain how the musculoskeletal system performs a squat using this model," or alternatively, "Demonstrate and articulate how the musculoskeletal system performs a squat using your own body." These alternative forms of questioning are examples of how the resources available to solve a task dictate how students cognitively engage with that task. In the first question, students' point of reference is an anatomical model, whereas, in the second, students' point of reference is their own body. Plausibly, engaging their whole selves in the learning of the A\&P recruits more cognitive engagement in performing the task. Lastly, we can ask students, "Demonstrate how the musculoskeletal system performs a squat by using your own 
body and making a step-by-step video," or alternatively, "Demonstrate how the musculoskeletal system performs a squat by using your own body in front of the class.” This is an example of how we can change the way students arrange the resources available to solve a task, simply by altering a few words in our questioning. These alternative forms of questioning cause students to cognitively engage in more complex and personal ways, potentially providing unique learning opportunities.

Acknowledging that states of the body modify states of the mind, relative to the task at hand, the resources available to solve that task, and how those resources are arranged to reach a solution, is a new direction available to A\&P instructors as they attempt to make their instruction more meaningful to students. The tenets of embodied cognition encourage us to carefully craft questions in a variety of ways that push our students to use knowledge differently and sophisticate their understanding of A\&P principles. This provided an invaluable insight to the conceptual framework driving this study.

\section{Learning In-context}

In addition to grounding the curriculum in theory, research has shown the need for A\&P students to learn in context (Wilkerson et al., 2009; Bergman et al., 2011). However, the foundations of A\&P knowledge have been established through, literally and figuratively, dissecting human form and function into isolated pieces. By doing so, we lead students to only appreciate these individual structures and systems in isolation. In reality, we know that the human body is one profoundly complex and integrated system that has been broken down into subsystems over the course of centuries so that we can better understand and articulate the nuances of each subsystem. This isolation or divide and conquer approach is the epistemology that A\&P has been constructed upon, but it has subliminally constrained our instruction and our 
perspectives throughout time. This isolation epistemology came about because we can only come to understand the world through the tools that we have at our disposal, and for most of anatomy's formative history that tool has been the knife (Myers, 2014). Our current knowledge results from thousands of years of cutting things apart. Over time, this led to the predominate contemporary curricular model, the "systems-based" curricular model, where each system is largely stripped of its greater bodily context as well as it's interactions with other systems. In this model preemptive units of content, such as chemistry, surface anatomy, and endocrinology are lectured to students before the material becomes relevant, rather than integrated into each unit when it is relevant and provides context for the other material in the unit. This effectively removes these fundamental A\&P principles and systems of their greater interactive context. This epistemology is particularly relevant for the musculoskeletal system and likely led to the instructional model for this content that dominates anatomy instruction today, in which each muscle and each bone is analyzed alone and removed from its greater musculoskeletal context. This is a disservice to the musculoskeletal system, as we know that the musculoskeletal system achieves the complex emergent property of dynamic movement through the activation of networks of concurrent muscles (Myers, 2014).

With this contemporary understanding of the musculoskeletal system we can foster opportunities for students to learn in-context. When learning in-context, facets of knowledge, or specific facts that establish concrete, context-dependent conceptions of content, can be integrated into schemes of knowledge, or generalizable patterns of reasoning that are less contextdependent and composed of several facets (Stein \& Galili, 2015). Our job as A\&P educators is to help students create schemes of knowledge out of the individual facets. The implications of these theoretical constructs are important, because if facets of knowledge are context-dependent, then we must teach our students the facets of knowledge (i.e., bones and muscles of the upper limb) 
in-context. Then, students can progressively learn by considering many facets of knowledge in their greater bodily context, which enables them to abstract generalizable patterns of anatomical and physiological reasoning, or schemes of knowledge. Further, well developed schemes of knowledge can guide the organization of new facets of knowledge as they are learned. In other words, since there is a lot of information to organize in A\&P, or many facets of knowledge that must be assembled into schemes of knowledge, instruction that fosters robust scheme construction enables subsequent learning to be more efficient. As educators, we have the power to shift our curriculum and help students develop these schemes of knowledge by teaching A\&P in-context, which was a final theoretical grounding in this study.

\section{Evidenced-based Pedagogical Practices}

The final component contributing to the conceptual framework of this research was the use of evidenced-based pedagogical practices. This literature was accessed by following the advice of many to "break down silos" by venturing into the wider literature of science educational research (Drake, 2014; Lowry 1992; Trust et al., 2017; Kalb \& O’Conner-Von, 2012). Some researchers are already privy to the bastion of evidenced-based pedagogical practices in the education literature and have validated the use of such practices in A\&P. Guided inquiry, flipped lab, and active learning approaches have all exhibited improvements in students' experiences in A\&P and thus were the strategies implemented in this study. These three

pedagogical practices are not mutually exclusive and may synergistically increase student engagement when synchronously integrated into curricula. 


\section{Guided Inquiry}

Guided inquiry occurs when teachers present a topic, question, or problem that students then actively address. Students design the means of pursing an understanding of the given topic, question, or problem with coaching by the instructor. Guided inquiry emphasizes the student's role as scientists and places a high value on students constructing information from their experiences, including observations and experimentation, rather than simply being told facts. Moreover, this approach is beneficial across content and contexts, from biology to chemistry to A\&P, and from K-12 to higher education (Hughes \& Ellefson, 2013; Farrell et al., 1999; Vanags et al., 2013; Nisa et al., 2017). Specifically, in A\&P, a handful of studies have demonstrated the benefits of guided inquiry approaches for students (Vanags et al., 2013; Brown, 2010; Rathner \& Byrne, 2013; Harrison et al., 2001; Casotti et al., 2008). The work of these scholars provided a fundamental piece to the conceptual understanding that drove curricular change in this study.

\section{Flipped Labs}

"Flipped" labs are another evidenced-based pedagogical approach that has been demonstrated to enhance students' learning experiences in a variety of contexts (Smith, 2017; Bakr et al., 2016; White et al., 2017). Traditionally, a flipped classroom is one where students listen to lectures or instructional videos outside of class and then, in class, students engage in discussions or activities. The goal is to put the more cognitively difficult activities, such as problem-solving, during class time when the instructor can scaffold the learning, while asking students to accomplish the simple tasks, such as vocabulary learning, outside of class. This can be done through a guided inquiry lens, as in this study, or through any other means of active learning. However, understanding the value of utilizing flipped lab experiences in concert with a guided inquiry approach further developed the conceptual framework being utilized. 


\section{Active Learning}

Much like the two previous strategies, active learning is an evidenced-based pedagogical practice that improves students' learning in many contexts, including A\&P (Michael, 2006; Rao \& DiCarlo, 2001). There has been a call for active learning approaches in A\&P for over two decades now (Drake, 1998). Instruction that supports active learning is teaching that positions students in the learning process as active generators of knowledge, as opposed to passive vessels to be filled with content. Guided inquiry and flipped lab experiences are often used as a means of achieving active learning and, as such, these three practices are not mutually exclusive but likely benefit from simultaneously being carefully constructed into curricula. Therefore, in this study, an emphasis was placed on shifting student's educational experiences from passive to active, whether that be through guided inquiry, flipped labs, or other means.

\section{Conceptual Framework Summary}

As indicated by Unge et al. (2018), the A\&P education literature lacks explicit theoretical underpinnings. To address this, I explicitly put forth the conceptual framework of this study, which is grounded in complex systems theory and embodied cognition. Contemporary conceptual perspectives of the human musculoskeletal system complement these theoretical constructs and provide an important means of learning in-context for students. Additionally, the conceptual foundations of evidenced-based pedagogical practices that serve to facilitate active learning reinforce the conceptual framework driving curricular change in this study. Together, these theories, perspectives, practices, and concepts create a sturdy conceptual framework to inform the curricular revision. 


\section{CHAPTER III: METHODOLOGY}

\section{Curricular Change}

In concordance with the guidelines put forth for curricular change in A\&P this study altered curriculum in three major ways: 1). The curriculum was grounded in learning theories; 2). Learning in context was promoted; and 3). Evidenced-based pedagogical approaches were implemented. These three major curricular changes were applied to a three-week laboratory unit covering the human musculoskeletal system.

\section{Complex Systems Theory Applications}

As previously discussed, self-organization is a relevant yet challenging topic for students to grasp. To facilitate students understanding of self-organization, they were introduced to the principle of parsimony when discussing homologous limbs across animal taxa (i.e. stylopod, zeugopod, autopod). Students were asked to compare the limbs of a cat skeleton and a fetal cow to human limbs, specifically, looking for similarities among them. These various forms of conserved structure illustrate the principle of parsimony in self-organization and expose generalizable patterns. After observation, students were guided via a whole-class discussion toward the understanding that even in different species, anatomical similarities result from shared ancestry. The goal was to introduce students to the idea of self-organization in a novel way that allowed a more cross-cutting understanding of the concept. Students were also simultaneously introduced through guided questioning and whole-class discussion to the multiscale hierarchies of the bones and muscles so that they could gather a more cross-cutting understanding of such hierarchies. The goal was to enable a generalizable understanding of this complex principle of human form and function. Additionally, at the beginning of the unit students were introduced to the concept of functionally bound structures to encourage them to 
consider the interdependence of the bones and muscles when creating the emergent property of movement. The goal of this approach was to foster cross-cutting understanding of interdependence that can then be applied to other contexts and content. Lastly, students were introduced to the concept of emergent properties at a basic conceptual level after being introduced to functional binding. Then, students had the opportunity to apply their understanding of this property during the laboratory activities. Emergent properties were also revisited at the end of the three-week unit as reinforcement. Through creating opportunities for students to appreciate and understand emergent properties, the goal was that they become able to apply this overarching concept to many other units and content disciplines.

\section{Embodied Cognition Applications}

In this curriculum, a multi-modal approach to questioning was developed in conjunction with evidenced-based pedagogical practices to compel students' engagement with progressively more demanding questions. Questions integrated throughout the laboratory activities were structured such that students' point of reference was their own body, recruiting more cognitive engagement in performing the task. Early questions were asked students to identify the movement associated with a set of directions using anatomical terminology. For example, students were given the following set of directions and asked to name the movement: step 1) bilateral contraction of the posterior and lateral deltoid muscles and latissimus dorsi muscles; step

2) bi-lateral contraction of pectoral and anterior deltoid muscles; step 3) bi-lateral contraction of the hand flexors leading to full hand flexion. This is basic set of qualitative biomechanical instructions on how humans use their musculoskeletal system to give a hug. In step 1 the arms are raised and pulled backwards constituting the opening phase of a hug; step 2 is the embrace brought on by adduction of the arms; and finally, the hands are brought into the embrace in step 
3. This is a relatively easy example of question that involves an everyday activity, which students can directly relate to their lives. By framing this everyday activity into a more cognitively demanding question, we are asking students to utilize the hug as a temporary scheme of knowledge, upon which they can construct a knowledge of the musculoskeletal system involved in the activity. Students' were asked to complete 4 to 5 of this type of question with their group during each lab, and each question posed slightly increased in difficulty within and across labs. An example of a much more complicated question is asking students to identify kicking a ball. The directions for kicking a ball are: step 1) uni-lateral contraction of hip, knee, and ankle flexors, extensors, and stabilizers causing one leg to be planted in the ground; step 2) uni-lateral contraction of the opposite leg's knee flexors and hip extensors causing full knee flexion and hip extension; step 3) contraction of the non-planted leg's knee extensors and hip flexors. In this example, step one constitutes grounding the plant leg; step 2 is the "pull back" phase of the kicking leg; and step 3 is the actual motion of kicking the leg. This question encourages students to appreciate the dynamism of movement and the different roles that muscles play through beginning to explore stabilizer and unilateral functions. While these questions greatly simplify the true complexity of movement, they give students opportunities to explore musculoskeletal functions where structures are positioned in their greater bodily context, the examples are relevant to their daily lives, and students must cognitively engage beyond simply identifying a structure and memorizing its generalized function. After completing these questions, the groups worked together to write a short paragraph qualitatively describing the biomechanics of a movement of their choice or a movement that was assigned to them. This task essentially reversed this questioning task so that the students were creating the steps of the movement, causing them to cognitively engage differently once again. 


\section{Learning In-context}

Rather than considering the skeletal and muscular systems separately, this curriculum simultaneously engaged students with both the bones and muscles of a given region so that they could build understanding of their interdependence in creating movement. This also provided students with opportunities to appreciate the bones and muscles in their greater bodily and musculoskeletal context. The humerus was no longer an isolated long bone with articular surfaces that got left out on a lab bench so that students could memorize each bony landmark; it was an integral contributor to movement of the upper limbs. This simultaneous exposure to facets of knowledge (i.e., bones and muscles of the upper limb) fostered students' construction of a scheme of knowledge into which they could integrate each structure. To apply these concepts, the three-week laboratory musculoskeletal curriculum changed from covering the axial skeleton, appendicular skeleton, and then muscles, to simultaneously covering the bones and muscles of the upper limbs, torso and lower limbs, then the head, neck, and other muscle types. This macroscale shift forced students to consider how the musculoskeletal regions work together in their greater bodily context to create movement. Moreover, complete and disarticulating skeletons as well as whole-body muscle images were utilized as the primary means of modeling the musculoskeletal system. Through these changes, the goal was for schemes of knowledge to be created that students could adopt and utilize to better understand the human musculoskeletal system.

\section{Evidenced-based Pedagogical Practices}

\section{Active Learning}

In this study, the activity sheets guiding engagement in the laboratory tasks utilized active learning strategies for an undergraduate musculoskeletal laboratory (Appendix C). Tasks 
included students creating their own diagrams of musculoskeletal anatomy and performing and biomechanically describing the musculoskeletal system's role in movement patterns.

\section{Guided Inquiry}

The activity sheets were also grounded in a guided inquiry approach (Appendix C). Initially students were introduced to the theoretical underpinnings of the musculoskeletal systems (e.g., interdependence of bones and muscles, emergent property of movement). Then students worked in teams to complete the activity sheets guiding them through the laboratory tasks. The first task was to develop a detailed sketch of the region covered during that lab period. Students were instructed to share the features they found important with their teammates to cultivate a qualitative understanding of bony landmarks. Students then observed the articular surfaces of bones, although they were not introduced to any terminology at that time. After completing their sketches, the students assembled a disarticulated skeleton based off their drawings and compared the two. Then, the students labeled their team-sketched diagrams using their textbooks, lab manuals, and online resources. This compelled students' discovery of the anatomical and physiological terminology and created intellectual necessity for students to know the terminology. After labelling their sketches, students labeled the remaining diagrams printed in their lab manuals while comparing these printed diagrams to their drawings. Finally, the teams of students completed qualitative biomechanical problem sets inspired by embodied cognition; this portion of the lab activities culminated in each team choosing their own movement, or being assigned one if necessary, and creating a qualitative biomechanical problem set for it. By enabling the students to discover the musculoskeletal system and its terminology, these activities constituted a guided inquiry approach that met the needs of this specific context. 


\section{Flipped Labs}

Students were asked to read over the lab manual and related diagrams for the region(s) that were going to be covered prior to entering the classroom. Then, once the students entered the laboratory, they were immediately engaged in the activities related to their outside of class preparations. The activity sheets facilitated students' engagement in the laboratory tasks (Appendix C). After the students had completed the activities for all three labs there was a small lecture to reflect, recap, and allow time for students to ask questions. This brief lecture also served to reinforce what students had just discovered over the previous three weeks and introduced them to content that was unable to be worked into activities due to time, fiscal, and contextual constraints.

\section{Curricular Change Summary}

\section{Experimental Curriculum}

The experimental laboratory curriculum used in this study was changed by grounding it in relevant theories, promoting learning in-context, and implementing evidenced-based pedagogical practices. In lab, the bones and muscles were looked at in their greater context by emphasizing the use of whole skeletons and considering how muscles of an entire region work together. As such, the bones and muscles of each region were simultaneously explored via a series of activities and the central question underpinning this curriculum was, how: how and why does the body move? This manner of instruction sought to emphasize how the complex musculoskeletal system achieves its higher-order functions and did so by compelling students to elucidate structure by first considering function. 


\section{Comparison Curriculum}

The comparison laboratory curriculum in this study was the unaltered curriculum that was being used at the time of this study. It covered the musculoskeletal system through a systems-based approach that was largely conventional in nature. Over three weeks of labs, students were introduced to the axial skeleton, appendicular skeleton, and muscles, respectively. Within each lab, the bones and muscles were examined predominantly through identification of structures, labelling, and memorization of terminology. Lastly, the central questions underpinning these labs were, what: what are the bones; what are the muscles; what does each of them do?

\section{Curriculum Prior to Both Treatments}

Prior to both the comparison and experimental treatments, students received the same instruction and content. Students had an introductory lab that exposed them to fundamental principles of chemistry and physiology, as well as anatomical orientation terminology. After the introductory unit there was one lab that covered the epithelial system, which used the conventional instructional model previously mentioned. In this microscope- and histology-based laboratory period, students were exposed to all the major epithelial and connective tissues at once. The central driving questions were based in, what: what are the epithelial tissues, what do they look like, and what do they do? In the context of this study, this curriculum implemented the conventional and the systems-based models. Additionally, as pre- and post-treatment measures were gathered in this study, this was the only curriculum the students were exposed to at the time of their pre-treatment survey administrations. 


\section{Research Questions}

Q1

The first research question was: To what extent do students receiving the experimental treatment exhibit an enhanced ability to organize their anatomical and physiological knowledge? This question is pursued because, as discussed earlier, when robust schemes of knowledge are constructed, they better enable the organization and subsequent learning of facets of knowledge. Therefore, given the large number of facets to be learned in A\&P, organizing facets into robustly built schemes of knowledge is a desired goal of A\&P instruction. It was predicted that students receiving the experimental treatment would exhibit an enhanced ability to organize their anatomical and physiological knowledge into relevant schema.

\section{Q2}

The second research question was: How does receiving the experimental treatment affect students' value of anatomical and physiological knowledge? The second research question was chosen to compliment the information gathered via the first, because on a pragmatic level, students must value information to dedicate time to learning it. Furthermore, students' value of this specific content and context remained unknown prior to this study. It was predicted that students receiving the experimental treatment would exhibit an increased appreciation for anatomical and physiological knowledge.

\section{Q3}

The third research question was: How does receiving the experimental treatment affect students' perceptions of the course? Measurement of student perceptions could add invaluable context to any observed differences regarding the above two research questions. 


\section{Experimental Design}

To measure the effects of this experimentally crafted curriculum on students' ability to organize their anatomical and physiological knowledge, value placed on anatomical and physiological information, and perceptions of the course, this curriculum was taught over the fall and spring semesters of 2019 to students of BSC 181 - Human Anatomy \& Physiology I, at Illinois State University.

\section{Participants}

This course is primarily composed of first- and second-year nursing students, with some third- and fourth-year students from a variety of other majors. Majors for the non-nursing students included biology, biochemistry, exercise science, and athletic training. Additionally, most students aspire to enter a healthcare career. Ninety-six percent of the 75 students that responded to the initial questionnaire in this study indicated that they intended to enter either primary or allied health professions after graduation (Figure 2).

Figure 2. Demographics of students who completed the pre-questionnaire.

\section{Pre-Survey Demographics $\mathrm{n}=75$}
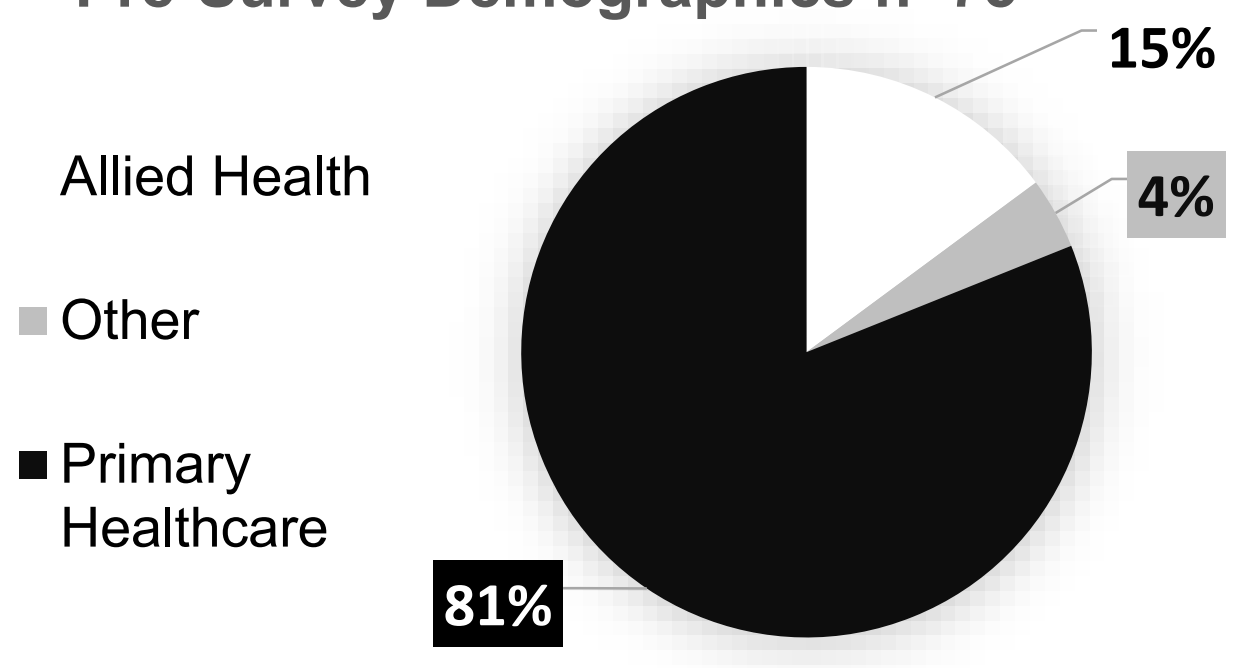

These students were typically aged 18-22. 


\section{Research Setting}

This research was conducted during the spring and fall semesters of 2019 at Illinois State University, an R2 public institution in the Midwest. The study was conducted in BSC $181-$ Human Anatomy \& Physiology I, taught in the School of Biological Sciences. The laboratory sections of the course served as the primary research setting for this study; the laboratory curriculum was the only curriculum altered for the purposes of this research.

\section{Implementation of Instructional Treatments}

Over the course of the spring and fall semesters of 2019, comparison and experimental curricula were simultaneously taught to different laboratory sections of the same course. In the spring, I taught two sections of the experimental curriculum while concurrently teaching two sections of the comparison curriculum. This design was initially constructed to negate any potential effects of different instructors and provide a means of direct comparison. To decide which sections were to receive the experimental curriculum and which to were receive the comparison, a coin was flipped. Prior to the coin flip the four potential experimental sections were arranged into two groups of two sections each; these groups were created to ensure that the experimental and comparison sections were comprised of students from similar majors. Then, a coin was flipped to determine which group received the experimental treatment and the other group received the comparison by default. After initial analysis of the spring semester data, sample sizes were found to be too small to carry out robust statistical analyses, so more data were collected in the fall of 2019 from experimental and comparison treatments. In the fall semester, I taught two sections of the experimental curriculum, while a different graduate teaching assistant from the same course taught four sections of the comparison curriculum. This potentially introduced instructor effects, which were tested for using an unequal variance t-test, 
with instructor predicting percent-change between pre- and post-treatment scores on the ALEQ; instructor effects were not detected (Table 1).

Table 1. Results of instructor effect testing means represent percent change in student ALEQ responses over time, in comparison treatment students, across two different instructors. Standard deviations, sample sizes, and p-values are also included.

\begin{tabular}{|c|c|c|c|}
\hline Semester & Mean \pm STD & $\mathbf{N}$ & p-value \\
\hline Instructor \#1 & $.034 \pm .05$ & 11 & \\
\hline Instructor \#2 & $.038 \pm .1$ & 16 & .89 \\
\hline
\end{tabular}

\section{Data Collection}

The research questions were addressed via a mixed-methods approach. The Anatomy Learning Experiences Questionnaire (ALEQ; Choi-Lundberg et al., 2017) was utilized to gather quantitative feedback about students' perceptions of the course and their value of anatomical knowledge. This questionnaire was originally devised by Smith and Mathias (2010) to gauge medical students' approaches to learning anatomy. However, a slightly altered version of this questionnaire was validated through exploratory factor analysis and contains 27 items that students could respond to on a 5-point Likert scale, some of which were reverse scored. These 27 statements load onto three factors measured by three subscales comprising the ALEQ: challenges in learning anatomy, applications and importance of anatomy, and learning in the dissection laboratory. In this study, consenting students were asked to complete this questionnaire immediately prior to instructional treatment (i.e., the three-week laboratory unit on the musculoskeletal system) and then immediately after instructional treatment, constituting pre- and post-treatment measures. The questionnaire was administered via Qualitrics, and a link to it was 
emailed out to students from faculty member in the School of Biological Sciences not involved in the teaching of the course. Demographic information was gathered on the pre-treatment questionnaire. Extra credit was offered for completion of questionnaires. These quantitative pretreatment and post-treatment measures were carried out in the spring and fall semesters of 2019. Qualitative data were also gathered to address the research questions of this study. Interview procedures differed between the spring and fall semesters, so that fall interviews could explore questions raised by analyses conducted in the spring.

In the spring semester, 7 consenting students took part in pre- and post-treatment interviews. These interviews were semi-structured, as they were driven by an a priori interview protocol from which the interviewer deviated as needed to pursue the research questions (Appendix B). The pre- and post-treatment interview protocols were identical, except they were asking about different A\&P content. The pre-treatment interviews asked students about epithelial tissues, which was the unit covered just prior to the instructional treatment, and the posttreatment interviews asked students about the musculoskeletal system. These interviews provided qualitative data about students' perceptions of the course and value placed on anatomical and physiological knowledge, as well as how they were organizing their A\&P knowledge at that time. During pre- and post-treatment interviews in the spring semester, students were asked to complete a concept-mapping task, which gauged students' abilities to organize their anatomical and physiological knowledge. The interview participants were broadly informed of what a concept map is and then asked to assemble a preset bank of terminology from either the epithelial or musculoskeletal unit into a concept map. The terminology was printed onto paper, laminated, cut into cards, and then magnetized so that students could create their maps on a whiteboard and use markers to draw in the framework of their maps. All pre-treatment 
interviews used the same set of terminology from the epithelial system, and all post-treatment interviews used the same set of terminology from the musculoskeletal system. These interviews were incentivized with $\$ 10$ gift cards for each interview.

Interview structure in the fall of 2019 was designed to follow up on remaining questions from the initial statistical analysis completed on the spring semester ALEQ data. Although broad and generalizable comparisons were not able to be made from these ALEQ data due to the small sample size, individual items on the ALEQ showed statistically significant change in favor of the experimental curriculum, despite the small sample size (Table 2).

Table 2. Means and standard deviations for statistically significantly different items from spring administration of the ALEQ, which informed the fall 2019 interview protocol.

\begin{tabular}{|c|c|c|c|c|c|c|}
\hline Item & $\begin{array}{l}\text { COMP } \\
\text { Pre }\end{array}$ & $\begin{array}{l}\text { EXP } \\
\text { Pre }\end{array}$ & $\begin{array}{l}\text { P- } \\
\text { value }\end{array}$ & $\begin{array}{l}\text { COMP } \\
\text { Post }\end{array}$ & $\begin{array}{l}\text { EXP } \\
\text { Post }\end{array}$ & $\begin{array}{l}\text { P- } \\
\text { value }\end{array}$ \\
\hline $\begin{array}{l}\# 4 \text { - I have problems learning anatomy } \\
\text { because the teaching styles do not suit me. }\end{array}$ & $\begin{array}{l}3.78 \pm \\
1.2\end{array}$ & $\begin{array}{l}4.23 \\
\pm 1.1\end{array}$ & .13 & $\begin{array}{l}3.33 \pm \\
1.3\end{array}$ & $\begin{array}{l}4.09 \\
\pm 1.1\end{array}$ & $.02^{*}$ \\
\hline $\begin{array}{l}\text { \#5 - I struggle to build on my anatomy } \\
\text { knowledge as I often forget what I learned } \\
\text { last semesterlyear/s. }\end{array}$ & $\begin{array}{l}3.46 \pm \\
1.2\end{array}$ & $\begin{array}{l}3.61 \\
\pm 1.2\end{array}$ & .35 & $\begin{array}{l}2.83 \pm \\
1.2\end{array}$ & $\begin{array}{l}3.57 \\
\pm 1.5\end{array}$ & $.04 *$ \\
\hline $\begin{array}{l}\text { \#6- There is so much to learn and the only } \\
\text { way to work is by trying to memorize it all. }\end{array}$ & $\begin{array}{l}3.18 \pm \\
1.2\end{array}$ & $\begin{array}{l}3.61 \\
\pm 1.38\end{array}$ & .15 & $\begin{array}{l}2.67 \pm \\
1.2\end{array}$ & $\begin{array}{l}3.30 \\
\pm 1.5\end{array}$ & $.05^{*}$ \\
\hline $\begin{array}{l}\text { \#18 - I will become part of the medical } \\
\text { profession once I can fully communicate in } \\
\text { medical (anatomical) language. }\end{array}$ & $\begin{array}{l}4.38 \pm \\
.89\end{array}$ & $\begin{array}{l}4.38 \\
\pm 1.2\end{array}$ & .14 & $\begin{array}{l}4.08 \pm \\
1.1\end{array}$ & $\begin{array}{l}4.61 \\
\pm .58\end{array}$ & $.02 *$ \\
\hline
\end{tabular}

Consequently, the interview protocol was designed to further investigate the nature of student's perceptions about the above items (Appendix B). These interviews happened at the end of the semester and did not include a concept mapping task because the primary goal of the interviews had shifted towards investigating the findings from the spring semester. Six students consented to participate in the fall of 2019 interviews. 


\title{
Data Collection Summary
}

To assess the effects of the instructional treatments on students' ability to organize their anatomical and physiological knowledge, value placed on anatomical and physiological knowledge, and perceptions of the course, a mixed-methods approach was utilized. ALEQ and interview data gathered from the spring and fall semester of 2019 provided insights into the instructional treatments' effects on students' perceptions of the course and what value they place on anatomical and physiological knowledge. The concept-mapping tasks completed by students in the spring semester allowed conclusions to be drawn about the effects of the instructional treatments on students' ability to organize anatomical and physiological knowledge.

\section{Data Analysis}

Three types of data were collected and analyzed from students in this study: ALEQ responses, interviews, and concept-mapping tasks. The following sections describe how each type of data was analyzed.

\begin{abstract}
ALEQ
Students responses to both the pre- and post-treatment questionnaires were exported from Qualitrics into Microsoft Excel. The ALEQ response data on individual questionnaire items from the spring semester was analyzed in IBM SPSS Statistics 25 (SPSS) using a two-sample equalvariance t-test (Table 2). The assumption of equal variances was tested for each item in Table 2 using SPSS (Table 3).
\end{abstract}


Table 3. Variances and p-values from homogeneity of variance tests on the four statistically significant items from spring 2019.

\begin{tabular}{c|ccc} 
Item & Comparison & $\begin{array}{c}\text { Variance } \\
\text { (EXP,COMP) }\end{array}$ & p-value \\
\hline $\mathbf{4}$ & Pre & $1.35,1.46$ & .46 \\
$\mathbf{5}$ & Post & 1.29 .1 .71 & .26 \\
& Pre & $1.42,1.41$ & .46 \\
$\mathbf{6}$ & Post & $2.35,1.53$ & .16 \\
$\mathbf{1 8}$ & Pre & $1.92,1.44$ & .25 \\
& Post & $2.23,1.62$ & .22 \\
& Pre & $1.42, .80$ & .09 \\
& Post & $.34,1.21$ & $.003^{*}$ \\
\hline
\end{tabular}

The results of the equal variances tests indicated equal variance between the experimental and comparison treatments for all items except item 18 on the post-treatment questionnaire, so this item was analyzed using a two-sample unequal variances t-test (Table 2). Only matched data were utilized for the remainder of the analyses, meaning that, only ALEQ scores from students who completed both the pre- and post-questionnaires were analyzed. The matched ALEQ scores from the spring and fall semesters were pooled after running a two-sample unequal variances ttest on the pre-questionnaire data, in SPSS, comparing the spring and fall semesters (Table 4).

Table 4. Means, standard deviations, sample sizes, and p-value from comparison of fall and spring pre-questionnaire data, conducted to validate poolability across semesters.

\begin{tabular}{|l|r|r|r|}
\hline Semester & Mean \pm STD & N & p-value \\
\hline Fall & $3.62 \pm .30$ & 20 & \\
\hline Spring & $3.81 \pm .47$ & 25 & .12 \\
\hline
\end{tabular}

The assumption of equal variances was not met for the pre-questionnaire data, and as such, an unequal variances two-sample t-test was used (Table 5). 
Table 5. Means, standard deviations, sample sizes, and p-value from homogeneity of variances test, used to determine the type of $t$ test utilized to assess poolability.

\begin{tabular}{|l|r|r|r|}
\hline Semester & Mean \pm STD & N & p-value \\
\hline Fall & $3.62 \pm .30$ & 20 & .02 \\
\hline Spring & $3.81 \pm .47$ & 25 & \\
\hline
\end{tabular}

The matched and pooled ALEQ score means were calculated for the entire questionnaire as well as for each factor, utilizing Microsoft Excel. The overall mean scores from the matched and pooled data were analyzed via a mixed ANOVA in SPSS (Figure 3).

Figure 3. Results of MIXED ANOVA on matched and pooled overall average ALEQ scores with means and standard error bars.

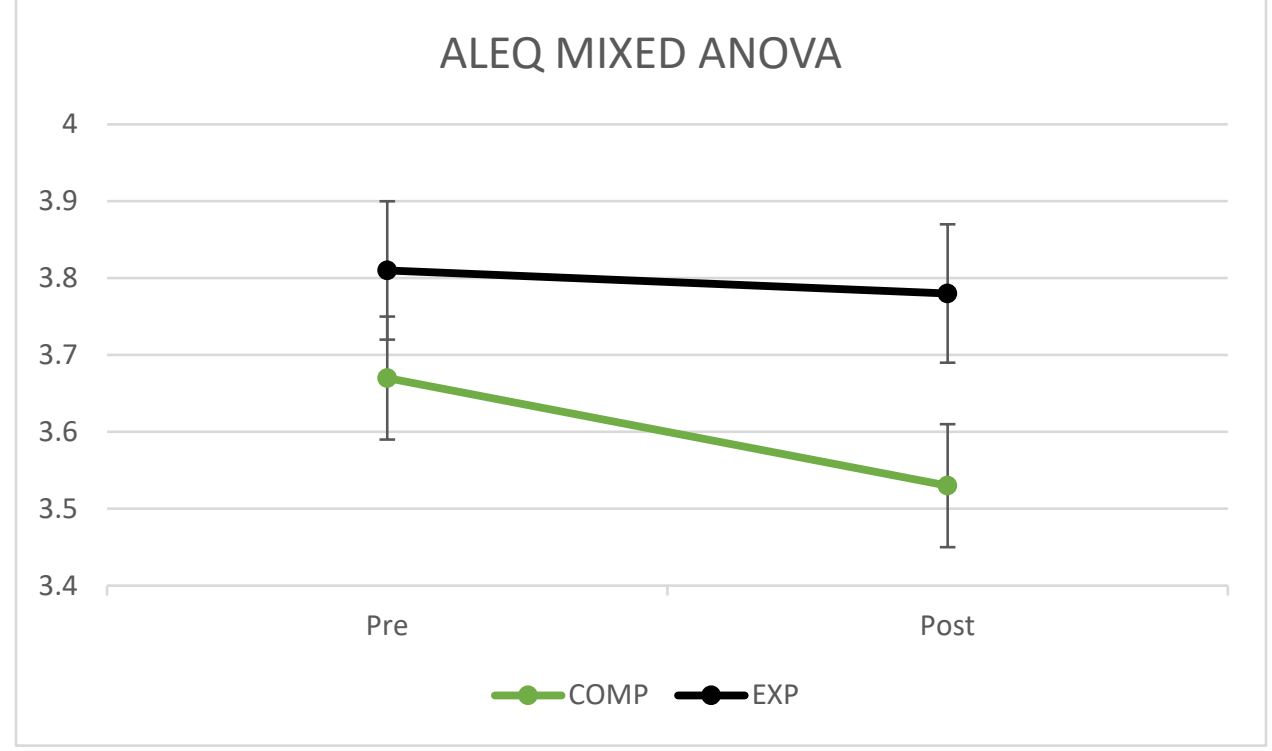

The assumptions for this ANOVA were also tested in SPSS (Table 6, Figure 4). 
Table 6. Assumption of normality for MIXED ANOVA test results including test, statistic, degrees of freedom, and the $\mathrm{p}$-value.

\begin{tabular}{lcllll}
\hline Test & Treatment & Time & Statistic & Df & p-value \\
\hline Shapiro & COMP & Pre & .975 & 27 & .723 \\
\cline { 3 - 6 } Wilk & & Post & .939 & 27 & .113 \\
\cline { 2 - 6 } & EXP & Pre & .932 & 18 & .214 \\
\cline { 3 - 6 } & & Post & .949 & 18 & .399 \\
\hline
\end{tabular}

Figure 4. Normality plots of matched and pooled ALEQ data. (a) shows the plot for the comparison treatment pre, (b) shows the experimental treatment pre, (c) shows the comparison treatment post, (d) shows the experimental treatment post.

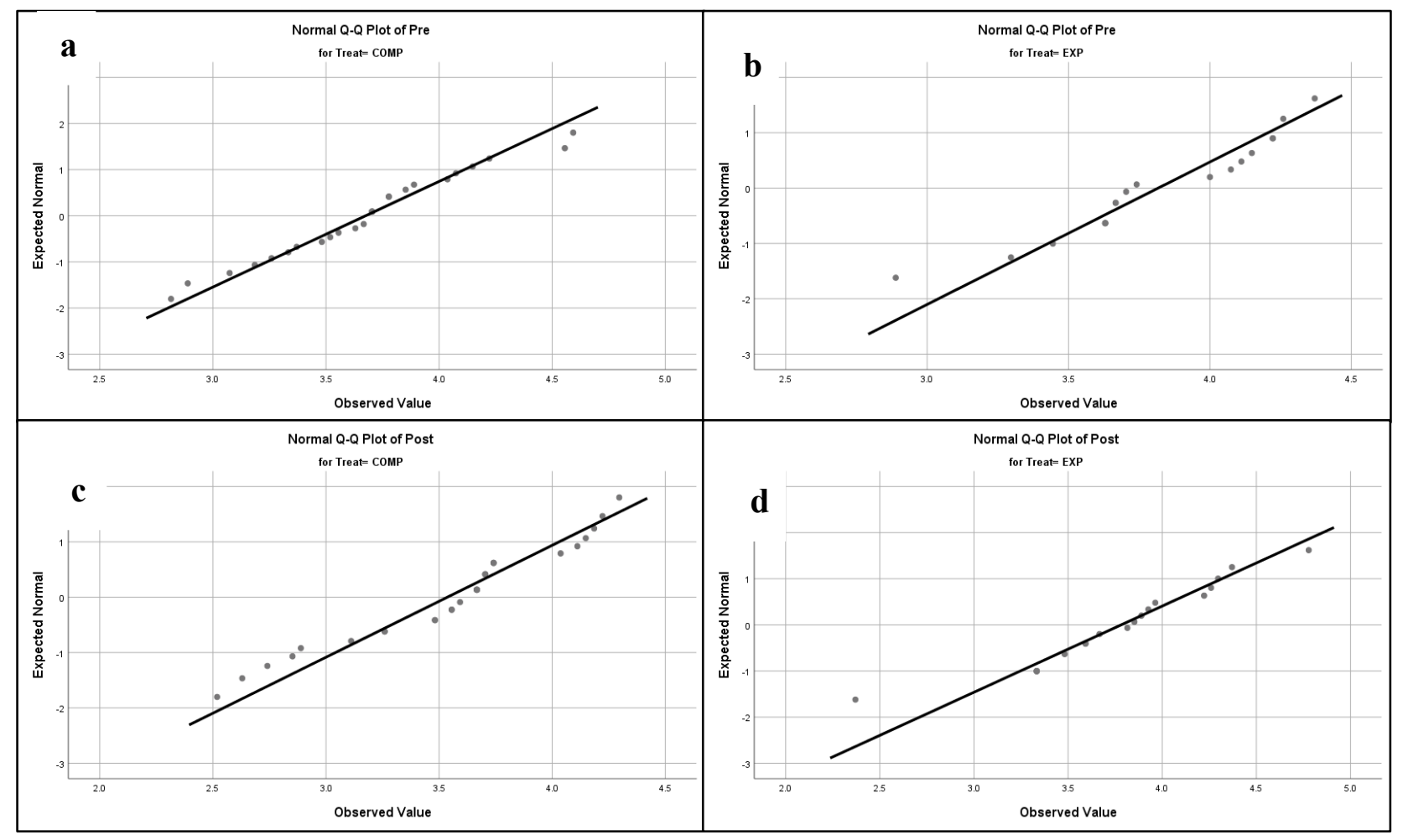

Lastly, the ALEQ average scores for each factor were compared across treatments in SPSS via a two-sample equal variances t-test (Figure 5). 
Figure 5. Results of comparisons of average ALEQ scores within factors and across treatments, displaying means and standard error bars.

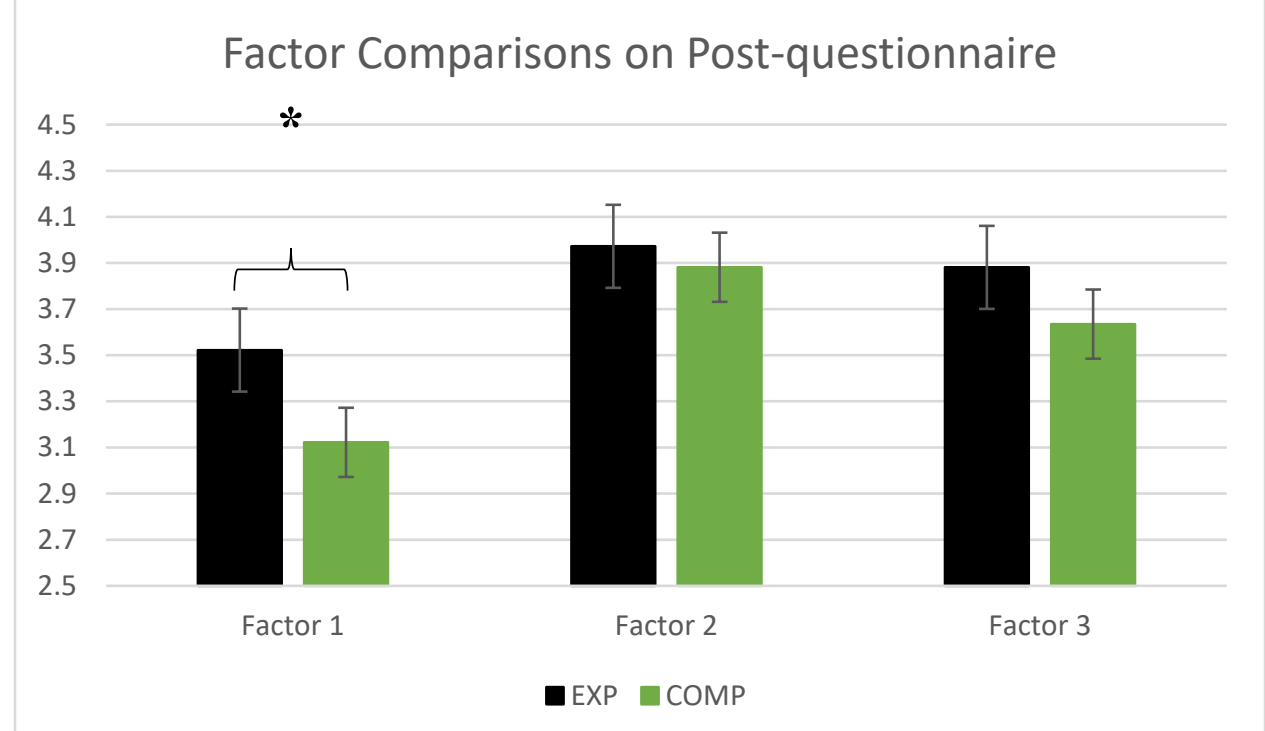

The assumption of equal variances was also tested in SPSS, and factor 2 was found to have unequal variances; therefore, factor 2 was analyzed via a two-sample unequal variances t-test (Table 7).

Table 7. Variances and p-values from homogeneity of variance tests on individual factors within the matched and pooled ALEQ post questionnaire data, analyzed across treatments.

\begin{tabular}{|c|c|c|}
\hline Factor & $\begin{array}{c}\text { Variance } \\
\text { (EXP,COMP) }\end{array}$ & p-value \\
\hline $\mathbf{1}$ & $.57, .68$ & .35 \\
\hline $\mathbf{2}$ & $.63, .18$ & $.002^{*}$ \\
\hline $\mathbf{3}$ & $.43, .22$ & .06 \\
\hline
\end{tabular}

\section{Interviews}

The interviews from both semesters were transcribed utilizing Temi transcriptions services (Appendix A). The spring interviews were systematically open-coded to identify emergent codes, using a grounded theory approach (Corbin \& Strauss, 2008). First, the preinstructional treatment interviews were open-coded from the comparison instructional treatment. Then, the post-instructional treatment interviews were open-coded from the comparison 
treatment. This process was then replicated for the experimental instructional treatment. After the open coding was completed, code lists were compiled for the pre- and post-instruction interviews from each treatment. Each interview was then axially coded based on the code lists compiled for each set of interviews within each instructional treatment, refining codes and using the constant comparative method as the coding progressed. After recoding, the product was a finalized codebook with which all the interviews were coded (Appendix D). All coding was done by hand on printed interview transcripts. The interviews from the fall semester were then coded utilizing the codebook produced from the spring semester interviews as an a priori codebook.

\section{Concept Maps}

The concept maps were coded with a set of four a priori codes applied the same way to all concept maps regardless of instructional treatment and pre- or post-treatment status. The first code was related to the scheme of the concept map and related to grounding in structure or function: Was it structurally-based or functionally-based? In other words, was the concept map fundamentally arranged around the structure cards or was the concept map fundamentally arranged around the function cards? Each map was given either a structure- or function-based code. The second code was concerning where this scheme came from; was the scheme studentcreated or was it class-adopted? In other words, did this student devise the organizational scheme on their own or did they simply adopt the scheme from how the material was presented in class? Again, each map was coded as student-generated or class-generated. The third code was concerning the presence, or absence, of integration of structure and function. Did the student simply lump all the structure cards in piles and then all the function cards in separate piles, or did they integrate the structure and function cards? Each map was a code of yes or no for integration. The third code is in some ways a precursor to the fourth, as the fourth code asks: Does this 
concept map constitute a scheme of knowledge? A scheme of knowledge, for the purposes of coding in this study, is an abstracted generalizable pattern where structure and function are interdependent, and this relationship is represented by the integration of cards and their organization. However, students may know that a structure is associated with a function but may not indicate the function's higher-order significance, in which case, that concept map was coded as an assemblance of facets rather than a true scheme of knowledge. Therefore, the fourth and final a priori code was, is this concept map a scheme of knowledge or is this an assemblance of facets? Each map was assigned the code scheme of knowledge or assemblance of facets. If there was a scheme of knowledge, this was then coded in one of two ways: structure determines function or function determines structure. The secondary code for scheme of knowledge was determined by the hierarchical categories into which students placed the cards. If the hierarchical categories were function cards, the map would be coded function determines structure, and vice versa.

In addition to a priori coding, the number of unused and incorrect cards were also enumerated for each concept map. Finally, after coding all the concept maps, each map was placed into one of three categories: highly organized, moderately organized, and poorly organized. Highly organized concept maps integrated structure and function into a scheme of knowledge, and their total number of unused and incorrect cards was 5 or less. Moderately organized concept maps integrated structure and function, though not consistently into a scheme of knowledge and their total number of incorrect and unused cards was 5 to 8 . Lastly, poorly organized concept maps did not integrate structure and function at all, and their total number of incorrect and unused cards ranged from 2 to 7. 


\section{Summary of Methods}

This study examined an altered three-week laboratory musculoskeletal curriculum in an undergraduate human A\&P course. The curriculum was altered by grounding it in relevant learning theories, promoting learning in context, and applying evidenced-based pedagogical practices. A mixed-methods approach was used to assess the impact of this altered curriculum on students' ability to organize information, appreciate the course, and value the content. Consenting students were asked to complete a validated questionnaire, concept-mapping tasks, and participate in interviews. These data waere then analyzed to determine whether this modified curriculum enhanced students' organizational abilities, perceptions, and values regarding anatomical and physiological knowledge. 


\title{
CHAPTER IV: STUDENTS’ DISPOSITIONAL SHIFTS IN RESPONSE TO UNDERGRADUATE MUSCULUOSKELETAL LABORATORY CURRICULA
}

\begin{abstract}
In the past 50 years several convergent factors have spurred unprecedented change in anatomy and physiology (A\&P) instruction. An explosion of biomedical knowledge, an increased demand for students well-versed in A\&P, and decreased resources for the course has provoked a vast array of research. However, most studies employ one of three strategies to enact change: testing the effectiveness of new pedagogies, exploring the utility of new technologies, or documenting learning in new contexts. By comparison, a much smaller body of research focuses on changing the $\mathrm{A} \& \mathrm{P}$ curriculum to improve student learning. To address this gap, the musculoskeletal curriculum for an undergraduate A\&P course was revised to align with evidenced-based pedagogical practices, ground it in learning theories, and promote learning in context. Students' perceptions and values related to the course were measured via the Anatomy Learning Experiences Questionnaire (ALEQ) and interviews, while students' knowledge organization were measured via a concept mapping task. Students reported the value of understanding how structures work together as opposed to memorizing what structures are because they see it as relevant to their future careers. Introducing students to the concept of functionally bound structures in conjunction with the curricular changes outlined may be a fruitful way of fostering students' understanding of the how of A\&P, while still arriving at the same knowledge of vocabulary. Future research should assess the curricular changes utilized across different institutional contexts, student populations, and content to validate their viability.
\end{abstract}




\section{Introduction}

During the last 50 years, anatomy and physiology (A\&P) educators have had to grapple with unprecedented change brought on by several convergent factors, including an explosion of biomedical knowledge that has saturated the anatomical and physiological curriculum with content (Leaung et al., 2006), increasing demand for primary and allied healthcare providers well-versed in A\&P (Kuyatt \& Baker, 2014), decreased resources such as scarce cadaveric dissections, fewer qualified instructors, decreasing funds, and less instructional time (Kuyatt \& Baker, 2014; Mitchell \& Batty, 2009; Mitrousias et al., 2018; Drake et al., 2009). Together these factors have necessitated A\&P educational, but most A\&P educational research examines one of three strategies to enact change: testing the effectiveness of new pedagogies (e.g., body painting, clay models, 3D printing [Finn \& McLachlan, 2010; Motoike et al., 2009, McMenamin et al., 2014]), exploring the utility of new technologies (e.g., virtual reality modeling, 3D software, online discussions, online instructional videos [Codd \& Choudbury, 2011; Mitrousis et al., 2018; Green et al., 2013; Langfield et al., 2017]), or documenting learning in new contexts (e.g., blended courses, near-peer teaching, interdisciplinary learning [Green \& Whitburn, 2016; Evans \& Cuffe, 2009; Hamilton et al., 2008]). While these three strategies to enact change are not mutually exclusive, they all share the same overarching goal of improving A\&P pedagogy for a curriculum that remains unchanged. For this study curriculum refers to the sequence and organization of content covered in the course, while pedagogy refers to how that content is taught.

By comparison, a much smaller body of literature focuses on changing the A\&P curriculum to improve student learning. Numerous initiatives, studies, and national reports have outlined the shortcomings of the conventional instructional model that dominates the discipline 
(AAMC, 1984; GMC, 1991; GMC; 1993 ACME-TRI, 1993; AAMC-HHMI, 2009; AMSA, 2006; Drake, 1998; Gibbs, 1992; Casotti et al., 2008). The conventional model is teachercentered and lecture-based; the instructor is positioned as the expert or gatekeeper of knowledge, while students are positioned as passive recipients of content. Content in this model is traditionally organized through a regional approach (e.g., limbs and thorax are explored as individual units), or more recently a systems-based approach; both necessitate an unwieldy amount of lecture hours to be delivered (Heylings, 2002; Ettarh, 2014). In this way, the conventional model demands memorization to cope with the large amount of information, provides few opportunities for students to relate information to their future careers or lives, and lacks integration across disciplines (Drake, 1998). Labs in the conventional model are typically procedure-driven with detailed step-by-step instructions through which students lack opportunity to experience discovery, become knowledge generators, and engage in scientific practices (Casotti et al., 2008). Additionally, this model is self-perpetuating, fueled by a heavy workload, a large amount of material, little opportunity to pursue topics in depth, little choice over the topics or methods of study, and anxiety-provoking assessments that reward simple recall of facts. These five undesirable curricular aspects synthesize to compel surface-level memorization rather than meaningful understanding (Gibbs, 1992). Additionally, the conventional model preserves the notion that if A\&P instructors are experts of the content, they then must be effective educators. However, there much literature demonstrating that experts do not reliably employ teaching practices that are known to be effective in fostering student learning (Berman, 2015; Bain, 2004).

Current guidelines call for student-centered, active learning that takes place through variety of multi-modal experiences (Drake, 2014; Lowry 1992; Darda, 2010; Sugand et al., 2010). The guidelines stress learning in context and revisiting material more than once (Drake, 
2014; Wilkerson et al., 2009). Creating integrated courses that facilitate interdisciplinary and community-based learning is highly recommended (Drake, 2014; Lowry 1992). Successful A\&P learning hinges on learning concepts rather than memorizing facts, but A\&P students often believe that the course requires incessant memorization (Miller et al., 2002). Therefore, there is a call to reduce the amount of factual material students must memorize and increase the connections they make between new material and material they have already learned (Griff, 2016; Darda, 2010). Additionally, inquiry-based labs have reliably shown to improve students' critical and analytical thinking skills and break them out of memorization habits, and this has been documented in A\&P labs (Casotti et al., 2008). Curricular change to implement these guidelines lags because lasting and substantial change is difficult to achieve (Silverthorn et al., 2006; Drake, 1998; Mattheis \& Jensen, 2014); reasons include "lack of support from academic leadership, unplanned class size increases and heavy teaching loads, insufficient time to develop a mindset for change, inadequate technology [and] funding, ... incompatibility of module's with instructors' established content and expectations, and personal factors" (Silverthorn et al., 2006 pg. 204). Furthermore, A\&P instruction is historically a-theoretical, and without being informed by educational literature, instruction in A\&P classrooms is direct and didactic, which was likely effective when situated in the context of cadaveric or other dissections that were once commonplace. However, as the opportunities for hands-on A\&P instruction have dwindled, didactic lecturing has remained and likely replaced hands-on instructional time. Furthermore, those who have taken and then teach A\&P may sometimes harbor a "rite-of-passage-mentality," believing that because they struggled to get through the course, their current students must struggle also, so they work to preserve the conventional model. Another factor opposing curricular change in A\&P is the presence of readily accessible resources (e.g. textbooks, exams, 
standards) that perpetuate the current manner of instruction. These "teacher-proof" packages deskill and devalue the role of the instructor as a transformative intellectual by having educators simply implementing predetermined content and instructional procedures (Giroux, 2002). Lastly, A\&P curriculum is also deeply institutionalized; many feel a certain set of content must be covered in an undergraduate A\&P course. This likely stems from an altruistic motive of providing students with the content knowledge that they need to be successful in their future careers. However, research argues that reducing the amount of content and making what remains more meaningful will provide students with a more impactful educational experience and a better foundational understanding of A\&P (Griff, 2016).

Despite the factors stifling curricular change, this study examined a novel approach in which the laboratory musculoskeletal curriculum for a Human Anatomy \& Physiology course was revised and then compared to a conventional approach. The laboratory curriculum was modified as there is a need to understand how curricular change in undergraduate A\&P laboratories may affect the student experience (Griff, 2016). The curriculum was altered by creating active learning opportunities through a guided inquiry approach that utilized flipped lab experiences, as there is a need to evaluate the active learning, inquiry-based, and studentcentered approaches called for across different contexts and populations. Lastly, there is a demand for students to come to understand the underlying anatomical and physiological principles in-context, so that their A\&P knowledge becomes more sophisticated than simple memorization (Wilkerson et al., 2009; Miller et al., 2002; Griff, 2016; Bergman et al., 2011). As such, the curriculum was informed by complex systems theory and embodied cognition, to support learning in-context and develop students' understanding of the underlying anatomical and physiological principles. Explicitly grounding the curriculum in these learning theories also 
served to address the lack of theoretical grounding in A\&P education literature (Unge et al., 2018).

This study enters the A\&P educational arena at a pivotal time as we try to cope with an increased demand for our students in the face of decreasing resources, especially when less than $40 \%$ of A\&P medical students feel like they know enough anatomy to competently practice, while $73 \%$ of them feel the hours of anatomy teaching are too few (AMSA, 2006). To potentially assuage these burdens, this study served to assess bold curricular changes called for in the literature. Most importantly, this study served to advance our understanding of how we can improve the educational experiences of A\&P students, a population that will go on to directly impact the lives of many throughout their careers.

\section{Material and Methods}

In concordance with the guidelines put forth for curricular change in A\&P this study altered curriculum in three major ways: 1). The curriculum was grounded in learning theories; 2). Learning in context was promoted; and 3). Evidenced-based pedagogical approaches were implemented. These were applied to a three-week laboratory unit covering the human musculoskeletal system to determine the extent to which the experimental curriculum improved student's ability to organize A\&P information into relevant schemes of knowledge, how the experimental curriculum affected students' values of A\&P knowledge, and how the experimental curriculum affected students' perceptions of the course. The conceptual framework based in evidence-based instructional practices, complex systems theory, embodied cognition, and learning in-context informed the curricular changes implemented in this study (Table 8; full rationale and examples are provided in Supplement A). 
Table 8. Summary of conceptual framework including: guiding theories, practices, and perspectives; the tenets of each concept; and the instructional implications of each concept.

$\begin{array}{lll}\begin{array}{l}\text { Theory, Practice, or } \\ \text { Perspective }\end{array} & \text { Tenets of the concept } & \begin{array}{l}\text { Instructional implication of } \\ \text { the concept }\end{array}\end{array}$

\begin{tabular}{|c|c|c|}
\hline Complex Systems Theory & $\begin{array}{l}\text { Examines the cross-cutting } \\
\text { principles of complex } \\
\text { phenomena that have multiple } \\
\text { causes and effects while } \\
\text { coexisting at many different } \\
\text { scales of time, space, and } \\
\text { organization. }\end{array}$ & $\begin{array}{l}\text { The cross-cutting principles } \\
\text { of self-organization, multi- } \\
\text { scale hierarchies, } \\
\text { interdependence, and } \\
\text { emergent properties were } \\
\text { applied to the curriculum. }\end{array}$ \\
\hline $\begin{array}{l}\text { Embodied Cognition } \\
\text { Theory }\end{array}$ & $\begin{array}{l}\text { States of the body modify } \\
\text { states of the mind relative to } \\
\text { the task at hand, the resources } \\
\text { available to solve that task, } \\
\text { and how those resources are } \\
\text { assembled. }\end{array}$ & $\begin{array}{l}\text { Questioning was changed to } \\
\text { compel students to } \\
\text { cognitively engage in more } \\
\text { complex and demanding } \\
\text { ways, often coinciding with } \\
\text { active learning techniques. }\end{array}$ \\
\hline Leaning In-content & $\begin{array}{l}\text { Thousands of years of A\&P } \\
\text { insights have arisen through } \\
\text { picking the human body } \\
\text { apart, producing an } \\
\text { isolationist mentality. } \\
\text { Learning in-context scaffolds } \\
\text { innate schemes of knowledge } \\
\text { in human organization. }\end{array}$ & $\begin{array}{l}\text { Bones and muscles were } \\
\text { simultaneously examined } \\
\text { through a functional lens. Use } \\
\text { of whole-body skeletons and } \\
\text { muscle diagrams was } \\
\text { emphasized. }\end{array}$ \\
\hline $\begin{array}{l}\text { Evidenced-Based } \\
\text { Pedagogical Practices }\end{array}$ & $\begin{array}{l}\text { Instruction can, and should, } \\
\text { be informed by well- } \\
\text { researched and evidenced- } \\
\text { based practices. }\end{array}$ & $\begin{array}{l}\text { Active learning experiences } \\
\text { were created through } \\
\text { implementing flipped labs } \\
\text { and utilizing guided inquiry } \\
\text { techniques. }\end{array}$ \\
\hline
\end{tabular}

\section{Research Setting}

This research was conducted during the spring and fall semesters of 2019 at an R2, public institution in the Midwest. The course was the first in a two-course sequence of human anatomy and physiology, taught in a life sciences department. The laboratory sections of the course served as the primary research setting for this study; only the laboratory curriculum was changed. 


\section{Participants}

This course is primarily composed of first- and second-year nursing students, with some third- and fourth-year students from a variety of other majors, including biology, biochemistry, exercise science, and athletic training. Additionally, $81 \%$ of students aspired to enter primary healthcare career, while $15 \%$ intended to enter an allied health profession. Participants were aged 18-22.

\section{Implementation of Instructional Treatments}

Over the course of the spring and fall semesters of 2019, comparison and experimental curricula were simultaneously taught to different laboratory sections of the same course. In the spring, the first author taught two sections of the experimental curriculum while concurrently teaching two sections of the comparison curriculum. To decide which sections were to receive the experimental curriculum and which to were receive the comparison, a coin was flipped. Prior to the coin flip the four potential experimental sections were arranged into two groups of two sections each; these groups were created to ensure that the experimental and comparison sections were comprised of students from similar majors. In the fall semester, the first author taught two sections of the experimental curriculum, while a graduate teaching assistant taught four sections of the comparison curriculum. This potentially introduced instructor effects which were tested for using an unequal variance t-test, with instructor predicting percent change between pre- and post-treatment scores on the ALEQ; instructor effects were not detected (Table 1).

\section{Data Collection}

The research questions were addressed via a mixed-methods approach. The Anatomy Learning Experiences Questionnaire (ALEQ; Choi-Lundberg et al., 2017) was utilized to gather quantitative feedback about students' perceptions of the course and their value of anatomical 
knowledge. The modified version contains 27 items to which students respond on a 5-point Likert scale. These 27 statements load onto three factors measured by three subscales comprising the ALEQ: challenges in learning anatomy, applications and importance of anatomy, and learning in the dissection laboratory. In this study, consenting students were asked to complete this questionnaire immediately prior to instructional treatment (i.e., the three-week laboratory unit on the musculoskeletal system) and then immediately after instructional treatment, constituting pre- and post-treatment measures. The questionnaire was administered via Qualitrics, and a link to it was emailed out to students by the second author. Demographic information was gathered on the pre-treatment questionnaire. Extra credit was offered for completion of questionnaires. These quantitative pre-treatment and post-treatment measures were carried out in the spring and fall semesters of 2019.

Qualitative data were also gathered to address the research questions of this study. Interview procedures differed between the spring and fall semesters.

In the spring semester, 7 students were interviewed by the second author. Interviews were semi-structured, driven by an a priori interview protocol from which the interviewer deviated as needed to pursue the research questions (Supplement C). The pre- and post-treatment interview protocols were identical, except they were asking about different A\&P content. The pretreatment interviews asked students about epithelial tissues, which was the unit covered just prior to the instructional treatment, and the post-treatment interviews asked students about the musculoskeletal system. These interviews provided qualitative data about students' perceptions of the course and value placed on anatomical and physiological knowledge, as well as how that knowledge was organized. During pre- and post-treatment interviews in the spring semester, students were asked to complete a concept-mapping task, which gauged students' abilities to 
organize their A\&P knowledge. The interview participants were broadly informed of what a concept map is and then asked to assemble a preset bank of terminology from either the epithelial or musculoskeletal unit into a concept map. The terminology was printed onto paper, laminated, cut into cards, and then magnetized so that students could create their maps on a whiteboard and use markers to draw in the framework of their maps. All pre-treatment interviews used the same set of terminology from the epithelial system, and all post interviews used the same set of terminology from the musculoskeletal system. These interviews were incentivized with $\$ 10$ gift cards for each interview.

Interview structure in the fall of 2019 was designed to follow up on questions that arose from statistical analysis completed on the spring semester ALEQ data, in which some individual items on the ALEQ showed statistically significant change in favor of the experimental curriculum, despite a small sample size (Table 2). No items on the spring semester ALEQ favored the traditional curriculum.

Consequently, the fall interview protocol was designed to further investigate the nature of student's perceptions about the significant items (Supplemental C). These interviews, again conducted by the second author, occured at the end of the semester; 6 students consented to participate in the fall of 2019 interviews.

\section{Data Analysis}

Three types of data were collected and analyzed from students in this study: ALEQ responses, interviews, and concept-mapping tasks. The following sections describe how each type of data was analyzed. 


\section{ALEQ}

Students responses to both the pre- and post-treatment questionnaires were exported from Qualitrics into Microsoft Excel, organized, and then analyzed in IBM SPSS Statistics 25 (SPSS). Initially, individual items from the spring ALEQ dataset were compared to detect areas of difference. Two-sample equal-variance t-tests were used for all items except item 18, which demonstrated unequal variance in the post-instruction, so this item was analyzed using a twosample unequal variances t-test (Table 2). Matched ALEQ scores from the spring and fall semesters were pooled after running a two-sample unequal variances t-test on the prequestionnaire data comparing the spring and fall semesters, which indicated comparability between the two semesters $\left(\mathrm{t}_{(41)}=1.55, \mathrm{p}=.12\right)$. The matched and pooled ALEQ scores for the entire questionnaire and each factor were analyzed via a mixed ANOVA, and the ALEQ mean scores for the first and third factors were compared across treatments via a two-sample equal variances t-test. Factor 2 was found to have unequal variances; therefore, factor 2 was analyzed via a two-sample unequal variances t-test.

\section{Interviews}

The interviews from both semesters were transcribed utilizing Temi transcriptions services. The spring interviews were systematically open-coded to identify emergent themes, using a grounded theory approach (Corbin \& Strauss, 2008). All coding was done by hand on printed interview transcripts. First, the pre-instructional treatment interviews were coded from the comparison instructional treatment. Then, the post-instructional treatment interviews were coded from the comparison treatment. This process was then replicated for the experimental instructional treatment. After the open coding was completed, code lists were compiled for the pre- and post-instruction interviews from each treatment. Each interview was then axially coded 
based on the code lists compiled for each set of interviews within each instructional treatment, refining codes and using the constant comparative method as the coding progressed. The interviews from the fall semester were then coded utilizing the codebook produced from the spring semester interviews as an a priori codebook.

\section{Concept Maps}

The concept maps were coded with a set of four a priori codes applied consistently to all concept maps regardless of instructional treatment and pre- or post-treatment status. The first code identified the map as structurally- (i.e., fundamentally arranged around the structure terms) or functionally-based (arranged around the function terms). The second code was whether the organizational scheme was student-created or class-adopted. The third code was concerning the presence, or absence, of integration of structure and function. Each map was a code of yes or no for integration. The third code is in some ways a precursor to the fourth, as the fourth code asks: Does this concept map constitute a scheme of knowledge, or an abstracted generalizable pattern where structure and function are interdependent, represented by the integration of cards and their organization. Students may know that a structure is associated with a function but may not indicate the function's higher-order significance, in which case, that concept map was coded as an assemblance of facets rather than a scheme of knowledge. If there was a scheme of knowledge, this was then coded in one of two ways: structure determines function or function determines structure. The secondary code for scheme of knowledge was determined by the hierarchical categories into which students placed the cards. If the hierarchical categories were function cards, the map would be coded function determines structure, and vice versa.

In addition to a priori coding, the number of unused and incorrect cards were also enumerated for each concept map. Finally, after coding all the concept maps, each map was 
placed into one of three categories: highly organized, moderately organized, and poorly organized. Highly organized concept maps integrated structure and function into a scheme of knowledge, and their total number of unused and incorrect cards was 5 or less. Moderately organized concept maps integrated structure and function, though not consistently into a scheme of knowledge and their total number of incorrect and unused cards was 5 to 8 . Lastly, poorly organized concept maps did not integrate structure and function at all, and their total number of incorrect and unused cards ranged from 2 to 7.

\section{Results}

\section{ALEQ}

Eighteen students from the experimental curriculum, across spring and fall semesters, completed both the pre- and post-questionnaire, while 27 students from the comparison curriculum completed both questionnaires. The fall and spring semester data was pooled after a comparison of the semester revealed that they were not significantly different $\left(\mathrm{t}_{(41)}=1.55, \mathrm{p}=\right.$ .12). The matched and pooled data was then determined to be comparable across treatments as the pre-questionnaire responses were demonstrated not be significantly different $\left(\mathrm{t}_{(43)}=1.11, \mathrm{p}\right.$ $=.27$ ). When analyzing the matched and pooled data, a significant effect of treatment was found in favor of the experimental curriculum, such that the experimental curriculum students had higher overall ALEQ scores $\left(\mathrm{F}_{(1,43)}=4.33, \mathrm{p}=.04\right.$; Figure 3$)$.

However, the effect of time, and the treatment*time interaction were found to be nonsignificant indicating that there were no significant differences in pre/post gains between the two curricular treatments $\left(\mathrm{F}_{(1,43)}=.654, \mathrm{p}=.42 ; \mathrm{F}_{(1,43)}=.233, \mathrm{p}=.63\right.$; Figure 1$)$. Notably, the matched and pooled average ALEQ scores dropped from pre- to post-questionnaire, indicating that students' perceptions and values of the course are decreasing over the three-week span (Figure 1). 
Individual factors on the ALEQ were also compared; students from the experimental curriculum reported significantly higher scores in factor one, challenges in learning anatomy $\left(\mathrm{t}_{(43)}=1.64, \mathrm{p}\right.$ $=.05 ;$ Figure 5$)$.

This indicates that students receiving the experimental curriculum perceived fewer barriers to learning or were more prepared to deal with barriers to learning. No significant differences were found for factor two or factor three, but factor three approached statistical significance $\left(\mathrm{t}_{(43)}=\right.$ $.44, \mathrm{p}=.33 ; \mathrm{F}_{(43)}=1.46, \mathrm{p}=.07 ;$ Figure 2$)$.

\section{Interviews}

Eighteen interviews were completed with 13 students spread across the fall and spring semesters. Several emergent themes emerged from the data: "career goals," "a lot," "memorization," “exclusion," and "how."

\section{Career Goals}

Twelve of the 13 students interviewed stated that their desire to enter a career in healthcare was the primary reason they value anatomical and physiological information. The 1 student who did not state this was a statistics major taking the course as an elective. Of the 75 students who took the pre-instruction questionnaire, $96 \%$ reported working towards future careers in healthcare, with $81 \%$ of students indicating aspirations to enter primary healthcare and $15 \%$ entering allied health, respectively. Most students viewed this course as foundational content for their future practices, while one student reported that $\mathrm{A} \& \mathrm{P}$ is the basis of critical thinking in nursing.

\section{A Lot}

Students simply feel that there is a lot of content in A\&P. All students interviewed indicated that they felt there is a large amount of material, while 2 students explicitly stated that 
they feel there is too much content to meaningfully understand it. Five students said that the course moves too quickly to develop an understanding of the material because there is so much to get through. Many of students reported that they would like changes in the depth versus breadth of material covered, suggesting that there should be three A\&P courses instead of two for the content to successfully be covered in depth. Other students suggested sacrificing depth and time spent on details so that they could achieve a more functional understanding of the content.

\section{Overwhelmed/Frustrated}

Seven of the 13 students interviewed reported that they felt overwhelmed or frustrated by the course, often in reference to the amount of material. A handful of students also indicated that they were frustrated or overwhelmed because they felt as if they were not developing the understanding necessary to effectively practice healthcare in their future careers.

\section{Memorization or Exclusion}

Students are overwhelmed by the amount of content they must learn in A\&P, often compelling them to surface-level memorization of material or exclude material altogether. All 7 students who reported feeling overwhelmed indicated that they either only seek to memorize material for the exams, or just completely exclude material they do not feel will be relevant or represented on the exams. Most students interviewed initially felt like they had to memorize every single detail in the course but over time learned that was not feasible, often leading them to exclude material outright or utilize shallow memorization techniques. Moreover, the majority of students interviewed indicated that to improve they simply need to work more, memorize more, study more, and employ more rote memorization strategies. 


\section{How}

All students interviewed indicated that it is important to understand how the body works. The 12 students pursuing careers in healthcare reported that they must know how the body works to have successful careers are correctly provide care, while some students, including the nonhealthcare student, also indicated that there is a broader and more general importance to understanding how your body works in everyday scenarios. Students have a desire to be able to apply a functional understanding of A\&P to their careers and to their everyday lives. However, many of the students feel like we are asking them to memorize content that they inevitably forget after their exams, serving to further frustrate them. Students recognize that their careers will not be structured like this course, and that they will have to engage with A\&P information very differently on the job. As such, they want change because "if it's going to be practical in the real world, we should make it practical while learning it" (participant interview).

\section{Student Architypes}

Two student architypes emerged from the data: students who seek to understand, understanders, and students who seek to memorize, memorizers. These two dispositions are not completely mutually exclusive as students can switch dispositions; however, these two architypes have very different experiences in the same classroom. Understanders seek a deep, relevant, and functional understanding of A\&P so they can go on to apply it to their careers and lives. Understanders often seek outside resources as the discourse in class is centered around memorization and content recall, not facilitating the deep understanding they are pursuing. As such, understanders feel that there is a misalignment between what they value, a functional grasp of content, and what the course emphasizes through assessments and lecture, which they feel is simple recall. This misalignment means that understanders are often forced into creating their 
own schemes of knowledge because the ones provided in class do not align with their disposition. In this way, students that are understanders seek to understand the how of A\&P but are asked what questions in their A\&P course. In contrast, memorizers are students that seek to memorize the content, which will get them through the course and the grade they want in the class. Memorizers primarily rely upon in-class materials and utilize repetition and rote memorization techniques to attain the content recall necessary to succeed in the course. Moreover, since the course's model of instruction aligns with their goals, these students adopt the schemes of knowledge presented in class and then simply attempt to memorize them.

As previously mentioned, these architypes are not mutually exclusive, and students may switch between the two when they see one as more relevant. For instance, one student chose to exclude learning the names of muscles but saw the epithelial tissues as relevant to their career and therefore sought a more functional understanding of those tissues. Generally, students receiving conventional instruction are pushed into becoming memorizers over time. Many students likely enter into conventional A\&P courses with an understander disposition. However, due to a fast pace, content-heavy, and lecture-heavy style of instruction that rewards surfacelevel content recall, these understanders are forced to become memorizers so that can simply make it through the course.

\section{Concept Maps}

No significant differences were found in students' concept maps when comparing them across treatments (Table 9). However, it is notable that all students' concept maps decreased in their level of organization from pre- to post-interviews (Table 9). 
Table 9. Results of concept maps including treatment, student pseudonym, interview, classifying information, and classifications.

\begin{tabular}{|c|c|c|c|c|c|c|c|c|}
\hline Treatment & $\begin{array}{l}\text { Student } \\
\text { Name }\end{array}$ & $\begin{array}{l}\text { 1st or } 2 \text { nd } \\
\text { Interview }\end{array}$ & $\begin{array}{l}\text { Structure (S) } \\
\text { or Function } \\
\text { (F) Based }\end{array}$ & $\begin{array}{l}\text { Student } \\
\text { Created or } \\
\text { Class } \\
\text { Adopted }\end{array}$ & $\begin{array}{l}\text { Integration } \\
Y / N\end{array}$ & $\begin{array}{l}\text { Scheme of } \\
\text { Knowledge } \\
Y / N\end{array}$ & $\begin{array}{l}\text { \% of cards } \\
\text { (incorrect, } \\
\text { unused) }\end{array}$ & Classification \\
\hline \multirow[t]{6}{*}{ COMP } & \multirow[t]{2}{*}{ Anna } & 1st & $\mathrm{F}$ & Created & $Y$ & $Y$ & 0,15 & High \\
\hline & & $2 n d$ & $S$ & Created & $N$ & $N$ & 0,17 & Moderate \\
\hline & \multirow[t]{2}{*}{ Jenny } & $1 s t$ & $S$ & Adopted & Y & Y & 10,15 & High \\
\hline & & $2 n d$ & $S$ & Created & $\mathrm{N}$ & $\mathrm{N}$ & 0,8 & Poor \\
\hline & \multirow[t]{2}{*}{ Sara } & $1 s t$ & S & Adopted & $Y$ & $N$ & 0,21 & Moderate \\
\hline & & $2 n d$ & $S$ & Adopted & $\mathrm{N}$ & $\mathrm{N}$ & 0,30 & Poor \\
\hline \multirow[t]{6}{*}{ EXP } & \multirow[t]{2}{*}{ Holly } & $1 \mathrm{st}$ & $S$ & Adopted & Y & Y & 5,15 & High \\
\hline & & $2 n d$ & $\mathrm{~F}$ & Created & $\mathrm{N}$ & $N$ & 21,0 & Moderate \\
\hline & \multirow[t]{2}{*}{ Raquel } & $1 \mathrm{st}$ & $S$ & Adopted & Y & Y & 15,26 & Moderate \\
\hline & & $2 n d$ & $\mathrm{~F}$ & Created & Y & $N$ & 8,0 & Poor \\
\hline & \multirow[t]{2}{*}{ Catie } & $1 s t$ & $F$ & Created & $Y$ & Y & 0,21 & High \\
\hline & & 2nd & $\mathrm{F}$ & Created & $\mathrm{N}$ & $\mathrm{N}$ & 0,17 & Moderate \\
\hline
\end{tabular}




\section{Discussion}

There is an alarming trend that emerges from the data collected in this study. More than $90 \%$ of participating students exhibited decreases in the measured student outcomes between pre- and post-measures. Comparison treatment student responses to ALEQ substantially decreased between pre- and post-measures, and while to a lesser degree, the experimental treatment students' responses decreased as well (Figure 3). This trend is underscored by the concept map data, as all students participating in concept mapping tasks demonstrated less organized A\&P knowledge in the second interview, compared to the first (Table 9). This could be due to a difference in content difficulty, as the first concept mapping task was on the epithelial tissues, and the second task asked students to map the musculoskeletal system. However, when examined in concert with the ALEQ data, which shows that student perceptions and values of A\&P decreased over time simultaneously with students' organizational ability, we must consider the possibility that either laboratory curriculum and/or the broader course format are undermining students' organization of their A\&P knowledge and an accompanying shift toward memorization, just to get by in the course. This hypothesis becomes particularly salient when the findings from thematic analysis of the interviews are also considered, as this study seems to have captured a dispositional shift from understanding to memorization. Students exhibited the ability to maintain the goal of understanding content at least until the third week of the semester, when the pre-assessment measures were administered. However, when transitioning from the introductory and epithelial tissues unit into the musculoskeletal system unit, which occupied weeks 4-6 of the semester, students felt that maintaining an understanding disposition would undermine performance in the course. The large amount of content and terminology in the 
musculoskeletal system was not conducive to understanding how the system works. Moreover, assessments that require simple recall predominated this unit and rewarded surface-level memorization. Therefore, students adopted the shallow memorization disposition called for by the content, instruction, and means of assessment. This shift was seen in 4 of the 6 students that participated in concept mapping tasks, and 5 additional students eluded to this dispositional shift in their interviews.

Nevertheless, the experimental laboratory curriculum examined in this study shows promise, indicated by comparison of pre/post ALEQ scores across the two treatments, in which the experimental treatment decreased less on factor 1, challenges in learning anatomy, than the comparison treatment. In other words, students were perceiving fewer challenges within the course. The experimental curriculum was constructed to generate active learning opportunities that are relevant to students' everyday lives and future careers. By teaching how functions are achieved and not constraining the curriculum to one system, students were able to genuinely explore how the body moves and why that is relevant to them, ultimately allowing students to come to the functional understanding they desired. This curriculum was also grounded in evidenced-based practices (i.e., guided inquiry, flipped labs, learning in-context), learning theories (i.e., complex systems theory, embodied cognition), and contemporary perspectives of the human body such that it aligns with prior A\&P education research findings. Considering the findings from this study and the literature it was built upon, we put forth a set of guiding questions to drive a laboratory unit addressing the musculoskeletal system (Figure 6). 
Figure 6. Proposed laboratory sequence

How \& why do we...

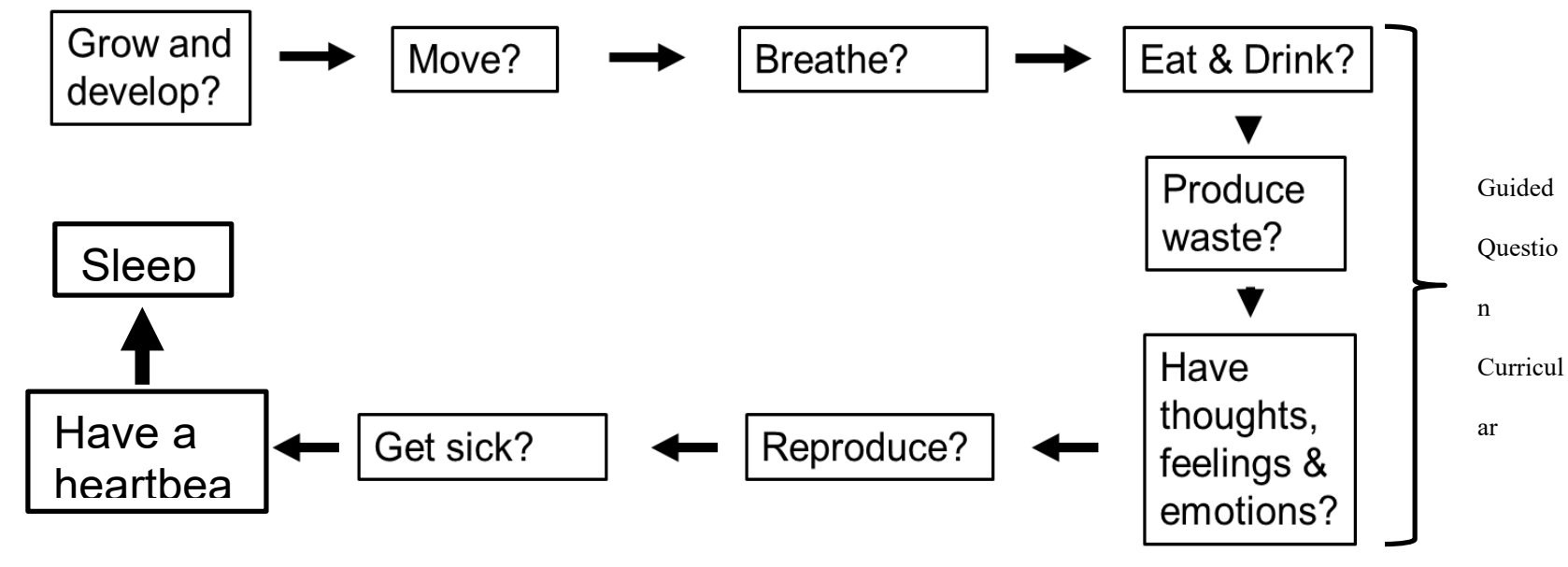

A question-driven curriculum such as this one would provide A\&P educators freedom to include all systems relevant to addressing one broad function that students are familiar with and likely have an existing scheme of knowledge of, enabling them to organize new A\&P facets within their existing schemata, something explicitly called for in the literature (Griff, 2016). Moreover, these broad overarching functions are what students explicitly stated they care most about during our interviews. As such, framing the curricula in this way may serve to foster increased student engagement, lasting-content knowledge, and an understanding of the underlying principles of anatomy. This curricular model may also serve to open the door for different forms of student assessment that reward a deep and functional understanding.

While the findings from this study suggest utility in this curricular model, there are some noteworthy limitations. First, the demographics of our participants are limiting because $87 \%$ of ALEQ respondents identified as White/Euro-American and 85\% identified as female. Moreover, the sample sizes are not large enough to draw broad generalizable conclusions. Additionally, there is a difference in difficulty of content between the pre- and post-assessments. Across both treatments, students were engaged with the epithelial tissues prior to the pre assessment and the 
musculoskeletal system prior to the post assessment. This difference in content difficulty could have potentially affected students' ALEQ scores. Another consideration is that the form of student assessment in lab was not changed due to feasibility constraints, and as assessments drive student learning and studying, there was little incentive for students to develop an understanding disposition or full-bodied schemes of knowledge. Last of all, the effects of a three-week unit on students' scheme building capacity, perceptions, and values are bound to be minimal, as these are all on-going long-term processes. Therefore, the curricular changes outlined in this study show promise, as they significantly improved long-term student outcomes in a short window of time, when students had little incentive change their disposition.

\section{Conclusions and Research Prospects}

Students seek a functional understanding of how A\&P systems work, rather than an encyclopedic knowledge of human form. When given the opportunities to develop a functional understanding of the how of A\&P, students exhibit significantly better educational outcomes when compared to students receiving a conventional curriculum.

Data collected in this study generated several evidenced-based hypotheses that deserve further attention. The first emergent hypothesis is that A\&P students have improved educational outcomes when the curriculum is framed around understanding how functions happen, specifically by focusing them on functionally bound structures, as opposed to identifying what structures are. This would occur because students feel that there is a lot of information in A\&P, which overwhelms them and leads them to adopt shallow memorization techniques or exclude information altogether. A second emergent hypothesis is that there are two basic archetypical students in A\&P, understanders and memorizers, and the disposition that emerges is prompted by amount of materials the students perceive they must memorize to be successful in the class. 
Further, A\&P students place a high value on A\&P knowledge, acknowledging its relevant to their future careers in healthcare and lives in general, but their value of A\&P knowledge decreases when they shift to the memorizer disposition. Future research should assess the validity of the outlined curricular changes across an entire semester or sequence of A\&P, and across varying demographics, to validate their utility. Also, future work could change assessment so that it reflects our goals of understanding. These are very important lines of research to continue as curricular change is something everyone can do to assuage the pressures placed on A\&P instruction today. 


\section{Literature Cited}

AAMC. (1984). Physicians for the twenty-first century. Report of the Project Panel on the General Professional Education of the Physician and College Preparation for Medicine. Journal of Medical Education, $59(11$ Pt 2), 1-208.

AAMC-HHMI. (2009). Scientific Foundations for Future Physicians. Association of American Medical Colleges and the Howard Hughes Medical Institute Committee Report, 46.

AMSA. (2006) A submission to the department of Education, Science, and Training's Medical Education Study. Melbourne: Australian Medical Students Association

ACME-TRI. (1993). Educating medical students: assessing change in medical education - the road to implementation. Academic Medicine, 68.

Bain, K. (2004). What the best college teachers do. Harvard University Press.

Bakr, M. M., Massey, W. L., \& Massa, H. M. (2016). Flipping a Dental Anatomy Course: A Retrospective Study Over Four Years. Education Research International, 2016, 1-9. https://doi.org/10.1155/2016/7097398

Bergman, E. M., Van Der Vleuten, C. P. M., \& Scherpbier, A. J. J. A. (2011). Why don't they know enough about anatomy? A narrative review. Medical Teacher, 33(5), 403-409. https://doi.org/10.3109/0142159X.2010.536276

Berman, A. C. (2015). Good teaching is good teaching: A narrative review for effective medical educators: Good Teaching Is Good Teaching. Anatomical Sciences Education, 8(4), 386394. https://doi.org/10.1002/ase. 1535

Brown, P. J. P. (2010). Process-oriented guided-inquiry learning in an introductory anatomy and physiology course with a diverse student population. Advances in Physiology Education, 34(3), 150-155. https://doi.org/10.1152/advan.00055.2010 
Casotti, G., Rieser-Danner, L., \& Knabb, M. T. (2008). Successful implementation of inquirybased physiology laboratories in undergraduate major and nonmajor courses. Advances in Physiology Education, 32(4), 286-296.

Choi-Lundberg, D. L., Williams, A.-M. M., \& Zimitat, C. (2017). A psychometric evaluation of the anatomy learning experiences questionnaire and correlations with learning outcomes. Anatomical Sciences Education, 10(6), 514-527. https://doi.org/10.1002/ase.1693

Corbin, J., \& Strauss, A. (2008). Basics of Qualitative Research (3rd ed.): Techniques and Procedures for Developing Grounded Theory. SAGE Publications, Inc. https://doi.org/10.4135/9781452230153

Darda, D. M. (2010). Observations by a university anatomy teacher and a suggestion for curricular change: Integrative anatomy for undergraduates. Anatomical Sciences Education, 3(2), 73-76.

Drake, R. L. (1998). Anatomy education in a changing medical curriculum. The Anatomical Record: An Official Publication of the American Association of Anatomists, 253(1), 28-31.

Drake, R. L. (2014). A retrospective and prospective look at medical education in the United States: Trends shaping anatomical sciences education. Journal of Anatomy, 224(3), 256260. https://doi.org/10.1111/joa.12054

Drake, R. L., McBride, J. M., Lachman, N., \& Pawlina, W. (2009). Medical education in the anatomical sciences: The winds of change continue to blow. Anatomical Sciences Education, 2(6), 253-259.

Drake, R. L., \& Pawlina, W. (2014). Multimodal education in anatomy: The perfect opportunity. Anatomical Sciences Education, 7(1), 1-2. https://doi.org/10.1002/ase.1426 
Ettarh, R. (n.d.). Anatomy Past and Present: Evolution of Curriculum and Teaching in Anatomy. Journal of Anatomy, 2.

Farrell, J. J., Moog, R. S., \& Spencer, J. N. (1999). A Guided-Inquiry General Chemistry Course. Journal of Chemical Education, 76(4), 570. https://doi.org/10.1021/ed076p570

Favero, T. G., \& Van Hoomissen, J. D. (2019). Leveraging undergraduate research to identify culturally relevant examples in the anatomy and physiology curriculum. Advances in Physiology Education, 43(4), 561-566.

GMC. (1991) Undergraduate Medical Education. The need for change. London: General Medical Council.

GMC. Education Committee. (1993). Tomorrow's doctors: recommendations on undergraduate medical education (pp. 1-28). London: General Medical Council.

Gibbs, G., Britain), C. for N. A. A., \& Britain), I. S. L. P. (1992). Improving the quality of student learning: Based on the Improving Student Learning Project funded by the Council for National Academic Awards. Bristol : Technical and Education Services. https://trove.nla.gov.au/version/28353819

Giroux, H. (2002). Teachers as transformatory intellectuals. EDucate, 1(2).

Griff, E. R. (2016). Changing undergraduate human anatomy and physiology laboratories: Perspectives from a large-enrollment course. Advances in Physiology Education, 40(3), 388-392.

Harrison, J. F., Nichols, J. S., \& Whitmer, A. C. (2001). Evaluating the impact of physical renovation, computerization, and use of an inquiry approach in an undergraduate, allied health human anatomy and physiology lab. Advances in Physiology Education, 25(4), 202210. 
Heylings, D. J. A. (2002). Anatomy 1999-2000: The curriculum, who teaches it and how? Medical Education, 36(8), 702-710.

Hughes, P. W., \& Ellefson, M. R. (2013). Inquiry-based training improves teaching effectiveness of biology teaching assistants. PLoS ONE, 8(10). https://doi.org/10.1371/journal.pone.0078540

Kalb, K. A. (2012). Breaking Down Silos, Building Up Teams. HEALTH PROGRESS, 9. Kuyatt, B. L., \& Baker, J. D. (2014). Human anatomy software use in traditional and online anatomy laboratory classes: Student-perceived learning benefits. Journal of College Science Teaching, 43(5), 14-19.

Leung, K., Lu, K.-S., Huang, T.-S., \& Hsieh, B.-S. (2006). Anatomy instruction in medical schools: Connecting the past and the future. Advances in Health Sciences Education, 11(2), 209-215.

Lowry, S. (1992). Strategies for implementing curriculum change. BMJ: British Medical Journal, 305(6867), 1482.

Mattheis, A., \& Jensen, M. (2014). Fostering improved anatomy and physiology instructor pedagogy. Advances in Physiology Education, 38(4), 321-329.

Mckeown P, Heylings D, Stevenson M, Mckelvey K, Nixon J, \& Mccluskey D. (2003). The impact of curricular change on medical students' knowledge of anatomy. Medical Education, 37(11), 954-954.

McMenamin, P. G., Quayle, M. R., McHenry, C. R., \& Adams, J. W. (2014). The production of anatomical teaching resources using three-dimensional (3D) printing technology: 3D Printing in Anatomy Education. Anatomical Sciences Education, 7(6), 479-486. https://doi.org/10.1002/ase.1475 
Michael, J. (2006). Where's the evidence that active learning works? Advances in Physiology Education, 30(4), 159-167. https://doi.org/10.1152/advan.00053.2006

Miller, S. A., Perrotti, W., Silverthorn, D. U., Dalley, A. F., \& Rarey, K. E. (2002). From college to clinic: Reasoning over memorization is key for understanding anatomy. The Anatomical Record: An Official Publication of the American Association of Anatomists, 269(2), 69-80.

Mitchell, R., \& Batty, L. (2009). Undergraduate perspectives on the teaching and learning of anatomy. ANZ Journal of Surgery, 79(3), 118-121.

Mitrousias, V., Varitimidis, S. E., Hantes, M. E., Malizos, K. N., Arvanitis, D. L., \& Zibis, A. H. (2018). Anatomy learning from prosected cadaveric specimens versus three-dimensional software: A comparative study of upper limb anatomy. Annals of Anatomy-Anatomischer Anzeiger, 218, 156-164.

Motoike, H. K., O’Kane, R. L., Lenchner, E., \& Haspel, C. (2009). Clay modeling as a method to learn human muscles: A community college study. Anatomical Sciences Education, 2(1), 19-23. https://doi.org/10.1002/ase.61

Myers, T. W. (2014). Anatomy Trains: Myofascial Meridians for Manual and Movement Therapists. Churchill Livingstone.

National Center for Science Education (2020, February 9). Evolution: Feel it in your fingers and feel it in your toes $\mid$ National Center for Science Education. (n.d.). Retrieved February 20, 2020, from https://ncse.ngo/evolution-feel-it-your-fingers-and-feel-it-your-toes

Nayak, S., Ramnarayan, K., Somayaji, N., \& Bairy, K. L. (n.d.). Teaching anatomy in a problem-based learning (PBL) curriculum. 3.

Nisa, E. K., Koestiari, T., Habibbulloh, M., \& Jatmiko, B. (2018). Effectiveness of guided inquiry learning model to improve students' critical thinking skills at senior high school. 
Journal of Physics: Conference Series, 997, 012049. https://doi.org/10.1088/1742$6596 / 997 / 1 / 012049$

Rao, S. P., \& DiCarlo, S. E. (2001). ACTIVE LEARNING OF RESPIRATORY PHYSIOLOGY IMPROVES PERFORMANCE ON RESPIRATORY PHYSIOLOGY EXAMINATIONS. Advances in Physiology Education, 25(2), 55-61. https://doi.org/10.1152/advances.2001.25.2.55

Rathner, J. A., \& Byrne, G. (2014). The use of team-based, guided inquiry learning to overcome educational disadvantages in learning human physiology: A structural equation model. Advances in Physiology Education, 38(3), 221-228. https://doi.org/10.1152/advan.00131.2013

Silverthorn, D. U., Thorn, P. M., \& Svinicki, M. D. (2006). It's difficult to change the way we teach: Lessons from the Integrative Themes in Physiology curriculum module project. Advances in Physiology Education, 30(4), 204-214.

Smith, C. E. (2017). The flipped classroom: Benefits of student-led learning. Nursing, 47(4), 2022. https://doi.org/10.1097/01.NURSE.0000513620.19174.90

Smith, C. F., \& Mathias, H. S. (2009). Medical students' approaches to learning anatomy: Students' experiences and relations to the learning environment. Clinical Anatomy, NA-NA. https://doi.org/10.1002/ca.20900

Stein, H., \& Galili, I. (2015). THE IMPACT OF AN OPERATIONAL DEFINITION OF THE WEIGHT CONCEPT ON STUDENTS'UNDERSTANDING. International Journal of Science and Mathematics Education, 13(6), 1487-1515. 
Sugand, K., Abrahams, P., \& Khurana, A. (2010b). The anatomy of anatomy: A review for its modernization. Anatomical Sciences Education, 3(2), 83-93.

https://doi.org/10.1002/ase.139

Trust, T., Carpenter, J. P., \& Krutka, D. G. (2017). Moving beyond silos: Professional learning networks in higher education. The Internet and Higher Education, 35, 1-11. https://doi.org/10.1016/j.iheduc.2017.06.001

Unge, J., Lundh, P., Gummesson, C., \& Amnér, G. (2018). Learning spaces for health scienceswhat is the role of e-learning in physiotherapy and occupational therapy education? A literature review. Physical Therapy Reviews, 23(1), 50-60.

White, A. O., Javier, L. K., Goldberg, N. R., Boucquey, V., Overman, J., Ochaba, J., Marsh, S., Huffman, D., \& Nicholas, A. (2017). Front and Back Flipping for Neurobiology! Developing a Hybrid Upper-Division Lab Course. Journal of Undergraduate Neuroscience Education, 16(1), A95-A101.

Wilkerson, L., Stevens, C. M., \& Krasne, S. (2009). No content without context: Integrating basic, clinical, and social sciences in a pre-clerkship curriculum. Medical Teacher, 31(9), 812-821. https://doi.org/10.1080/01421590903049806

Wilson, A. D., \& Golonka, S. (2013). Embodied cognition is not what you think it is. Frontiers in Psychology, 4, 58. 


\section{REFERENCES}

AAMC. (1984). Physicians for the twenty-first century. Report of the Project Panel on the General Professional Education of the Physician and College Preparation for Medicine. Journal of Medical Education, 59(11 Pt 2), 1-208.

AAMC-HHMI. (2009). Scientific Foundations for Future Physicians. Association of American Medical Colleges and the Howard Hughes Medical Institute Committee Report, 46.

AMSA. (2006) A submission to the department of Education, Science, and Training's Medical Education Study. Melbourne: Australian Medical Students Association

ACME-TRI. (1993). Educating medical students: assessing change in medical education - the road to implementation. Academic Medicine, 68.

Bain, K. (2004). What the best college teachers do. Harvard University Press.

Bakr, M. M., Massey, W. L., \& Massa, H. M. (2016). Flipping a Dental Anatomy Course: A Retrospective Study Over Four Years. Education Research International, 2016, 1-9. https://doi.org/10.1155/2016/7097398

Bergman, E. M., Van Der Vleuten, C. P. M., \& Scherpbier, A. J. J. A. (2011). Why don't they know enough about anatomy? A narrative review. Medical Teacher, 33(5), 403-409. https://doi.org/10.3109/0142159X.2010.536276

Berman, A. C. (2015). Good teaching is good teaching: A narrative review for effective medical educators: Good Teaching Is Good Teaching. Anatomical Sciences Education, 8(4), 386394. https://doi.org/10.1002/ase.1535

Brown, P. J. P. (2010). Process-oriented guided-inquiry learning in an introductory anatomy and physiology course with a diverse student population. Advances in Physiology Education, 34(3), 150-155. https://doi.org/10.1152/advan.00055.2010 
Casotti, G., Rieser-Danner, L., \& Knabb, M. T. (2008). Successful implementation of inquirybased physiology laboratories in undergraduate major and nonmajor courses. Advances in Physiology Education, 32(4), 286-296.

Choi-Lundberg, D. L., Williams, A.-M. M., \& Zimitat, C. (2017). A psychometric evaluation of the anatomy learning experiences questionnaire and correlations with learning outcomes. Anatomical Sciences Education, 10(6), 514-527. https://doi.org/10.1002/ase.1693

Corbin, J., \& Strauss, A. (2008). Basics of Qualitative Research (3rd ed.): Techniques and Procedures for Developing Grounded Theory. SAGE Publications, Inc. https://doi.org/10.4135/9781452230153

Darda, D. M. (2010). Observations by a university anatomy teacher and a suggestion for curricular change: Integrative anatomy for undergraduates. Anatomical Sciences Education, 3(2), 73-76.

Drake, R. L. (1998). Anatomy education in a changing medical curriculum. The Anatomical Record: An Official Publication of the American Association of Anatomists, 253(1), 28-31.

Drake, R. L. (2014). A retrospective and prospective look at medical education in the United States: Trends shaping anatomical sciences education. Journal of Anatomy, 224(3), 256260. https://doi.org/10.1111/joa.12054

Drake, R. L., McBride, J. M., Lachman, N., \& Pawlina, W. (2009). Medical education in the anatomical sciences: The winds of change continue to blow. Anatomical Sciences Education, 2(6), 253-259.

Drake, R. L., \& Pawlina, W. (2014). Multimodal education in anatomy: The perfect opportunity. Anatomical Sciences Education, 7(1), 1-2. https://doi.org/10.1002/ase.1426 
Ettarh, R. (n.d.). Anatomy Past and Present: Evolution of Curriculum and Teaching in Anatomy. Journal of Anatomy, 2.

Farrell, J. J., Moog, R. S., \& Spencer, J. N. (1999). A Guided-Inquiry General Chemistry Course. Journal of Chemical Education, 76(4), 570. https://doi.org/10.1021/ed076p570

Favero, T. G., \& Van Hoomissen, J. D. (2019). Leveraging undergraduate research to identify culturally relevant examples in the anatomy and physiology curriculum. Advances in Physiology Education, 43(4), 561-566.

GMC. (1991) Undergraduate Medical Education. The need for change. London: General Medical Council.

GMC. Education Committee. (1993). Tomorrow's doctors: recommendations on undergraduate medical education (pp. 1-28). London: General Medical Council.

Gibbs, G., Britain), C. for N. A. A., \& Britain), I. S. L. P. (1992). Improving the quality of student learning: Based on the Improving Student Learning Project funded by the Council for National Academic Awards. Bristol : Technical and Education Services. https://trove.nla.gov.au/version/28353819

Giroux, H. (2002). Teachers as transformatory intellectuals. EDucate, 1(2).

Griff, E. R. (2016). Changing undergraduate human anatomy and physiology laboratories: Perspectives from a large-enrollment course. Advances in Physiology Education, 40(3), 388-392.

Harrison, J. F., Nichols, J. S., \& Whitmer, A. C. (2001). Evaluating the impact of physical renovation, computerization, and use of an inquiry approach in an undergraduate, allied health human anatomy and physiology lab. Advances in Physiology Education, 25(4), 202210. 
Heylings, D. J. A. (2002). Anatomy 1999-2000: The curriculum, who teaches it and how? Medical Education, 36(8), 702-710.

Hughes, P. W., \& Ellefson, M. R. (2013). Inquiry-based training improves teaching effectiveness of biology teaching assistants. PLoS ONE, 8(10). https://doi.org/10.1371/journal.pone.0078540

Kalb, K. A. (2012). Breaking Down Silos, Building Up Teams. HEALTH PROGRESS, 9. Kuyatt, B. L., \& Baker, J. D. (2014). Human anatomy software use in traditional and online anatomy laboratory classes: Student-perceived learning benefits. Journal of College Science Teaching, 43(5), 14-19.

Leung, K., Lu, K.-S., Huang, T.-S., \& Hsieh, B.-S. (2006). Anatomy instruction in medical schools: Connecting the past and the future. Advances in Health Sciences Education, 11(2), 209-215.

Lowry, S. (1992). Strategies for implementing curriculum change. BMJ: British Medical Journal, 305(6867), 1482.

Mattheis, A., \& Jensen, M. (2014). Fostering improved anatomy and physiology instructor pedagogy. Advances in Physiology Education, 38(4), 321-329.

Mckeown P, Heylings D, Stevenson M, Mckelvey K, Nixon J, \& Mccluskey D. (2003). The impact of curricular change on medical students' knowledge of anatomy. Medical Education, 37(11), 954-954.

McMenamin, P. G., Quayle, M. R., McHenry, C. R., \& Adams, J. W. (2014). The production of anatomical teaching resources using three-dimensional (3D) printing technology: 3D Printing in Anatomy Education. Anatomical Sciences Education, 7(6), 479-486. https://doi.org/10.1002/ase.1475 
Michael, J. (2006). Where's the evidence that active learning works? Advances in Physiology Education, 30(4), 159-167. https://doi.org/10.1152/advan.00053.2006

Miller, S. A., Perrotti, W., Silverthorn, D. U., Dalley, A. F., \& Rarey, K. E. (2002). From college to clinic: Reasoning over memorization is key for understanding anatomy. The Anatomical Record: An Official Publication of the American Association of Anatomists, 269(2), 69-80.

Mitchell, R., \& Batty, L. (2009). Undergraduate perspectives on the teaching and learning of anatomy. ANZ Journal of Surgery, 79(3), 118-121.

Mitrousias, V., Varitimidis, S. E., Hantes, M. E., Malizos, K. N., Arvanitis, D. L., \& Zibis, A. H. (2018). Anatomy learning from prosected cadaveric specimens versus three-dimensional software: A comparative study of upper limb anatomy. Annals of Anatomy-Anatomischer Anzeiger, 218, 156-164.

Motoike, H. K., O’Kane, R. L., Lenchner, E., \& Haspel, C. (2009). Clay modeling as a method to learn human muscles: A community college study. Anatomical Sciences Education, 2(1), 19-23. https://doi.org/10.1002/ase.61

Myers, T. W. (2014). Anatomy Trains: Myofascial Meridians for Manual and Movement Therapists. Churchill Livingstone.

National Center for Science Education (2020, February 9). Evolution: Feel it in your fingers and feel it in your toes $\mid$ National Center for Science Education. (n.d.). Retrieved February 20, 2020, from https://ncse.ngo/evolution-feel-it-your-fingers-and-feel-it-your-toes

Nayak, S., Ramnarayan, K., Somayaji, N., \& Bairy, K. L. (n.d.). Teaching anatomy in a problem-based learning (PBL) curriculum. 3.

Nisa, E. K., Koestiari, T., Habibbulloh, M., \& Jatmiko, B. (2018). Effectiveness of guided inquiry learning model to improve students' critical thinking skills at senior high school. 
Journal of Physics: Conference Series, 997, 012049. https://doi.org/10.1088/1742$6596 / 997 / 1 / 012049$

Rao, S. P., \& DiCarlo, S. E. (2001). ACTIVE LEARNING OF RESPIRATORY PHYSIOLOGY IMPROVES PERFORMANCE ON RESPIRATORY PHYSIOLOGY EXAMINATIONS. Advances in Physiology Education, 25(2), 55-61. https://doi.org/10.1152/advances.2001.25.2.55

Rathner, J. A., \& Byrne, G. (2014). The use of team-based, guided inquiry learning to overcome educational disadvantages in learning human physiology: A structural equation model. Advances in Physiology Education, 38(3), 221-228. https://doi.org/10.1152/advan.00131.2013

Silverthorn, D. U., Thorn, P. M., \& Svinicki, M. D. (2006). It's difficult to change the way we teach: Lessons from the Integrative Themes in Physiology curriculum module project. Advances in Physiology Education, 30(4), 204-214.

Smith, C. E. (2017). The flipped classroom: Benefits of student-led learning. Nursing, 47(4), 2022. https://doi.org/10.1097/01.NURSE.0000513620.19174.90

Smith, C. F., \& Mathias, H. S. (2009). Medical students' approaches to learning anatomy: Students' experiences and relations to the learning environment. Clinical Anatomy, NA-NA. https://doi.org/10.1002/ca.20900

Stein, H., \& Galili, I. (2015). THE IMPACT OF AN OPERATIONAL DEFINITION OF THE WEIGHT CONCEPT ON STUDENTS'UNDERSTANDING. International Journal of Science and Mathematics Education, 13(6), 1487-1515. 
Sugand, K., Abrahams, P., \& Khurana, A. (2010b). The anatomy of anatomy: A review for its modernization. Anatomical Sciences Education, 3(2), 83-93.

https://doi.org/10.1002/ase.139

Trust, T., Carpenter, J. P., \& Krutka, D. G. (2017). Moving beyond silos: Professional learning networks in higher education. The Internet and Higher Education, 35, 1-11. https://doi.org/10.1016/j.iheduc.2017.06.001

Unge, J., Lundh, P., Gummesson, C., \& Amnér, G. (2018). Learning spaces for health scienceswhat is the role of e-learning in physiotherapy and occupational therapy education? A literature review. Physical Therapy Reviews, 23(1), 50-60.

White, A. O., Javier, L. K., Goldberg, N. R., Boucquey, V., Overman, J., Ochaba, J., Marsh, S., Huffman, D., \& Nicholas, A. (2017). Front and Back Flipping for Neurobiology! Developing a Hybrid Upper-Division Lab Course. Journal of Undergraduate Neuroscience Education, 16(1), A95-A101.

Wilkerson, L., Stevens, C. M., \& Krasne, S. (2009). No content without context: Integrating basic, clinical, and social sciences in a pre-clerkship curriculum. Medical Teacher, 31(9), 812-821. https://doi.org/10.1080/01421590903049806

Wilson, A. D., \& Golonka, S. (2013). Embodied cognition is not what you think it is. Frontiers in Psychology, 4, 58. 


\section{APPENDIX A: INTERVIEW TRANSCRIPTS}

Interviewer:

Catie:

$\underline{00: 50}$
I have some questions ask. Basically I'm going to be asking you questions about your anatomy knowledge and also your experiences in the course. And I just want to preface it with, I never took A\&P, I took comparative anatomy but it was over 20 years ago. So when I ask questions like I'm genuinely just trying to understand what you're saying and not quizzing you or testing or anything like that. Um, so, um, well first I just want to know how A\&P is going for you. Like have you encountered any challenges or barriers?

Honestly like I took it in high school and I got like a really good grade. I got an A and I thought like, oh like this, will just A\&P 1 will be just like how it was in high school. But like honestly it's not like honestly I'm struggling. I got an 82 on the first test and I was just surprised by it. Like I didn't think I did that well when I took it, but I didn't think I did that bad. So I was like disappointed. And I think like, it's sort of how like she teaches it. I don't like how like at least this is how my bio class is too, how they like have the powerpoints printed, but then they like erase some of like the words and then you fill it in. Then like you can't really like listen to what they're saying at the same time cause you're worried about filling it in. So I guess I think that's sometimes hard for me to like follow along to like what she's 
saying because that's important, but then also filling all the words so then I just get really frustrated and distracted in class.

Interviewer:

$\underline{01: 45}$

Catie:

Interviewer:

Catie:

Interviewer:

Catie:

Interviewer:

Catie: $\underline{01: 55}$

$\underline{02: 15}$

$\underline{02: 28}$

$\underline{02: 36}$

$\underline{02: 37}$

$\underline{02: 37}$

$\underline{02: 37}$
So you're like trying to pay attention to two things at once, um, any challenges with the lab?

MMM, I like it. The lab quiz was really hard. I thought, I think I got like an 86 on it, which I was still like disappointed about. But, um, no, I like the lab. Yeah. I mean we haven't liked dissected anything yet, but so far it's been like, okay. Like microscope work.

Cool. Alright. Um, so generally speaking, why do you think it's important for you to learn anatomy knowledge? Like in general, what is the value?

I think knowing like what the anatomy is is important. Especially just like the field that I'm going into.

What is that?

Nursing.

Okay.

So you can like treat the patient based off of it and also just like to know how your own body works. I feel like that's super important. I don't know. I always have but yeah I don't 
necessarily think like, I think it's important like whatever but like to know like the tiniest pink like thumb and your pinky like... I'm so sorry bone your pinky like that's important. But I feel like the physiology behind it is like more important. Like knowing how to like treat it and like what's actually going on.

Interviewer:

Um, so is there any specific anatomical knowledge that you find to be really important for you as a future nurse? Like is there anything that's very particular to your career goals?

Catie: I feel like I don't like the inside of the body. I feel like knowing like the heart is really important nowadays. I work on an ambulance, I'm an EMT too. So like we see a lot of patients with like, like CHF and like all these heart problems. So I think knowing like how that works is important, um, the heart for sure. I think like every part of the body.

Interviewer:

Yeah. Is there a particular area of nursing you want to go into?

Catie:

I'm hoping either travel nursing because I'm double majoring in Spanish as well or um, like flight nursing, emergency room nursing, something like that. So like for that you like really, you have to know everything.

Interviewer: Yeah. So can you comment on what your understanding of the content has been so far? Like you talked about your grades, but 
that's a bit different than like, how you are actually understanding it?

Catie:

$\underline{04: 09}$

Interviewer:

Catie:

Catie:

Interviewer:

Catie:

$\underline{04: 49}$
Yeah, I get it. Like actually like understanding is like to me, like more important than what I get on my grades. And like that's what my parents have always like taught me too. Um, I feel like as of right now l've just been like memorizing to try and get a good grade on the test and not necessarily like if she, if my teacher like came in there and like told me to like apply all this stuff, I would have no idea. So I feel like I need to find like a better study strategy. Cause I've just been...

To like link the memorization...

Yeah.

To be able to actually use it in the future. Cause like right now I would be like, I have no idea. So for this next stuff I'm going to try like different study habits and stuff.

Yeah. Do you know you're going to try?

Well I've been using my computer to take notes, this chapter instead of like printing out the powerpoints and writing things down, which I don't know if that's been better or worse because sometimes she'll like, like not, she'll like go off the powerpoing and like draw stuff on the board and then I'Il have to like quickly 
like get out a pen and paper to like draw it. So I don't know. I guess I'll see. But I've been taking notes on my computer instead of paper. Yeah. I don't know.

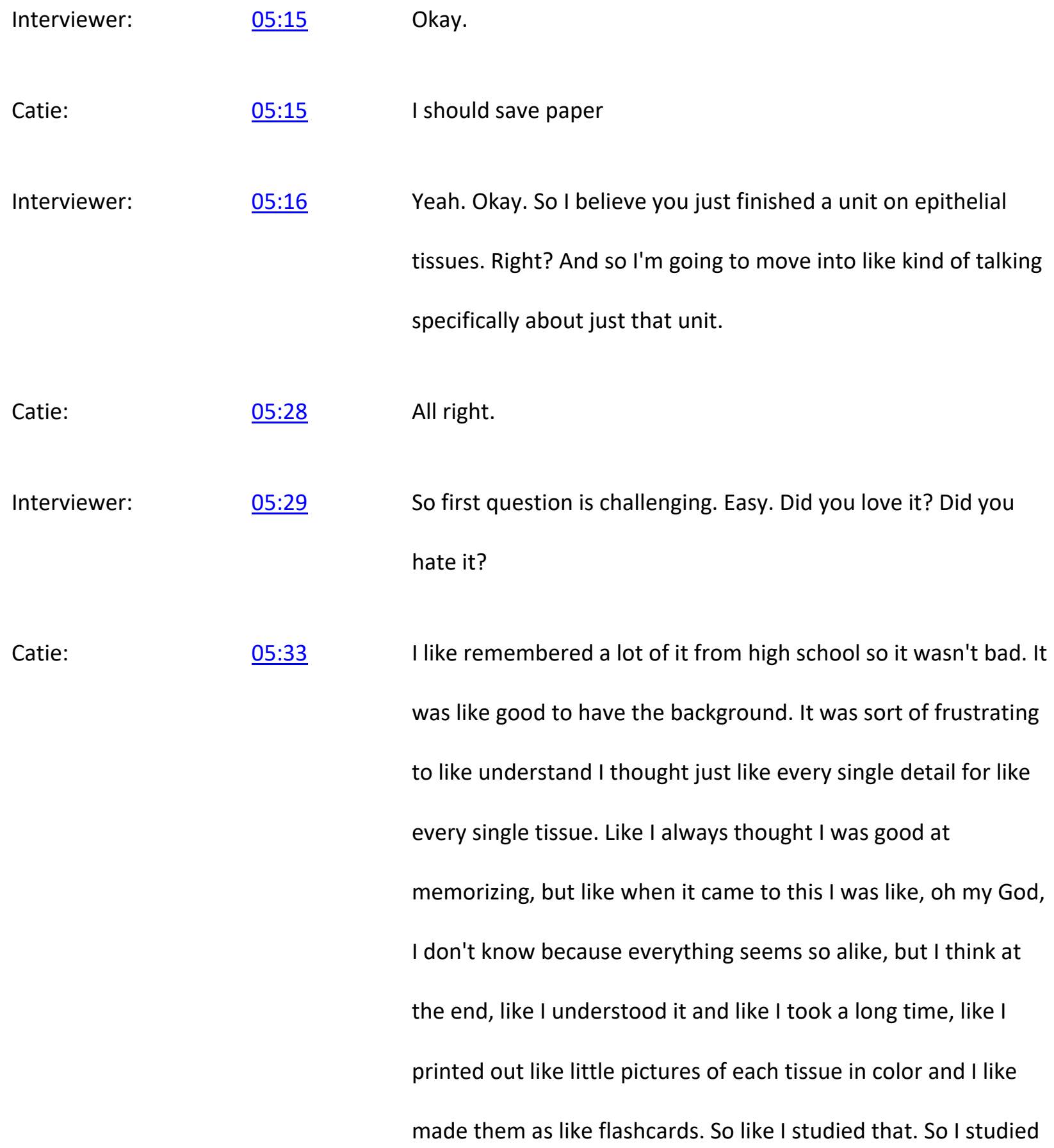


mostly like what they looked like and not that what they did, like structure versus function.

Interviewer:

Catie:

$\underline{06: 09}$

Interviewer:

Catie:

Interviewer:

$\underline{06: 17}$
Yeah.

So was just like, probably that wasn't the best, but it helped me like know what each tissue was. Yeah.

Cool. Okay. So, um, you mentioned a few of my next question is what are some things that enabled your learning? So you mentioned that you like have flashcards, you've really paid attention to the structure so that you could identify them and distinguish them. Anything else?

06:35 Mmm... I made a quizlet it is sort of like the same thing. I know we kind of made like a study group, some people from like different anatomy labs. So someone else made a quizlet and like sent it to us. We were all kind of like sharing it and that really helped. Um, also actually like looking back at the PowerPoint that we studied in lecture helped cause it talked about like all the structure and function.

So how do you look back that PowerPoint? Is it recorded or... I don't know how the course is structured. Like do you mean going back to the slides? 
Catie:

$\underline{07: 08}$

Interviewer:

$\underline{07: 43}$

$\underline{07: 53}$

Catie:

Interviewer:

Catie:

Catie:

$\underline{08: 21}$
Yeah, like going back to like the slides and just like looking at like the notes that I took when I was in class as well as like, you know, the notes that were just like already on there from the teacher so looking back there. Yeah. And then also in my lab manual too, like that helped because we had to like draw like every single like tissue and then there was like questions in it that I did beforehand. So like I looked it up in the book and that honestly was probably the first time I opened up the book. So that was good because I like the books and I've been using it more after I had to do that.

Um, what about organization? Like how do you feel like you organize all of your knowledge about all of these epithelial tissues? Is it organized or was it just memorize all these terms?

I feel like it's like organized like in a sense... Like I dunno, like I made a lot of flashcards for the tissues, but my knowledge of it like now is probably like kind of jumbled, just cause like I haven't studied it in awhile. Like, I feel like I knew it and I memorized it for that.

08:19 For the test you mean?

08:19 For the test, yeah.

And then I'll probably go back and do it again for the final. But then after, I don't know, just sometimes like I have a hard time 
seeing like, oh like what's the point in knowing this? But like I don't know till this point.

Interviewer:

Um, so if you had to give like an elevator speech, like on what is the point of knowing epithelial tissues? Like what would be the big takeaway from this unit?

Catie:

Nobody knows. Me and my friends were actually talking about this today. We were like, oh we're so excited to like get into the skeletal system now cause like now like, oh we might actually use this, but I don't know. Like it might be important to know if someone has like something like growing in their skin or like one of their organs or, I don't know. And then you could like maybe like know, what tissue it comes from and I just don't know. And I feel really bad because I know it's probably going to be important. But right now I'm just like, I have a hard time like seeing the bigger picture of it all.

Interviewer: made a concept map?

Catie:

$\underline{09: 33}$

No.

Interviewer:

Okay. I'm so, no, that's fine.

Catie:

$\underline{09: 36}$

Oh, like with those? 
Interviewer:

Catie:

Catie:

Interviewer:

$\underline{11: 20}$

Catie:

Interviewer:

Catie:

Catie:
Yeah. Okay. So like let's say, I don't know why I'm just giving an example. Okay. So like I, if I want to draw a relationship, like I'm making a map of how I understand that relationships can only startups. And so like if I want to say that these are responsible for filtration, I would do something like that. Okay. You know what I mean? Um, and so you can use all of them. You can use, you don't have to use all of them. Um, if you find that you need something that isn't here, I posted here and we can like write words on here if you want. Um, and you know, I'm just going to give you a little bit of time to like create how you see this information relating to me. To it, you know, and, um, bring up her, I don't know anything. So, um, there's no question they feel better. There's no correct answer. There's no, I mean, everyone thinks of this stuff differently, right? So it's organized differently. Go ahead. So have at it...

11:10 I'm trying to think of the word... Can I make a word.

13:06 Do I need to use all of them?

$\underline{13: 07} \quad$ Nope.

13:07 I don't know. I'm trying to like, remember the function.

13:13 I feel bad if Eric sees this and it's like all wrong. 
Interviewer:

Interviewer:

Interviewer:

$\underline{13: 55}$

Catie:

Catie:

Interviewer:

Interviewer:

Catie:

Interviewer:

Catie:

Interviewer:

Catie:
By the time he looks at it, it'll be like long after the course.

So can you add like what the markers just kind of like lines?

Yeah. Connecting ideas.

Okay.

I dont know if this makes any sense at all.

That's okay.

16:10 So with the simple cuboidal, you have these two listed, there are those, can you start with that one and maybe explain?

16:19 Well, like it could sort of like go along in like the other like simple section, but I said that simple cuboidal is responsible for secretion and absorption.

$\underline{16: 29} \quad$ Okay so its both of them.

16:31 Yeah. Both of the functions. Yeah. Just like how this one was built.

16:37 Okay. So can you start up there then at squamous and talk about...

16:44 Yeah, so squamous, just like the general term and then it goes to simple squamous, simple meaning like single layered. So I'm 
like, remember that this is found in the lungs and it's like for diffusion and filtration, of like oxygen and stuff in the alveoli. Um, and yeah, I put that... It could fit in simple just because it's single layer and then these are all stratified. So like I remember that there are multiple layers that I can't really remember what each of their functions are, but I sort of think that because there are multiple layers they're for protection, I can't remember either.

Interviewer:

$\underline{17: 33}$

Catie:

$\underline{17: 35}$

Interviewer:

Catie:

Catie:

Interviewer:

Catie: $\underline{17: 44}$

$\underline{17: 47}$

$\underline{17: 50}$

$\underline{18: 22}$

$\underline{19: 09}$
Okay. It's fine.

And then the rest I'm just going to not, cause I really don't remember. I really don't want to like say something so wrong.

I mean, there's no consequences of being wrong.

I know.

Um, I feel like this could be either stratified or simple. I just don't want to like organize this and I'm going, it's like...

So you're saying there can be columnar or cuboidal cells in a single layer or multiple layers.

Mhmm so like multiple layers, stratified. Then the single layers, simple. So yeah, there is stratified columnar, stratified cuboidal, and then simple columnar. Is that okay? 
Interviewer:

$\underline{19: 24}$

$\underline{19: 47}$

Catie:

Interviewer:

$\underline{19: 55}$

Interviewer:

$\underline{20: 02}$

Catie:

Interviewer:

Catie:

Interviewer:

20:12

20:10

$\underline{20: 12}$

$\underline{20: 10}$

Okay.

of forces you to think about the relationships between things.

So I'm going to give you a concept map with these same terms.

It is not the correct, the concept map.

judge. I'm going to take a picture of them just kind of cause I the cameras going the video camera but I'm sure I can read right.

could like relate.

Yeah. So I mean in general it's a great way to study cause it kind

It's just another concept map of these.

Okay.

And I just want you to comment on it. And if this makes sense to you. Are there things that are wrong or right or you're totally like, if there's things, if there are things that are wrong, you're free to change it. Cross off linkages. What do you think...

Catie: $\quad \underline{20: 42} \quad$ I don't get why this like... the Top?

Interviewer: $\quad \underline{20: 42} \quad$ Yeah, why? Why does it not make sense? 
Catie:

$\underline{20: 50}$

Catie:

$\underline{21: 08}$

Interviewer:

$\underline{21: 10}$

Catie:

21:11

$\underline{21: 51}$

Catie:

Interviewer:

$\underline{21: 56}$

$\underline{22: 01}$

Catie:

Catie:

Interviewer:

Catie:

Interviewer:
Oh, I get it. It's like squamous columnar, then cuboidal. So squamous can be simple and then its stratified here.

Well like this makes sense. I know that this is right.

What is that?

simple squamous filtration, absorption. Pseudo stratified and transitional for excretion... Like again I'm pretty sure transitional is the one that's in the bladder, I think. Then it's like... I dont know.

They're saying that this isn't right. This is just like, I feel like this is like, right, but like if someone's like personal way of thinking about it.

Well that's how all concept maps are. That's why they can't really be right.

Right. Like I feel like I don't know how to change it. I probably wouldn't put this at the top just because I'm kind of confused by that. I'd probably be like simple and stratified.

$\underline{22: 17} \quad$ Okay.

22:17 And then go from there.

22:23 So can you tell me what like simple and stratified refer to? 
Catie:

Interviewer:

$\underline{22: 33}$

$\underline{22: 33}$

Interviewer:

$\underline{22: 35}$

Catie:

Interviewer:

$\underline{22: 42}$

Catie:

Catie:

Interviewer:

$\underline{23: 23}$

$\underline{23: 30}$

Catie:

$\underline{22: 53}$

$\underline{22: 42}$

Interviewer: $\quad \underline{23: 44} \quad$ Okay.

So like simple is like single layered and then stratified is like multiple layers.

Okay.

So like I get that.

And then what are these three refering to? Are these like...

It's like the shapes of them.

Okay.

So like squamous is like flat. Columnar is like column shaped and then cuboidal is more like circular.

Um, yeah, I mean I guess it makes sense. I would probably just put like these two at the top and then these under and then list all of the different types of tissue and then like their own functions like underneath. Like I wouldn't like do like this, like I would just say stratified columnar and then stratified cuboidal, but they probably have the same function...

Do you happen to know the functions? I don't. I'm just asking.

Um, I don't. Yeah, I don't know what I would change I mean just besides like putting simple and stratified at the top.

Interviewer: $\quad \underline{23: 44} \quad$ Okay. 
Catie:

$\underline{23: 44}$

Interviewer:

$\underline{23: 52}$

Catie:

$\underline{24: 01}$

Interviewer:

Catie:

Catie:

$\underline{24: 57}$

Catie:

Interviewer: $\underline{24: 20}$

$\underline{24: 21}$
Yes. So you're saying you would divide it basically into two columns, but then under each of simple and stratified, you would have all three of these?

Yeah, like underneath. Yeah, exactly. And then, yeah, I like how they like grouped things together and everything. I would just do it like, can I write on this?

Yeah, go for it.

I would do like, and then I would say like the different shapes, so like, I don't know then it's going to look kind of like theirs. So like and then like the same thing here.

And then like all like the different, like simple and then simple's like functions like filter and then any other simple, but they don't have, they didn't like list like... Oh simple cuboidal. I'll put that here. Yeah. If this makes any sense at all. I wouldn't have to write simple again.

Just because its at the top.

Yeah. You know, and then you would do the same thing for the stratified. 


\begin{tabular}{|c|c|c|}
\hline Catie: & $\underline{25: 41}$ & Yeah, if that makes sense. \\
\hline Interviewer: & $\underline{25: 45}$ & Yeah, it does. \\
\hline Catie: & $\underline{25: 46}$ & $\begin{array}{l}\text { Sorry if my answers arn't that good. I learned stuff. I wish I } \\
\text { remembered more. }\end{array}$ \\
\hline Interviewer: & $\underline{25: 55}$ & $\begin{array}{l}\text { That's all right. Is there anything else that you, I'm done with all } \\
\text { my questions. Do you have any questions for me? }\end{array}$ \\
\hline Catie: & $\underline{26: 01}$ & I think so. So like what's this for? Is this for \\
\hline Interviewer: & $\underline{26: 05}$ & $\begin{array}{l}\text { Yeah, we're basically trying to understand how like we could } \\
\text { better present an anatomy education, like anatomy content } \\
\text { specifically in the lab. And so... }\end{array}$ \\
\hline Catie: & $\underline{26: 20}$ & Okay not like this, cause this is really confusing. \\
\hline Interviewer: & $\underline{26: 23}$ & Not like this. \\
\hline Catie: & $26: 24$ & $\begin{array}{l}\text { I don't like that. I don't know. I like how like the lab like manuals } \\
\text { like set up where it's just like, I dunno, it was like, okay this is a } \\
\text { simple squamous cell. Here is a circle that you need to draw it } \\
\text { and this is what it should look like. What are the functions? } \\
\text { Okay. Number two, this is like a symbol cuboid. All this loot I } \\
\text { supposed to look like. Not like, all like spread out. }\end{array}$ \\
\hline Interviewer: & $26: 49$ & Yeah. \\
\hline
\end{tabular}


Catie:

$\underline{26: 51}$

Interviewer:

$\underline{26: 56}$

Catie:

$\underline{27: 18}$

$\underline{27: 28}$

Catie:

Interviewer:

$\underline{27: 42}$

Interviewer:

$\underline{27: 42}$

$\underline{27: 49}$

Catie:

Catie:

Catie:

$\underline{27: 58}$
I like it more. Just like linear. Linear. Yeah. Yeah.

So stepping back to your comment earlier though, where you were like, well right now everything is kind of jumbled and you've memorized everything and you're not sure how it's all organized in your head. Is there a way that you think would, if it were presented differently, it would help you to organize it?

Hmm. I know this is like, supposed based like in lab, but like if I were to say like in class,

I don't know. I feel like it's more of like a me thing. Like I need to like figure it out cause like, I like Eric or my teacher.

yeah.

We're actually, we're thinking more of like how the manual, for example, the curriculum supports your organization.

I like the lab manual. I think it really helped me study for the test too. And it really helps with the, the lab quiz.

It did.

Like, I know I didn't like get the grade that I wanted, but I mean I only got like four wrong, out of like 25 or something. So like it wasn't bad? I just think part of myself, but I liked how it was organized and how the questions were asked. 
Interviewer:

Catie:

Interviewer:

Interviewer:

28:28

$\underline{28: 24}$

$\underline{00: 00}$

Interviewer:

$\underline{00: 44}$

Interviewer:

$\underline{28: 16}$ okay. Yeah. Cool.

All right. Well, um, I will email you in a couple of weeks and we'll do this again. Okay. Um, and then when we're done and if anything comes up in the Internet, in the interim and yell questions or whatever, just send me an email, let me know. Okay. I will. No, your answers are awesome. You perfect. Hopefully they'll be better at the end of the year.

Okay. So, uh, this is going to run very similarly to last time and um, so I have some questions and then we'll do a concept map on the board and then I'll have you respond to one. Um, oh, okay.

Before I forget, you wanted Amazon right?

00:55 So, uh, since we last spoke, um, any new challenges or how is A\&P going? 
Catie:

$\underline{01: 02}$

Interviewer:

$\underline{01: 25}$

$\underline{01: 25}$

$\underline{01: 26}$

Interviewer:

Catie:

Interviewer:

Catie:

Interviewer:
Um, it's going well. It's just like a lot of memorization. Like for lab, I have a lab quiz tomorrow and it's on muscles and bones, but I took like the bone test for the actual like lecture like awhile ago. So I'm gonna have to like review all those and study the muscles cause I'm...

Cause spring break was in there?

Yeah.

Um, so is it difficult then... That It's like this quiz is on muscles and bones together. But you did bones by themselves or...

01:39 Yeah, I just think as like a lot to memorize, like all of the different like processes and like articulations. But I mean like our teacher was talking about today in lecture. Like you could figure out muscles just by like their names cause like it's very like self explanatory.

$\underline{01: 54} \quad$ Yeah.

01:54 So yeah.

$\underline{01: 55} \quad$ Okay. So last time I asked you, why do you think like anatomical knowledge is important? Um, have you had any new revelations regarding that since we last talked? I mean, was there like a unit 
that you covered that you're like, Oh I never thought of that or...

Catie:

02:14 Um, not really. I guess it's like important to know the muscles. Like I just like gave someone like a shot in their arm because they had to get medication. I was like reading the directions and it said like something about like, oh, like a deltoid muscle. So that was important. So like I knew where that was.

Interviewer: $\quad$ 02:31 $\quad$ Yeah
Catie:
$\underline{02: 31}$
So, yeah.

Interviewer:

$\underline{02: 33}$

Cool. I guess. Um, so like how do you think you have understood the content so far? Like aside from studying and everything, like I'm, I guess I'm asking about your understanding of it. Like is it easy to understand? Are there things that um, are there certain areas that the course that are more difficult or easier to understand than others?

Catie:

I think so. I'm really gonna like memorizing like where muscles and bones are. So that's why I usually save it to like a few days before the test to like stud those or like the lab quiz, but definitely like, I don't know. I'm better at like memorizing then like understanding the concepts. There's something called like a neuromuscular junction and you have to know like the, I dunno, there's like two parts. There's like one is like the neuromuscular 
junction, the other one is like a coupling response. But yeah, I'm having a hard time understanding that.

Interviewer: $\quad \underline{03: 34} \quad$ Yeah.

Catie: $\quad \underline{03: 34} \quad$ But I'm good at like memorizing.

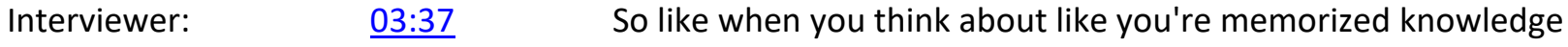
and that conceptual understanding that's more difficult, what do you think is going to be, what is most relevant to your future career do you think?

Catie:

Definitely not knowing what a neuromuscular junction is probably just knowing like the names and like locations of stuff. Um, but yeah, no, I'm like, I dont think I'm ever gonna have to like know that in my future. Yeah, I dunno.

Interviewer:

I guess I'm not necessarily asking about that particular thing. I'm just asking more about memorized knowledge versus understood knowledge, like the stuff that you understand the processes or whatever it is, it doesn't have to be that particular area.

Catie:

Yeah. Obviously I think it's more important to like understand things and just memorize them. But like sometimes that's hard to do for me. I mean it's like, I feel like it's hard to like learn all these names of the bones, like without like memorizing them 
and like sometimes forgetting them like 30 years from now someone's going to ask me like, oh, like label the skeleton. We'd be like, maybe, I mean, I don't know. But like I think like learning it now and like memorizing and just like repeating it will like help me further down like the way cause like, I don't know, I'll just have like background knowledge so I might forget it. But if I looked at like a like a diagram for a few minutes, I'm sure I would like pick it right back up again.

Interviewer:

$\underline{05: 07}$

$\underline{05: 08}$

$\underline{05: 08}$

Interviewer:

Catie:

Interviewer:

Yeah.

So why do you think that is then? It's easier for you to memorize them.

I don't know. Maybe I do like retain it a little. Like obviously like I feel like I do, but...

05:21 I mean honestly that's how I was like a lot of biology, a lot of people who were biology majors and really excelled in biology. Just you can give me anything to memorize and I'm good. Like I can memorize like nobody's business...

Catie:

But then it's like, do I really understand it? Can I like apply it. That's why I don't like micro bio because our teachers are just 
like, oh you have to learn this, but then you have to apply it. Or My tests are not memorization. So it's, I'm like, yeah, yeah.

Interviewer:

$\underline{05: 52}$

But it's so relevant to your career and future nurse?

Catie:

$\underline{05: 55}$

Yeah.

Interviewer:

$\underline{05: 55}$

Yeah.

Catie:

$\underline{05: 55}$

I know. It's just like a hard, I know you're a biology teacher, so I'm sorry.

Interviewer:

$\underline{06: 04}$

No, that's fine. I mean, like I said, I was that student, I was you where I was like give some to memorize.

Catie:

$\underline{06: 13}$

Yeah.

Interviewer:

$\underline{06: 13}$

Um, okay. So the next few questions are just about the musculo-skeletal system.

Catie:

$\underline{06: 22}$

Okay.

Interviewer:

$\underline{06: 22}$

So I've asked about like just general core stuff, so, but uh, so this particular section of the course, is it more or less difficult than other sections?

Catie:

$\underline{06: 33}$

Um, I definitely think that this is like the most difficult for me right now just because it's a lot to memorize. Again, the memorization... But just also because I have like a ton of other 
tests this week, so I hope that's not going to like take away from how I learn. But like sometimes it's like hard to prioritize like the homework definitely was like difficult, more difficult to me this time cause it's like a hundred questions all online. And like I did find myself having to look up like more questions than usual online. So I'm like nervous about that...

Interviewer:

$\underline{07: 06}$

Catie:

$\underline{07: 08}$

$\underline{07: 22}$

Interviewer:

Catie:

$\underline{07: 32}$
Were you given that over break?

Yeah. That's just when I did it. It's not due for like another week but I did it over break. So I'm sure if I like studied a little bit more before I did it or like made the study guide before cause I made the study guide after I did it, I would have been better. But yeah.

Okay. Um, so you mentioned the homework but I'm wondering what are the things that have enabled your learning of this content specifically the musculo-skeletal system.

Probably like diagrams. I like the lab manual how it's all like just diagrams we have to label. But then also the study guide that we use in class just has like a bunch of like diagrams that I just like look at over and over and she makes like powerpoints that you just like go through and like each slide, like just like an Arrow points to like a different part, so I think that's cool. So I just like go through all those like every night. 


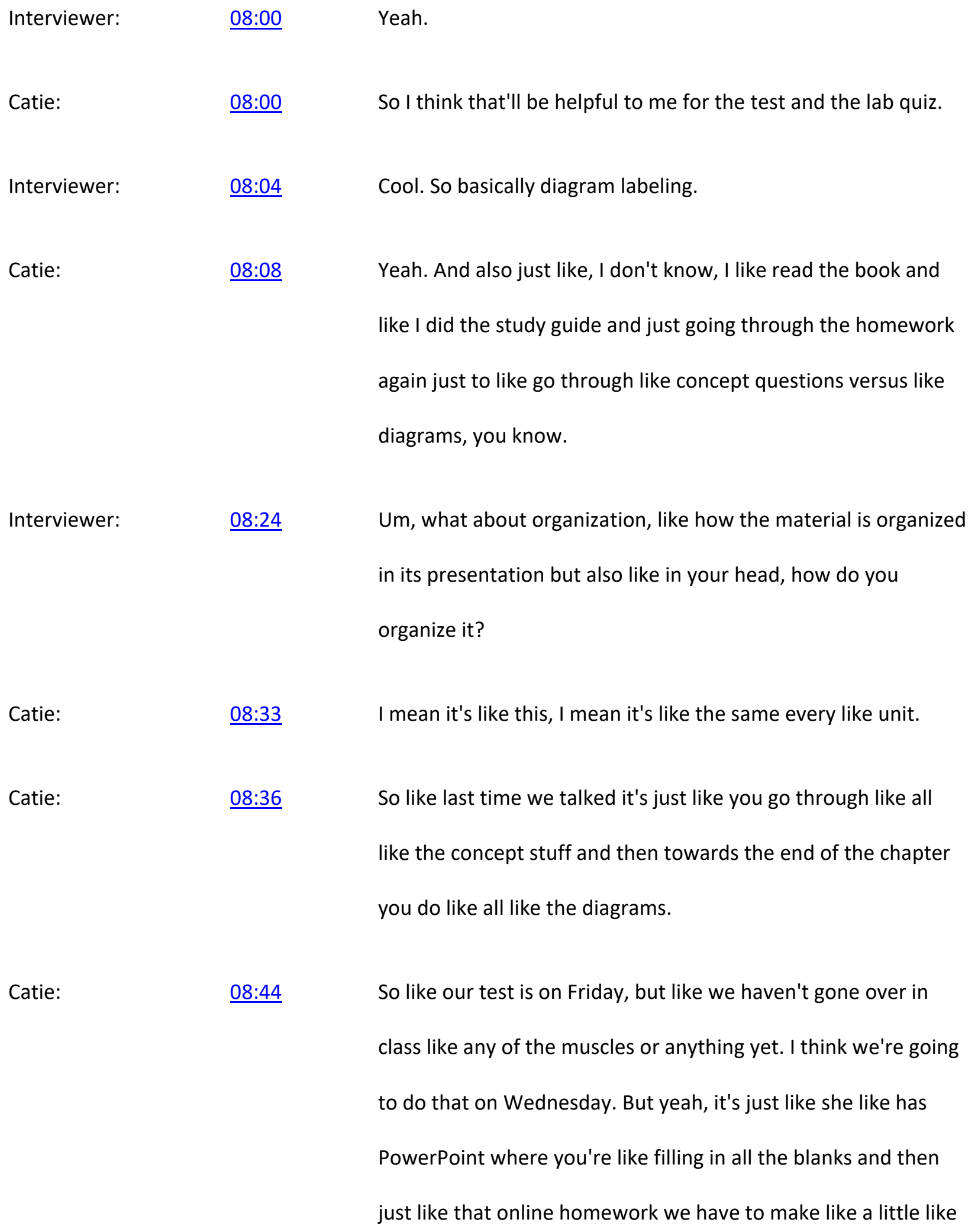


fake tests. Like 10 question tests and submit it. So it's like the same.

Interviewer:

Catie:

Interviewer:

Catie:

Interviewer:

Catie: $\underline{09: 10}$

$\underline{09: 10}$

$\underline{09: 25}$

$\underline{09: 25}$

$\underline{09: 28}$

Yeah.

I guess I kind of like that, but I tend to always make like very like easy, broad like questions for the assignments. Like I know some of my friends like go so in depth, but I'm like, like, like I don't know, it's like why do I have to, if I'm going to get full points anyway.

Yeah

I know it's kind of lazy.

Um, so for this section, what do you think is the big takeaway for it? Like as a future nurse, like the muscular musculoskeletal system, like what's the big takeaway for you?

I guess knowing where all the muscles are. I feel like, like I said, they're not going to ask me like, oh, how does this process work? Or like at like maybe like knowing, I just think it's important to like know what things are like, oh, like this smooth muscle, okay. That has like has one nucleus per cell and it's not striated. And like all that and like cardiac and skeletal, like I think it's important to know like the difference between that, but I think that things like I'll actually use and apply in my job or 
like.. The muscles, At least that's my understanding of what my profession is going to be like. I don't know like what it would actually be, but...

Interviewer:

$\underline{10: 24}$

Cool. Okay. Um, so what I have up here on the board are a whole bunch of terms that are related to the musculo-skeletal system, like the appendicular system. And, um, I'd like you to just kind of group them or organize them in a way that makes sense to you. And, um, you know, you can use the markers and you can make new cards if you want to move those around.

$\underline{10: 57}$

$\underline{11: 44}$

$\underline{11: 53}$

Catie:

Interviewer:

Catie:

Interviewer:

Catie: $\underline{14: 04}$
All right. I don't have to use all of them do I? I feel like I'm just going to group them in like a stupid way.

I mean there are no correct answers here.

Like these are all the upper extremity muscles: the lats, the deltoids, and the pectorals, they're like all like... The Lat is in the arm right?

I don't know.

This is so embarssing. And then below it, the triceps and the biceps Brachii I and then like the hands and then the glutes, the quads and the hamstring, and then the foot and I guess structure could be like short and then long bone. Um, and then movement like adductors would be like towards and then 
abduction would be away. Dorsiflextion is like when you flex something up like your foot and then plantarflextion in would be like, down. So that's just like movement. I don't really know where to put the other like four.

Interviewer:

$\underline{14: 48}$

$\underline{15: 19}$

Catie:

Interviewer:

Catie:

Interviewer:

Catie:

Catie: $\underline{15: 45}$

$15: 53$

$\underline{15: 55}$

$\underline{15: 58}$

$\underline{16: 00}$
Cool. Alrighty. Thanks. Um, so remember this is not the correct one. There are no correct concept maps. That's the beauty of them. Um, and just take a look. Um, and I'm just curious what your response is. You can compare to yours if you want, you can mark on it and change things or correct things up to you.

Yeah, I mean that would make sense. That muscles are like, well, I dunno, I always thought like bones were for protection, I guess that they're both pointing there. But I'd always think that like overall like bones were more protective than muscles. But I guess it's like...

How can you envision muscles protecting?

They protect the bones. It's kind of like, I guess.

How so?

How do they protect the bones?

They just like cover them. 
Catie:

Catie:

$\underline{16: 18}$

Catie:

$\underline{16: 24}$

$\underline{16: 46}$

$\underline{16: 47}$

Catie:

Catie:

16:57

$\underline{17: 31}$

$\underline{17: 40}$

Catie:

Catie:
Interviewer:

I don't know I guess like, if we were like just bones, we'd be like so rigid. So I guess they like protect like other things.

I agree with like they store stuff.

Mm and they move and structure. Yeah. Um, yeah. I like how they did this. That's what I did to how it all like moves down.

Can you explain?

So like this would be like, like what are your muscles?

Quadriceps, hamstrings?

MMM. I don't know. I wouldn't put adductors here, but I'll go over that. So it goes like from the top of the leg like down. So I like that cause that like puts in like an order we could like see it. Like this is like the top of the leg and that like works like down. Um, I don't get why they put adductors I guess because maybe like the gluteal muscles can like adduct the quadriceps and hamstrings?

MMM. Yeah. And then it like moves down to like the lower leg and again they put plantar and dorsi flexion here. But I would 
just like put it in its own section and just like, right, like oh like adduct... To bring closer to.

Catie:

And then I would say like plantar and dorsi and then just like say what they are. I mean it's like cool cause they like give examples of like where are they can be found. So I guess that's nice. But then I also like how on the side it says like movement and then it goes the pectorial, deltoids, lats, biceps, triceps. So it like moves from here down. So I like that. So I like this. I guess the only thing I would change was like yeah, that I like cause I did the same thing cause I feel good about that. Um, but yeah, and I like how they put like what all their functions are and how they like overlap with each other.

Catie:

So I like that.

Catie:

$\underline{18: 57}$

Yeah.

Interviewer:

Like the functions of the skeletal muscles and the bones?

Catie:

Yeah, because it like shows just like their relationship with each other. Cause I guess that helps cause like in actual class, like we had one test on bones and the next one's going to be on skeletal muscles. But like the application of like how they're all like connected somehow like through here is like nice cause I know in lab like the quiz I'm going to take tomorrow will be like everything. So it was like good to see. 
Interviewer:

Catie:

Interviewer:

Interviewer:

19:33

19:34

Catie:

Interviewer:

19:39

Catie:

Interviewer:

19:49

19:46

Interviewer:

00:00

And then today's the 21st. Okay. All right. So the first thing I'm going to say is, um, like I'll be asking you about your anatomy knowledge a little bit. Okay. And, um, I've never taken AP and I took comparative Anatomy like 20 years ago more than that. And so when I ask you questions, I'm not at all like testing you or quizzing you. I'm just trying to understand what you, how you think about it.

Raquel:

Okay. 
Interviewer:

$\underline{00: 47}$

Raquel:

$\underline{00: 58}$

00:59

Interviewer:

$\underline{00.59}$

Raquel:

$\underline{01: 08}$

Um, yeah, I like it. I mean, specifically like to this course or like teacher. Professor Wise?

Interviewer:

$\underline{01: 16}$

Yeah. T to the specific to this course in specific to the knowledge, the anatomy, knowledge.

Raquel:

$\underline{01: 21}$

Um, yeah, I mean, I really like it. I took it in high school and it was different. I mean like, um, I like it a lot better here, just like how it's explained and stuff.

Interviewer:

$\underline{01: 33}$

Okay. Um, so what was different than that?

Raquel:

$\underline{01: 37}$

Just like how it's explained is alot better. I mean, I like how Dr

Wargo explains it. It's like how she makes connections, like, and how she like draws everything out. It's alive. It's really helpful. And um, I mean like, I just think it's really interesting. I'm a nursing major, so like kind of a nerdy about this stuff. So like this is what I want to do with my life essentially. So like I like, I just think all that's really interesting, like how the body works 
and how it's so complex on so many different levels. Like that just really interests me already.

Interviewer:

$\underline{02: 11}$

So. Yeah. Cool. Um, so have you encountered any challenges in the course at all? Like are there, as far as like learning the material?

Raquel:

\section{$\underline{02: 22}$}

I mean, I didn't do too well on the first lab quiz, I think like when it comes to seeing things on slides versus seeing things on pictures. But that was the first thing I noticed where it was like, okay, there's a difference. I'm like, a slide, versus, a picture of something is way different from me. Like, but that might be like specific to me personally, like looking at things through a microscope versus looking at it on a picture, which is how I studied. It was like just different was my personal experience. And then just anatomy when you come into it, which is in high school, I'm glad I took it in high school before I came here. It's a lot of material when you come into it and it's a lot of, if you attempt to memorize it is not going to work.

\section{Raquel:} you have to like know it and like if you like dissect the words, it helps you. So like, I think that has helped me a lot to, like in high school I made the mistake of trying to memorize everything and instead of learning it instead of actually like saying like, okay, you know, you can break down the words and a lot of things are 
named necessarily for what they do and their name because oh like if you break it down, like osteoblast means like bone building and like once you make those connections and things just start to get a lot easier. And so like if you attempt to memorize everything, it's just an overwhelming amount of material. But once you realize like, oh, things have connections, that makes a lot more sense.

Interviewer:

$\underline{03: 58}$

Yeah. Cool. So, I mean, you've kind of already touched on this, but like why do you feel like A\&P knowledge is important or useful or valuable?

Raquel:

Yeah, I mean like just specifically for my field nursing, I think it's important. You know, like you just gotta know where you know, the lungs are, you got to know, got to know where the vein is to put in an IV. Like you just got to know those sort of things. Or like even like right now we're learning the bones. Like, I mean I'm, I'm not going to go into, you know, I'm not going to be, um, I don't, I can't think of the words, but I'm not going to be a bone nurse. I'm not going to help. Like that's just doesn't, not necessarily my interest, but like, I want to work in the ER so I might, you know, encounter a break. And it's important to know like, you know, when you're communicating with a doctor like, okay, like yes, it's in the radius. Like you got to know those kind of words to be able to interact. But even like if you're not, it's 
kind of helpful. Like, just like, you know, one day when I have a kid in the doctors, sometimes they just kind of like talk above you and it's kind of Nice having that knowledge to be able to just understand what you're saying. Like, oh, this is serious. Oh, it's, it sounds more scary than it actually is. It's kind of Nice to be able to like translate that. Like even like with some of my friends I'm like, don't worry, like not as bad as it seems like it's just a lot of big words but it really means blah blah blah.

Interviewer:

$\underline{05: 26}$

$\underline{05: 42}$

Raquel:
Yeah. Cool. Um, so you've already also kind of touched on this a little bit, but I want to know like how have you been understanding the content so far? Like how do you go about really understanding it and knowing it versus just memorizing? has helped too, but Dr Wargo helps a lot of like explaining it and like drawing the pictures and doing that. And I think because there's so many levels to the class, it's like you go to lecture, but then there's also the homework and the homework goes a lot with the textbook and so you go lecture and she'll explain it all. And so that really helps. But then also like, okay, maybe you do it, it didn't completely understand it and you're doing the homework and while you're doing the homework. You have the textbook open and let's say you still don't understand it and it 
takes you to that one section of the book and I will like read that section and I'm like okay that helps.

Raquel:

\section{$\underline{06: 28}$}

Raquel:

$\underline{07: 24}$

Interviewer:

$\underline{07: 38}$
But then also there's the lab section and I feel like the lab also does a good job of like going along with what we're doing in class and it's not like super far off because last semester I was in a different class, a science class and it was like just super, not even, on the same page and so like I try to last the last test we had I didn't do as good of a job but now I'm trying to like after we finish a chapter, make sure that I could, I do quizlets tell help me study and making sure that I have a quizlet completed by the end of the chapter. And so then I can like, you know, be studying that chapter before the task. Maybe I'm not like, you know studying it every day. I'm not going to lie and say I study it every day, but like at least by the end of the chapter, I have a quizzlet completed so that I can be like, okay, I'll study it ahead of time because last chapter, last test I realized, okay, wow.

Maybe I do... Because I studied a week before. But even that I was like, okay, I need to be studying ahead of time. So I feel like if I study like a chapter at a time, that's like a more manageable material. Yeah.

And I think that even creating the quizlet is a way of studying. Yeah. Cause it's like you have to think about it as you're going cool. 
Interviewer:

Um, so you just finished a unit on epithelial tissues. Correct. And so these questions I'm asking are really just about that unit. Um, so the first is, you know, challenging, easy, fun, awesome. You hated it. What were your, what were your impressions of the Unit?

Raquel:

$\underline{08: 05}$

Interviewer:

$\underline{08: 11}$

$\underline{08: 12}$

$\underline{08: 18}$

Interviewer:

Raquel:

$\underline{08: 20}$

Interviewer:

$\underline{08: 30}$

Raquel:

Interviewer:

$\underline{08: 34}$

$\underline{08: 34}$

Just cause it was it because of the amount of material or the

Raquel:

$\underline{08: 38}$ type?

It was not awful. I mean, it was, it was a little challenging, but yeah. Okay.

Why was it challenging?

Um, still a lot of like new material.

So it wasn't material that was in your high school A\&P course?

Um, a lot of it was reviewed. Yeah. But it's still just a lot of going back and relearning it and just applying it.

Okay. So is it safe to say it was challenging then?

Yeah

I feel that's like the type, yeah. 
Interviewer:

$\underline{08: 40}$

Raquel:

$\underline{08: 53}$

Interviewer:

Raquel:

Interviewer:

Raquel:

Raquel:
Okay. What about it? I mean it's basically cells, what do you think it is about just learning cells that is more difficult than say learning digestive system or something easier?

I think cells sometimes are harder because it's not something that you can just like straight up look at. Like, I mean like it's easy to picture the digestive tract. It's not as easy to picture a cell because it's so little, so small. So, but it yet at the same time it does so much for your body. And so I think for your human brain kind of like conceptualize such a small thing doing so much, it's like, yeah,

$\underline{\text { 09:22 }} \quad$ it just doesn't jive.

09:23 Right. Yeah.

09:24 Cool. So what were the things that really in the course that supported your learning of this material since it was challenging? What things work for you?

Going to lecture, taking the notes, the homework. Just like

What's the homework like? Um, it's a lot of like questions but I think because there's a bunch of different types of, like some of them are like labeling, but then some of them are multiple choice and some of the have a video with it. And so there's multiple different types of questions. It makes you like, you're 
not just in a routine of going like just clicking through them. It makes you like actually have to think through it. And I think because not all of them are covered in lecture and makes you actually have to open the book and look for them. So it makes you actually have to do like outside work where you still have to like look into the material. It's not just like, oh I remember this. Like it still makes you actually have to look for it.

Interviewer:

Yeah. How much would you use the book if that didn't compel your usage of the book, you know?

Raquel:

Interviewer:

$\underline{10: 36}$

$\underline{10: 29}$

I would still read it because it's still just like goes over it again.

\section{Raquel:}

Interviewer:

Raquel: $\underline{10: 50}$

$\underline{10: 51}$

$\underline{11: 04}$
Yeah. Yeah. Um, how about how it's organized, like how the epithelial tissues were organized in class or like how you organize all those tissue and cell types like in your head.

What do you mean?

Um, well, I mean like there are different ways to kind of categorize the tissues or categorize the cell types. And so I, I mean, I'm guessing

Muscle and nervous? 
Interviewer:

$\underline{11: 05}$

$\underline{11: 16}$

Raquel:

Interviewer:

Raquel:

Interviewer:

$\underline{11: 55}$

$\underline{11: 55}$

$\underline{12: 12}$
Yeah, perhaps. Okay. So that would be one way. Okay. Um, by system for example. Um, and I'm assuming that it was like presented in such a way that it was $\backslash$ organized somehow.

Yeah, that's how it was. It was like muscle nervous, those types of, thats kind of like, I think I'm like a visual person, so like that's like when I think about it, I think about how it was on the lecture slides and then that's how I kind of like think about them.

Yeah. Okay. So you kind of took that organization you'd like, that's how you think about it now. Um, and then if you had to like give an elevator speech on what is the takeaway from this unit? Like what's the most important thing for you as a future nurse about from the epithelial tissues unit? What's the big takeaway?

Okay.

And I'm not really concerned about what Dr Wargo says is the big takeaway I'm concerned with like what have you taken away from it? Like what is the relevance of this unit to you in your future career?

That there is multiple different levels of tissue. Like there's muscular and nervous and no, I guess that's it. Yeah. 
New Speaker:

$\underline{12: 24}$

Interviewer:

$\underline{12: 32}$

Raquel:

Raquel:

Interviewer:

Interviewer:

Raquel: $\underline{15: 40}$

$\underline{16: 21}$

$\underline{16: 30}$

$\underline{16: 54}$

$\underline{16: 56}$
All right, that's fair. Okay. So the next thing is I'm going to ask you to do a concept map. Have you ever done that before?

Not really, no. Okay. So concept map is basically like you have all these terms and let's say that you know, these two are connected in such a way that you would essentially just draw a line between them in the label, the connection to describe how they're connected. And so I know that this is probably wrong, but that's the idea is that you draw lines between the terms and kind of describe how they're related to each other. Okay. Um, and you can use all of them if you want or you don't have to. It's totally up to you. There's really no correct way to do this. Okay. Go for it. And then if you find that there's a term that you need the does not up there, you can create a new, okay.

Do I, I don't have to use all of them right

Well honestly [inaudible] I

Remember there are no correct answers.

Okay. Can you explain?

Okay. Well so they're either like simple or stratified except for like psuedostratified cause it's just kind of like, it's a weird one and I put simple squamous, simple columnar, simple cubodial under those cause they're all simple and then stratified under 
the stratified and simple or stratified simple means like it has one layer, stratified meaning that it has two, and then I put, I put squamous, columnar, cuboidal under the simple cause they're all simple and stratified under the stratified.

Pseudostratified I just left in the middle cause it's just a weird ones. I didn't want to classify it as some more stratified and so then I put like what they all do under it.

Interviewer:

Okay. So these are all functions down at the bottom? Yeah. And you've ordered organized it essentially kind of like a heart hierarchical grouping.
Raquel:
$\underline{17: 41}$
Yeah.
Interviewer:
$\underline{17: 42}$
By shape.
Raquel:
$\underline{17: 43}$
Yeah.
Interviewer:
$\underline{17: 44}$
Is that fair to say?
Raquel:
$\underline{17: 46}$
Not necessarily by shape but kind of like by like just kind of like by the layers that they have.
Interviewer:
$\underline{17: 53}$
Okay. Yeah I understand. Okay. So I have, this is by no means the correct concept map.
Raquel:
$\underline{18: 03}$
Okay. 
Interviewer:

$\underline{18: 03}$

Raquel:

Raquel:

Interviewer:

Raquel:

Interviewer:

Raquel:

Interviewer:

Raquel: $\underline{18: 20}$

$\underline{18: 31}$

$\underline{18: 57}$

$\underline{19: 04}$

$\underline{19: 08}$

$\underline{19: 10}$

$\underline{19: 14}$
Have a seat and I'm just curious what your reaction is to this one and what differences do you see? What similarities that you can mark on it? If you see things that are you feel are wrong, feel free to edit. Do you want a peanut butter cup?

I'm good, thanks.

So is this just supposed to be like I have no for me when I like do something I would have it be like, I don't know. I can't like looking at this just makes me feel like, cause if the simple cuboidal is coming off the squamous Columbia are cuboidal like is this saying like the simple cuboidal like comes from that or is like similar to that?

I dont know, I mean I think perhaps this would help if we put like slashes.

Oh, okay. Okay. Yeah.

So it could be any of those three.

Okay.

So how does that simplify it for you or make it make more sense?

19:27 I mean it doesn't really, I mean they're going to be honest. Like I can see, I can see like it's simple, squamous and columnar, 
simple cuboidal, stratified and like stratified squamous and its protection lining, covering. Like those are the functions of that stratified columnar and cuboidal and then that's the function.

Interviewer:

$\underline{19: 55}$

Raquel:

$\underline{20: 06}$

Interviewer:

$\underline{20: 13}$

Raquel:

Interviewer:

$\underline{20: 25}$

$\underline{20: 29}$

$\underline{20: 30}$

Interviewer:

New Speaker:

$\underline{20: 36}$

$\underline{20: 37}$

Interviewer:

Raquel:

$\underline{20: 24}$
No.

Anything you want to say about your knowledge of the deal tissues that we haven't covered?

No.

No. Okay. Um, well, I will probably send you an email over the weekend and trying to schedule that second interview.

Okay.

It does this time work for you generally? Yes. Yeah, so l'll just try to make it the same time.

Okay. Okay. All right. Thank you. 
Interviewer:

Raquel:

$\underline{20: 49}$

Interviewer:

00:02

Raquel:

New Speaker:

00:10

$\underline{00: 32}$

Interviewer:

Raquel:

Interviewer:

Raquel:

$\underline{00: 06}$

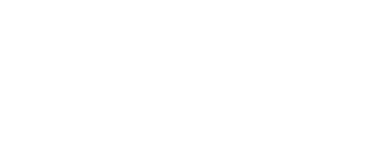

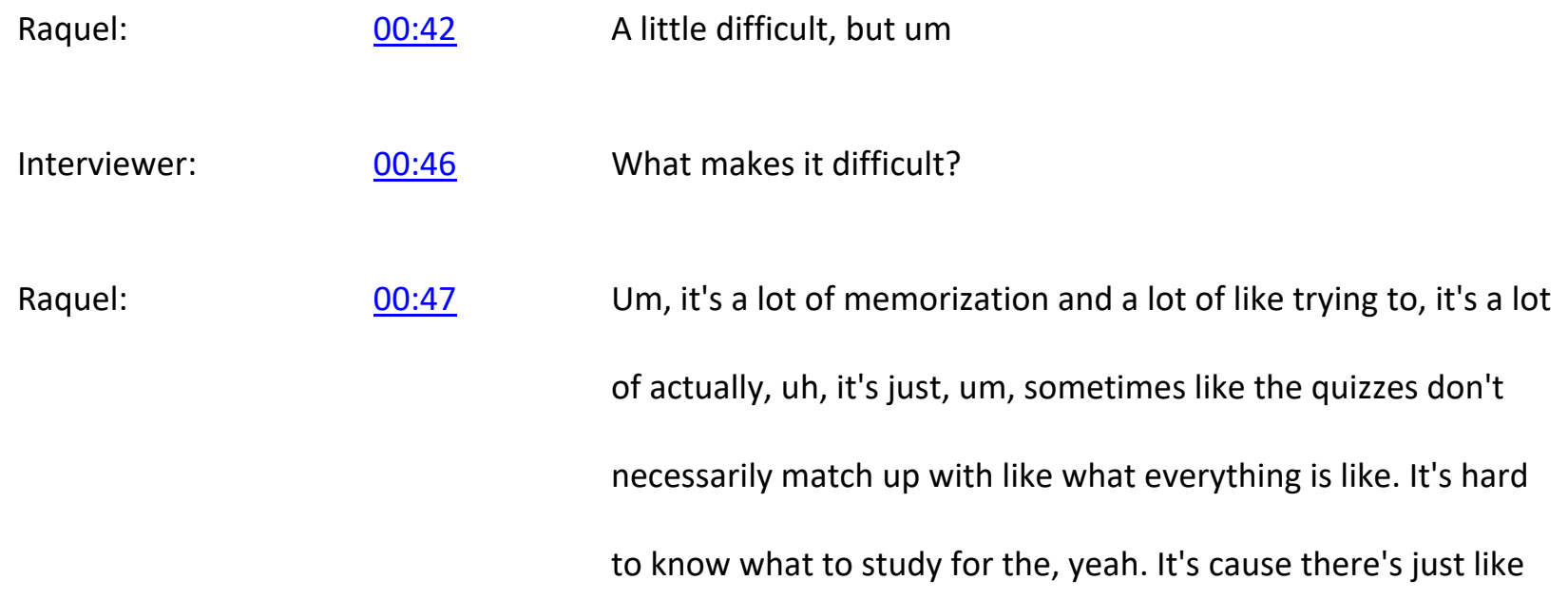


so much material and so it's hard to identify what to focus on and what not to focus on. Yeah.

Interviewer:

$\underline{01: 22}$

$\underline{01: 40}$

Raquel:

Interviewer:

$\underline{01: 50}$

$\underline{02: 04}$

New Speaker:

Interviewer:
So, um, how do you feel about like learning the material? Like it as far as your understanding that that goes said more difficult to understand list of gold like this or is it just the amount of material that makes it harder?

I think it's the amount that makes it hard. Not necessarily like concept wise because if you like like some of, like yeah, I guess its just the amount of material that makes it hard.

Yeah. So last time I asked you like, why do you think anatomical knowledge is important? And I'm wondering have you had any changes in your thoughts on that since last time we talked?

Yeah. So, um, just like even by talking to other nurses as I've been like taking anatomy, I don't necessarily agree with what I said originally and the fact that maybe I'll use all this knowledge later just in the fact that okay, maybe I need just a basic knowledge but I won't necessarily need all of this detail, that level of detail.

Um, so compared to other areas of the A\&P course so far, like how does your understanding of this area compare like of what was going on? 
Raquel:

$\underline{02: 52}$

(1)

Interviewer:

$\underline{03: 49}$

Raquel:

Interviewer:

Raquel: $\underline{04: 02}$

$\underline{04: 04}$

$\underline{04: 06}$
I think conceptual, conceptual wise, I understand the concepts, it's just the actual like labeling the muscles and labeling the bone is where I get tripped up because I could tell you all the processes, all everything functions super easily. It's just labeling everything that gets me, which I think is the exact opposite for a lot of people because I'll be like, oh, how was the quiz? They'll like, oh, so easy and then I'll take it and I'Il be like, that was so hard. I didn't understand what you're talking about. But I think like as I've gone through I've realized that like I think a lot different than most people. Like I think like understanding the processes and understanding how like everything actually works. I think that's easy and I get that really fast... With labeling, that takes me forever. I can't label or memorize or do anything like that, but a lot of other, most people can.

Yeah. So what, what things are helping you or enabling your learning of that material? Like maybe it's in class or maybe it's outside of class. Are there tools that you're using?

For like labeling or just the concepts?

Both.

Um, I think labeling, I used this one website, I don't know what it's called, but like it's like the first one that pops up if you type in the bone and quiz labeling. And so if I just like, it's like a game 
and you just like match the bone to whatever. It's the part. And so like if I play that over and over again I can get it. And I also, I have like a tablet so I can mark out. Like I just wiped out the like other words. Yeah, I just knock out the diagram where it and I just labeled him over and over again.

Interviewer:

$\underline{04: 38}$

$\underline{04: 39}$

Raquel:

Interviewer:

$\underline{05: 11}$

Raquel:

$\underline{05: 42}$
Yeah.

But then like processes and like concepts. I like that doctor Wargo like relates it to just normal things or like she uses her hands a lot to explain things like the sliding filament theory. She like used her hands to like demonstrate it and like I'm very visual person, so like as I'm like reading it, I'm like, oh that's the thing she did with her hands. And like, so it makes that seem a lot easier.

Okay, cool. Um, what about organization of the course and also like how you organize the knowledge is does that help or hinder your learning of the material? Um, I mean like, you know, there are all these bones and muscles that you have to memorize. Are there certain ways that you categorize all of those bones and muscles to like kind of take them in chunks?

Um, I basically just do it how she does it in my notes. So like, like the notes right now, our by like, fibrous or connective or like just whatever she has it labeled by is, kind of like how stick to. 
Interviewer:

Raquel:

$\underline{06: 04}$

Interviewer:

$\underline{06: 36}$

Raquel:

Interviewer:
Do you feel like that helps?

Yeah. Yeah. I mean, I like, I just, I like to get on, I'm like a visual person, so I'm going to visualize the notes. Yeah. So I'm like, I'm going to visualize the powerpoints, so I like, I'm not gonna be able to, if I rewrote everything and like I would literally probably have to like rewrite all of the notes in a different way to categorize them and then have to think about how I rewrote them in that way. But then I would probably get confused about, oh wait, am I thinking about this way or am I thinking about this way? So it's easier for me to just stick to the one.

Yeah. Cool. So from this unit, what has been like your takeaway, like as a future nurse? Like what is your big takeaway from this unit?

06:51 Um, well, we've been studying about the muscles and the skeletal system and I guess, I mean, it's really hard to summarize. Um, we basically just been studying the bones and muscles, so there's not like an overall, like conclusion about it except for the fact that you have bones and you have muscles and they work together to make you move and live. Yeah. Be a human being.

Okay. So on the board we have list of a bunch of vocab words you'll probably recognize. And um, again, I'm just going to ask 
you to organize them in a way that makes sense to you. You can group them together, draw lines between them that show relationships. Um, whatever makes sense to you. You don't have to use all of them.

Interviewer:

Interviewer:

Raquel:

Interviewer:

Raquel:

Interviewer:

Interviewer:

Raquel:
10:56

$\underline{07: 43}$

$\underline{10: 23}$

$\underline{10: 24}$

$\underline{10: 39}$

$\underline{10: 52}$

$\underline{11: 18}$

$\underline{11: 22}$
Go for it. [inaudible]

okay. Can you explain?

Uh, yeah, so I put, I kind of just like, and so these are like the muscles and then the structure, regulation, movement, protection storage. Think about that on top of that. And then the long board short bones and I put them in the columns.

Oh, Okay. So the long bones are plantar flexors, Dorsi flexors, short bones are our hands on servers and extensors, intrinsic hand muscles.

And their on the muscle side.

Oh, okay. Yeah, I read short bones, but then I didn't like it didn't click that I was reading muscles. Okay. And then, um, can we draw on the board just so it's clearer? Yeah, like short bones.

And then what are all those together?

I just kind of like group like these as like what they do and then I just kind of like all of this is left ove. 
Interviewer:

Raquel:

$\underline{11: 43}$

Interviewer:

$\underline{12: 02}$

Raquel:

$\underline{12: 25}$

$\underline{12: 42}$

$\underline{12: 46}$

$\underline{12: 57}$

Interviewer:

Raquel:

Interviewer:

$\underline{13: 00}$

Raquel:

$\underline{13: 02}$

$13: 00$

Interviewer:
Okay. Are there any ways that you can like sub divide those muscles that long list of muscles?

Uh, yeah. I can attempt to divide them by like...

if not, that's fine too. That's just,

Okay. I kind of like then divided it up by like where they are. Like I kind of think of these all together cause they're on that upper half of your body and these are kind of like lower middle area and then these are like your foot, and this should be like the lower middle area.

Okay. Can you just label them.

Yeah.

So you're saying the one on the far left is upper?

Yeah.

And then gluteal that...

Your middle area. And then you obviously have like, I obviously like the feet and the hands don't go together, but they're kind of like smaller muscles, so I kind of think of them together.

Okay. What about the latissimus dorsi and peroneals? 
Raquel:

Interviewer:

$\underline{13: 22}$

Raquel:

$\underline{13: 29}$

$\underline{14: 10}$

New Speaker:

Raquel:

$\underline{14: 42}$
Interviewer:

I dont remember so I just put them somewhere.

That's totally fine. All right. Anything else?

No

Um, so just like before I'm going to show you a concept map is not the correct one, right? It's just another one. And um, you can compare if you want or just comment on what you see. You can correct things if things don't make sense to you.

I mean I think this is also divided kind of like similarly how I did it with like the bigger muscles until like, like the, yeah, like the bigger muscles into the smallest muscles. They kind of like going from bigger into smaller, which is kind similar to how I did it. But then they like use like, like skeletal muscles and they put like what they all do, which like they both provide protection, storage, movment, structure regulation.

Do you agree with that? That both skeletal muscles and long and short bones do that?
$\underline{14: 48}$
$\underline{14: 50}$
$\underline{14: 59}$
Raquel:
Interviewer:
Interviewer:
Yeah, all of them.
Yeah. Okay. Anything else?
Do you know why these arrows are here? And that's a genuine question. I don't know why. 


\begin{tabular}{|c|c|c|}
\hline Raquel: & $\underline{15: 03}$ & No \\
\hline Interviewer: & $\underline{15: 06}$ & Okay. \\
\hline Interviewer: & $\underline{15: 19}$ & All right. Is there anything else you want to say with this? \\
\hline Raquel: & $\underline{15: 22}$ & $\begin{array}{l}\text { Maybe it's because like, I mean like these both have like flexors. } \\
\text { So I was thinking you'd be like, they do similar things is what } \\
\text { that person was trying to say. I was thinking like movement, like } \\
\text { if it's the movement, like they do similar things, but I don't know } \\
\text { if it's like, is it like talking about like a pectoral muscle is similar } \\
\text { to the gluteal? Like I don't know if it is like pointing directly at } \\
\text { that or, I'm not really sure. I'm thinking maybe like if they're } \\
\text { trying to convey that like they're similar muscle. Like they can } \\
\text { do similar things cause like it'll flex or flexion is like obviously } \\
\text { like a hand flexor plantar flexor are going to be able to do a } \\
\text { similar movement just in a different location in the body. }\end{array}$ \\
\hline Interviewer: & $16: 13$ & $\begin{array}{l}\text { Okay. I see. So maybe like if you were to label these, it would be } \\
\text { something like moves like, or moved similarly. }\end{array}$ \\
\hline Raquel: & $\underline{16: 25}$ & Yeah. \\
\hline Interviewer: & $\underline{16: 28}$ & Anything else? Do you have any questions for me now? \\
\hline New Speaker: & 16:38 & $\begin{array}{l}\text { I think maybe more like, just like a general inquisition. Like what } \\
\text { is this being used for? }\end{array}$ \\
\hline
\end{tabular}




\section{Raquel:}

Interviewer:

$\underline{16: 47}$

Interviewer:

$\underline{00: 01}$

Holly:

Interviewer:

Holly: $\underline{00: 28}$

\section{$\underline{00: 28}$}

$\underline{00: 28}$

$\underline{00: 40}$
Well can you tell me that?

Yes, I can, I'm going to shut off the camera though.

Okay. So first thing I'm going to say is, you know, I'm going to be asking some questions about your anatomy knowledge and you know, I never took AP and I, um, I took comparative anatomy but that was over like 20 years ago. And so when I'm asking you questions like I'm not trying to quiz you or test you, I'm like genuinely just trying to understand how you think about this stuff.

Yes.

Okay. Um, so the first question I have is just generally, how is A\&P going for you? Have you encountered any challenges, barriers over the course, things you've loved?

It's, yeah, I really like it a lot. It's fun. It's like what I'm interested in what I wanted to do for a career I want to do medicine. So, um, it's very interesting to me. So far it's been no issue for me to like spend time like looking at it and studying it because like I'm interested like most classes, like I can't just sit and read a textbook in this class. 
Holly:

$\underline{01: 01}$

Interviewer:

Holly:

Interviewer:

Holly:

Interviewer:
I could sit and read the textbook because it's interesting to me.

So, so far I wouldn't say it's been like super tough. It's just been like time consuming. But like that's okay cause I like it. Yeah.

Yeah.

01:12 Um, so you kind of implied this is super relevant for you. This is what you want. So what are your future career plans?

01:20 I'm a biology major and a Spanish minor. Um, as of right now, it's not definite, but I definitely want to do something. In the career field of medicine, whether that be med school or an accelerated nursing program to eventually be like a practitioner or something in the field of like medical research, like immunology, like vaccines. That's very interesting to me. Um, so something along those lines.

01:44 Cool. All right, so you're like kind of remaining open, but it's still

01:49 I'm a freshman so I've got a little bit of time to feel it out.

01:52 Yeah. Well, welcome. Um, I like didn't even dawn on me that you might be a freshman actually, so that's awesome. Um, so what is it specifically about anatomy and physiology knowledge that you think is like really important or useful? Um, maybe in general, but also, um, given your future career in healthcare? 
Holly:

Holly:

Interviewer:

$\underline{02: 55}$

$\underline{03: 02}$

Holly:

$\underline{02: 52}$
I think in general it's really important for everyone to have like a basic understanding of how they work because it's you and you know, you carry the systems that we're talking about. It's not like it's something that, oh, you might see one day in the field like a fossil or something or like an entire ecosystem you might visit someday. It's something you carry with you and that you see every single day and that you deal with, you feel, you feel those nerve impulses. So it's really interesting and I think important to understand like how your own body works so that you can understand your health as well as like health of people that you care about.

Um, and then hopefully live a better life because of that. Yeah.

Okay. And what about like as a future nurse or doctor or nurse practitioner?

Yeah. Um, as that definitely for me it's very important to like, have very good like information fluency to understand it. Because, um, in order to treat my patients in the future, I'm going to have to understand, you know, how their bodies work, how the systems work so that I can understand how certain conditions work and how those conditions affect them. So it's, you know, be a proficient and you know, a good provider. I have to be able to understand how the body works. Yeah. 
Interviewer:

$\underline{03: 30}$

Holly:

Interviewer:

$\underline{04: 26}$

$\underline{03: 50}$

$\underline{04: 41}$

Holly:
Okay. Um, so you were talking about how you're really interested in the content so far and it's totally relevant, easy to study. I'm curious how your understanding of the content has been so far. Like, um, how do you feel your understanding of anatomy and physiology has changed?

I would say it's definitely improved and gotten better. Like I had a pretty good general knowledge base. Um, just because like I said, I'm very curious person. I want to go into medicine. So like I just like read stuff like that because I'm interested in it. I watch videos, those type of things, but It definitely, um, has increased because l've never taken like an actual like anatomy class before this. I've had tons of bio classes, I've had like medical terminology and those kinds of things where you cover a lot of like the surface details, but I've never like gone into detail about like tissue type or like bone development and that and that's really interesting. So yeah.

Cool. Um, okay, so apparently you just finished a unit on epithelial tissues and so the next set of questions I'm going to ask, it's just like based off of that particular unit not the whole course so far.

Gotcha. 
Interviewer:

Holly:

$\underline{04: 47}$

Interviewer:

$\underline{05: 24}$

Holly:

$\underline{05: 34}$
So first thing, what are your impressions of that unit?

Challenging. Easy. You loved it, you hated it.

Yeah, it was a lot of information definitely. And all that stuff

that I hadn't covered in the past. Definitely very interesting. Um, things that I have touched on in the past, like different tissue types and like their functions but never like to the point of like necessarily like there like shape and the difference between different types of epithelial tissue and what they do and where they're found and that. I can't say I've covered that before that I remember going in depth before it. Like I have, um, in this class. Yeah. So definitely it was a lot of information to cover lots of number. I wouldn't say I'm perfect at it by any means, but I definitely know a lot more known when I didn't, when we started.

Cool. Um, so what were the things that enabled your learning of this content? Like things that you did or things that happened in the class or...

Um definitely going to lecture. Um, drawing pictures is a big thing for me cause I'm a very visual learner so making sure I understood it that way. And then in lab, like I really do like the lab portion of the class too because um, it is a very visual thing with like using microscopes and diagrams and things along those lines. Um, so definitely that I read textbook and the 
homework definitely in the class helped too, I think because it was very similar. Um, in terms of like what she wanted us to know too, like for the actual test. Yeah.

Interviewer:

$\underline{06: 09}$

Holly:

Interviewer:

$\underline{07: 01}$

$\underline{07: 09}$
Nice. And then what about how the information was organized? Like they're kind of two things. Two ways to think about this question. Like, no doubt it was presented in an organized way. It was organized somehow it's presented. But I'm also curious about how you organize, like how you think about epithelial tissues. Meaning like do you... are there categories that you think of them or like...

06:34 So like for epithelial tissue in general or just like tissue types of general cause like the way that my brain works, it's like, like I feel you'll tissue and then dropped down from that. And then you have simple and stratified and then somewhere in the middle there you have like transitional and pseudo stratified, which are kind of in their own category. Um, so it's sort of like, like this like hierarchy, if that makes any sense.

Yeah. Um, so how does that compare to how it was presented in class? I'm curious, I'm just asking cause I don't really know since I'm not in the class.

Holly: Um in class is very different. Um, it's more like just sort of like she goes through like slides over and like the way she describes 
it, I really do like, and she does a lot of analogies and that's very helpful. Um, but I would say like definitely like, um, my studying on my own definitely helped with my understanding more just because there was more visual, um, things and diagrams on those lines of helps.

Interviewer:

$\underline{07: 37}$

Holly:

Interviewer:

$\underline{08: 01}$

$\underline{08: 14}$

$\underline{08: 19}$

$\underline{08: 23}$
Can you give an example of analogy that she used that helped you?

Oh yeah, I was just using one of these because I'm a tutor at the visitor center and I was just using this for like, my tutees is like... Um Tight junctions and desmosomes. So like a tight junction is like two pieces of paper that are glued together, where a desmosome is like a staple. So it's fixed at a point, but there's still some mobility. So that was like one that was really useful. Yeah.

Cool. Um, okay, so if you had to like kind of give the elevator speech or the big takeaway from the epithelial tissues unit, like what is the take home message for that unit for you?

Of just epithelial tissues or tissues in general?

Well, just that unit, like of that.

Okay. Um, I'm trying to think about how to put this. Um, so like from the tissues unit in general, um, I would say that tissues 
differ based on their function and also they're like shape and structure help determine that function because how they're shaped helps them do their job. Um, and that goes for every sort of tissue. So that would be like the most general way to put it. And then they're broken down into, you know, the four categories of yeah. Connective, epithelial, nervous, muscle. Yes, my brain that's like, yeah. So it's broken down into those four. And then from there it's like you start super general and then you get wider and wider. So sort of like a pyramid and more specific as you yes. As you get lower down. Yeah.

Interviewer:

09:18

Okay. All right. So you know, you've kind of already described like how you do this, but I'm going to ask you to create a concept map. Have you ever done this?
Holly:
$\underline{09: 28}$
Yes.
Interviewer:
$\underline{09: 28}$
Alright, so can you just want to dive in or do you need an explanation?
Holly:
$\underline{09: 32}$
Um, I can just dive in.
Interviewer:
$\underline{09: 36}$
Okay, go for it.
Speaker 3:
$\underline{09: 41}$ These are functions. So like, would you like... Oh there is not labels for it. That one doesnt want to stick. Transitional is kind of its own thing. I dont need these. 


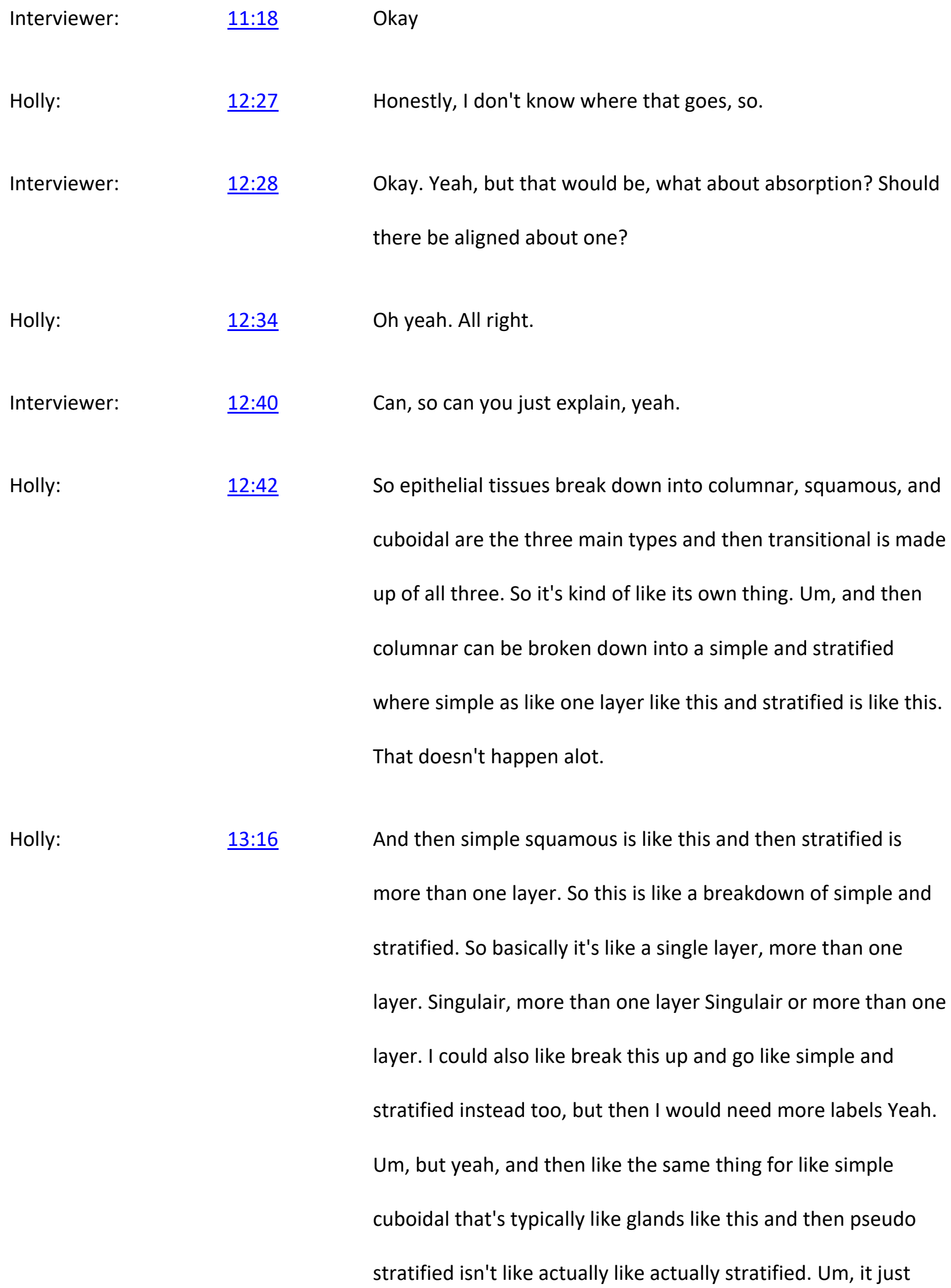


appears like it because it's like this, so like looks like in stacked on top of each other. But really it's one layer.

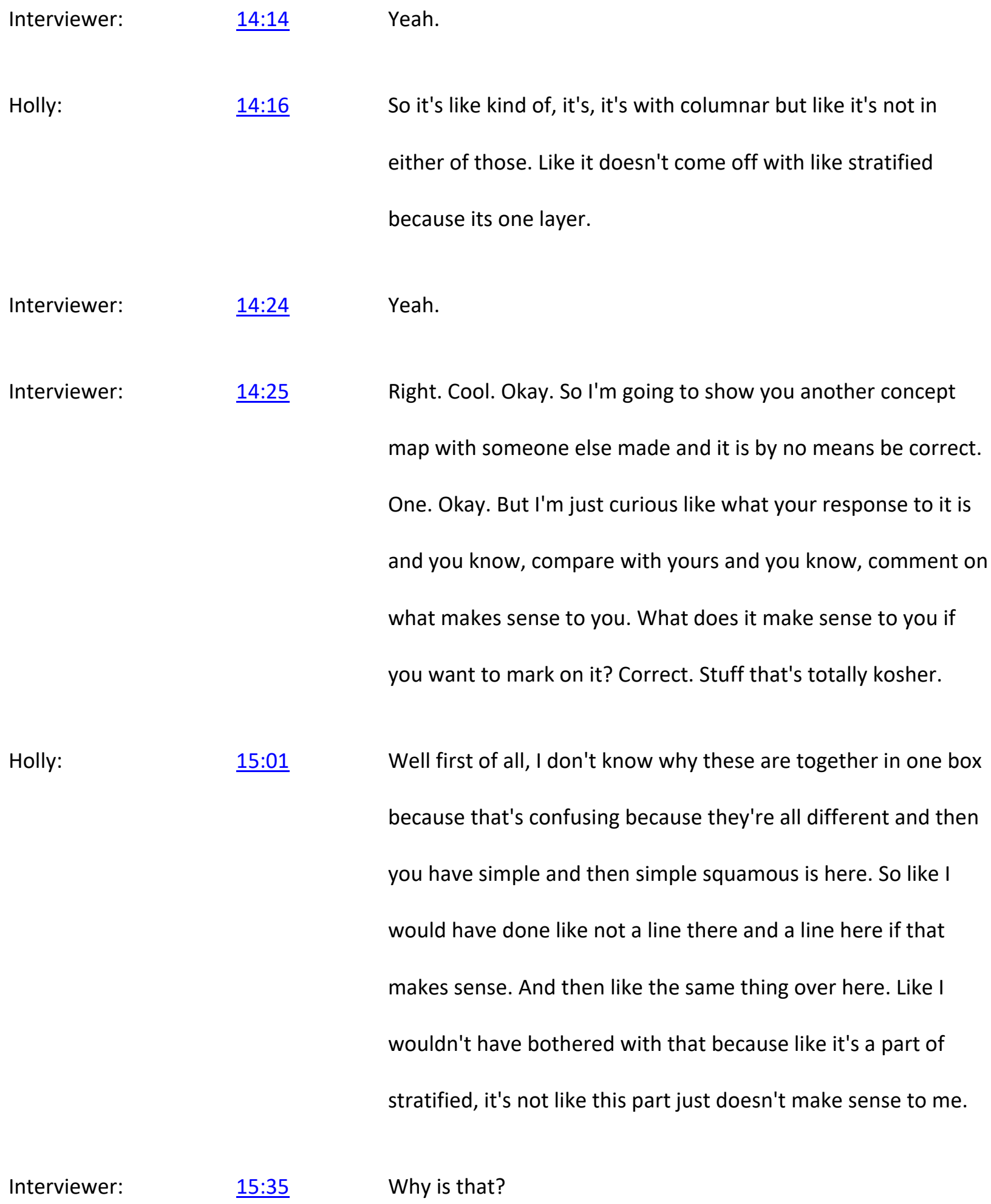


Holly:

$\underline{15: 36}$

Interviewer:

$\underline{16: 03}$

Holly:

$\underline{16: 05}$

$\underline{16: 31}$

$\underline{16: 31}$

Holly:

Interviewer:

$\underline{16: 39}$

Holly:
Because like it has all of them in there. Like it doesn't, it has all

of them like at one time and it's like it doesn't have any distinction between the three types. So what's the point of having that there? You might as well just write epithelial tissue. And then like this I would have kind of like, I have to do that too. Like that just, yeah.

Okay. Anything else here?

And then I would have had like, there's no like separate, see that's right. There's no separate one for um, columnar, but there is her simple and stratified. So like you need one here.

Okay.

Yeah, I don't know, that just doesn't really make sense to somebody that for me.

Okay. So you had mentioned you divided them by columnar, squamous, and cuboidal, and transitional kind of, and you said that you don't need these over here because when you don't need that, but you said you could have done it in a different way where you

Yeah, but then I would just have to make more labels so that didn't make a lot of sense to do it that way. 
Interviewer:

Holly:

Interviewer:

Interviewer:

Holly:

Interviewer:

Holly: $\underline{17: 02}$

$\underline{17: 04}$

$\underline{17: 15}$

this is groups more into like based on distinction, um, because the difference between stratified and simple is a lot more simplified I think. Then the difference between like the three types of like columnar, cuboidal, and squamous, like, like those three are so different in their function and their formation and everything, whereas stratified and simple just has to do with like the number of layers. So I don't think it makes a lot of sense to like start there. Like those are more like smaller distinctions. I think it's bigger distinctions that way.

17:56 So you're saying like bigger distinctions kind of higher up on the hierarchy.

$\underline{17: 58} \quad$ Yes. It's easier.

$\underline{18: 00} \quad$ Yes. Makes Sense.

18:02 Yes. 
Holly:

$\underline{18: 05}$

Interviewer:

Interviewer:

Holly:

Interviewer:

$\underline{19: 01}$

Holly:
Yeah. Again, like the big picture at the top and then break that down into little things and then break that down into little things like the pyramid structure, which you can kind of even see.

$\underline{18: 13} \quad$ Right.

18:13 But like, yeah, so I guess what I hear is that you could have done a similar pyramid with stratified and simple. It was just sort of like more complicated under each one of them. You would've had to have listed columnar, squamous, and cubodial, which would have kind of almost made two pyramids.

18:33 Yeah, yeah, yeah. So like it would have been stratified, simple and then columnar, squamous, cubodial... columnar squamous, cubodial... columnar, squamous, cubodial off of all of those. And then also I think that that lacks the connection between like, what is simple squamous? It's like more split up, you know? So it's like keeping things more compact, easier to understand.

Okay, cool. Alright. Well those were all my questions for you. Do you have any questions for me?

Nope. 
Interviewer:

Holly:

$\underline{19: 20}$

Interviewer:

Interviewer:

Holly:

$\underline{19: 31}$

Interviewer:

Interviewer:

$\underline{19: 42}$
Nope. Okay. So probably this weekend I'll send you an email trying to schedule the second one. And, um, do you prefer an Amazon gift card and stuff?

Yeah, probably.

All right.

I mean, I mean, it doesn't really matter. Well ordered them. Yeah. I feel bad because you didn't get a choice. Um,

No, I probably would've picked the Amazon cause you can get more stuff on Amazon.

Yeah, for sure. Yeah. Um, and yeah, I mean, as long as you don't have any questions for me.

Okay. All right. Thank you.

Juan:

$\underline{00: 06}$

Starbucks.

Interviewer:

$\underline{00: 08}$

So, um, my name's Interviewer, I forgot to introduce myself. Um, I'm a faculty member here in biology and before we get started, I just want to say that like, you know, throughout this 
interview I might be asking you things about your knowledge of anatomy, but I know nothing. I never took an A\&P course. I took comparative anatomy like over 20 years ago. And so when I ask questions, like, I'm genuinely just trying to understand what you're thinking and what you're trying to say and I'm not really testing you or anything. That's not what the purpose of this, okay?

Juan:

$\underline{00: 57}$

Okay.

Interviewer:

$\underline{00: 57}$

Um, so first can you just talk about like challenges and or the, have there been any barriers or anything in your A\&P course so far?

Juan:

$\underline{01: 09}$

I mean, just from like all the terms, I'm trying to memorize it because I mean like, it's just a lot to remember.

Interviewer:

Yeah.

Juan:

$\underline{01: 16}$

And, um, I'm trying to find like different ways of memorizing it and like such, I just speaking every day at least or talk to their friends about it because I have a lot of friends that are like science majors. So like we'll talk about it and that'll help me remember it. I didn't do much like studying for the first exam because I had a family passed away so I didn't really study as much but I'm trying to find more methods and for the second exam. 
Interviewer:

$\underline{01: 42}$

Juan:

Interviewer:

Juan:

Interviewer:

Juan:

$\underline{02: 29}$

Interviewer:

Juan:

$\underline{02: 35}$
Okay. So what so far have you found that works? Like do you make flash cards, do you do a quizlet, is there any method that you use?

01:51 Um, I do find some quizlets online, which are very helpful. I do do flash cards though, but I want to like, make like bunches of flash cards, like information about the head, talking about like the anatomy of it and then after that and go in depth about the muscles and then the skeletal so thats what really helps me cause that like bunches everything under this one general term.

Cool. Yeah, I mean, so provide some organization to it kind of.

Yeah.

Very cool. So generally speaking, why do you think anatomy knowledge is important? Like, I mean perhaps relevant to this question or what would your career goals? Like? What are you studying for?

Um, I'm planning on going to medical school, so I mean, I do find that like, is it important for that?

Yeah.

Other than that, I mean it's just really interesting, especially since you're just looking about the human body, which is your 
own body that's going to be dealing with for the rest of your life obviously. And um, yeah, I don't know, just like really interesting. It's, it's a good conversation starter too, whenever, you're talking to someone.

Interviewer: $\quad \underline{02: 53} \quad$ Yeah.

Interviewer:

$\underline{02: 55} \quad$ I'm trying, I'm just reflecting on all the weird conversations I've had. It's like random people making small talk because you have all those scientific knowledge. I understand. Um, so how well did you feel like you've understood the content so far? Like you've mentioned that, um, memorizing the bulk of the information is hard. Um, and then you've talked about some things that you do to help with that. But I guess I'm asking about like how do you feel your understanding of anatomy has been evolving over the course of the semester?

Juan:

I mean, I'm definitely learning a lot more cause like I never. I didn't have Anatomy in high school, so really this is all just new to me and, um, yeah.

Interviewer:

$\underline{03: 48}$

Okay, so I believe that you just finished a unit on the epithelial tissues. Is that true?

Juan:

$\underline{03: 53}$

Yeah. 
Interviewer:

$\underline{03: 53}$

$\underline{04: 12}$

Juan:

Interviewer:

$\underline{04: 45}$

Juan:

$\underline{05: 01}$
I'm relieved that you say that. Um, cause you know, I don't really know about the course. Um, so the next few questions I'm going to ask are just specific to epithelial, like that unit. Um, so the first, I mean, challenging, easy. What did you think of that unit? What did you like, what did you dislike?

I mean, the stuff about the tissue, the epithelial, it was like, it was a lot to take in; but I mean that's how like most lectures are. You just kind of like add all that on to your previous knowledge of what you just learned. And not only that, it's just that, um, I have to try and keep memorizing the stuff that we were just taught. Cause I mean like this ain't the only course I'm taking. So I got other courses to worry about. Like they got a quiz this Friday that I'm more putting my focus towards rather than Anatomy but since the exam is next week I'm going to be trying to like to focus as much time as I can on the weekend on the lecture.

Yeah. Cool. So, um, is there anything specific that helped really organized or helped you, helped you learn or anything just during this unit that's different than what you've been doing otherwise?

Um, no, I've just been doing the same thing. I mean, if the, if I ever do find a better method, I'll make sure to mention that in our next interview. 
Interviewer:

$\underline{05: 10}$

Juan:

$\underline{05: 22}$

Interviewer:

$\underline{05: 31}$

$\underline{05: 45}$

Juan:

Interviewer:

Interviewer:

$\underline{05: 49}$

$\underline{05: 51}$

$\underline{06: 10}$

$\underline{06: 10}$
Okay. Um, so what do you think the big takeaway from that epithelial tissues unit is? Like what's the take home message?

I didn't really, I didn't really go over the slides for it. So like I can't really like say anything, but most importantly,

Well let me clarify. I don't really care what the instructor says. Is the take home message, I'm more concerned with like what I want to take away from. What did you take away from it? Yeah. What's the, gist of what you got from that unit.

I can't honestly remember that without going into it and I'm thinking I didn't really take anything from it.

Okay. That's fine. That's totally fair.

Okay, next I'm just going to ask you to do this like task on the board and so I kind of need this, um, basically like vocab words. Okay. And, um, I'm gonna ask you to like create a concept map. Have you ever done that before?

No

Okay, so like a concept is essentially just like a network between different ideas and like you arrange them however you want and then draw connections between them. And then, um, like you might label the connections, like for example, if stratified 
cells function for excretion then that's what you would draw.

Now, I know that they don't, and to be honest, at the beginning of this week, I did not know that I've learned that from doing these interviews. So, but the point is, is that, um, l'd like for you to just arrange these however you want. You can use all of them. You don't have to use all of them. If you find that there is a term that you need to describe something and it's not there, you can create more. Um, and I'm just going to ask that you create your map and then I'll ask you to kind of explain it.

Speaker 1:

$\underline{07: 15}$

$\underline{07: 17}$

$\underline{07: 18}$

$\underline{09: 30}$

Juan:

Interviewer:

Juan:

$\underline{09: 47}$
Okay. So go for it.

Oh right now.

Yeah, and you know, you can use any color you want.

For me to go like further into it. I kind of have to like review some of this stuff. I don't really like remember much from it. But I know like some of these are terms we used in lab. Such as looking over into the tissues in a microscope or...

So what about those that are set like separate than over there?

Well these are like, that's what I was trying to tie it into. Like some of these I feel like I remember seeing some of these words and um, I know they just connect to that somehow. It just really kind of like pul everything together. 
Interviewer:

$\underline{10: 03}$

$\underline{10: 15}$

Juan:

Interviewer:

Juan:

Interviewer:

Interviewer:

Juan:

$\underline{11: 07}$
That's fine. And then I noticed that you separated over here. Excretion, secretion, filtration, simple. Is there a reason for pulling those out?

Um, some of those go hand in hand together. Like one effects the other or like we just went over some of them in just one slide.

10:22 Yeah. Oh, I see what you mean. So like excretion, secretion, those kind of go together.

$\underline{10: 28} \quad$ Yeah.

10:33 All right. Um, well you can go ahead and have a seat. I have, I have a concept map that someone made. Here it is by no means the correct one. Um, and in fact I'm going to ask you to like comment on it. If there's anything you see with that is incorrect or doesn't make sense to you or anything like that. And if you want to draw on it, you're welcome to, here is a pen.

11:00 If you want to label connections, that would be fine. Um, I'm just curious what your response to this is.

I mean, yeah, it's, I feel like it is a good concept map. However, when I was picturing it in my head, I feel like there should be a lot more lines, like stuff that's just, I feel like as a like not kind of 
like a spider web but more complex than that. Cause that's kind of how like anatomy it is.

Interviewer:

Juan:

Interviewer:

Juan:

Interviewer:

Juan:

Interviewer:

Interviewer: $\underline{11: 37}$

$\underline{11: 37}$

$\underline{11: 44}$

$\underline{11: 45}$

$\underline{11: 46}$

$\underline{12: 13}$

$\underline{12: 17}$

$\underline{12: 33}$
Yeah.

So like all of these are connected, so like in one another. That's why I feel like there'd be like more connections to it rather than just,

All going towards the central one.

Yeah.

So like for example, I mean there could be potentially a connection between, I don't know, pseudo stratified and transitional and what does that say, stratified squamous. Yeah. Do you have an idea of what that connection is? Or like what would be like, what might you label that line between the two?

Not at the moment. Sorry.

That's okay. I don't either, um, but I see what you're saying that it's like this particular map, everything kind of goes to a central idea. Whereas you're saying that anatomy in general is more interconnected.

Yeah. Cool. Do you have any other comments about this one? 
Juan:

Interviewer:

$\underline{12: 46}$

$\underline{13: 21}$

Juan:

Interviewer:

$\underline{13: 32}$

$\underline{13: 48}$

New Speaker:

Interviewer:

$\underline{14: 03}$
Um, no. No, not so far. No.

Okay. Well, um, let me make sure I've talked about everything I'm supposed to. I do have one question. Like comparing what you've done up here on the board with this, do you see a difference in organization? Like are they organized differently?

I would say yeah. I mean, I don't know. I just probably would have rearranged it differently to provide a better understanding, but that's just like, you know how I would learn from it.

Yeah, I mean, I think that that's, that's an important thing about content maps. There's no specific correct. Like one way to do it. Um, all right, well I think we're done unless you have any questions for me.

Um, I mean if, if it really helps you guys with your research or to like provide my like way of doing this and then bring it back for the next interview. To like show how like I would cope, my way of doing this and then bring it like.

Yeah, I mean, if you, if you feel like there's like after kind of mulling it over and thinking about it, um, if you want to provide something that is totally helpful. Um, but I mean, you don't necessarily need to, I think that for the research purposes, we're kind of curious and like how unprompted or without 
studying, like, how do you think about these things in here? Like how do you organize them, you know?

Interviewer:

$\underline{14: 30}$

Juan:

Interviewer:

$14: 37$

$\underline{00: 10}$

$\underline{00: 11}$

Interviewer:

Sara:

Interviewer:

Sara:

$\underline{14: 36}$

Interviewer:

(a)

$\underline{00: 41}$

$\underline{00: 42}$
Okay.

Um, do you want some peanut butter cups?

Okay. your Starbucks card.

Okay.
Yeah. Um, so if you want to, that's fine, but certainly you're not required to.

Okay. All right. Well, thanks for coming in. No problem. Enjoy

So, um, first I just want to explain that, you know, throughout this interview I'll be asking you about your anatomy knowledge and, um, I never took AP and I took, took comparative anatomy but it was over 20 years ago. So when I ask questions I'm like genuinely just like, I don't know. So no part of this is like a test or I'm not trying to like, you know, test what you know or anything. I'm just trying to understand what you're thinking.

00:44 I'm good. 
Interviewer:

$\underline{00: 47}$

Sara:

Interviewer:

Sara:

Sara:

Interviewer:

Sara:

Interviewer:

Sara:
Um, I've learned that they're hard to talk with them in anyway, but they're delicious. You can take them to go to.

Okay.

Um, so first all, how are, how is anatomy or A\&P going so far? Like challenges, barriers, things you love?

01:01 Um, it's definitely harder than like any size than I've ever taken.

01:05 Like I've, I've always been good at chemistry. That's easy. It's a lot of like more study, which is good because I'm a nursing major. So I actually just had a meeting with my advisor and she said that it's good that I'm taking like I'm taking anatomy and microbiology at the same time.

Yeah.

01:23 And she said it's good because both of those are really like challenging and we'll get you ready for the nursing program. So I mean it's, it's going okay. It could be better. But now I know kind of the format of quizzes, tests, exams, stuff like that.

01:39 Okay. So what do you think could make it better?

01:42 Probably me just, um, setting more time aside to study. Like I, I think I kind of thought that it would be like, it would like click 
faster. But um, actually like Eric did tell us that he, we were like, how do you know all this?

Sara:

Interviewer:

Sara:

Interviewer: $\underline{01: 59}$

$\underline{02: 25}$

$\underline{02: 40}$

$\underline{03: 00}$
Like so easily. He was like, well, I've been taking it for awhile. Like this is harder than anatomy 2 because you're kind of like putting out a foundation first and you have to, it's harder. He like using analogy, like a puzzle. Like it's harder to start the puzzle then like put it in the last piece. So like probably just me like putting more time aside to study and actually prepare my materials and stuff and like not just wait till the last minute to have studied.

Yeah. Cool. Um, so generally speaking, um, like w why do you think the knowledge that you're gaining in this course is useful or important?

Well, I, for me it's useful just because of my major in like nursing. I have to know a lot of the stuff, how things work, where everything is. Um, just how everything functions and stuff. So it's like probably more important to me than any other, like a lot of other or, yeah.

Yeah. Okay. Um, is there anything specific that you're learning right now that you feel is particularly important for you as a future nurse? 
Sara:

$\underline{03: 10}$

Interviewer:

$\underline{03: 34}$

$\underline{03: 39}$

Sara:

Interviewer:

$\underline{04: 02}$

Sara:

$\underline{04: 27}$
Um, we just started bones and kind of the structure of bones, how they heal, how they grow, stuff like that. And in the lab we're learning like where everything is like, we had to label, a bunch of diagrams. I think that's important to like be able to know what everything is all on the body and where it is to help like get the right treatment for the patient or something.

So this is just kind of to put it into context, is there any particular area of nursing that you want to go into?

I want to be in nursing ethicist. So my, that's not really like kind of like the bedside nurse kind of. That makes sense, but that's what I want to do. But they say you always change like you change, you never know. Like you could go in thinking you want to be something but come out and being something completely different. So that's what I want to do right now.

Yeah. Cool. Um, so you mentioned that you know, you've kind of adjusted how you think you need to approach studying and things like that, but um, I guess I'm curious like how do you feel like you're understanding the material so far? Like how has your understanding been built, or not, so far by the course of anatomy?

Um, good question. I don't know. Uh, I think like everything builds Kinda from the first chapter through on, like you have to 
kind of understand like the basics first and that's, that's kind of hard if you like fall behind. So I think like just everything like builds on each other, if that makes sense.

Interviewer:

$\underline{04: 51}$

Yeah. Like it's foundational.

Sara:

$\underline{04: 52}$

Yeah.

Interviewer:

$\underline{04: 54}$

Okay. Can you give an example?

Sara:

$\underline{04: 56}$

Um, well I know in the first chapter we talked a lot about DNA and like we talked a lot about how stuff can, kind of like grow. And like right now we're talking about like burns and like treatments and stuff. So like kind of how like those cells can like a duplicate and kind of grow again to help heal like a burn and stuff and kind of like what you need to do in case like some of that cell like in third grade where it's like some of those cells aren't going to come back, so you have to like either put on like a skin graph or something like that. So it's kind of just like how, yeah. Things

Interviewer:

$\underline{05: 33}$

It's hard to understand how healing happens without understanding cell division.

Sara:

$\underline{05: 36}$

Yeah. Yeah. 
Interviewer:

$\underline{05: 40}$

Sara:

Interviewer:

$\underline{05: 48}$

Sara:

Interviewer:

Sara:

(1)

Interviewer:

$\underline{05: 52}$
Um, so I think that you relatively recently finished a unit on epithelial tissues.

05:47 Yes.

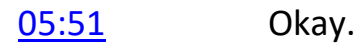

Um, so, well first of all, how did you like it? Easy, difficult, fun.

05:58 Um, I liked looking at them just because like a lot of them under the microscope, like they looked kind of cool and interesting and like sometimes slides just to go through slides isn't the most fun thing. But I think the thing that I like struggled with was knowing where they were kind of in the body. Like, um, like transition, like transitional, um, or transition cells. Those are in like your urinary bladder because like those can stretch easily, to to like, in with your bladder, you want them to be able to stretch and like when it's full or not. So I think that was the biggest thing was like figuring out where everything is, but then kind of once you know, like the, like what they do and like what's in it, then it kind of like makes sense. But I liked it. Yeah.

Yeah. 
Sara:

$\underline{06: 50}$

Interviewer:

Sara:

$\underline{07: 03}$

Interviewer:

Sara:

$\underline{07: 47}$
I liked it better than like mitosis and miosis and stuff.

06:56 So during this unit, what were the features of the course that really enabled you to learn this material?

Probably just looking at them like, because if you just get, like in the lab manual, he gave us like a bunch of pictures of them, but actually like looking at them because not all like of that type of cell is going to look the same. Like in that type of tissue is going to look the same underneath in every single slide. Like there's differences and they all like kind of look alike. So you'd have to be able to like figure out which one is which. So I think just looking at them cause I like if I get hands on experience with it than I like learn it better rather than just flipping through pages. Like I like seeing it happening or like in action. So yeah, it was probably like,

07:41 Okay, what about the organization? Um, like how things are organized?

Um, I thought it was organized well because he like went through them, like in the kind of what they did. And everything. Then he, you got to like actually look at them and you've got to draw them out and stuff. So I think it was like the organization was good because you've got to like learn about it and then 
actually doing something hands on, figuring out like what it was like, what am I looking at?

Interviewer:

Sara:

Interviewer:

Sara:

$\underline{09: 10}$

$\underline{08: 11}$

$\underline{08: 23}$

$\underline{09: 00}$ what, what's the big take home message for you?

Um, probably just knowing where like each of those were, because each of those tissues act in a different way. They do different things and like if for some reason that like something in the body isn't working right or like you know what type of tissue is there, that could be because of the tissue. That's why 
it's not functioning right or something like whether it's

protection or just like something else that has to do with it. So that was like the biggest takeaway from you was knowing where everything was to like kind of piece together why that wouldn't be in like working properly.

Interviewer:

$\underline{09: 47}$

$\underline{09: 55}$

$\underline{09: 56}$

Interviewer:

Sara:

Interviewer:

Sara:
Okay. So we're going to move to this little task on the board and I'm going to ask you to create a concept map, have you ever done that before?

Yes.

So the idea is that, you know, you have like two ideas and you might draw a line between them and label that line. Like, you know, whatever you want to write. I mean I realized that, well I don't know, maybe pseudo stratified columnar, do surface lining or covering, I don't know. Um, but the idea is that you connect the ideas together in a way that makes sense to you.

$\underline{10: 26} \quad$ Okay.

10:27 There isn't a right or wrong answer. You can use all of them. You don't have to use all of them. Um, so go ahead.

These are just like different types. 
Interviewer:

Sara:

Interviewer:

Sara:

Sara:

$\underline{13: 24}$

$\underline{12: 18}$

$\underline{12: 28}$

$\underline{12: 31}$
Like doing it, write that down. Yeah, that's fine. I mean are you, when you're done I'll ask you to explain it so that it will just be on this

So like these are pretty much like the two different types of like epithelial tissue, so like there is simple, which is one layer, and then stratified which is like multiple layers. And then you have, these are like the different kind of types. A lot. Cuboidal is more like square (cubed), columnar, more like a column. Um, squamous is like flat. So if it's like a simple cuboidal, it's like one layer of more like a huge like cubes like so versus like a Columbo is like more kind of like that. And then the Squamish is like more flat. So like then a stratified would be multiple layers of this or like one of those like there's different types and like pseudo stratus, stratus by looks looks like it has a lot to, this should be probably be on its own.

of layers because, so it's like, it's kind of like this, but they're like nucleuses are in different places. So it looks like it has a lot of layers but it's really not. Um, and transitional has like all 
different types of it type of like cuboidal and squamous. So it's like a combination of all of that. But yeah, so like these kind of all go together because it's like, well why are to layer with these are kind of like the exceptions of it. And then these are just like what the definition of each of the types of shapes.

Interviewer:

Okay, cool. Okay. Um, I'm going to give you another concept map, which is not by any means to the correct one.

Sara:

$\underline{14: 17}$

Okay.

New Speaker:

It is just another one. And, um, I just want you to comment, like kind of compare yours to the one up there. You can write on this if you feel like something's wrong, you want to correct it or whatever. Um, I'm just curious what you think of this one compared to that. The one you made.

Sara:

MMM,

Sara:

well, I don't know why this is in the middle cause I guess, yeah.

Okay. So that's like kind of why I did down there. But it's saying like there was like different shapes and then there is different types, but, um, I mean it could be organized better, but I don't really like know, I honestly don't remember a lot of the, like what they do besides a couple of them. So I know which ones do, I'm pretty sure simple squamous is like protection, um, or 
like linings and coverings. But there's, I think that's right. I don't, I honestly don't remember

Interviewer:

$\underline{15: 39}$

Interviewer:

Sara:

Interviewer:

$\underline{16: 40}$

$\underline{16: 48}$

$\underline{16: 49}$

$\underline{16: 53}$

$\underline{16: 53}$
Okay, its no big deal.

But um, is there anything on here that you would disagree with?

That these are put in? I'm not sure if like, like that's right, but these are like pseudo stratified transitional or like two different, like two different things. Like they look different so I will put that link in different separate. Um, I don't think filters right, maybe, but yeah, I would like set up different way too. I don't like how they did like that was in the middle cause that's east who are like the main and then you have like different types of each of them. But yeah. All right.

That's basically all the questions I have for you. Are there, um, is there anything else you want to say or any questions for me?

I don't think so. No.

You want one of those now?

Okay.

All right. Well thank you very much for coming and I'll send an email like probably this weekend trying to set up the second one right here. 
Sara:

$\underline{17: 04}$

Interviewer:

$\underline{17: 05}$

$\underline{00: 04}$

Interviewer:

Sara:

Interviewer:

$\underline{00: 45}$

$\underline{00: 25}$

Sara:

Interviewer:
Okay. So today's going to go, Whoa, is going to go very similarly to last time. I'm going to start off with some questions and then we'll do a concept map and go from there. Um, so any new challenges or anything like that in the course so far since last time we talked.

Well, yeah, because we learned, we're learning like all the bones and the muscles, muscles. So that's just been hard. Like it's a lot of like information to just like take in rather than like the first couple, the first exam and first quiz and lot was, but

Okay. So it's the, it's just the amount of this unit yeah. Is more than any of the previous units.

$\underline{00: 53} \quad$ Yeah, for sure.

00:55 Um, so last time I talked to you or I asked you about why you think like your anatomy knowledge and your physiology knowledge is important. Have you had any new like relevation revelations now? Elevations, revelations regarding them? 
Sara:

$\underline{01: 12}$

Interviewer:

$\underline{01: 34}$

$\underline{01: 47}$

Sara:

Interviewer:

$\underline{02: 01}$

$\underline{02: 28}$

$\underline{02: 33}$
Um, just pretty similar to what I said last time about just me being in nursing. Like I have to know all that stuff just to be in that field. And it's, it's pretty much been the same. Like that's kind of what like gets you through it. Like I have to know this. So you need to like sit down and study it.

So you feel like even when we're talking about like the mass of terms in this skeletal muscular unit, Musculoskeletal Unit, like even all of those terms, you're like, I'm going to need to put this.

I think most of them, yeah, just you'd have to know a lot of them and like depending on the field you go into, you know, it might change what, what you know, but you have to be ready in case you like whatever field you go into.

Yeah. Okay. Um, so like you kind of mentioned like the difficulty in learning the content because of the, just the sheer massive number of terms. Um, what about your understanding of it? Like how, how has your understanding of anatomy in general changed?

MMM,

I dunno. I think like with the first unit we learned a lot about how stuff like works and like that's, that's kind of what we're doing now. But it's more like where a lot of things are. And also 
like both like joints and muscles. Like what we're learning about right now. It's like there's just a lot of information on um, like how things work and stuff and like only where it is. But like if it has like extension or flexion or like what it does and that's like, that's kinda been hard. And like the names of the muscles are just like super long and so that's kind of hard.

Interviewer:

But yeah. So [inaudible] like comparing this unit then with your previous units, like, um, is it safe to say is more difficult?

Sara: I think that is personally but because I feel like this one it's a lot of diagrams and you like, yes, the muscle names like kind of, they do have hints in them on where they are and like what they do. But like your hamstring muscle has like so many of so many like muscles in it that it's like, okay that might give me a clue. But like there was a tiny muscle right next to it that's literally in the same place. So it's like, I think it's more difficult than the past units. It's just cause it's a lot of terms and information to know and a lot of them are similar too.

Interviewer: Yeah. So it's easy to confuse them.

Sara:

Yeah.

Interviewer: When they have similar names, are they in like similar locations too? 
Sara:

$\underline{04: 09}$

Interviewer:

$\underline{04: 27}$

$\underline{04: 47}$

$\underline{04: 49}$
Yes, it's probably or like shapes or something like femoris would be like in your femur and there was like a Brevis or longus, so it's like long or short, and there's like different prefixes and suffixes that like help.

Cool. Um, so you've already said that this is like more challenging in this particular system. Um, what are the things that have enabled your learning of this particular section of the course, either in the course or outside of the course?

Like what has helped me with it?

Um, well I have watched a lot of youtube videos and she gives us youtube videos. But like I've looked about that like looked up more and stuff cause that I like, like to see it rather than just somebody telling me, me like she does on the like just saying, oh this sort of does like I like seeing it happen cause I can like, like with the different types of joints and stuff, like a ball and socket versus like a pivot. I like seeing how those move and that like helps me. So I've done that. And then I've also, like I, I've tried to like split up what I like, what we learned. So like if we learn it in class that day, I have like a running like quizzlet and so I'll put in that information when that day and then I'll study that and that, that night, like what we learned that day. So I'm not like like waiting until the last minute, the week before the exam 
to study at all. So I've been trying to like split it up more and like study constantly rather than it's like cramming.

Interviewer:

05:49 Yeah, that's a good practice to get into. Like going over it at night before you go to bed.

Sara:

$\underline{05: 54}$

Yeah.

Interviewer:

$\underline{05: 55}$

Like what you learned that day?

Sara:

05:56

Yeah.

Interviewer:

$\underline{05: 57}$

I mean there's all sorts of research that sleep helps transfer things too long memory, long term memory.

Sara:

$\underline{06: 03}$

Cool.

Interviewer:

$\underline{06: 04}$

Um, what about the organization? Like how, not just how this is organized in class, but it's, I mean you could talk about that too, but I'm also curious like how do you organize, do you have a way to organize all of these new terms in your head?

Sara:

$\underline{06: 19}$

Um, well for cause like the first chapter of this unit is like joints and so I've like made a chart or whatever that has like the different types of joint, kind of like a concept map, but like what goes in what. And that kind of like helps split it up because there's a lot of terms that like sound similar or look similar but they're like completely different. 
Interviewer:

Sara:

Interviewer:

Sara:

Interviewer:

Sara:

07:14
Yeah.

06:42 So l've just been trying to like organize them and like categories of what goes together and same, well, like the muscles and stuff. And then I've just been trying to like, um, with the different types of like prefixes and suffixes that with the muscles, like trying to know all those so that if I forget the muscle for some reason I can like try to piece it together like if I know those.

07:04 But so when you say when you group them together by what goes together, what is like the category?

07:10 What do you mean?

07:10 What determines whether or not it goes together?

Well, like for joints there's like, um, names, I'm like the functional groups and then like the structural I think. And then there was like in those there's like three different types and then in on those three different types there's more types of though. So it's kind of like, um, if you, I know all the functional ones that's like, those are like based on what they do. So if it's like, if it's an unmovable joint or like a movable joint and then there's different names for those. So I've just been like, if that makes sense. I don't know how to explain it but just like 
knowing that this is named after like what it does and this is named after her like where it is this or something like that.

Interviewer:

$\underline{07: 54}$

I get it. Cool. Um, so what's your big takeaway from this particular section? Like you given your future career as a nurse, like what are you taking away from this section? What's the take home message?

Sara:

$\underline{08: 10}$

Um, like the actual information or just the class?

Interviewer:

$\underline{08: 15}$

I mean for you personally. Like what are you taking away?

Sara:

$\underline{08: 17}$

I'm taking away that I'm gonna need to like figure out a different way probably to study like how I changed the way I'm doing it now where I'm studying like more cause my nursing advisor, like I'm taking anatomy and microbiology at the same time and she said like that's going to be good practice for nursing school because it's a lot of, it's a lot of information. It's a lot to study and I've just taken away that like I can't wait until the last minute on like a lot of stuff cause I did do that the first exam and I didn't do as well as I wanted it to. So like I've just been trying to think about that and like um, that's pretty much what I've taken away from like the class.

Interviewer: like the muscular skeletal system? 
Sara:

09:02

Interviewer:

Interviewer:

Sara:

Sara:

Sara:
Um, I have just like taken away kind of like, um, the different, just like all the information that of the different like where it is and stuff because it could be where I go into some type of nursing where I want to do something with that and I need to like know those and also like with the functions of each of it is and like how a muscle interacts, how it does everything and just like the science behind it and also like where it is.

09:30 Cool. Okay. So we're going to turn to or concept map up here and basically the same as before. You have a whole bunch of terms and if you could organize them in a way to make sense to you, draw lines between them. If you need to do, describe relationships. Um, you don't have to use all of them. You can if you want.

09:51 Go for it.

10:09 These are kind of like weird. We haven't really talked about, well we've talked about them but I don't know what I do with like um, these are kinda hard.

10:50 These were like upper extremity muscles. These are like lower extremitym, in regards to like where they are like this is one part of the body

[inaudible] yeah, I don't really know another way. 
Interviewer:

$\underline{12: 02}$

Sara:

Interviewer:

Sara:

Interviewer:

Sara:

Interviewer:

Sara:

$13: 16$

$\underline{12: 13}$
Like, so the ones that you left out, why are they not getting placed?

Well these are like kind of what these are like what they do. But I feel like a lot of the muscles like are part of movement and like it's not on here but like there's a lot of ab muscles protection of your internal organs. But I don't like theres not really ab muscles listed. Um

12:37 Are there any over there then you're not sure about? Like, you don't know.

12:47 I don't know that I don't remember that. I don't remember these two. I'm trying to put them, I'm like, I know

$\underline{12: 55} \quad$ You recognize it.

12:56 Yeah, like I recognize them but I can't remember what they are.

13:07 So for any of the ones that you've categorized, do any of them participate in these functions over here?

Um, well a lot of them are movement like your triceps and biceps, like extension flexion and then like movement of your elbow relies on like your biceps and triceps. So like a lot of it is movement. Um, 
Interviewer:

Sara:

Interviewer:

Sara:

Interviewer:

Sara:

$\underline{15: 08}$

$\underline{14: 29}$
What about the other regulation, storage, protection, structure?

13:51 We'll structures like bones, right? But like you're the structure of your like body is your bones and then you're like muscles attach your bones. But I don't know, like I don't know about regulation or storage. And then like I said about protection is like the one example that I can like think of is just your, there's a lot of like external, internal oblique muscles and like a bunch of stuff that'll help protect your internal organs.

All right. Well, just like before I have a concept map here that is not the correct one. Right. It's just another one. And um, and just, I'm curious like your response to it, you can comment on it. Compare if you like correct it, mark on it, totally up to you.

$\underline{14: 50} \quad$ It's like splitting up like your muscles versus your bones. And it's saying that they both do all of them, like protect storage, movement, structure and regulation.

15:04 Do you agree with that?

I don't really know. I don't really know how, like what muscles, like what it means by storage, like storage, storing, but I don't really know about that, but I feel like, yeah, they're all like pretty. Right. Um, and then its just splitting up like this is a lower extremity. This is upper extremities than then, um, this is 
obviously all your hand and then this is like all on your feet. So I guess it's like kind of splitting it up into like further if you keep going lower or like upper and then, um, I don't, not that, I don't know about that part of the bottom where it says hand muscles. Yeah. Um, I guess that's just saying that both of these categories are intrinsic.

Interviewer:

What do you think that means?

Sara:

$\underline{16: 21}$

I don't remember what it means. We just learned that when I don't remember seeing that it would mean something with like movement.

Interviewer:

$\underline{16: 35}$

But what do you think these arrows going back and forth through for two?

Sara:

$\underline{16: 42}$

Um, I don't know. Maybe. I don't know.

Interviewer:

$\underline{16: 59}$

Neither.

Sara:

$\underline{17: 00}$

I don't know.

Interviewer:

$\underline{17: 03}$

Is there anything else you want to say about this?

Sara:

$\underline{17: 08}$

I don't think so. No. 
Interviewer:

Sara:

Interviewer:

Sara:

Interviewer:

$\underline{18: 23}$

$\underline{18: 28}$

$\underline{18: 28}$

$\underline{17: 25}$
So I think it's interesting that up here you were like, you know, I don't think any of these participate in these functions, but here you're like, yeah, sounds good.

I don't know. I like, I obviously I can see like bones and muscles both contribute to like structure and protection. Like your rib cage protects your lungs, etc. But I, I still don't, I don't know about like regulation or storage. Like I don't know what that means. Like what do they mean by that? So that's why I didn't want to put that up there. But, and then movement, like your bones have joints and that moves and then also your muscles obviously, like constantly. Yeah.

17:59 So the two that you're not so sure about our storage and regulation.

18:02 Yeah, I mean, I know like in muscles, like there's a calcium storage and when the calcium is released, that helps the muscle contract, but I don't know, like about, about that part or regulation.

All right. Um, if you don't have anything else about this, do you have any questions for me?

Nope.

Nope, we're done. Thank you. 
Interviewer:

$\underline{00: 01}$

Anna:

Interviewer:

Anna:

$\underline{00: 46}$
Okay. So first I just want to explain that like, you know, throughout this interview I'll be asking questions about your anatomy knowledge and, and like I never took an AP course. I took comparative anatomy as an Undergrad that was over 20 years ago. And so when I ask questions, I'm not trying to quiz you or like test you in any way. I'm just really trying to understand like what you're thinking. Don't feel like there are really correct answers to any of the questions I ask.

Okay.

Okay. So first thing is I just, I'm curious how A\&P is going for you. Like how have you liked it so far? Challenges, barriers, things you love about it.

I like it a lot actually. I think that's like half the battle is just like being interested in it because it is a lot of information. But um, it's a little challenging just in the beginning cause it's kind of boring. I was like, this is what... Cells. Okay. Like I'm not interested in that. But like I think the further that we get into it the more interesting it will be. But I find that the workload is manageable because I'm interested in it. Like I want to like retain information. I think it all just comes down to me. Like this is my major elective, so I'm not like, it's not required for my major. So I took it voluntarily and I think it's going well for me so far. 


\begin{tabular}{|c|c|c|}
\hline Interviewer: & $\underline{01: 22}$ & So what is your major? \\
\hline Anna: & $\underline{01: 23}$ & Medical ed sciences. \\
\hline Interviewer: & $\underline{01: 24}$ & $\begin{array}{l}\text { Well cool. So man, that's like one of those that I wish I knew } \\
\text { existed when I was in undergrad. }\end{array}$ \\
\hline Anna: & $\underline{01: 32}$ & I hear that a lot. \\
\hline Interviewer: & $\underline{01: 35}$ & $\begin{array}{l}\text { Um, okay, so and what are your general career plans? Just } \\
\text { curious. }\end{array}$ \\
\hline Anna: & $\underline{01: 40}$ & $\begin{array}{l}\text { So basically after I graduate, like a master's degree isn't } \\
\text { necessary, but I want of course at some point I want to go for } \\
\text { my masters, but I want to go back home to Chicago and work at } \\
\text { like University of Chicago, Loyola, Rush, something up there just } \\
\text { in the lab. And then eventually because it's a national } \\
\text { certification. }\end{array}$ \\
\hline Interviewer: & $\underline{01: 56}$ & Yeah. \\
\hline Anna: & $\underline{01: 56}$ & $\begin{array}{l}\text { So then after that I can just kind of go anywhere I want, but I do } \\
\text { want to like get some, a good foundation where I'm familiar in } \\
\text { Chicago. }\end{array}$ \\
\hline Interviewer: & $\underline{02: 03}$ & Yeah. This is totally awesome. \\
\hline
\end{tabular}


Interviewer:

Anna:

$\underline{02: 17}$

Interviewer:

$\underline{02: 17}$

$\underline{02: 19}$

Anna:

Interviewer:

$\underline{02: 19}$
Not relevant to the interview I'm just super interested, have you ever been to the Charles Morris stem social?

No.

You've heard of that?

No.

Okay. It's basically every year. Charles Morris was a chemistry professor here and um, he was African American, he established this like endowment to give scholarships to students of color who are majoring in a stem field and at the social every year where they give the awards out, they also have um, an alum come back and talk. And so this is why I asked is because this year, um, her name was Regina Williams and she started out as a medical lab scientist here and then she went on and got her master's and now she is an epidemiologist for Chicago public health, like Cook County public health. And it was just, I dunno, it very similar to like, you know, your career plans. And so she left to talking about how she would love to like have interns from Isu comment, do summer internship with the, you know, public health department for Cook County and stuff. But I just think at school she started as a medical lab scientist.

Anna: $\quad \underline{03: 20} \quad$ No, that is really interesting. 
Interviewer:

Anna:

An:

Interviewer:

Anna:

$\underline{03: 42}$
So, okay. So generally speaking, like as a future medical lab scientist, what do you think the value or the, the usefulness of... Importance of like anatomical knowledge is.

I think that just like straight up anatomy won't really be beneficial just because like I feel like it'll just be all this information with that like solidified purpose. But with the physiology component of it, I think that it will be just a little more useful because when you obtain these samples, like they're from people and you want to know like where they come from, just like you can kind of narrow it down because it is a lot of things that it could be or it couldn't be. And I feel like anatomy and physiology will just help me like narrow it down.

04:10 Oh, cool. Yeah. Um, so how has your understanding of the content been so far? Like you talked about like your enjoyment of the class, which was cool, but like, um, are there things that facilitate your understanding of the content? Things that dont?

Um, I understand a lot of it actually, and I think it just comes from, generally speaking, I understand bio a lot more than I do chemistry or physics or whatever. And I think it's just because bio has such a direct real world application and so with anatomy, physiology its no different. And in the beginning it was a little like fuzzy just because we're talking about cells and like covalent bonding and it's like, okay... But now we're talking 
about but now we're talking about bones and skin and that can directly relate it to me. And so I understand it a lot easier and I grasp it a lot easier just because it's applicable to me as a person.

Interviewer:

$\underline{05: 02}$

$\underline{05: 13}$

$\underline{05: 13}$

Interviewer:

Anna:

$\underline{05: 19}$

Interviewer:

Anna:

$\underline{05: 34}$
Yeah. Cool. Um, so apparently you just finished a unit on epithelial tissues and so the questions I'm going to ask next are just about that unit.

Okay.

Um, so first of all, did you like it challenging? Easy? Um, what were your thoughts?

It was born boring, but I think it's important to have that basis early on. It's like you have to get through the boring stuff to get to the coolest stuff. Um, it wasn't that challenging just because its information that l've heard of before.

Where have you heard it before, I'm curious?

High school anatomy, it didn't go into as much depth, but anatomy is one of those things that for some reason I just don't forget. So just hearing that information, like it all came back to me so it was pretty easy and I just kind of breeze through it. 
Interviewer:

Anna:

Interviewer:

$\underline{06: 18}$

$\underline{06: 23}$

$\underline{06: 27}$

Interviewer:

Anna:

Interviewer:

Anna:
Okay, cool. Um, so the next question is what do you think enabled your learning of that content? You mentioned your high school anatomy course. Was there anything that happened in this course?

Um, actually doctor wargo like provided us with a lot of resources just to like help that information stick because it wasn't a lot of application in that unit. It was just like you either know or you don't. And she provided like, well we have to make practice test questions and then we have like a practice test online and like homework, you know, so it was hard to avoid that information. Like it was hard not to remember what these things did cause you're just practicing.

Yeah. Cool. And what about how the information was organized?

Um, as far as like presented in lecture or...

Or more like how the knowledge itself is organized. Like what did you come up like what organization of that knowledge did you come away with?

Um, I learned, I think it was most beneficial when I worked with the bottom up and I started from like the most common type of epithelial cell and where you will find it, to like the least 
common epithelial cell and where you would find it and things like that.

Anna:

$\underline{06: 49}$

Interviewer:

Anna:

Interviewer:

Anna:

$\underline{07: 48}$
So just kind of remembering like the bigger picture type stuff and not really focusing on like the minute details.

So I mean I love that idea of remembering like always kind of placing things in the bigger picture. Sometimes you do have to remember the minor details, but if you can put it in context then so much easier to remember it. Like you have this bigger picture. So what do you think in the class... Do alot of people do that or is that just your habit?

07:16 I think that's just my habit, but also like just like the way that, cause she gives us all of the powerpoints side. So just like having that access and having it all filled in and I can annotate it how I wanted it and things like that definitely helped because in a lot of classes like the professors don't give out their powerpoints but she does and that definitely helped me in understanding cause it was a lot of information.

07:37 Yeah. Cool. Um, so if you had to like explain like the elevator speech on epithelial tissues and why it's important, like what's the take home message for that unit?

Um, tissues, makeup, organs, organs, organ systems and organ systems makeup you and if you don't understand these tissues 
and their functioning, then you'll have a harder time understanding organs and everything after that.

Interviewer:

$\underline{08: 00}$

Anna:

Interviewer:

Anna:

Interviewer:

$\underline{08: 19}$

$\underline{08: 19}$

$\underline{08: 08}$

$\underline{08: 10}$

Okay, cool. I mean that's like a genuine elevator speech when I asked that question there. It's usually not in elevators. No, I love the elevator version of anything.

Awesome. Okay. So the next thing I'm going to do is on the board and I'm just going to ask you to make a concept map. Ever done that?

No.

Okay. So the idea is that like let's say, um, I don't know, I'm trying to get something that makes so much sense. Okay. So let's say you have these two ideas and there's a connection between the two. And um, ideally you would like label the connection. Now this is probably, this is not correct, but the idea is that you kind of draw a map that connects the terms and then you kind of describe what the connection is between the terms and you can use all of them if you want or you don't have to. Um, and yeah, when you're done, if you find that you really need a term that isn't here, you can create anyone if you want.

Anna: So then like all of these... 
Interviewer:

Anna:

$\underline{10: 48}$

Interviewer:

Anna:

Interviewer:

Anna:

$\underline{11: 29}$

Interviewer:

$\underline{11: 36}$
So can you explain what these brackets are and what they're pointing to and things?

So basically all three of these tissues, cuboidal, simple columnar, squamous all aid of filtration and absorption.

Okay.

And like diffusion of simple squamous is found in the lungs I believe. And then columnar or stratified columnar, and squamous are linings and coverings and protection. Like I know that I think stratified squamous is on the lining of your mouth and stuff. And then as far as pseudostratified columnar and transitional, they're rare. I know these are found in like the ovaries to help push like eggs along and stuff. And transitional is in the bladder so I just put excretion and secreation.

11:25 What about the ones that are off to the side. Did they not fit in anywhere?

These are just umbrella terms for these here. So it was kind of out, I don't know. I don't even remember stratified cubodial.

Awesome. Cool. So I'm going to show you a picture of another concept map someone else made. And it's not by no means the correct one. There's not really a way to have a correct concept maps on, but I'm just curious like what your thoughts are in 
response to this and if you want to mark on it and correct stuff and you're totally welcome to, but I'm just curious what you think, how you see these two different from each other.

Anna:

$\underline{12: 12}$

Interviewer:

Anna:

Anna:

$\underline{12: 34}$

Interviewer:

Anna:

$12: 38$

Interviewer:

$\underline{12: 49}$

$\underline{12: 55}$

Anna:
I feel like this one has just more of like a dichotomous key type effect. Where like...

Okay.

And I feel like mine is more straight forward. I mean I understand it more, but I could be biased cause I made it. But this one just kind of has like a lot going on and like roads that lead to nowhere kind of.

And like what about simple squamous, you know, whatever it is. I feel like it's like ambiguous.

Okay.

And Mine isn't as detailed, but I would, I had, so I just, um, this isn't like my first choice for learning something.

In terms of how yours is organized versus this one, do you see a difference in organization? Mine was kind of driven off of function or as, I feel like this one's kind of driven off of like process of elimination kind of thing. 
Interviewer:

Anna:

$\underline{13: 10}$

Interviewer:

$\underline{13: 22}$

$\underline{13: 41}$

Anna:

Ann:

Interviewer:

$\underline{14: 07}$

7)



connection to how it's taught or anything. How is it organized in

how it's presented? Is it presented, like is it organized by

function or is it organized by like, let's talk about shapes and..

Um If I can remember correctly in both the lab and the lecture,

it was presented from like, um, each individual and then we

talked about its function and then I guess on your own you

could have made the connection that like you could have

grouped them together and stuff, but they were, yeah. But

there are presented individually, I think, and in the lab and went

into more detail just because if there was pictures and slides

and stuff like that. But yeah. Yeah. It was definitely an individual approach.

Anna:

$\underline{14: 13}$

I do not. 
Interviewer:

Anna:

Interviewer:

$\underline{14: 19}$

$\underline{14: 21}$

$\underline{00: 00}$

Interviewer:

Anna:

Interviewer:

$\underline{00: 19}$

$\underline{00: 19}$

Okay.
Have any other comments about anatomy or at the tissues or anything.

No, no, no.

All right. So, um, what will happen is probably over the weekend I will send you an email trying to schedule that next one. Okay. And um, is generally the stick, the timeframe? Yeah. Okay. Yeah. So I'll probably just try to a couple of weeks out trying to get you at the same time. Okay. Take another one. No, they were good though. I normally don't like dark chocolate, but that's good. Yeah. I mean, the peanut butter does it right. Peanut butter to me is, oh, I could just eat it by this group call. It's definitely a quick, all right.

This is gonna go very similar to last time I'm going to ask some questions. We'll do a concept map.

Okay. So um, any new challenges in the course since the last time we talked?

Anna:

$\underline{00: 26}$ because I' $m$ interested in it, but the people in my lab have been like complaining nonstop and like, and it's been like rubbing off 
on me a little bit, but I have to just like keep tunnel vision till the end of the semester. But they like dying and I don't know what I'm missing.

Interviewer:

Anna:

Interviewer:

Anna:

Interviewer:

Anna: $\underline{00: 48}$

$\underline{00: 48}$

$\underline{00: 52}$

$\underline{00: 57}$

Yeah.

I don't know why it's so difficult for them, but for me it's relatively the same.

Is it the amount of like just?

I think it's because like they don't know what to study and like it's, you have to condense 150 sides down to a 50 question test. Like you have to be realistic about what's going to be on it. And I think that they just overwhelm themselves and they just try to memorize it all. And I'm like, you can't do that, but they'll learn it.

01:17 So what are you doing thats different like?

01:19 Um, well I know that this material is less familiar because we started let the muscles and the physiology behind that and I'm not, like I dont recall that much from it. So I started studying earlier, in smaller chunks just to like, I'm not completely overwhelmed come testing. So that's basically all I've been doing differently was just studying. 
Interviewer:

$\underline{01: 39}$

$\underline{02: 04}$

Anna:

Interviewer:

Anna:

$\underline{02: 41}$
Okay. Um, so last time I asked you like, why is anatomy knowledge important? And You provided your answer and I am wondering if you, like if you've had any changes from what you thought before, um, or did you like realize that, oh, this is way more important than this particular set of information is more important than I ever thought it was or anything like that.

Um, if anything, I've just noticed how it all just kind of builds off of each other. So it's hard to say like what's more important than another thing because like the tissues are important, but the tissues make up the bones and the bones are important and like it just kind of builds like that. So I think it's hard to say like something's more important than the next thing because it's all cumulative.

02:22 Yeah. Okay. Um, so we talked about your studying and how you've changed, your studying a little bit knowing that this material was less familiar. I'm curious about your understanding of the content though. How's that going?

Um, well, a lot of it, the anatomy part of it is just memorization. You know, you have to know what the muscle is and what it does. And that part you just either have it or you don't. But as far as the physiology part, um, it's a little more abstract to me in a way. Cause we're talking about like muscle contraction and things like that and those things when you hear it the first time 
it's going to be like sensory overload. But I think I'm a visual learner. So me like watching youtube videos on like how a muscle contracts or what things play a part in it is helping me understand that a lot more. So just taking my visual aids for sure has helped me.

Interviewer:

Okay. So it's interesting you said that, um, when it comes to learning the anatomy and memorizing it, does understanding that play a role in that? It's either you have or you don't, but there's no...

Anna:

You have to understand like vocab, but it doesn't go as deep as a physiology just because anatomy is just like, what is, what does this do? Where is it, you know, but physiology is more of, you have to be able to wrap your head around these concepts and it is anatomy and physiology. So, you know, I do have to understand the anatomy to a degree but not as like much of a degree as if it's part (of the course).

Interviewer:

$\underline{03: 53}$

Okay. So, um, we've been talking a lot about the muscular skeletal system cause that's what you've done most recently. Did you have another unit in there? Like you had epithelial tissues last time we talked...

Anna:

$\underline{04: 06}$ Joints and joints and then oh yeah, skeleton, joints and the muscles. 
Interviewer:

$\underline{04: 12}$

$\underline{04: 25}$

Interviewer:

Anna:

Interviewer:

Anna:

Interviewer: $\underline{04: 27}$

$\underline{04: 31}$

$\underline{04: 57}$

$\underline{\text { 05:01 }}$

$\underline{05: 14}$
So the Musculo-skeletal system is the only thing that you've had since epithelial tissues. So, um, it's not, you're good. It's not challenged. Like it's not overly difficult.

I don't think so. No.

So what things, you mentioned youtube videos. What other things have enabled your learning?

Um, I've taken Dr. Wargo goes notes and made them my own because her powerpoints can have a lot of information. It's hard to let cut down on what I don't understand and what I need to focus on. So basically after class everyday... We go through like 20,30 slides and in a lecture and I just take the time out and I just condense the notes and I'll make them into jargon that I can understand because I'm the person who has to understand it.

Yeah. So how do you do that? Do you like rewrite the notes in your own words or do you...

As she goes, I kind of like highlight like key details and then after lecture I just kind of write it down in my notebook. But you know, I reorganize it and I just like condense them down so it's not as much material or it doesn't seem like as much.

Cool. Um, what about organization and not necessarily organization and you can talk about organization of how it's 
presented in the course, but I'm also curious about like how do you organize all this knowledge in your head?

Anna:

A lot of it you just kind of learned through life. Like I learned, like I know where the Pec is, I know like where the deltoids are. So like those things I don't need to write down and memorize. But as far as being organized for this course, her, her notes are pretty cut and dry and she doesn't give out diagrams or anything. So you just have to kind of seek those extra resources on your own. And I keep organized just like in a notebook like her, like her notes are organized, but like they're not organized in a way that I fully understand it, which is why I take the extra step to reorganize my notes.

Interviewer:

Yeah. So what is your takeaway from this unit? Like thinking about your future career and like your experience in the class. Like what is the big takeaway from this unit?

Anna:

MMM, this if I feel like once we get past this unit were going to be past all the foundational stuff and we're going to be able to move into more interesting material. Like I know next is the nervous system and it's not as much like anatomy. I feel like I feel a little bit more of a function, which isn't really that I'm excited for it. But I think after this it'll be less of what is this, what does it do? And I kind of like mundane material, so I'm just, uh, mentally checked out and I'm glad the test is on Friday, 
but um, that was just my takeaway from it. Like it's gonna end soon.

Interviewer:

$\underline{06: 56}$

$\underline{07: 23}$

$\underline{07: 23}$

Anna:

Interviewer:

Anna:

New Speaker:

Anna:

Interviewer: $\underline{08: 43}$

$\underline{08: 31}$

$\underline{08: 39}$

$\underline{08: 47}$

$\underline{08: 50}$
Yeah. So up here we have some like vocab words from the section that you... The unit that you just finished. And same as before. Like organize them in a way that makes sense to you. You can draw on the board, create categories, label them, whatever. You don't have to use all of them. Um, all right, go for it.

MMM.

So I just kind of broken down into structure and movement. And then once I've created the movement, I just kind of broke it up into like lower half an upper half...

And then these ones that are over on the side, storage side of the floor, um,

I just didn't see like a use for them.

And then paroneal muscles. Do they go anywhere?

I don't know.

Yeah. Um, okay. So can I ask that you just label them so that when I take a picture... you can label them now, I won't tell you 
how to label your concept map. I just remembered I didn't give you your card. So I'm doing that right now.

Anna:

$\underline{09: 32}$

Interviewer:

Anna:

Interviewer:

Anna:

Interviewer:
Okay. Alright, thanks.

09:36 Um, okay, so here is another concept. Now remember this is not like the correct one, it's just a different one. And I'm curious what your thoughts are on it. Like you can compare to yours. Um, you can correct it, you can mark on it, there are things you disagree with.

10:04 It does go into more detail, like as much detail as you can.

$\underline{10: 06}$ Okay, how so?

10:09 Because it breaks it down more into movement and then it kind of has like the upper half and the lower half. But then up here it's the skeletal muscle and what it does and then the long and short bones and what they do. And I didn't go into that on mine. So I think it just breaks it down further instead of giving like these like kind of like big chunks. And that's about it. I think it goes from like the biggest muscle groups, like you know, smaller ones even smaller than that, which is nice. I think this one just has a more depth over

And then this has like both of these pointing to all of the functions. 
Interviewer:

$\underline{10: 44}$

$\underline{10: 59}$

Anna:

Interviewer:

$\underline{11: 08}$

$\underline{11: 15}$

Anna:

Interviewer:

Interviewer:

Interviewer:

Anna:

11:52
And I'm curious like you had mentioned movement and structure, like how do you feel about these participating in also like protection and storage and regulation?

MMM, I feel like its, I feel like it's like stating the obvious in a way, but I guess I needed to be stated in order to further down.

So how can you give an example of like how one of these participates in one of those odd ones?

So like skeletal muscle protection in a way. It protects your bones and then, um, storage, I know that they store calcium or sodium or something like that. And then for long and short bones, like you wouldn't think that like regulation is one of them, but, um, they participate in like red blood cell formation.

11:37 Oh. So it's kind of like an ambiguous concept, but, yeah.

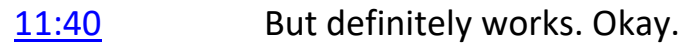

11:45 You see anything that's, that you feel is wrong? Or incorrect?

I don't know why these arrows are like going back and forth between like the lower half muscles and the upper half muscles cause like, I don't know. Like what their relation would be other than the fact that like they're on the body and they participate 
in movement... and then same thing goes down here too, like I don't know what the relation would be besides movement.

Anna:

Anna:

Interviewer:

Anna:

Interviewer:

$\underline{12: 32}$

Interviewer:

$\underline{00: 02}$

Jenny:

Interviewer:

00:09

$\underline{00: 09}$

Okay.

them.

And, um, we will always put pseudonyms in so that it's never obvious who it was. And so is there a particular pseudonym you

Jenny: $\underline{12: 15}$

$\underline{12: 15}$ those arrows.

pectoral muscles. Like those are the larger muscle groups you said?

Yeah

Smaller than that. Hand flexors and Plantar flexors. Hmm. Okay.

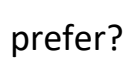


Interviewer:

$\underline{00: 20}$

Jenny:

Interviewer:

Jenny:

Interviewer:

Jenny:

Interviewer:

$\underline{00: 53}$

$\underline{00: 53}$

$\underline{00: 41}$

Jenny: $\underline{01: 06}$

No. Okay. I always ask people because it's like their chance to like name themselves if it, even if they don't, you know, like their name or whatever. But otherwise we'll just come up with something.

Okay.

So before I begin, I just want to explain that, you know, I'm going to ask questions about your anatomy knowledge, but I myself never took $A \& P$.

Okay.

I took a comparative anatomy as an Undergrad that was over 20 years ago. And so you are truly the expert. Like when I ask follow up questions, I'm not testing you or anything, I'm just trying to understand what you're saying.

Okay.

Okay. Cool. Um, so, um, first of all I just want to ask like, have you encountered any challenges or barriers in A\&P course so far this semester and what are they? Um, I mean like I had a lab today and it was basically about all of the bones that are in like the skull and vertebrae and I don't know. It kind of was just overwhelming, like the amount of stuff 
that you need to memorize only because like a lot of things look very similar. And then there's like, like the certain protrusion that you have to like specifically name and then some regions have and some don't. But um, besides like, just having a lot of stuff thrown at me... I think that is like the only thing so far.

Interviewer:

$\underline{01: 39}$

Jenny:

Interviewer:

Jenny:

Interviewer:

Interviewer:

Jenny: $\underline{01: 44}$

$\underline{02: 05}$

$\underline{02: 09}$
So it's like the amount of material?

Yeah, definitely.

Anything else?

Not really...

Um, so when you're like in class and your, you know, all this stuff is like getting thrown at you and you feel like it's drinking from a fire hose, kind of, um, like how does that make you feel about the course? Like, um, how are you feeling about the course?

Like, are you feeling like, hell yeah, I can do this or...

It definitely feels like a mountain in front of me. Um, I'm a senior, so I've taken a lot of courses at this point. So, you know, if I was a freshman, I'd definitely be overwhelmed. I'd definitely be like, this is way too much. I can't do it. And even for me, even though taken classes for four years now, sometimes I will feel 
frazzled and be like, Oh God, this is a lot. But if I started taking a deep breath and be like, all right, this is definitely doable. It's like running a sprint. Like it sucks, but it's doable.

\begin{tabular}{|c|c|c|}
\hline Interviewer: & $\underline{02: 37}$ & Yeah. \\
\hline Jenny: & $\underline{02: 38}$ & Um, but yeah, it's definitely a lot of material. \\
\hline Interviewer: & $\underline{02: 41}$ & $\begin{array}{l}\text { Yeah. Yeah. Um, so do you feel like being the amount of } \\
\text { material that you're learning, given all of that, do you feel like } \\
\text { that all of that knowledge is important and applicable? }\end{array}$ \\
\hline Jenny: & $\underline{02: 57}$ & $\begin{array}{l}\text { I feel like for certain, I don't want to say it's not applicable } \\
\text { because a lot of it is, but when it comes down to like the nitty } \\
\text { gritty stuff, like I'm not going to have to know, like if, you know, } \\
\text { in the future I want to be a nurse, like I don't need to know the } \\
\text { little protrusion that's in one of the very rare bones like, of } \\
\text { course. But there's a lot of that little stuff that I feel like we } \\
\text { don't have to use. And then sometimes even on tests, like you'll } \\
\text { learn everything, but then it will only ask you like } 50 \text { questions } \\
\text { that are based on like whatever the professor chooses. }\end{array}$ \\
\hline Interviewer: & $\underline{03: 30}$ & Yeah. So it's just like a sampl or fraction. \\
\hline Jenny: & $\underline{03: 32}$ & Yeah. Which can be really overwhelming. \\
\hline
\end{tabular}


Interviewer:

Jenny:

$\underline{03: 43}$

Interviewer:

$\underline{04: 03}$

$\underline{04: 20}$

Jenny:
So, um, can I, I mean this might put it into context. Can I ask what your career plans are? You said nursing?

Yeah. So basically, right now I'm a psych major and I just want to finish that out cause I'm like a semester away from graduating. Um, and then I'm taking all the prereqs to get into the nursing program. There's an accelerated nursing program, which is basically for people that already have their bachelor's degrees. So I'm planning to do that. So, yeah.

Yeah. Yeah. Cool. Okay. Um, is there anything specific about anatomy and physiological knowledge that you feel is really important for your particular career path?

I feel like definitely like knowing about the skin layers is important cause, you know, nurses work with like IV's and stuff. And knowing how to like, like determine to how someone looks and like, I'm sure we'll get into like blood pressure and all that stuff. But in terms in of anatomy, like knowing, um, anatomical positions really important because you need to know like, you know, if on the chart it says like posterior... You actually got to know where that is. You can't just be like, oh, I guess it's like somewhere here. Um, but you know, just basic like knowledge of like the bones and like what everything is honestly. Like you got to know that. But um, I feel like a lot of the material is like supplemental. Like it helps a lot to like help you understand 
more because you know, they can throw a lot at you, but it's all some, it's useful. Yeah.

Interviewer:

$\underline{05: 18}$

Jenny:

Interviewer:

Jenny:

New Speaker:

Jenny:

$\underline{06: 06}$
Yeah. Um, so, so far in the course, how well do you feel like you've understood the content? Are you doing well? Do you feel okay about it?

Yeah, I think I'm doing pretty well. Um, I will say though that the first exam was mostly like review and from like bio 196 \& 197 I think. But, um, I didn't really study as much as I should have. Like I started studying like two days beforehand, which, you know, now I know not to do. Not that I got like a bad grade on the exam. I got a B like an 80, but I know I can do better. Right. Um, it hasn't been too hard really.

06:01 Um, so apparently you just finished like epithelial tissues?

06:06 Yes.

Okay. So I'm just going to ask a few questions that are specific to that unit. Okay. So the first is challenging? Easy?

06:13 I think it's pretty easy. Yeah. It wasn't too bad. It was a good like course to wade into the waters. Not Treacherous yet. Its like I can handle it. 
Jenny:

$\underline{06: 26}$

Interviewer:

$\underline{06: 39}$

Interviewer:

$\underline{07: 14}$

Jenny:

$\underline{07: 20}$

Interviewer:

Jenny:

$\underline{07: 33}$
Yeah. So, um, what things about learning it kind of enables your learning? Like are there things about the course or how you approach studying or like what is supporting your understanding of it?

Um, I think like definitely pictures and diagrams help. Um, I also use like, I don't know, you know when you have like certain amount of things you have to remember and you come up with like 20 names to remember them. So I'll do that to remember like the skin layers and then what else? Definitely like quizlet, flash cards help um, videos on youtube but also like go into depth.

So these are things that are not necessarily assigned in the course, but you're finding them online to study.

Yeah, because sometimes like, I don't know, we have this Pearson online module thing where you basically do a hundred questions. Great big whole, like exam material.

Yeah.

And that helps. But they're only like one or two multiple choice questions on like very specific things that you know are probably not going to be on the test. So I feel like that doesn't really help as much except for the diagram labeling part. That stuff is really helpful because you know, it's hard to find like a 
website that has that type of like flash Adobe thing where you like, you can actually match this stuff

Interviewer:

$\underline{08: 04}$

Jenny:

Jenny:

$\underline{08: 06}$

$\underline{08: 22}$

Jenny:

Jenny:

$\underline{08: 52}$

Interviewer:

$\underline{08: 05}$
Yeah drag and drop.

Yeah. So when it comes to the epitheial tissues, like how do you, what is your way for organizing all of that knowledge? Like is there a particular way that you organize it in your head or are you, you just trying to like memorize it all?

So I definitely organize it like layer by layer because I remember, um, the professor was like, there's the top layer, the epidermis, and then the middle layer, the dermis and hypodermis. And then you kind of like have those main points and then those little bullet points within those. So, you know, with the epidermis there's four different layers. So then like a little thing I came up was, is like shrimp, ritz, and spicy, basil.

Which like, I know it sounds funny, but like spicy basil is like the basal spinosum and then stratum basal, which is like the base.

Yeah. 
Jenny:

$\underline{09: 03}$

Interviewer:

09:13

Jenny:

Interviewer:

Jenny:

Interviewer:

Jenny:

Interviewer:

Interviewer:

Jenny:
09:29

09:48

09:48

09:50

$\underline{09: 53}$

$\underline{09: 54}$

$\underline{09: 58}$

10:03
So like things like that help me memorize it, but also like drawing it out helps to like, you know, have the general structure of it.

Okay, cool. So, um, like if you had to give an elevator speech on, like what is the takeaway from the epithelial tissues unit? What do you think is the most important? Like what is the takeaway then?

Epitheial tissues. Uh, three main layers. A lot of Keratin. Uh, a lot of, I don't know. Yeah. Basically that I guess, I don't know. Skin it's important.

Yeah.

It's like everywhere.

Yeah.

That was a bad elevator speech.

That's fine. Lots of Keratin. Yeah.

Okay. So we're going to move to the board and what I have up here are just a whole bunch of like vocab words from your epithelial unit.

Yeah. 
Interviewer:

$\underline{10: 03}$

Jenny:

Interviewer:

Jenny:

Interviewer:

Jenny:

Interviewer:

Jenny:

Jenny:

Interviewer: $\underline{10: 10}$

$\underline{10: 12}$

$\underline{10: 25}$

$\underline{10: 25}$

$\underline{10: 46}$

$\underline{10: 46}$
Um not really.

Okay. So it's basically like you essentially just take terms, and draw links between them.

Okay.

And maybe explain what that link is, so maybe excretion is their function, so you would say functions to...? I have no idea if that is really what it does... But it's like you, you can use all of them. You don't have to use all of them. If you find you need to use something that isn't there. I have a post-it here.

Okay.

So I'm just going to let you create like how you think about the relationships between all of these and then maybe you could just walk me through it. So go for it.

Okay.

\section{2:42 Do I have to use all of them.}

$\underline{12: 43} \quad$ No.


Jenny:

$\underline{12: 45}$

Interviewer:

$\underline{12: 52}$

Jenny:

$\underline{13: 22}$

Interviewer:

$\underline{14: 05}$

$\underline{14: 24}$

\section{Jenny:}

So I'm just going to keep it at that because I feel like that's hard. It's not hard but...

So I'm going to take a picture. Just her, I mean I have it recording but I'm taking this just to make sure the words can be read, can you explain?

Basically these are like the types of like shapes that cells can have so there is squamous, which like splits into simple and stratified. Simple as basically like a thin layer and stratified is like lots of layers. Then columnar again simple one single column of columnar cells, and then stacked columnar. And then pseudo stratified is like, it looks like stratified but it's not. So they're kind of like jig-jagged everywhere. Same with Cuboidal, simple cuboidal, single layer stratified by where there's like stacked layers of cuboidal.

Okay cool. So again, I don't know, I think by doing these interviews, maybe I'll learn some anatomy, but I mean how did these three types like differ in the body? Like what did they do differently?

Um, I know that, um, like squamous cells or tissues or whatever, are usually found like in the lungs I think. Kidneys, I may be wrong? I know it's in the walls, but it helps with like filtration I guess like these are, this is like a function of that... These are 
like functions, you can find these in like the kidneys, they make ducts.

Interviewer:

Jenny:

Interviewer:

Jenny:

Interviewer:

Jenny:

Interviewer:

Jenny:

Interviewer:

Interviewer: $\underline{15: 20}$

$\underline{15: 11}$

$\underline{15: 11}$

$\underline{15: 30}$

$\underline{15: 41}$

$\underline{15: 41}$

Okay.

Cause I remember these look like a revolver.

Okay. Oh yeah. Um, and then so you were saying about the top filtration in line during our functions.

Yeah. So these kind of look like this and they kind of like, it's weird. They look kind of like that.

Okay.

But these are found in like the lungs, somewhere else. Um, I think this also just like, it's basically like the breakdown, the shapes. It can be like simple or stratified shapes of, um.

16:19 So I feel like I need to take the picture.

$\underline{16: 21} \quad$ Yes.

16:21 Okay. All right. So do you feel like this captures it? It's like represents how you're thinking about it.

16:47 So I have this one completed. The thing about concept maps is that there's never a correct answer. It's just, it's how people think of it. And when I saw this I thought, oh, there might be 
other ways to think about this too, but this is like really complicated. Well, I'm going to give you this, like I would, I would like for you to just kind of comment on this and notice that none of the connections are labeled and if you feel the need to label, anything, if you feel like something is wrong you would want to scratch out something, I'm just asking for you to comment on it.

Jenny:

$\underline{17: 32}$

Interviewer:

Jenny:

Jenny:

Interviewer:

Jenny:

Interviewer: $\underline{18: 06}$

18:08

$\underline{17: 41}$

$\underline{17: 41}$

18:03

$\underline{18: 13}$
This is really confusing to me because it kind of is like messy in a sense.

Okay.

Um, it's just like too much at once. I feel like, cause I like to look at every single one and then I'm like all these lines and you know, I'll probably follow the line back to the top and be like, okay, that's the main point here.

But like why even have that as the main point?

You know, you could just give everything connects?

Yeah. Like it should be little subsections. Well I guess this is like a subsection.

Okay. Can you explain that subsection or so like anything you put up there? 
Jenny:

18:19

Interviewer:

$\underline{18: 27}$

Jenny:

Interviewer:

Jenny:

Interviewer:

Jenny:

Jenny:

Interviewer:

Jenny:

Interviewer: $\underline{18: 28}$

$\underline{18: 32}$

$\underline{18: 35}$

$\underline{19: 00}$

$\underline{19: 10}$

$\underline{19: 26}$

$\underline{19: 30}$

19:32

$\underline{19: 33}$
Yeah. So like the simple squamous, I have it as like filtering the absorption, which I guess...

You put it on the left side, yeah, yeah.

I didn't study that, that well. That's funny.

It's not wrong. I'm not saying this is right.

Okay. It's just, I guess like that's like the functions of simple Suquamish wish I kind of had on that side too. Um, yeah. I don't know why these are like, well I guess these are all like types of shapes or whatever.

So you're saying like simple, simple squamous. And then what does that say... straified, pseudo-stratified and are all types of these?

Well, they're all different shapes, I guess, because this is not the same as, but these can be. Okay.

Yeah. All right. I don't like this. I hate it.

Get it out of here.

I hate it. Burn it. Okay.

So what about this over here? Can you try to make sense of what these connections are? 
Jenny:

$\underline{19: 39}$

Interviewer:

$\underline{19: 54}$

Jenny:

Interviewer:

Jenny:

Interviewer:

Interviewer:

Interviewer:

Jenny: $\underline{19: 59}$

$\underline{20: 01}$

$\underline{20: 01}$

$\underline{20: 10}$

$\underline{20: 10}$ $\underline{20: 43}$ more sense. I probably don't even need that. Okay. Because that is the Ep...

So when it says stratified squamous, like what are these two?

Those are like the functions I guess.

Okay.

Um, yeah, there's no need for this because it just complicates things.

Okay.

Um, so this is revealing my anatomy, ignorance. When this person who created this kind of stratified squamous connected to squamous columnar or Cuboidal, I'm assuming there's not stratified squamous that are up the cuboidal version, right? All stratified squamous are squamous?

That correct? Wait, I don't know.

I don't know either. Well, I know it's just like, there's a lot of big words right now. It's like, okay. I'm trying to think of what I learned. 
Jenny:

$\underline{20: 57}$

Interviewer:

Jenny:

Interviewer:

Jenny:

Interviewer:

Jenny:

$\underline{21: 13}$

$\underline{21: 13}$
I guess this is also, can there be a stratified squamous columnar or cuboidal? That just sounds like a mouthful and it sounds fake. So I don't think so.

Okay.

Because how you have them arranged up there, you've essentially separated these because they're different. Yeah. I think that there's like, I don't know if this is an actual like thing, there's like columnar, cubodial. I know that there's columnar and then there's cuboidal cause that's how we learned it. Cause there's like, you know.

21:39 Like they're mutually exclusive.

21:40 Yeah. They're not like saying the same thing.

21:43 So you're saying, can I use the pen that we should like put slashes in there because they're not describing each other. It's basically just saying it's one or the other.

Yeah. Yeah. Yeah, that changes everything. Okay. I was looking at it as one word and I was like, what is that? I don't know that. But then it was split into three different boxes but then yeah. It makes a lot more sense. 
Interviewer:

Jenny:

Jenny:

Interviewer:

Jenny:

Interviewer:

$\underline{22: 50}$

Jenny:

$\underline{22: 57}$

Interviewer:

Jenny:

$\underline{23: 07}$

$\underline{23: 14}$ $\underline{22: 17}$

$\underline{22: 10}$

$\underline{22: 20}$

$\underline{22: 48}$

$\underline{22: 48}$
So how does it, how does the rest of it makes sense if you put those in?

MMM.

I guess it like serves as the main heading cause those are the main types of like shapes. We have squamous, columnar, and cuboidal. And then from that you can have either like simple or stratified and then it goes down to like simple squamous and then simple cuboidal. And then let's go to that later. Stratified squamous, squamous and stratified columnar and cuboidal and then there is pseduostratified and transitional. So that makes a lot more sense.

Okay.

I still hate it.

Oh, okay. That's fine. You're allowed to hate it. Let me look at my list here and make sure.

I'm so glad you split those cause I was, I was very stressed and I was like, why am I looking at this? But now it makes a lot more sense.

That's everything. Do you have any questions for me?
That's not in our book or anything? 


\begin{tabular}{|c|c|c|}
\hline Interviewer: & $\underline{23: 15}$ & No. \\
\hline Jenny: & $23: 15$ & Okay. \\
\hline Interviewer: & $\underline{23: 15}$ & $\begin{array}{l}\text { Um, although I find it to be a good study tool to create concept } \\
\text { maps and things because it really pushes you to think about } \\
\text { their relationships, which think }\end{array}$ \\
\hline Jenny: & $\underline{23: 27}$ & $\begin{array}{l}\text { Yeah, I definitely need to do that for this, um, set of chapters } \\
\text { because, um, like Eric was saying basically that, um, there's a lot } \\
\text { of bones and then there's a lot of bone markings and like ways } \\
\text { to classify how they're different from each other in different } \\
\text { sections. So just like, no, the bones first and then where they } \\
\text { are in the markings and all that. So it's basically like making a } \\
\text { concept map or some organizational organizational tools. So } \\
\text { you're not just looking at like } 500 \text { terms and you're like, all right. }\end{array}$ \\
\hline Interviewer: & $\underline{24: 04}$ & $\begin{array}{l}\text { Yeah. All right, well I am done. If you, um, have any questions } \\
\text { for me afterwards or anything, just my email's on there. }\end{array}$ \\
\hline Jenny: & $\underline{24: 15}$ & Okay. \\
\hline Interviewer: & $\underline{24: 15}$ & And, um, or you can just reply to the emails i've sent you. \\
\hline Jenny: & $\underline{24: 18}$ & Okay. \\
\hline Interviewer: & 24:18 & $\begin{array}{l}\text { Um, and I will be emailing you in a couple of weeks to set up } \\
\text { another time. Generally speaking, does this time work? }\end{array}$ \\
\hline
\end{tabular}


Jenny:

Interviewer:

$\underline{24: 25}$

Interviewer:

00:00

Jenny:

00:34

Interviewer:

00:39

Jenny:

Interviewer:

00:55

00:45

Jenny:

Interviewer:

00:59

Jenny:

00:59

$\underline{00: 55}$

Interviewer:
We have an exam this Friday, which like I didn't know.

Yes.

Okay. Yes, works for me too. Sounds good. So that's when I'Il probably suggested very beginning. All right. Thank you. Thank you. Enjoy your Amazon gift card. I will. So you use it.

Um, so since we last talked, how are things going in class?

Um pretty good. Um, you know, I'm not failing, which is good.

What has happened in the class since we last talked. Have you had another exam or?

Um, I think we had another exam and then we've been like learning muscles now and then, I don't know, that whole spring break thing threw me off.

Yeah.

Oh.

Cause I was like, okay. Like there's no way there'd be an exam right after spring break but there is, so yeah. But I'm just going over the course material on too much crazy stuff.

So has anything, like when it comes to, I believe last time when we were talking about like, why is this information important? 
Have you had any relevations regarding that? Like do the units that you've covered since we last talked, have you found other ways that your anatomy knowledge is it more, is important that you hadn't thought of before?

Jenny:

Interviewer:

Jenny:

Jenny:

Interviewer:

Jenny: $\underline{01: 41}$

$\underline{02: 02}$

$\underline{02: 02}$

$\underline{02: 24}$

$\underline{02: 26}$

$\underline{02: 26}$
I mean, I feel like I still stand at the same place. Like it's pretty useful, especially like with what I'm going to go into and um, I guess it's like cool to know like the specific names, like the scientific names of muscles and sort of be like, well yeah, like traps, like yeah, Trapezius, or like the lats.

Or there is like gym speak.

Yeah. And then like textbook speak, but it's cool to know like actually the functions because you know, I'll do like planks and pushups and like tricep like whatever's, but I never really thought about my triceps, like flexing in a sense.

Like I always thought they just didn't do anything cause they're just there.

Yeah.

And I would only be working them out if I was like actually pushing against something. But you know, when you do this as like flexing, which I didn't know. 
Interviewer:

$\underline{02: 35}$

$\underline{02: 46}$

Jenny:

Interviewer:

Jenny:

$\underline{03: 27}$
Yeah. Cool. Um, so you feel like your understanding the content well and everything?

Yeah, I'm definitely, after taking the first few exams, I think that I've gotten to like grasp how to like study a little bit better I think hopefully. Well see, but um, it's definitely less daunting now. Like before I was like, Oh God, there's so much stuff. But I've learned to kind of ignore some things but like focus more so on other things. But there is also like that random like question that I thought would it be on the exam, but it is.

03:19 So have there been certain areas of A\&P that are more understood than others?

I feel like, well example today, we had a lab quiz so we had to like name all the bones and name certain muscles and you know, everyone knows your gluteus maximus and like, um, biceps, triceps, like that's easy stuff. And I was like, okay, like I don't really need to study that, but on the study guide or like the labs that we had to look at, it was every single muscle from like head to toe, like every single one. And I looked at it and I was like, I'm not even going to study this because I know that like $90 \%$ of this isn't going to be on the exam and what I ended up not studying, there's probably like one question where I didn't know and I was like, all right, like this is okay. Like I would've rather just like done what I did not study to not stress 
out and gotten like the same grade as If I did study, stress myself out and got a worse grade or something, just wasting my time on.

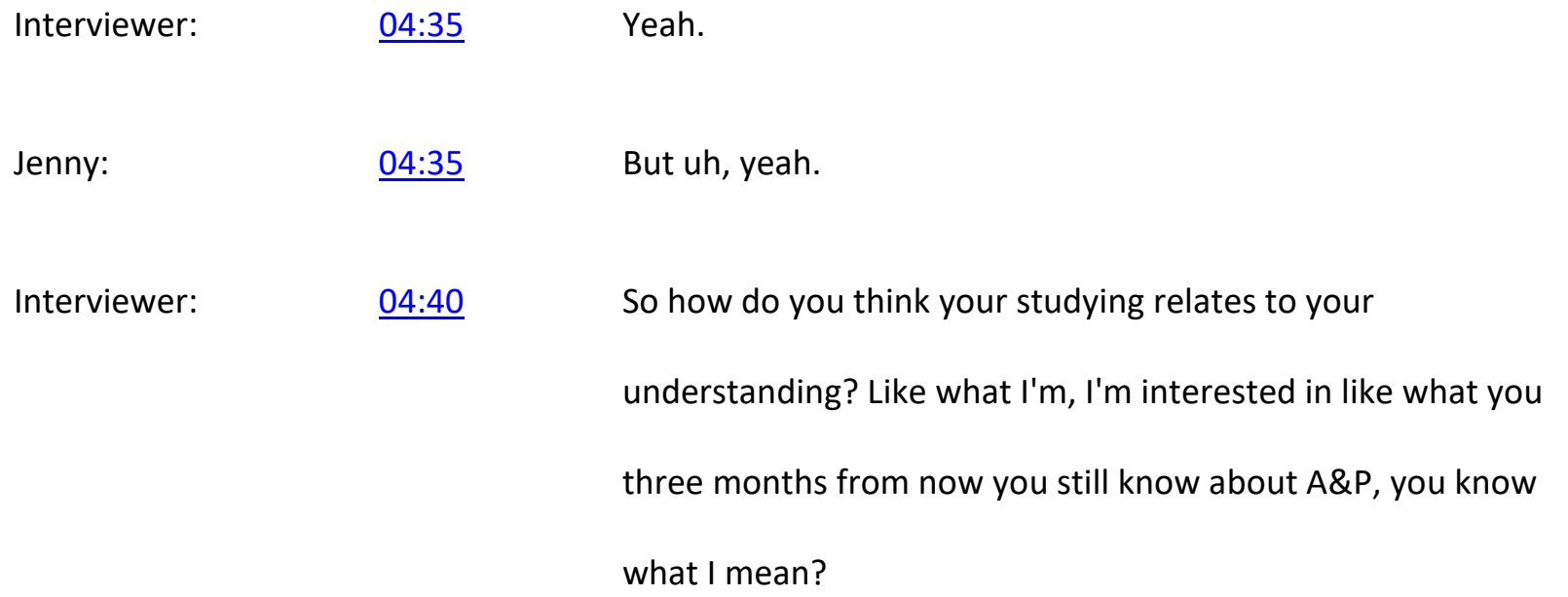

Jenny:

Okay. Yeah. Like, I think now at this point, I've learned to ignore like a lot of it like I details. I know it's bad because I should know all the details, but when it comes down to it, you need to know like the main bones, the main muscles and maybe like muscles that are like crucial in the functioning of the body. Like I don't need to know like this one muscle right here. Like I'll probably need to know this one because it connects to the femur and like all that. But you know, I definitely think that some of the muscles and like things that we have to know, like aren't really necessary. I mean they are, but just I guess more so how Dr. Wargo like focuses the course. She's like, know everything we're like, Oh God. But in reality it should be like know these specific 
ones and you know, just go over like every single thing. But obviously you can't go over everything in 50 minutes. So.

Interviewer: $\quad \underline{\text { 05:56 }} \quad$ Yeah.

Interviewer:

$\underline{06: 02}$

Um, so we've already kind of talked about this, but these questions are specific to the musculoskeletal system. Um, and they're just, I mean first compared to the other material you've covered. Challenging, easy, like in the middle. About the same.

Jenny:

$\underline{06: 19}$ I definitely think that It's not like harder, but there's just more. There's more muscles in the body then bone, I think, probably. Well probably, um, but again, like I had spring break in between these, so that might be a big factor, but I didn't feel motivated to like learn every single muscle, which, you know, for the last exam I felt very motivated to like learn every single like bone, every single bone landmark. I think it's just because in the back of my head it's like, I know she's not going to test us on all this.

Interviewer:

$\underline{07: 03}$

So. So you're kind of, you're like separating skeletal system from muscular system?

Jenny:

$\underline{07: 13}$

Yeah.

Interviewer:

$\underline{07: 13}$

And I'm kind of asking like, because in my mind those are one system working together. 


\begin{tabular}{|c|c|c|}
\hline Jenny: & $\underline{07: 20}$ & Yeah. \\
\hline Interviewer: & $\underline{07: 20}$ & $\begin{array}{l}\text { So how does that system learning that system together differ } \\
\text { from learning say epithelial tissues or like the other units you've } \\
\text { encountered? You know what I mean? }\end{array}$ \\
\hline Jenny: & $\underline{07: 32}$ & $\begin{array}{l}\text { Well like, I think epithelium tissues and stuff, were more like a } \\
\text { cellular basis. It's like more like focused in on like one thing, } \\
\text { whereas like the bones and the muscles you have to know like } \\
\text { so much of like every single part. But then again you could also } \\
\text { like group them into smaller parts, but even then the names are } \\
\text { like so complicated that like you'd think that it's something but } \\
\text { it's not. }\end{array}$ \\
\hline Interviewer: & $\underline{08: 02}$ & $\begin{array}{l}\text { Yeah. So all right. So what I'm hearing is muscular skeletal } \\
\text { system is more difficult than other stuff. }\end{array}$ \\
\hline Jenny: & $\underline{08: 11}$ & Yes. \\
\hline Interviewer: & 08:11 & $\begin{array}{l}\text { Um, so what aspects of the course or what other things maybe } \\
\text { even outside of the course enabled your learning of these } \\
\text { things? }\end{array}$ \\
\hline Jenny: & $\underline{08: 23}$ & Okay definitely, this website called purpose games. \\
\hline Interviewer: & $\underline{08: 26}$ & Purpose Games? \\
\hline & $\underline{08: 27}$ & \\
\hline
\end{tabular}




\begin{tabular}{|c|c|c|}
\hline Interviewer: & $\underline{08: 27}$ & What is it? \\
\hline Jenny: & $\underline{08: 28}$ & $\begin{array}{l}\text { So it's basically like a website where people can make their own } \\
\text { like point and click quizzes. }\end{array}$ \\
\hline Interviewer: & $\underline{08: 33}$ & Oh, cool. \\
\hline Jenny: & $\underline{08: 34}$ & $\begin{array}{l}\text { So you'd have a picture, a diagram that you point to like one } \\
\text { place and then you put in whatever it is. And I've made some } \\
\text { for the diagrams that she's provided and I'll like label them and } \\
\text { then I'Il like quiz myself, get a perfect score. Um, but then } \\
\text { there's also ones that people have already made and I'm } \\
\text { thinking that they were in the same class because like the things } \\
\text { that I'll make is the same thing as they will. But um, that's really } \\
\text { helped. Um, there are some that are very detailed like straight } \\
\text { from the lab manual and then the ones that are like, I dunno } \\
\text { like simmered down to like what you need to know, at least for } \\
\text { the muscular system.. yeah, muscular system. }\end{array}$ \\
\hline Jenny: & 09:20 & $\begin{array}{l}\text { I've really done like the main points instead of like every single } \\
\text { one. Yeah, that's helped a lot. Um, I think that's the only thing } \\
\text { I've really been using. }\end{array}$ \\
\hline Interviewer: & $\underline{09: 27}$ & Yeah. \\
\hline Jenny: & $\underline{09: 27}$ & And like drawing it out. \\
\hline
\end{tabular}




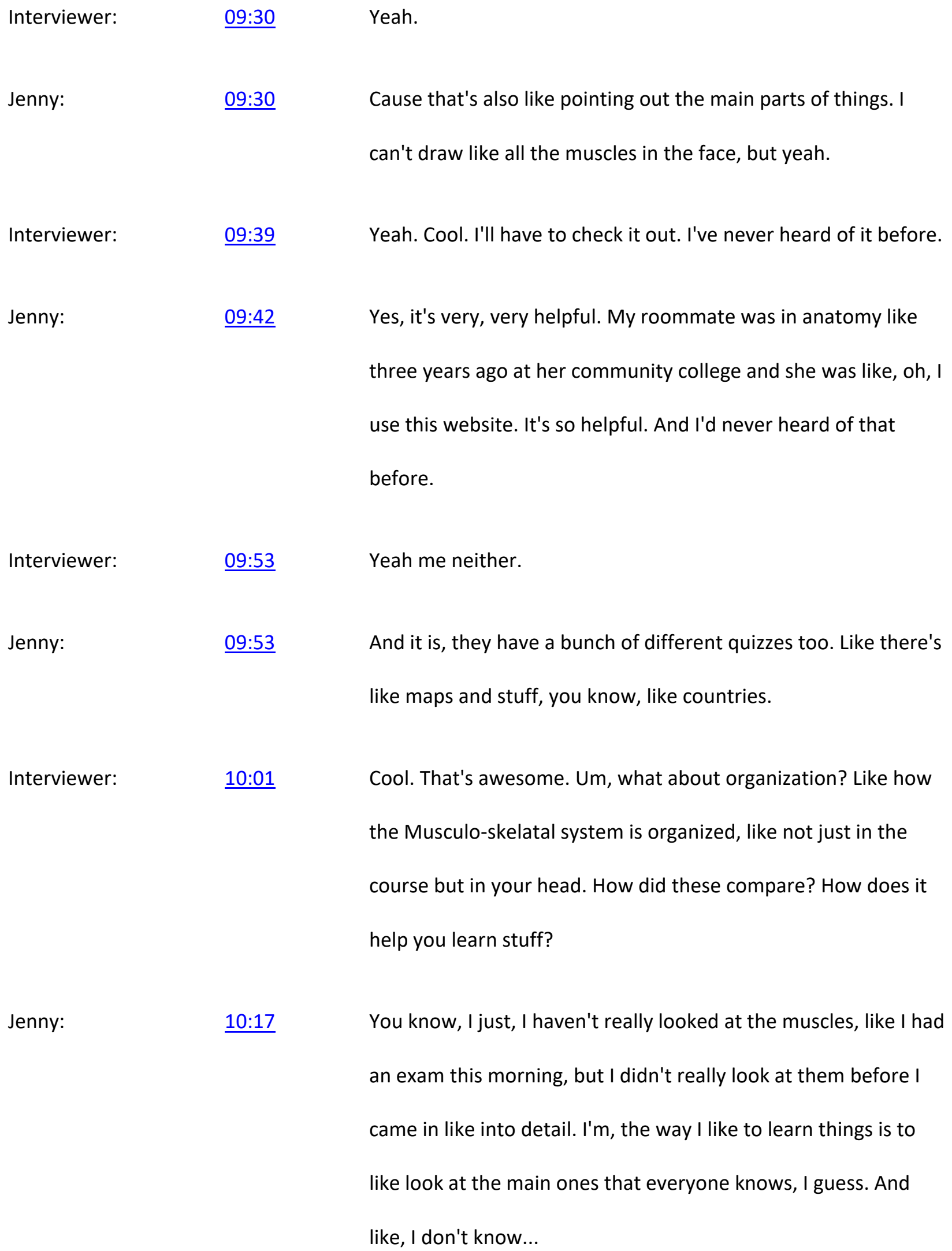


Interviewer:

$\underline{10: 41}$

Jenny:

Interviewer:

Jenny:

Interviewer:

Jenny:

Interviewer:

Jenny:

Interviewer: $\underline{10: 48}$

10:45

$\underline{10: 48}$

10:57

$\underline{11: 03}$

11:18

$\underline{11: 18}$
Just kind of tack onto there as you learn more maybe.

Yeah. Like go from like vague to specific.

Yeah.

Um, and I've learned now like not to get too specific because its going to be on the quiz.

Yeah. So do you feel like in your career where you need to know on those specific things?

I feel like let's say if I was like a podiatrist, like foot doctor, I would have to know every single bone in the foot in the muscles that attach to maybe like here and like here and like its fine.

Yeah.

Um, you know, I'm trying to be a nurse. I feel like I need to know like the skin layers and maybe like arteries and veins to an extent like muscles. I don't think I need to know every single one. Not every single one but most so.

11:39 Um, um, so from the musculoskeletal system. What is your big takeaway? Like what's kind of the whole point of you as a future nurse learning this unit? Like what is the takeaway for you? 
Jenny:

Interviewer:

$\underline{12: 20}$

Jenny:

Interviewer:

Jenny:

Interviewer:

Jenny:

Jenny:

Interviewer:

$14: 45$

Jenny:

Interviewer:

Jenny: $\underline{12: 20}$

$12: 24$

$\underline{12: 25}$

$\underline{12: 26}$
$12: 58$

Oh Gosh, this again.

All right. Okay.

Okay. Can you explain?

14:47 I grouped all the muscles

$\underline{14: 51 \quad O k a y .}$

14:51 Um, these are like things that you do. So like the functions, I guess these are like hand stuff. Um, I guess these are over here. 
Well, there are along the book, whatever bones in the hand. So, um, classification of bones, muscles, description slash functions, and stuff that is kind of grouped together.

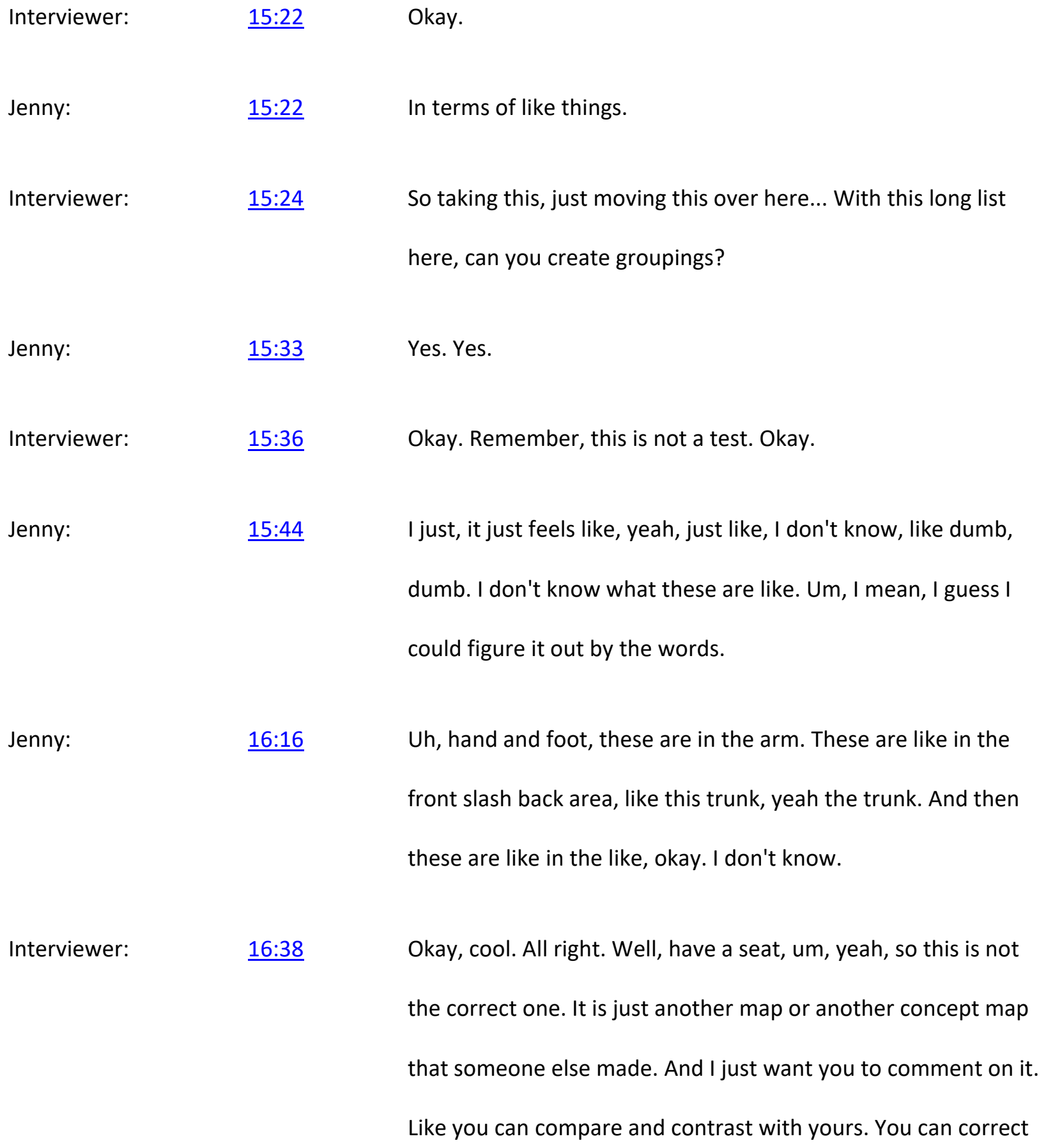


it if you think there are things wrong. This is the beauty of the concept map because there are no real correct answers.

Jenny:

$\underline{17: 29}$

Interviewer:

Jenny:

Interviewer:

Jenny: $\underline{17: 51}$

$\underline{17: 55}$

$\underline{18: 36}$

$\underline{18: 48}$
I feel like these two shouldn't be separate. Wait, nevermind.

Both are not muscles. Duh. Okay. I mean, don't, I don't really see anything wrong with it. I guess.

Can you try to explain to what it's saying?

Well, I guess it's saying like off of the appendicular skeleton slash like appendicular area. It includes like the muscle, skeletal muscles, um, and long \& short bones. Which do these things... Which protect, storage, yeah. Functions. And when it comes to movement, you know, this box does a lot. So does this one, but this is like legs and arms, I guess, which is kind of what I did, exactly what I did.

What do you think these arrows going back and forth refer to? Between the legs and arms.

Oh, that could be like extension and like, cause they were saying that like what one does the other un-does. So like there's always two forces like working with each other. It's like when this is working, this isn't, well that doesn't make sense that they both could be working at the same time. So I guess you could take out that Arrow. MMM. Not really sure. 
Interviewer:

Jenny:

Interviewer:

$\underline{19: 28}$

Jenny:

Interviewer:

Jenny:

Interviewer:

Jenny:

Interviewer:

Jenny:
So that principle, when something is working, something else is when something is doing, I don't know. It sounds antagonistic to me.

Yeah.

Um, are there examples of that in here? Maybe not between these two, but like what would be an example?

19:37 Like this and this, or like this whole thing, this is like getting shorter. This is getting longer. And then when you're going like this, this one's getting longer and this one's getting shorter. Um, that's the only one I know. Um, I think there's also this one, quads \& hams. So l'd assume it's the same. MMM hmm.

20:07 What would be the opposite of your glutes? Is that like abs?

20:14 I don't know. I was reviewing this last night at like 12. I was like I probably just to..

$\underline{20: 20} \quad$ I'm just wondering...

20:20 There is something that does it though. I don't know what it is.

20:25 What about this bottom half here?

20:28 I'm assuming that plantar has to do with like something that has to do with your foot or ankle. Um, I didn't do my online module 
thing and it has this thing where it tells you like the prefixes, which is really helpful but there's only like one question about those. Um, cause I see that there's like flexors in both of these and I'm sure that... Maybe plantar flexors means like foot flexors and then like dorsi means like hand, but I'm not sure.

Interviewer:

$\underline{21: 14}$

Jenny:

Interviewer:

Jenny:

Interviewer:

Jenny:

Jenny:

Interviewer:

21:21

$\underline{21: 21}$

$\underline{21: 36}$

$\underline{21: 54}$

$\underline{21: 56}$ m assuming that these have to do with like feet and these have to do with hands and I guess like people should know that is like opposites of each other. Like arms and legs would be like this opposite.

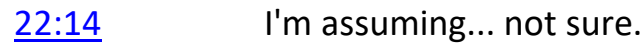

$\underline{22: 15} \quad$ What does this bottom one say? 
Jenny:

$\underline{22: 17}$

Interviewer:

$\underline{22: 26}$

Jenny:

Interviewer:

$\underline{22: 32}$

Jenny:

$\underline{22: 40}$

Interviewer:

Jenny:

Jenny:

Interviewer:

Jenny:
Intrinsic hand and foot muscles. Right.

So again we have these arrows going back and forth between hand and foot.

Yes.

Like we have between arms and legs. Any idea what those referred to? Genuine question.

I think that it's just like the opposite nature, like goes hand in hand with each other like hand and feet and then like arms and legs.

22:49 You have anything else to add or comment on?

23:01 Not really. I just, I don't like these concept maps. Like I like more, um, it's like downwards I guess or like sideways, like linear organization cause I don't like these more like lines, like crossing over and doing all that. Cause it's like I lose track really.

You said I could rearrange this? Right?

Mhmm.

These all have the same function, so technically, you could just like get rid of them all that is like that. Just straight lines, not the whole crossing thing. 
Jenny:

$\underline{23: 57}$

Interviewer:

$\underline{25: 11}$

$\underline{25: 25}$

Interviewer:

Jenny:

$\underline{25: 40}$
Yeah. Um, I don't, I don't really see the need for these either. It's like you could just group them in a different way. Okay. I get it. These are like legs and then these are like for specific, but in terms of like slash, ankle, these are like arms and these are like hands... Specific, um, if anything you could just do like this whole thing, maybe you to do this on this side and then this on this side because arms and legs and not legs and arms, but that's just me personally. Um, I see where they're going with this though. I just don't like the way it's organized.

It's fine. Yes. Yes. Anything else? I think that is all. Okay. Do you have any questions for me?

Okay. We're done. That's it. That's all. Cool. Yay. Cool. As long as the last one. Yep. Okay.

Actually I like doing this. Yeah. I just wish I knew what it was like before and like what we can, you know, once he's done.

Interviewer (00:04):

All right. So, um, first thank you for being willing to be interviewed. You're really helping out. Um, not only are you contributing to, you know, our improvement of anatomy education, but you're also helping Eric get his degree. So that's really great. Um, so I have a lot of questions to ask you and I first just want 
to say that, you know, there are really no right or wrong answers. It really is just like whatever you think.

So feel free to be honest. Um, and so do you have any questions for me before we get started?

Shawn (00:39):

No

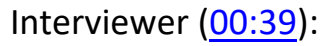

All right, so generally speaking, how's the course going for you?

Shawn (00:44):

It's fine. Yeah, I mean how, so like, um...

Interviewer (00:51):

Well first can I back up? Can I ask like what your major is.

Shawn (00:54):

I'm a stats major with a bio minor.

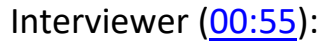

Oh, cool. So may I ask what your career trajectory,

Shawn (01:02):

Uh, statistics.

Interviewer (01:03):

Just a corporate statistical level job or something like that? 
Shawn (01:06):

Yeah.

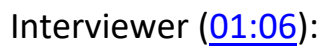

So why the biology minor? You just have an interest.

Shawn (01:09):

Uh, because you only need three classes after statistics to get a bio minor. So it's pretty simple to do and one of them is the 100 level class and the other two are 200 level classes.

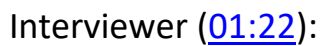

Yeah. Cool. Well I ask because there's this whole field of biomath, like we have, you know, a master's program in and everything. So I thought maybe that's the direction you're going, but.

Shawn (ㅁ1:34):

It could be.

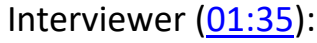

Yeah. Cool. Okay. So you say, of course it's going fine. What is it that you like about it?

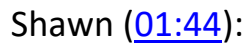

Uh, what do I like about it? I mean, I think it's interesting. I think, uh, anatomy in general. I mean I do like science. I mean if I hadn't gone into statistics, I, I was also looking into science at the time I didn't know much. I didn't really like biology. I've actually liked biology a lot more since I've been here. Um, I was looking more like physics, but, I actually, I like learning and I think biology is a really cool thing to learn about. So I mean that's the aspect that I like about it cause it's something that... I wouldn't know if it's 
like helpful. I mean it can be helpful like learning about about anatomy for like everyday and future life. But it's, it's something that's interesting, like it's applicable because it is your body and it's everyone's body. So I mean there are certain things that you learn like, Oh, okay. You know, there's stuff like that.

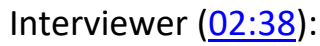

So that's like anatomy in general. What about, is there anything in particular to the lab, how that is going specifically?

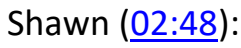

Uh, well, the lab has got pluses and it's got minuses I think is there's a lot of work, there's a lot of unnecessary things that we do. Like just the amount of microscope work we do. And I understand, and I actually have talked to Eric about this, that like, okay, a little microscope work just so that people get familiar with it and things like that. But I think almost weekly or biweekly microscope work of like drawing pictures with a pencil and I'm never going to use again or even look at again. And it'[s just silly. When I have something like the internet, I can be like, what's that cell look like again? And there it is in color versus my mechanical pencil. Um, I think the lectures are really good, but there's a lot in short amount of time and if you miss something on them, there's no going back because we don't get a copy of it.

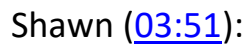

We don't get any, you know, we don't get any sort of note outline on it, so you can make sure that we have covered everything. Maybe, you know, like in lecture we have a note outline, so it's like, Oh well I didn't get this one note does someone else have it, maybe I can get it from them. There is none of that. So like specifically for me, I've had, uh, at least on two different quizzes, multiple questions where I'm like, I don't know, I don't know anything about this. And I go back in my book and I'm like, that's cause I 
never wrote about it because I probably missed it on the note or something like that. Or he said it once and it never got written down. And so I never studied it and then its on the quiz and now I'm being penalized.

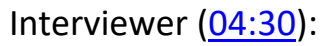

Yeah. So there's a lot of material and it's hard to get it all down and if you don't get it all down then there's no like safety net?

Shawn (며:40):

Yeah.

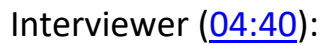

Okay. Um, so what about your understanding of the content?

Shawn (며:53):

My understanding of the content is probably a little bit different than a lot of other people's understanding since I already have multiple biology classes under my belt, 101, 196, 197, genetics, cell biology, evolution and then I'm taking mammalian biology right now too. So in some of those higher ones don't matter but like one 101, 196, 197 they deala a lot with, and cell biology, with cellular structures and how all that works and like how does synapses work? And, and like just today we have the test and on the nervous system and you know, it's like how does the action potential flow down the axon and things like that. It's like, Oh, I've already had that.

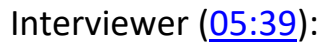

Yeah. All that is in 197. 
Shawn (05:42):

Yeah. So a lot of this has already been done and dealt with and you know in cell biology, there was a lot that like, even in genetics, that like was revisited in anatomy. So for me it's, it's one, it's almost hard because I'm like, I already know this stuff. It's tough to study for something you already know. But the, the material for me anyways, it's really just learning bones. Once we got past learning bones, it's, kind of boring.

Interviewer (여:12):

Okay. So, um, you know, I don't teach A\&P, so I know that it's a lot of nursing majors. And do you have idea of what year they are?

Shawn (무:26):

Uh, for my experience, almost all like freshman, maybe sophomores

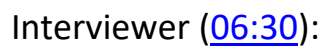

Because I think they do have to take 196, 197. But it sounds like perhaps they haven't taken that before or maybe they don't have to take cell.

Shawn (으:37):

I don't think they take it or maybe they take it in conjunction. But I know like the one of the girls that I sit across from in lab, this is her first semester or a year at least. Um, so yeah, it's probably her first semester. She's like, yeah, she's going back home to take anatomy because it's not going well for her. So I don't think there's a big background for them in a lot of this stuff. And realistically. I mean, it really shouldn't be because the level in which we are going into these processes and how they all work is so fundamental. Like they're not getting into anything specific, really specific, it's superficial. 
Interviewer (무:24):

Yeah. So this is helpful because, you know, the way our program is structured, um, for most of the upper level classes, you just need 196 and 197 but it sounds to me like cell and perhaps genetics and these other classes really helped to deepen your understanding to the point to where it's just review.

Shawn (07:48):

Yeah.

Interviewer (무:48):

Okay. Um, so yeah. Do you feel like you understand some areas of the course more than others? Like some content areas?

Shawn (무:59):

Well, yeah, I mean I think I understand a lot of the stuff that I've taken classes in before, obviously. Um, and also I understand the bones, like for the stuff that I was unfamiliar with, specifically bones and how that works in, uh, inferior, superior, all those terms and stuff, that was probably the most complicated part for me because I don't know that stuff. So, specifically, again, the bones I dd understand it and I totally, I think I did actually really well on it. The muscles when we learned the muscles, which was kind of in the same section, uh, that was harder because it's just a lot and they're all overlapping. Bones are easy they don't overlap as much. Um, but yeah, I mean that stuff that I did, I felt pretty comfortable with it.

Interviewer $(\underline{08: 55})$ :

Okay. So now you feel comfortable with it, but at the time it just, you felt like, Oh, this isn't review.

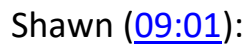


Yeah, I was like this. Okay. This part is not review.

Interviewer (이:03):

Okay. Um, so would you say that kind of your strongest areas are those that were review? Like I'm going to remember correctly, and correct me if I'm wrong, tissues. Um, like neuron functioning, action, potentials, genetics, cell structure. Okay. But then the weaker areas were things not covered in previous courses, like bones, muscles, skeletal stuff. Okay. Um, so you've already mentioned that it's a lot, like, I've heard that phrase a lot. So how do you feel about the amount of content in the course?

Shawn (09:45):

I mean, it's a lot, but the amount is actually very little. I actually think there's, it's a very light class when it comes to content. Because nothing has gone into a detail. So it feels like a lot, cause it's like, Oh, there's all this stuff, but you're not like in the dirt with it, you know,. Like today, uh, the exam we were studying for today so it's real easy to talk about, like how a nerve works, you know, in this class it's like, okay, it goes down axon and then this happens, blah, blah, blah. And then, you know, it goes to the cleft you know? OK. But like when you do it in like a class where it's more specified and you're actually like really getting into it, you can't just have a, okay, I have an overall understanding of how this works. In those classes. You actually have to know how things work because questions are, the questions on the test are a lot wordier.

Shawn (10:45):

Maybe its a teacher thing but her questions in anatomy are vert basic. They're very like, Hey, what is this thing do? Or how does this thing do it? Like whereas other classes, I felt like it was like, if this and this happens and then this and this happens, how will these react blah, blah, blah, blah, blah. And like there you really had to pay attention to every word in the sentence. Whereas in anatomy. It doesn't feel that 
way. So I am just kinda like, I just kinda gotta have a basic understanding and I'll be okay and I'll get it. So it's, it's a lot... And viably so... I guess in a way it is a hundred level class, whereas I'm comparing these to 200 level classes, and even one 300 level class, so there should be a level of difficulty in the questioneering. But uh, the amount of material, I don't think it's that that bad.

Interviewer (11:45):

Okay. Um, and so, so I understand correctly the amount of material you don't think is that bad because the, even though the breadth might be a lot, you're not going into a whole lot of depth?

Shawn (11:58):

Yeah.

Interviewer (11:58):

Okay. And so what do you think the relationship is between what it is that you have to learn and how you study? Like given that the course is a lot of breadth, but not a lot of depth, how does that influence how you study?

Shawn (12:17):

For me it's, it's just, uh, how well do I think when I'm studying? How well do I feel like I know this specific area and, and how much detail, you know, like basically I'm looking like, do I have a good understanding of this area? I'm not looking for specific details.

Interviewer (12:42):

Okay.

Shawn (12:43): 
Um, when it's, when it's memorizing things like, you know, like the brain or something like, obviously that's different. I have to actually know all the little spots and points and whatever. But like when it's a movable or, or an actionable thing that's happening, it's, it's more just, it's more just a good understanding versus... And I think that's part of that is also maybe because this is my last semester, so I'm kinda tired... I'm finding that it's a lot harder to study for this class than it was for other classes just cause I'm like, I'm done.

Interviewer (13:20):

Yeah, I understand. Yep. It's hard to stay committed when you're already thinking about the future. Alrighty. So, um, you've already kind of touched on this, but generally how would you describe your strategy for learning the content in this course?

Shawn (13:37):

I would say it's the same as I do for all my, especially biology courses, just a strong arm memorization. I've come up, over my years here, with my strategy on how I memorize and the amount of time I memorize. I'm known through my friends as someone who studies a crazy amount of hours... Probably almost unhealthy. But, but that's just the way it goes. And for biology, uh, specifically what, uh, like I'll study for10 hours at home and I'll study for half an hour. I'll take a little break. Maybe watch TV show, I'm checking my phone or something and then I'll go back and it's like, and I just repeat that process over 10 hours and I'll just sit on my couch with a, with a notebook next to me or in my hand just reading that and taking a break and, you know,

Interviewer (14:31):

So that was my next question. What do you actually do when you're studying? Is it going over notes?

Shawn (14:35): 
So it depends on the class. So what I do, uh, generally, and I haven't actually done yet for anatomy, um, is I rewrite all the notes, which for me, one hour of class takes about two hours of redoing the notes because I'm drawing pictures, I have pens and markers and highlighters and it's very detailed. And so I rewrite all the notes and then just reading them over and over.

Interviewer (15:07):

Okay. So when you're rewriting them, I always, I'm fascinated by this because I never did this as a student, but I talked to like very capable students all the time who do this. And I'm trying to figure out why it's helpful and the reason really my question is what are you thinking about when you're rewriting them? Because I've observed teaching 101 which again are non-majors freshmen, totally different type of student I guess. Uh, because they don't really have the interest. And they also haven't developed the maturity yet. But what I've observed is that a lot of times when students are rewriting the notes, it's just mindlessly copying down words, you know.

Shawn (15:56):

It is, I don't think about anything.

Interviewer (15:57):

You don't think about it when you do it. So why is it helpful?

Shawn (16:00):

So it's helpful this in this aspect. I believe maybe there is some cognitive remembrance in writing, very small, but I do believe there's some there. But also when I, when I'm studying my own words and my own drawings and you know, cause it's not just writing words for me. I mean like genetics I actually always want to frame that book that I made. It was beautiful, but, uh, I was actually, sad like I'm not 
going to look at this thing again. Um, but i'm when I'm studying it, I am memorizing those pages and my own words are easier to memorize than a PowerPoint slide or a piece of paper, print, computer, paper. So in the test I'm visually flipping through my notebook, uh, and being like, Oh yeah, okay, it's this. And sometimes I'Il be like, I don't remember this question. I never remember this question. I'll be like, and I'm like literally going like, it was on the bottom of this page. It was right above this drawing. What is it? Anything. I'm trying to read it in my head. And so that's how it's helpful to me. It's not the writing, it's when I review it. I can memorize my own writing way better than I can memorize a slide.

Interviewer (17:21):

So what about this issue of memorization versus actually being able to use the information?

Shawn (17:28):

Well, college isn't about learning information to use it. It's about memorization.

Interviewer (17:32):

Right. But that's my that's kind of my question. Do you feel like at any point lecture or lab you are not developing the understanding that's being called upon? Does that make sense?

Shawn (17:45):

Um, for like... Are you talking like for use later down the road after that class ends?

Interviewer (17:54):

In the class.

Shawn (17:54): 
Um, I am memorizing so that I can maintain as much of the information I can for 16 weeks. That's it. That's what gets me through the class.

Interviewer (18:07):

Okay. What about within that 16 weeks, do you ever feel like you're asked questions, are asked to do something that requires more than memorization?

Shawn (18:15):

No.

Interviewer (18:16):

Okay. All right. So now go to the other question, like further on down the line. Do you feel like this way that you're going about learning the content is going to help you in some way outside of the class?

Shawn (18:41):

It depends. So, like through my years of growing up, I had to learn this. Is that like, I'll say something like, Oh, that's easy we learned that in school when we were kids and people were like I don't remember any of that. Like I dumped all that. While I was like, no, I remember that knowledge. Like, you know, like I don't know how you could forget some of that stuff. It's just in your head. And uh, so I think I'm odd in that aspect. Uh, but so I do think there is some information that is definitely useful and it will be, I guess used later on and, and uh, it's hard to imagine. It depends on exactly. Exactly. But you know I don't think of myself as very smart but I'm very knowledgeable. I like to know a little about a lot of things. If it interests me I read it, if it doesn't interest me I don't.

Shawn (19:41): 
And people will be like really, how do you know that? You know how I lightning rod works and I'm like, well I saw it online once and I read it and I watched the show Chernobyl. Then I spent three weeks researching nuclear power plants and how they work. Well that never helped me. No, but I know it so good. It could one day and A\&P is the same way. Like there's a lot of things that we are going to learn in this class and I'm not going to remember, uh, in six weeks, but some stuff will stick and what has stuck could help.

Interviewer (20:15):

Okay. Um, so do you feel that this course is organized in a way that helps you understanding of material, like specifically the organization of the course?

\section{Shawn (20:27):}

I do. I think it's actually organized pretty well. It's very like, okay, we're going to work on this and then we're gonna work on that in order to work on that. You know? And I think that the specifically the body is actually very easy to understand that way. And I was like, I want to work on this system in the body. It does get affected by other systems. But we could just for our understanding of the very basic level, we can just talk about that. Um, and I actually think the lab, and this is one of the most interactive labs between the lab and lecture, usually lab and lecture, they have nothing to do with each other or it's two totally different classes. I could take them in different semesters that would not affect any, this class actually I think, sometimes I learn things in lab or lecture and they apply to both for both those tests, which is actually kind of nice and a little helpful in studying aspect. So, yeah.

Interviewer (21:21):

Cool. So, um, just out of curiosity, do you have lab before lecture or during the week?

Shawn (1:26): 
Yes, I have lab Monday night and then I have her on Tuesday and Thursday.

Interviewer (21:30):

Do you feel like that helps you to have like a more hands on practical?

Shawn (21:35):

No. No, because they're different paces. So they cover the same material. They're different paces like in lab last week we, we stopped, we finished the nervous system. And this week we were talking about the eyes and we dissected eyes. Well today I had a test on the nervous system. So like they're not always there. Yeah, they're not on the same page, which is fine at the end that's fine. But yeah they overlap but not completely. So I've studied for my lab quiz, which helped me study for my lecture test.

Interviewer (22:25):

All right. So, um, do you feel like you remember material from previous units?

Shawn (22:34):

uh, yeah, I think I do. I mean, yeah, obviously to a degree, but yeah.

Interviewer (22:42):

Is there anything that could help you to better remember things from previous units

Shawn (22:48):

Well, I mean, there's always things that could probably help you, but at the same time it would probably interfere with what you're learning at that time. Like, like if we started talking about what muscles affected by different nerves to like help us remember muscles that we already did... Well now we're 
going to be taking away from their nervous system. So I don't really think, I think it's actually just ended for this, for this specific course the way its broken up I think its actually better this way.

Interviewer (23:19):

So do you feel like the units could build up with each other?

Shawn (23:30):

Maybe a little bit, but for the most part, no. I mean I think there's obviously there's some connection obviously cause they all do work together. But realistically I think that that's not necessarily necessary for this course.

Interviewer (23:43):

Okay. Um, so generally speaking, we're just going to talk about the unit on the bones and muscles. So how do you feel about that unit?

Shawn (23:52):

I mean, I enjoyed it cause I was actually learning, you know, I mean I hated muscles cause for some reason it just wasn't interesting to me. I didn't really care. Uh, the bones I thought was really cool cause I don't know much about the bones. Like I knew a couple of the names and that was about it. Um, and I knew how I connected.

Interviewer (24:08):

So this is interesting. You cared about the bones but not the muscles?

Shawn (24:11): 
Yeah, I didn't really care about them. I don't know. I don't know actually. Both are kind of neat. You know, they're just the way they interact and stuff. Cause I know how muscles interact. Maybe that's it. Maybe that's because I done the nervous system before so I understand how muscles move. I know, you know, the sliding the sliding actions and things like that, uh, you know, like we had to go way into more detail and cell biology and stuff like that. And so just naming the muscles, I don't know, I guess I just wasn't really interested in it's cause that's just like, Oh this is this and this and that. And it was like whatever. But the bones, it was also like you had to learn like the parts of the bones, which was horrible. But at the same time it was interesting because I didn't know they had those parts and learn. Kind of like learning what those parts did. Like, you know, a condyle. versus, you know, something like that or all these little bumps and nicks and stuff. I didn't know any of that. And I was like, Oh, that's really neat. And they all have this and, and things like that. So that was kind of interesting to.

Interviewer (25:16):

So was it just knowing that they have them that interested you or was it something else?

Shawn (25:21):

Yeah, something, it was just my, it was more of a quest for knowledge. It was just a, just knowing about them it was, I was like, wow, that's crazy. I had no idea. Like, why? Why does this have this, this bump here? Oh, that's where this attaches and attach it. Oh, okay. You know, before it's like, Oh, there's a top and there's a bottom and then there's the middle part this long, you know, that was it.

Interviewer (25:47):

Yup. Okay. So you know, my next question, given that the course is mostly nurses and pre-professional people, it makes a lot more sense. But you know, my question is, what do you think is most important 
for you as a future blank to understand about bones and muscles, but you don't necessarily need to know about bones and muscles.

\section{Shawn (26:05):}

None of it, I remember I filled that out on your thing and I was like none of it's important to me, this class is to be honest, very trivial and meaningless. Funny. I am taking it because I have to to get a minor. Uh, I'm taking mammalian biology, not because I want to learn about mammals and I'm not going to be doing statistics on mammals. Probably not. Uh, this school says you need these courses, so I'm here.

Interviewer (26:30):

Yeah. Well, I guess the question, I'm going to just modify the question and just as a future knowledgeable person, like do you feel like, what do you think is important for you to know about your bones?

\section{Shawn (26:42):}

Mmm, I mean, I just think a basic understanding of how your body works is, I don't, I don't think there's any, uh, anything bad about just learning about you and the world around you. Just in general in any aspect. And if, if anatomy is part of that knowledge that you want to possess, I think it's, it's very crucial. Uh, I come from a family that works in the health field and I don't, so they talk about a lot of words that I don't get and about things and I don't understand. So maybe one day I can contribute in the conversation. Yeah.

Interviewer (27:16):

Cool. Um, so do you feel like this particular unit is structured in a way that it is developed, your understanding of bones and muscles? 
Shawn (27:27):

Yeah, definitely. Definitely, yeah. I mean I really, I have a way better understanding than I did before.

Interviewer (27:33):

Okay. Um, what do you, what is it about the structure of this particular unit that helped you to understand that? I mean, I guess I'm thinking of how the unit is organized?

Shawn (27:47):

um, I think we did a very good job of just going through it, you know, just literally taking the time and going through everything. And in the detail too. Specifically the bones. I mean, we had so many PowerPoint presentations that I was able to review, you know, going over, they were highlighted, things pointed out and just, you know, and also I can look at my arm and go, okay, that's, yeah, okay, now I see how that works and things like that.

Shawn (28:24):

Um, the muscles were harder because more of it was like, it's just diagrams with like pictures that things pointed to and when things are like layered on top of the other things it's kinda hard to get that three dimensional image. Whereas bones, it's, it's real easy because nothing's ever blocking the other one really, uh, where muscles, it was much harder to do. So, you know, but that's just a, I think that's just an issue with how the body's made. Like you can't always get a perfect view of the, uh, thigh muscle, a part of the thigh muscle that's buried under three other muscles in every diagram.

Interviewer (29:08):

Yeah. So this is interesting. This has not come up before in previous interviews, this issue of you mentioned even earlier that the muscles are all overlapping. 
Shawn (29:16):

Yeah.

Shawn (29:16):

And that makes it difficult to really visualize. And, and now that you say that, I kind of remember also having a struggle because diagrams always have those striations on muscles, which makes it all have the same texture. And so it's hard to tell one from another, you know? And so it sounds to me like we're kind indicating that flat two dimensional diagrams, there's, they've worked fine for bones, but with muscles they're lacking.

Shawn (29:54):

Yeah. So there's a vast issue with not being able to see it. I mean just take a leg (bones), if I take a picture on the right side or the left side or the front and the back, I can tell you where the heel is. I can tell you where... I can show you it doesn't obstruct itself that much. Then we'll take one from the top and take them from the bottom. Like, it's not that big of a deal, but then when you start talking about muscles, you have muscles that they're not up and down. They're lateral. So one, three dimensional picture doesn't do it. Which you, I mean, what would be really helpful is this is if the school has some sort of 3D model that like every anatomy thing has it, you know, you can take things apart and show this is how this works because muscles contract and it's hard to sometimes visualize on a 2D Oh, it's connected here and here.

Shawn (30:55):

And like, what does that look like? What does that pull in or what's that, you know, so that, that's difficult 
Interviewer (131:02):

Again, because I don't teach A\&P how is that, how are the muscles currently in lab? How are they currently explored? Do we have three dimensional models?

Shawn (1:11):

No.

Interviewer (1ㅣ:11):

Is it just with two dimensional diagrams.

Shawn (1ㅜ:15):

Yeah, we just did two dimensional diagram. We have, I mean, think we had like four skeleton bones and no muscle.

Interviewer (1ㅣ:20):

Okay. Um, I keep losing my place on my list of questions. So how do you feel about your ability to communicate what you know about bones and muscles and anatomy in general? Like if you had to explain to someone else?

Shawn (1ㅜ:42):

Um, I'm generally a pretty good teacher, so I mean my ability to communicate ideas and like bring them down to a level that people can understand. I mean, I was teaching my mom genetics, but she got it. So I think I know (how to communicate).

Interviewer (31:57):

Okay. So you feel confident enough in your understanding, you'd be able to translate it. 
Interviewer (르:00):

Um, so do you feel like it's important to be able to do that with anatomy? Like if you, again, your future encounters with anatomical content are probably limited.

Shawn (르:16):

Well, I mean, yeah. I mean, are you talking as a, as a student or as like the professors teaching the students?

Interviewer (르:27):

To someone else, like maybe your mom or maybe your doctor or maybe you know.

Shawn (르:39):

Well, yeah, I mean I don't see how that could be not important, but at the same time, um, I think that It's something that people have to either learn over time or they're just born with it. Like some people can show and tell people how things work but there's professors on this campus that can't explain their own subject very well. And I've had teachers where I'm like, he should not be teaching this class. He should be teaching doctor classes. Cause he does not know how to dumb it down to our level.

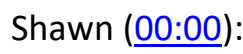

I think that's super beneficial if you could explain it, but you can have success without that probably.

(00:07):

All right. Um, so how would you describe the teaching style that you've experienced?

Shawn (00:11): 
Um, the teaching style. I think it's okay. I think if I had like had to compare my other biology courses I think is one of the better ones. Uh, just for how it's set up with a note outline, um, that we have to fill in if we want, which I don't know why you wouldn't, but it's followed fairly strictly, but it's still covers everything we need and we're tested on. So it's fine. Really. I mean it's, there are, I think there are some things that could be better. I wish that we did. And, uh, I think our note outline is lacking visual representation. So there's a lot of like images and stuff on the screen and then none of those are in our books or in our notes and we're not allowed to take pictures of them.

\section{Shawn (01:17):}

So you know, when I see this great picture that describes something and then I just have it in black and white words. So that's really like there's a disconnect there, which I just don't understand, which is the professor's choice. Uh, and in lab I think it's kinda the same thing there are these great slides and have great pictures and, but we're not allowed to have access to that. Uh, we have to go off what we've written down in our two hour lab.

\section{(01:44):}

Do you know why is it a copyright issue?

Shawn (01:47):

Uh, actually I had a talk with Eric about this. She believes believes that if she gives us those notes, we won't come to the lab, which I see. There is an argument to be made there. But I would, I would say, okay, well then do something else that you supplement that which we do.

Shawn (무:06): 
We have, we have attendance, we had to sign in every day and we have lab quizzes.But also you could just make small homework assignments. You know, like we never have homework for lab. There could be, there's questions in our lab manual. Okay, fill out these questions. The TA just checks it. That would offset people who don't come to lab, don't get those points, therefore their grade suffers. Uh, where I think the policy now I think actually punishes people. Everyone, it basically punishes everyone.

\section{$\underline{(02: 44)})$}

I mean specifically about the diagrams, the diagram.

Shawn (므:47):

I don't know if some of them are her hand drawings. Oh, okay. So yeah, that's not, that's definitely not copyright.

\section{$\underline{(02: 55)})$}

All right. Um, so does this teaching style help or hinder? I feel like you've talked about both of those.

\section{(03:13):}

So just, and you've kind of touched on this, what teaching style do you think would better support your learning? So you've mentioned like access to those notes and diagrams and things from the lectures.

Anything else?

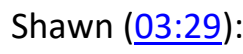

Mmm, I would say less tests. We have six tests in this class and it's ridiculous.

\section{(무:39):}

Okay. 
Shawn (03:39):

It's ironic we actually talked about it last night. I mentioned something to Eric about it last night in lab. It's, it's ridiculous to have six tests. Like we have a test today and we have a test a week from Thursday. That's crazy. To have two classes and another test. Um, I think it should be four tests and you do more information in, but for each test, um, also that would give you more days to actually go over again. Besides that I think that's probably about it.

(04:24):

So earlier you had mentioned it's a lot of material and a lot of the material is review for you. Um, but you mentioned for that one section that wasn't a review that was new for you. You've mentioned that it felt like a lot. I'm wondering if there were fewer tests and therefore more material on each test.

(며:46):

How would that influence, like that feeling of, wow, this course has a lot of material. You know what I mean?

Shawn (며:52):

Um, well obviously yes. So more information per test, but at the same time, those, the first two tests, uh, were I believe the first eight weeks of school. So now you've done two tests in, in half the year. The second half is four tests. So everything's right now, everything's crammed. So that section specifically was kind of where I want it for tests through the year, quarter half.

(05:34):

Yeah.

Shawn (모:34): 
And then, you know, so that's actually, I think it would have been fine. Yeah, it's a lot of material, but it's also, are you going to spend the time to study it? And I don't think I didn't study that much for those tests and I did fine on them. Um, so I didn't feel like, Oh my God, overwhelmed. I've yet to feel overwhelmed in this course. I felt like, yeah, that's a lot. But I just kind of sit down and do it. If you're dedicated and you just want to spend the time to do it.

\section{(06:05):}

Yeah. Okay, so we're kind of stepping back, going general and we've kind of already talked about this, but I'll just revisit it. Is an anatomical and physiological knowledge important?

Shawn (06:21):

Yeah, I think it's important.

(06:22):

Okay. Why?

Shawn (ㅁ:24):

Uh, why is it, why is the knowledge of that important? I mean I think it's just important to know. It does not hurt to know about how your body works. I mean it's the one thing you're always going to have.

(06:39):

Okay.

(06:40):

And so we've already talked about this too. Do you feel like it's important in your career as a statistician?

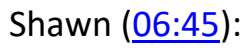


Obviously it has very little do with my career and you know say that get a job, I don't know, counting toes or something statistically. Yeah.

\section{$\underline{(07: 25)})$}

Okay. Um, so just last question. Do you feel like this course is structured in a way that helped you develop an understanding of those important aspects of anatomy?

Shawn (무:36):

Yeah, I think I have a much, much better understanding of that.

$\underline{(07: 43)})$

All right. So do you have any questions for me?

Shawn (무:45):

No.

$\underline{(07: 46)}$ :

All right. Well thank you very much. We're done. I have here, let me turn off the camera and then I thought.

Interviewer (00:01):

Okay. Um, so first I just want to thank you, um, because not only are you helping her get his master's degree, but you're also helping to improve the quality of the instruction that happens in anatomy and physiology. Um, when I ask you questions, I just want to remind you that this isn't really, there are no right or wrong answers. We just want your honest, um, feelings and opinions about the course. And, 
um, yeah. Are there any questions before we get started? All right, so generally speaking, how has the course going for you?

Andrea (무:06):

Honestly, it would have been been going worse but Eric made it a bit better because I meet with him every week to go over the course and what is going on, what I can improve on. So that has been helping me a lot. And the last exam I didn't really get what I wanted but I'm moved up like almost like $20 \%$.

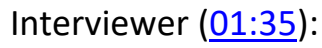

Oh wow. Nice. That's really cool. Um, so what about the lab portion specifically?

Andrea (ㅁ1:42):

The lab portion... that's not really.... What I'm having issues with is more of the lecture. Cause I feel like the lab is like a break down of one part of the lecture. So let's say it's like a quarter of the lecture. So it's not really something that is very like hard or tough to cover it.

Andrea (미:15):

This is a lot of information to like take in.

Interviewer (ㅁ2:24):

Okay. So you're saying that the lab, the lab is better cause it's like less dense?

Andrea (미:30):

Yeah.

Interviewer (며:30): 
Okay. So how do you feel about your like understanding of the content? You mentioned you talked about your grade a little bit, but what about like your learning of the content of the course?

\section{Andrea (므:43):}

I think I'm starting... Cause I met with lecture professor yesterday and I was telling her like the reason why I improved is because I actually understand what I'm studying. And that took a lot of research and a lot of on my own like studying and researching and trying to figure out what it is because I feel like they give you the information but you have to take a further step to like honestly understand it by like actually researching more about it.

Andrea (이:19):

So I think it, it made it easier when you actually know what it is. That way you can kind of like put two and two together when you're taking the exam. Like at first I really didn't know what was going on. It was more of just me memorizing.

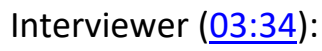

Okay. So you said before it was kind of like you're memorizing and now you're really taking the time to understand the material and study for understanding instead of memorization. What is the difference between those two together? Like the difference, your memorization versus understanding.

\section{Andrea (우:55):}

The difference between those two is like... She told me I would give you your study guide but the study guide is like a general... It's like just telling you to like note this but like it's telling you to go deep into it. It's just telling you what you need to study for.

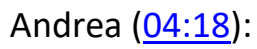


But it's not, it's not like a question, it's not giving you Oh this is what it's going to be an exam. So for me like memorizing, cause what I would usually do is I would do the study guide and then I'll memorize the answers and the questions. But on her exam its not like that. Like it's nowhere like those questions are answered, you would see some words. But if you don't know what those words are, you just memorize the answer. You wouldn't be able to honestly answer the question. So for me, like this past exam, I did like $50 \%$ of the study guide. And then I was just going through the powerpoints... I was going through the self study tests. Like I was using other materials and I wasn't focusing on the study guide.

Andrea (모:08):

And when I was doing the self study tests, it doesn't give you the answers. So if you keep taking it, you have to like research what is, what are you doing wrong? So for me it's like if I see a word, I don't know, I would look it up and see what this word is. So I feel like even if the exam wasn't still like the self study, it helps me better because when I see a word I can put it together and like look at the answer choices and reason through it.

Andrea (05:41):

So memorization, I feel like it would work if the study guy or whatever you memorize is actually the question.

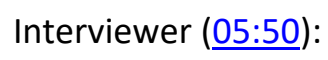

Cool. Okay. Um, so do you understand some areas of the content more than others? And why do you think that's so?

Andrea (으:03): 
Um, I feel like I don't understand... Like, so for example the images and knowing body parts, I can understand what their function is, but it's hard to actually like know what they are and know like how they look like and stuff like that. And I feel like the reason why is like in my other classes they tell you like... This is what it does, but not really show you where it is, what it looks like.

Andrea $(\underline{06: 42})$ :

So, just everyday stuff like you know where your mouth is and like just stuff like that. But actually knowing like where all the systems are is what is really confusing for me because I've never experienced that. Like I did it in high school, but that was like almost four years ago.

Interviewer (무:02):

So you're saying that like you can remember the functions and you can kind of connect those functions to the names of things? But when it comes to combining that with like what you see on a diagram or you know, actually finding it on the body, it's, that's where it becomes hard. And that's because in previous classes you've talked about like this system does this, this system does, but you've never really spent time actually identifying, is that what you're saying?

Andrea (무:31):

Yeah.

Interviewer (무:31):

Okay. We didn't talk about this, but just for my background knowledge, like what is your major?

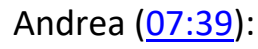

My majors are community health promotion and psychology. 
Interviewer (07:42):

Cool.

Andrea (07:42):

And I'm taking this class for pre PA school requirement.

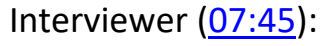

Very cool. That sounds awesome.

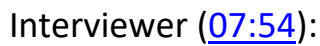

Um, so what would you say is your strongest area of understanding in the class so far? Like what do you understand the best?

Andrea (요:09):

I feel like I haven't gotten there yet because now I'm just working on like learning how to understand it. So, I mean the topics we've had so far, like I didn't really understand it because I didn't spend time actually understanding it. It was more like memorization. I feel like that is something we college students like think about because we have a lot to do...

Interviewer (요:40):

Like we have a lot to study and so you know, we just want to memorize it temporarily, take the exam and then move on to the next one. So for me, I haven't really found that topic yet because I'm still working on how to and stuff so. Well which one do I find the most interesting? Definitely none of the skeleton or learning all the body parts. Um, I think the nervous system.

Interviewer (09:15): 
What is it about that one that's interesting to you?

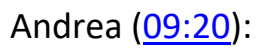

I think it's like, it makes sense like trying to like remember stuff like, like from more from like the words you can know what it is. Like I was telling my professor like I get to break it down like with a chunk of it and like what does this mean? What does that mean? So I feel like that's what it is. Like you can, it's easy to like understand what it is just by like knowing the word or like knowing the prefixes and stuff. So like knowing like the Latin and Greek roots and knowing what they stand for. And then some of them is like just kind of common sense cause it's like something we've heard of trying to like remember something like the mortar and sensory, like sensory those are you senses and motor is movement and stuff.

\section{Andrea (10:25):}

So stuff like that. It's like easier to comprehend cause it's kind of like you've heard it sometime in your life and that was easier for me. And just in general the drawings and the diagrams and the images were not too complicated. It was, it was like, I remember the other topic, you have a whole thing that you have to memorize each part of it, but they're breaking it down for you. Like the dorsal root ganglion is where like... So like the breaking everything down so it's easier to like remember it happened in one diagram or if it has a whole bunch of them.

Interviewer (11:10):

So you're saying like the materials that you were provided for the nervous system, like the diagrams were just more specific, like each diagram had fewer things?

Andrea (11:22):

Yeah, definitely. 
Interviewer (11:24):

Okay. So how do you feel about the amount of content that's in this course?

Andrea (11:28):

I honestly like, I understand its a lot and they are tying to teach us everything and get through it, but I feel like they really need to like rearrange things because even like my professor sometimes it's hard for her to get through everything cause there's a lot...

Andrea (11:56):

And I feel like if it's hard to teach everything then it's going to be hard for us to comprehend and know everything. You get what I'm saying? So because my thing is I feel like the whole college system is, it's training us to like memorize stuff and not actually know things.

Andrea (12:13):

The whole point of learning this is for us know it. So when we get out there in the real world we can make use of it. But if I just memorized everything through college and I get out there... They're like you should have learned this.

Interviewer (12:24):

So I totally agree with you. You said that it's like it trains you to memorize.

Andrea (12:34):

Because it's a lot. Like imagine me having to do homework 150 questions... even if it's an extra grade, which I mean having to deal with that, another homework, self study assignment and then having to learn stuff for the exam is just too much. 
Interviewer (12:53):

Okay. So what would it look like if it were training for understanding instead of memorization?

Andrea (12:59):

I think it would be more like focused, like we would have a homework. But one thing about the homework that I don't like is it's a lot... Like I think after each chapter we should break it down. So let's say instead of 150 questions make it 505050 questions. I think we cover sometimes two chapters. So like break it down after each chapter we have a homework due rather than having all that for one exam. Does that make sense?

Interviewer (13:30):

And so it's like fewer questions but more frequent.

Andrea (13:34):

Yeah. And then, um, what would it look like? Less information. Like actually breaking things down for for understanding, not memorization. And I just feel just like generally a lot. Like I understand its a lot because we're talking about the whole body system by talking about like the whole human body. But then also like make it a bit relatable. Like it is just... This is the information. There you go. Not really related when it comes to like lecturing

Interviewer (14:20):

So by relatable you mean...

Andrea (14:25):

Giving examples... Give us things we can relate it to; which she does sometimes and like those help. 
Andrea (14:36):

Like we were not born with all those medical terms in our head. But if you're relating it to something we're familiar with it makes it easier to understand and sometimes it's like you look at it from a different perspective.

Interviewer (15:06):

Yeah. Okay. So generally, how would you describe your new strategy for learning all the content?

Andrea (15:15):

Well the new strategy that I think is helping, is focused on learning the big stuff and I just feel like the things underneath it would just fall in place.

Andrea (15:29):

When you actually like... When it comes to the nervous system, know what does the actual nervous system do. Then now when you know what it does... So like focus on the big part first and then slowly break it down. But if you're just focusing on the chunk and not even knowing what the big part is itself, it's harder to put it together.

Interviewer (15:55):

So like by the chunk you mean like the minutia, the little words?

Andrea (16:04):

Like focused on what the skeletal system does... So then when you know what it does, you can break it down like okay, if it does this, which part of it does this? Which part of it does that and I feel like that's something then like that was helpful to me. 
Interviewer (16:16):

Yeah. Cool. Um, we've talked about this a little bit, but I'm going to ask it again just so we can make sure. Do you feel like this course is organized in a way that develops your understanding of the material?

Andrea (16:38):

Kind of, and I said kind of because we have labs and they do not cover everything like... One quarter butI still feel like it's more of a hands on like practical. So we're actually like honestly understanding it and like sometimes like he, he gives us like stuff to do with your partner and stuff, like we're doing sensory tests and like poking them and stuff and stuff like that.

Andrea (17:07):

So like stuff like that like helps. But in like the self study tests... Like we have some stuff to help us understand it and the lecture but when it comes to the actual lecture itself, I wouldn't say its helping us understand it.

Interviewer (17:27):

So how would you change the organization? So to better support your understanding.

Andrea (17:35):

First of all, I think we need an Anatomy 1,2, \& 3; three courses, because if you're trying to fit all that into one... I heard it, it gets worse from here. So I'm a real scared to take Anatomy 2. Honestly I just want to get past this first and then think about it. But I feel like this is a lot for a one semester course. It's just so crazy cause people know like anatomy and physiology is hard... Like when I took told my friend I was gonna take anatomy \& physiology they were like... wooo.

Andrea (18:10): 
So it was like we know its hard but like there's a way to make it easier for us by breaking things down. Like if this was the only class I've taken this semester, then I'd have a it. But I have other classes too. But I find myself, if I'm thinking about Anatomy in my other class I'm mixing things up because there is too much. My other classes are also science classes. So I find myself mixing things up and my teacher has to be like, I think that's for your other class. So anatomy is making me crazy basically. But I think breaking things down, we definitely do need like three anatomy. I mean it's going to help them get more money. But l'd rather take three anatomy classes than cover all this in one, cause like what's the point if I'm not gonna remember it?

Interviewer (18:56):

Yeah, that's a good point. Um, so do you remember material from previous units?

Andrea (19:05):

Some of it...

Interviewer (19:09):

What would help better help remember that material?

Andrea (19:10):

If I could understand the material then I'd be able to remember it.

Interviewer (19:16):

Okay. So do you think it's going to be different for this? Like you've kind of changed your study strategy, so weeks from now are you, are you going to be able to reflect back on this material?

Andrea (19:27): 
I think so. Definitely. Mostly like when I went over the exam with her because I like to do that because even if it's not going to be on the next exam... It still helps me know where I went wrong, like how I should have changed my thinking and like it still would help me remember it in later in the future.

Interviewer (19:49):

Yeah. So that kind of pertains to those questions. Do you feel like the units could build off of each other?

Andrea (19:54):

Yeah.

Interviewer (19:54):

How so?

Andrea (19:58):

Because there are some things from last unit that we used this unit. But I wouldn't say... I feel like the PNS and the CNS like was kind of reoccuring in some words...

Interviewer (20:30):

Okay.

Andrea (20:37):

Yeah. I can't remember. I cant think about some but I remember some words being reoccuring.

Interviewer (20:42):

Yeah. Cool. Um, okay, so my next questions are about the bones and muscles unit specifically. So first, how'd you feel about the unit? 
Andrea (20:52):

It was hard. It was too much. And I feel like that is something you should break down too. Like there is no way I'm going over everything. There's just no way, not everything at once. Imagine studying all that in two weeks for an exam. No.

Interviewer (21:14):

Yeah.

Andrea (21:14):

Yeah.

Interviewer (21:16):

Yeah. Okay. So it's just so much material and it's not enough time to learn all of that material.

Andrea (21:23):

Because we have an exam like every two weeks and imagine all the homeworks we have during those two weeks.

Andrea (21:25):

Like when I remember my professor was asking... what are, what are your study hours? They're very limited. They're very limited. Cause once I'm done with my homework, now I have to focus the study and it's like I don't have that much.

Interviewer (21:42):

Do you feel like the homework is studying? 
Andrea (21:44):

No. It's a 150 questions that's not studying... That's, Oh I got to get those questions done so I can get my points because even if I'm trying to comprehend it, which I always try, imagine just clicking next question and it just keeps... Like there's no way I'm going to remember all of this. 150 questions. I remember what it talks about.

Andrea (22:12):

Sometimes I will find myself not having enough time to finish it. I know it says on her thing two to three hours. That's not true. That's not true. I'm on that homework six hours later still trying to figure out what this is... Cause for the homework, it is more like textbook wise. Not really like lecture cause imagine like lecture. She has a powerpoint. All those 150 questions... I'm not going to find in her PowerPoint. So now it's like I have to dive to another one. You use the textbook rather than using her powerpoint, which her powerpoint is what the exam would.

Interviewer (22:49):

Okay. So what do you think is most important for you to know as far as bones and muscles go as if future PA?

Andrea (23:06):

So my boyfriend right now, he's a nursing student and when I asked him some of this stuff, he's like, I don't remember because we're not using it. Like we're learning something different. Like, I feel like this is more like a general, like just knowing cause you're going into the medical field, but it's not really major specific. It's not really like field or career specific. So I just feel like it's good to like know what they are, like maybe their functions, but we shouldn't have to go this deep, if I'm not trying to be your surgeron and saw on the bones. I don't know. I just feel like it's too, like we're going too deep into it. 
Interviewer (23:50):

So do you feel like the unit is developing the understanding that you need as a future PA? The unit you mean by like the unit on bones and muscles?

Andrea (24:07):

I think some things I can take from it, but I wouldn't say all like $100 \%$. Yeah. Like some things I'm like, Oh, I probably know this, but I wouldn't say $100 \%$. And like those days I know I need to know it because it's very current. Like I've seen it in my other classes. So it's something. Yeah. But the other ones like I'm not going to be telling somebody however many bones you know what I'm saying? It's not something I'm going to make use of.

Interviewer (24:39):

Right. Can I ask what your other classes are? What is some of the material shows up?

Andrea (24:43):

Um, I remember my nutrition class, like we talk about some things we talk about here. I didn't know how much nutrition had science through. I started taking it and um, even my public health, even my environmental health class, somethings overlap from there.

Andrea (25:01):

And with the biology class I have before, yeah.

Interviewer (25:08):

What biology class was one 96 or 97 ?

Interviewer (25:19): 
All right. Um, so how do you feel about your ability to communicate this information to other people? This information meaning about bones and muscles. Like would you be able to?

Andrea (25:42):

I think it's actually like it'd be fun if you like doing it with somebody that actually understands it. Like when I do it with my boyfriend. Um, it's fun but also is very challenging cause now I have to act like I know everything. And when you have somebody that like, yeah, but I think it's easier. It makes it easier.

Andrea (26:03):

Like I remember when I was studying for this, like I asked him because he breaks it down, its like the professor its another student...

Andrea (26:06):

I think people probably know like, Oh you like you're given all this information but like they know which one that is most important to take that and they can teach it to people. So when you're discussing it with somebody else, it's easier than when the professor, the professor has a lot of knowledge about it. So they're trying to share their knowledge, but it's like what do I really need to know.

Interviewer (26:39):

It's almost like your strategy for studying is like you look at the big picture first and then you like breaking them into small pieces, from big to small. And I think a lot of times I know I do this, I'm guilty of this. I explain something, but I'm like here's all the detail. And you know, sometimes you just have to start big and break it down into what you really need to know.

Interviewer (27:03):

So do you feel like you are able to communicate that way? 
Andrea (27:08):

Yeah. But not for everything. The only things I really understood I'm able to communicate. I think it's fun when you're actually able to though.

Interviewer (27:21):

Yeah. Cool. So, um, how would you describe the teaching style that you've experienced? Physiology, like lab and lecture wise?

Interviewer (27:34):

Hmm. I mean lab is what were most interested in.

Andrea (27:42):

I feel like it's a lot of like PowerPoints and honestly we dont even use are lab manual that much anymore. Which I don't really mind because I figure the lab manual is probably ten times harder but I feel like it's not really what I expected in a lab when it comes to like practical wise, but maybe it's just anatomy and physiology. Cause I can't compare chemistry to anatomy and physiology.

Andrea (28:26):

But teaching style wise I think we spend a lot of time on learning the material but not really knowing the material. But I wouldn't say there is much to be changed because I'm looking at like the reality of it. Like is it really changeable or is this just how we have to do it? But I still just feel like there are certain things like power point wise like not focused too much and all the things on a PowerPoin... Like pick out like the most important stuff and then further explain that stuff.

Andrea (29:11): 
I would say so it's like if you have all this in a PowerPoint then like pick up the most important things and then further explain it. Which for me like I don't really mind cause I asked for extra help anyways but I just feel like the other people like if they're sitting in the class and hearing you say all this stuff like do they really understand it? Like, I remember asking like in class, I would sometimes I'Il like ask my friend and she was like, she doesn't understand that. So it's like just for people, do they really understand end every single thing on the PowerPoint. So maybe say something. Talk about it. So you know it is better for us for you to cover $75 \%$, but we know the $75 \%$... than to cover $100 \%$ and we only know $10 \%$, yeah.

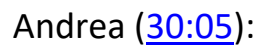

Um, but then again, is that what he was told to do? You know what I'm saying? Is that what he has to cover? And I feel like that's the problem for this course. Like the professors and the instructors have a certain amount of things they have to cover and they'd have to cover it If not, they'll get in trouble. It's not really about them, it's also about the system and the way it's set up.

Interviewer (무:30):

Yeah, for sure. Okay. So, um, just, I already know the answer to this, but um, anyway, um, do you feel anatomical and physiological knowledge is important?

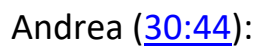

I feel like all of it is, but it's specific to what you're doing.

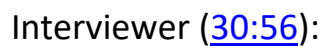

Okay.

Andrea (숭:56): 
I'm saying like it is important. Like some people need some... Like depending on what field you're going into you need to know some part of it. But I wouldn't say one person has to know everything about it. Even doctors, I don't think they need to know everything about it.

Interviewer (1ㅣ:14):

So do you feel like anatomy, physiology, knowledge will play a role in your career as a PA?

Andrea (1ㅜ:30):

Mhmm.

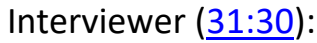

Why?

Andrea (1ㅜ:30):

Because let's say the doctor communicates something with me or like say something anatomical... Like using an anatomical word like I already know it. Like when we were learning like lateral and like stuff like that. Like if the, if the, I remember my lab instructor was saying if the doctor or whatever asks you about lateral or superior.... And if I didn't know that... and was like what are you talking about? Like above? Below?...

Andrea (르:08):

But I feel like stuff like that would help with communicating with other medical personnel.

Interviewer (르:14):

Yeah. Um, so do you feel like this course has been structured in a way that enabled you to develop that understanding? 
Andrea (르:32):

Not really.

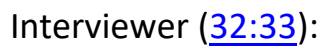

Okay. Can you say more?

Andrea (르:35):

Hmm. I feel like there's not a lot of practical stuff. It's more like information, information, information, and if it's going to be practical in the real world, like we should make it practical while learning it.

Interviewer (르:57):

I get it. Um, so earlier you talked about how, like when we were talking about communicating and information, you said it's, it's fun to like, when you understand it and you can talk about it with someone else who knows the material it's real satisfying communication.

Interviewer (3:21):

Um, like what, what do you think the course would look like?

Interviewer (00:00):

What would it look like if it gave you opportunity to do that?

Andrea (00:09):

Lecture wise, I feel like compared to like other lectures I've had, it's like honestly it's just like sitting there and just watching her talk. That's how I feel. I don't know who really asks questions. I can count how many people ask questions in that class. I know them, but I feel like everybody's just looking, just 
hearing her talk for almost an hour and 15 minutes, but we're not really having that time to communicate that information. Like, Oh, you said this earlier, does this relate to this? I know she has office hours, which is 10 minutes. I just feel like by the office hour time I already forgot it because I didn't really understand while you were teaching and so I feel like, like I said again, she has a lot she has to cover and she wants to try to cover it before the end of the class, but give us some time to communicate the information because if you're just reading all this stuff for me, I can't put it together.

Andrea (01:14):

I don't know what this one is. And I was telling my friend in class, like if I'm confused on one thing, I'm stuck on that, then I can move on because I don't understand this. And I'm pretty sure it relates to more of the things your talking about. So I feel like even people that ask her a question. I feel like they kind of just interrupt because we don't really have a pause to talk, but that's what I mean... Practical even communicating. Asking questions and you answering my questions. It's practical, like that's something I'm going to have to do when I get into the real world. I have to communicate with somebody. So it's like I said, it's still a lot of work for this course. It's a lot of information. So what if we break it down? We're able to talk about it now. She doesn't have as much to cover in one, even one class period. We meet twice a week and it's a lot we cover in those two.

Interviewer (며:11):

Yeah. Cool. Awesome. Those are all my questions. Do you have any questions for me?

Andrea (무:18):

So like what, like what is the research about? What is the research is a research, right?

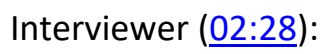


Yep. Um, so Eric has been trying to find an alternative way to teach anatomy and physiology generally speaking, but he's really focused in on the bones and muscles unit and he is really trying to help students, I mean almost precisely what you've talked about. Actually I feel like if you don't become a PA you should become an educational researcher. Um, but he is trying to figure out ways to better support students, um, linking functions with all of those parts that they have to remember because understanding the function just as you said and really helps you to understand. What the parts look like, why do they look like that? Like why is their structure the way it is? It's because it serves a particular function and when there's this meaning behind it that really enables them to like learn through understanding.

Andrea (무:30):

Again, I feel like some of the parts, like I said, like there's a way you can break it down like so ventricular like this is the way you can break those words down. Then we'll be able to understand it. But I feel like sometimes we just talk about it and like there are some other like Greek words, some of them like they labeled those parts because of some where it's located. Something like we don't really dive into this or is it really hard to remember it? But if you remember, Oh it's in this part. So it would be called this girl.

Andrea (04:01):

I'm saying cause I feel like we should dive in more into that so we can remember it like it was, we know it's around this region, we know it should be called this or should we call that? So I feel like we need to focus on what the meaning of the actual part is, the word, the words. So now we can know like what the function is too.

Interviewer (며:19): 
Yeah. So something that keeps showing up in these interviews that I'm doing are precisely that. Like really diving into Latin and Greek roots and understanding those and then linking them to the body parts so that you have an understanding.

Andrea $(\underline{04: 33})$ :

Cause that's how the name, the part of the room. I know like she's covered in like once or twice and like actually remembered that cause that's like we were more, we're almost all familiar with Latin because this is not just an that time vibe. Like we use it in every, it's an every year it's in every class or every topic or every subject. So if you're using something very familiar, great, that would help us. Yeah.

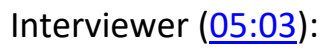

Okay. So that's basically what Eric is doing.

Andrea (05:06):

That's good. I'm glad he's interested in it.

Andrea $(\underline{05: 15})$ :

Oh Eric, you're great.

Andrea (05:21):

He's really, really good.

Interviewer (00:01):

Okay. All right. So my name is Interviewer, um, faculty member in biology and also the director of CMS, which is center for math, science, technology. And, um, first I just want to thank you for being willing, 
you're allowing Eric to get his master's degree. Um, you're also, you know, allowing for us to really collect data so that when we, um, create, intervene physiology instruction, it's informed by evidence and can really be an improvement. Okay. Um, I'm going to ask some questions. I just want to remind you that this isn't really a test. There are no right or wrong answers. This is you just telling us exactly what you think and, um, we're really just interested in understanding your experiences in the course of they can be used to inform instruction in the future. Um, so any questions please. Okay. All right. So generally speaking, how is the course going?

Maddie (미:03):

I really like it and it's going well for me at least. Um, I took anatomy in high school like my senior year, but that was, I'm a junior now, so it was like three years ago. But so that helped a little bit in the course, but I was always interested in anatomy. I want to be a dentist and orthodontist. So that also helps a lot, that kind of stuff. I really liked the course. Awesome.

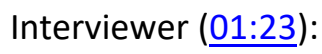

Um, so what about the lab portion of the course specifically?

Maddie (01:28):

Um, I like the lab just because I have Eric as actually a TA. So I like the PowerPoints. I like the, I'm more of a note taker. I'm not so huge on labs. I don't really like labs in general, but I do enjoy that lab just because we get a lot of time to like go over the material first instead of it feeling like rushed and we have like the power points and everything.

Maddie (01:49):

And then you do like the lab itself. So I really like that at least. 


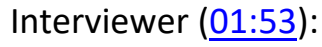

So what is it about the PowerPoints that you like?

Maddie (무:56):

It's just very detailed. I feel like it's like I' $m$ in the lecture and taking notes and I take notes like I do in the lecture the same way in the lab. So actually I have it later today.

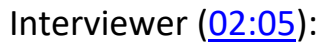

Okay. Um, why do you mention that you usually don't like labs?

Maddie (며:11):

It stresses me out. I always feel like something is going to go wrong. Like it's more I guess like chemistry type labs... cause I know there's like experiments, something could like really go wrong, but I don't know, just kind of stresses me out a little bit. The lab portion.

Maddie (며:26):

I mean I guess because yeah, like I always feel like I'm not good at procedures in the lab.

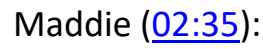

Like just hands on just cause it's, I mean I guess it's not so much in anatomy, just labs in general. I'm always like worried. Like if the procedure... That I'm going to do something wrong... I think that's more of the big thing with anatomy. I do like that. I like the dissections cause you can actually see it and it helps me study. So it's more the anatomy ones don't stress me out. Its just labs in general.

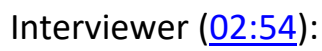

Okay. So how do you feel about your understanding of the content? The course? 
Maddie (므:59):

So I feel really good about it. I like my course because my teacher gives a lot of memory cues and like visuals and that's what kind of what I learn off of. I liked all the assignments that go with that... Even though they're like assignments and nobody wants to do like extra homework.

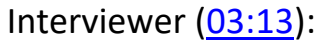

What are the assignments?

Maddie (이:16):

So there's homework, there's um, an extra credit like self test, you can take it as many times and then you get extra credit I think no matter what score you get. But like I was trying to get like the full score to see you can get like the full three points, um, the other than there was no homework. And then there's an assignment too that it's just, you make up like test questions. So it's kinda like you're the teachers you can see like what kind of the questions will maybe be like on the test.

Maddie (무:38):

So it's kind of a lot, but I like it because it helps me study for it. So I appreciate that we have so many assignments for it and it's also extra points that are being added in the grade book besides the tests.

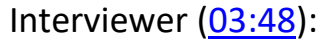

So what are the homework assignments? How are they structured?

Maddie (이:52):

It's through mastering A\&P. So I believe they're around like 150 questions. So you kind of just do it as you go along... So I don't have to like cram it all in like a few days before. And there's just questions basically on everything that we've learned, there's like diagrams and I think like true or false or things 
like that. And then you get a point if you get the question correctly, but if you don't, you get like three more times to do it.

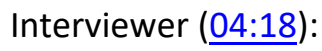

So how do you feel that affects your learning? Like you mentioned getting the points. I'm not concerned about points.

Maddie (04:24):

Yes, yes. It's it's nice to have the points but also it helps me study a lot with the tests. It helps me see what the questions will be like possibly on the test.

Maddie (04:37):

So I don't know. I'm more of like a practice learner... Like I have to like do tons of like interactive things where like I rewrite my notes. I do obviously do the homework, so it helps me.

Interviewer (며:47):

Yeah.

Interviewer (며:47):

Cool. Um, so do you feel like you understand some areas of A\&P more than others?

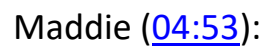

Um, I don't know... Because when I was in high school we more went over I guess... Like the first couple of units I felt like I understood more because I also have a minor in chemistry too. So like the chemistry unit, I knew a lot more just because I've been through so many chemistry classes and it was more of like 
the like basic chemistry that we were going over. So that was like more of a review for me. Um, I guess like the tissues too I remembered that from high school.

Maddie (모:22):

Um, just like, I guess the bones helped me a lot too. But then there's such certain things that I couldn't remember as well from high school that I had to really brush up on. And now we're in the, um, nervous system unit and we didn't really do much of that in high school, so that's kind of all new for me. So that was a little bit more challenging.

Interviewer (오:37):

So you're saying that the stuff that you did in high school was review, was there something done specifically in your high school class that helped?

Maddie (무:46):

Well I was in a two hour class, so I guess I kind of got more material. Um, my teacher also gave us like her power points. Like I still have those, I still have my notes from high school, so that helps a lot. Also, I was in the two hour course for the first semester. We got to shadow in the hospital. I got to see a lot of this stuff. So I think that also helped me. Um, and then second semester we just had a two hour class only, so we just got a lot of materials.

Interviewer (ㅁ:10):

Okay, cool. Um, so if you were to have to like do a survey or an inventory of all of your A\&P knowledge, what areas do you think are the strongest and which are the weakest? Like you mentioned the nervous system.

Maddie (으:25): 
Yes. Um, I would say l'd say so far the nervous system since probably been the most difficult just because yes, I didn't cover it, but also it's hard for me to visualize as much because there's just so much, like it's hard for me to visualize it where I think when we went over like the bones and stuff, I could, okay this bone was here, this bone was here. Like it's hard for me to try to find like the areas of the brain I guess that these nerves are in.

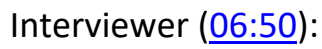

So I think that if you like literally feel your nerve, I mean that can cause pains. Um, okay. So how do you feel about the amount of content in the course? Like you, it sounds like you've mentioned before that you really like how detailed things are. Can you say more about that?

Maddie (무:10):

Yes. Um, so I really like the way the lecture is. It's a little fast because we only have it twice a week for only like a few hours. So it's very fast paced. But I do like the amount of notes that we get cause it helps me like really know the details. Like I said, I really liked the details cause I feel like if you just get a broad overview of something you don't really know, like I don't feel like you should be memorizing it. I feel like you should be able to apply it to like your own, like body or other people's.

Interviewer (무:37):

So, so how does the detail help you apply it?

Maddie (무:41):

Um, so just knowing it, I feel like, I don't know. It helps me. I don't know its hard to describe it. I don't know.

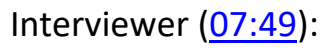


Here is why I ask, so maybe you could just enlighten... A lot of people feel like there's so much detail that they're just memorizing in triage to stay afloat and that doesn't leave anything left to be able to apply it to anything. It seems like there's just so much to know.

Maddie (요:09):

Gotcha. Yeah, I understand that. Um, yeah, certain parts of it I definitely feel like overwhelmed with, I guess like this chapter, like we didn't have as much material, but I still feel overwhelmed because it's harder for me to grasp. But then the other units that we've had... I do like that I can look back on my notes and then with the amount of detail, it's more like I'm still in the lecture and I'm still like, I can read it and still like understand what's going on.

Maddie (요:35):

Like I didn't just write the notes super quickly and then like look back and not even know what I even wrote. So that.

Interviewer (요:40):

So if you were to have to like tutor or provide advice to someone who's in this boat where they feel like there's so much detail, I can't, it doesn't allow me to apply. How... What would you do? To like tutor them?

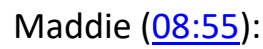

I would say to start early... With studying, like, especially with the homework, cause there's a lot of questions. It's like 150 or like around that much. It's usually around a hundred for each one.

Maddie (이:05):

So it's actually due like the day of the test. The homework and all. 
Interviewer (09:11):

So it's like one homework per unit?

Maddie (무:13):

Yes, exactly. There's like one assignment per unit and everything. Like the... How you make up your own questions per unit. So I always try to start early.

Maddie (무:21):

I know it's hard just because all the other classes that I have, I'm sure other people have like... Just I'll test every single week. So it's always difficult for me. But I think just start early, taking like an hour after the lecture just to like do some of the homework that you know, like as you go along it's not as overwhelming in the long run. So I think studying early. I like to write things down. So between flash cards, I like to write, I know to like to fill the diagrams, like I just do a lot to study for it. But I guess it depends on what study habits another person will have or what helps them.

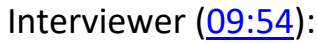

Well, that was kind of my next question is what is the relationship between the amount of information and how you study?

Maddie (10:05):

Um, it's definitely a lot of information. Um, I don't, I just try to.

Interviewer (10:11):

Like you already said like you start early.

Maddie (10:12): 
Yes.

Interviewer (10:12):

Um, what else?

Maddie (10:13):

Yeah, so I start early. Um, like I said to, I like to go through the book, I like to look at all the figures because even though we kind of have the figures in class, but sometimes we'll get like the notes just cause not everything could fit in the lecture and it'll talk about like this area of the brain and we don't have a figure for it... So I like to look in the book to see it cause then I can actually visualize what it is that I'm learning. So that helps me a lot. Like I said, the note cards helped me because not only am I just writing it down again, but I'm also then going back to the note cards and quizzing myself.

Interviewer (10:43):

Cool. Um, so it sounds like my next question doesn't really apply cause you've already talked about this. My question is what is your strategy for learning the content? But it sounds like your multiple strategies.

Maddie (10:55):

Yes. Um, I do that with every class. So like I guess it depends on the class too, but I've always just been like that with studying. I have to do multiple things... I mean that'd be nice if I had like a photographic memory or something. But yeah, it just helps me like going through them over and over again to learn it, not just memorize it, which is what I like to do.

Interviewer (11:20):

Um, so do you feel like the way that the course is organized, is it organized in such a way that it really develops you understand the material? 
Maddie (11:31):

I believe so. I think I would say like, the only thing that I, I guess don't particularly like about the course is that we don't, I mean I guess that's with any course, we don't have a lot of time to go through. So it is kind of rushed, including in lab too. It's sometimes very rushed just because we only have it one day a week for like two hours. So you have to get everything in. So sometimes it's hard to like... That's why I do have to go back on my notes like a lot. Even like right after the lab or right after the lecture because I just like writing it down but I have to go back and like really look at it cause it's super fast.

Interviewer (12:02):

So when I mentioned organization you kind of went into timing, there's not really time to fit everything in. Um, what about how it's organized by unit? Like for example, it sounds like you have units based off of systems.

Maddie (12:21):

Yes, I really like it that way just because you're focusing on one thing and you're not like applying it. Like we're not doing like bones with the nervous system together. Cause that would even make it more stressful trying to figure everything out. So I do like the way that the notes are organized, like the lectures and just like the units in general.

Interviewer (12:38):

How can you think of any benefits that there would be if it were organized by saying um, I dunno head and then you started everything about the head, and it had all the muscles, all the bones, all in all.

Maddie (12:51): 
I think it would be beneficial. Um, especially for me just with like wanting to be like a dentist, orthodontist, especially the head area cause I'm going to have to know like shoulders up most of it. And we haven't really gotten into that or maybe we, like we in other systems or units but, I think it would be beneficial both ways.

Interviewer (13:15):

So I have a question. This is totally again, me going off script.

Interviewer (13:22):

So like right now you're learning it unit by unit, you know, like system by system. And I'm wondering like for example, when you're learning the nerves right now, um, are you able to, because you've already covered the muscles in the bones, can you then use them as landmarks for learning the nerves?

Maddie (13:42):

Yes. Cause a lot of the names are like similar and like I really enjoy like including my teacher does a lot of like the Latin roots. And I learned that in high school too. Like Latin roots, It really helps, it's helped me in science a lot knowing that kind of stuff. So yeah, I think like knowing like the bones or even the muscles, like you could then take that name and it shows up again like in the head or shows up again like somewhere else.

Interviewer (14:06):

So you're saying the Latin roots can kind of serve as the links between and systems?

Maddie (14:11):

Yeah. 
Interviewer (14:12):

Cool. All right. So, um, my next question is do you remember the material from previous units?

Maddie (14:18):

Um, I would say so, yes.

Interviewer (14:20):

And then, what would help you to better remember that material? So then it really kind of, you can like build on top of it. Just like you were saying, the Latin roots. Is there a way that we could better facilitate? Like you've learned this, know let's build on that as a foundation.

Maddie (14:40):

I'm not sure. It's... I know it's so hard to fit everything in. I do think that I remember a lot from past units but I don't think that I remember everything from past units just because I'm constantly learning more... Then I take a test and then I'm learning another thing... Then I take a test and it's just like constant and it's like that in every class... So that's always been a struggle for me is like I guess remembering everything. But I'm trying to think of like a way that would make it better cause I know we don't have a lot of time in the course... But like even like a review of like past units are like things that would be beneficial.

Maddie (15:15):

I know like everything you should know for like med school or something like that... but like little things that would be beneficial that probably show up on like the MCAT or like the DAT or something like that. That' $d$ be nice to have like a review session of like old units. It doesn't have to be like during class time, but like another day. That's like optional for people. I would really like that. 
Interviewer (15:32):

So do you feel like the units inherently build off of each other? Like even if the instructors don't have time to like review and all of the information from before? Like does the content build off itself?

Maddie (15:44):

I think so. Yeah. Cause we had um, we started off in the bones and then you learned that stuff and then it made the muscles easier to learn cause the names are very similar. So I think we are building off of it.

Speaker 1 (15:55):

So I think that's why I do remember like a lot from past units... Rather than like just forgetting all of it, all together.

Interviewer (16:01):

Okay. So, um, we're gonna turn specifically to the unit on bones and muscles. So how do you feel about the unit in general?

Maddie (16:10):

Um, I really liked it. Um, we did that one little bit ago. That was like two units ago. The muscles were a little bit more challenging. That was probably like... I still did good on it... But that was probably like my worst test so far just cause there were so many and it was a week that I had like a ton of other tests. So that also didn't help me at all. But um, yeah I thought like my teacher, she went over all of them in like class and she gave us like PowerPoints with like interactive ones that we could do.

Maddie (16:39):

She even gave us an extra assignment for extra credit for the muscles. That was just like going through them again for us. So like that extra practice helped with it but it was little more challenging. 
Interviewer (16:48):

So, um, what do you feel is the most important for you to know about bones and muscles as like a future orthodontist specifically for you? What is the most important?

Maddie (17:01):

I would say like for sure the locations and everything, that'Il definitely help. I'm assuming that a lot of things and like dental school will be like, the names will be similar or like you'll have to know like where this is and like the head or the mouth. So if the locations and yeah, the functions obviously too.

Interviewer (17:18):

Um, so do you feel like this particular unit was organized in a way that supports understanding that you need?

Maddie (17:27):

Kind of, this is were on the nervous system now and I think it was kind of, I know it's like kind of building, but it's hard for me to like connect it. Cause we were in like bones, muscles and now just like nervous is something different all together... So I think that was like a bigger jump than between bones and muscles. Like going from bones to muscles like that unit. But so it's a little more hard for me to it.

Interviewer (17:50):

Um, so is there anything as far as your organization that you would change in this unit?

Maddie (17:58):

So I wish we had more time. I don't think the test came up any quicker than the other ones, but I definitely felt like it was a lot quicker, like through the unit. Um, I also know that last class we didn't get to finish the notes, so that was kind of hard. So I had to go through them on my own, she gave us like 
the notes online so we had to go and like find them and like rewrite them ourselves. But it doesn't help me as much being in the class and learning it.

Interviewer (18:28):

What about lab?

Maddie (18:29):

Um, lab is rushed too, and it is only once a week and it is a lot of time in the lab. Like I definitely feel like I'm there for a long time throughout the day. But yeah, it just seems sometimes very rushed just with like everything that we have to learn. Like are last quiz, we had two weeks in between. We had two lab sessions before the next one came up and it was so fast. Yes.

Interviewer (18:57):

Yeah. Um, okay. So how do you feel about your ability to communicate this information. Like if you were to have to explain things...

Maddie (19:08):

Good. I know like Eric had to, he had us fill out like a survey just to see what he wanted to change. So I felt like I wrote a lot down, like my opinions on things with the lab. And then I know my teacher just had like a survey too, like a few weeks. I feel like I'm like, I'd rather tell somebody if like I want something to be different than it helps future classes and I don't feel like, I hope it doesn't like offend like anyone thinking a certain way. and I appreciate like Eric and my teacher, like wanting to make the course better because it shows me that they really care about like our grades and not even just our grades, but like us learning and like being able to apply that to like a future job or like future courses that we're going to take. 
Interviewer (19:53):

Yeah. Cool. Um, so what about like communicating specifically the information about bones and muscles? Like imagine if you have someone in your dental chair and you need to explain to them what, what's going on. Um, do you feel confident in explaining the concepts in class?

Maddie (20:12):

I would say so. Um, definitely not everything just because I don't remember everything from every unit, but I would feel confident on it. I'm also taking the second one, so I feel like that'll help a lot more to like really reinforce what I was learning. And then, yeah, I think that once I'm at a dental school, I'll get to see it too. What I will be, I guess applying from this course.

Interviewer (20:38):

Okay. So, um, what is the teaching style that you've experienced in amp? Like, how would you describe it?

Maddie (20:44):

I don't know. I don't know if I have like a good word for it, but, uh, I think it's very, like my teacher does a lot of memory cues and a lot of like going through like a process with like the nervous system and she was, um, explaining it, like comparing it to like money because a lot of people like work with money and we could like then apply it to that process. So I really enjoyed that. I also enjoy like the pictures, like she draws a lot too. She gives us a lot of diagrams. Like I'm very, I'm a very visual learner, so I like that of it.

Interviewer (21:18):

Um, what about lab lab?

Maddie (21:20): 
We kind of do the same thing. I just, it's more like actually seeing it like dissections and stuff. So I like that event.

Maddie (21:34):

I would say they're very similar. Um, I don't, I don't know. In lab, I mean Eric does draw like on the board and stuff, but we more have the pictures in the PowerPoints where like in lecture we don't always have them in the PowerPoint so she draws them herself. But I would say they're really similar with like their teaching style. I think that's why like I like learning from Eric and I also like learning from my teacher and then I can kind of like connect the two. And also like in lab we've had a lot of labs that have been before lecture, cause I have mine on Monday, so like it's usually before our Tuesday class.

Maddie (22:07):

So I do learn like, or at least start the learning process of like learning what we're going to cover in lecture. So I like that part of it too.

Interviewer (22:14):

So you like having that more hands on stuff before you get the lecture?

Maddie (22:20):

Yes.

Interviewer (22:20):

Why?

Maddie (22:20): 
I just see, I just think it's, it starts the process of me trying to learn it and then I can see it. And then when I'm in lecture I can think, Oh I, I saw that yesterday or I saw this few days ago. So.

Interviewer (22:32):

Cool. Um, is there anything that you would change about teaching style lab or lecture that would help you more?

Maddie (22:41):

Um, for lab I know that it's, like I said, it's really rushed and I know this is all just cause we don't have a lot of time. But I would change it more I guess for... Like I feel the lecture part of lab is very rushed. But then I also feel like sometimes at the end we don't have a lot of time to do the dissection or anything. So I guess like split up the time more evenly. But I know like I said, it's impossible to do so I understand that.

Maddie (23:05):

Um, and then in lecture, yes, sometimes it's rushed. Like the notes are like sometimes we don't finish the unit. Like I said before, the next test. So then we have to like go online and try to like find the notes and like that's fine. Like I don't mind doing that. It's just, I like learning it too, cause I don't feel like I'm really... I feel like I'm like cramming it in last minute or something.

Interviewer (23:27):

Okay. So, um, last questions are kind of general. Okay. So do you feel anatomical and physiological knowledge are important?

Maddie (23:37):

Yes. So especially with what the career I want to go to. So, yeah. 
Interviewer (23:41):

So why, I mean, why is it important generally and then specifically for you?

Maddie (23:45):

Um, well, generally if you want to be a doctor, I feel like you need to know that stuff. So how are you going to help them? If not? And then specifically I guess to me, yes. With my career and like what I want to go into, I'm going to need to know like specifically the shoulders up but I'm going to need to know everything too.

Interviewer (24:01):

Yeah. Um, so you do feel like that A\&P will play a role in your career...

Interviewer (24:11):

So do you feel like this course was structured in a way that enabled you to develop an understanding of the important aspects of $A \& P$ that are specific to your career?

Maddie (24:20):

Yes. Um, I know that we went through like muscles, bones and everything, so I think that will help me a lot. Um, we didn't spend a ton of time on like the facial stuff, just, I don't know if we're going to get to that at some point, but that's more what I'm going to be needing. So I guess that's one thing that we didn't go over it. Like we went over like a few bones in the face, but it wasn't like everything. So that's just something I guess that is just something that I'll learn in like anatomy two or something, or maybe dental school.

Interviewer (24:47):

All right. That's all I have. Is there anything else? Do you have any questions for me? 
Maddie (24:53):

Oh, no, don't think so. Okay. Alright, cool. Thank you very much. Let me turn this on.

Interviewer (00:05):

Alright. So my name's Interviewer, I'm a faculty member in biology. You are, you know, helping Eric in his degree, but you're also helping us to, um, you know, collect data that's really going to inform an anatomy and physiology education and hopefully improve it. So. Perfect. Um, keep in mind as we go through this interview, there are like, there are no right or wrong answers that are no, you know, we're really just looking for your honest assessment of what's going on in the class. Do you have any questions for me before we get started?

Margo (00:46):

No.

Interviewer (ㅁ00:46):

Okay. So generally speaking, how has the course?

Margo (무:52):

Um, it's definitely a lot, but I'm like excited because this is like one of my first like... Cause I'm a nursing major... So like this is one of the first like nursing type of classes. So like I'm more interested in it rather than like my Gen Eds where I was like this, does any of this even matter.

Interviewer (ㅁ1:11):

So what year are you?

Margo (01:13): 
I'm a sophomore. Yeah. So, um, being in this class, like I'm interested in it. So even though it might be like a lot of information or like sometimes complicated information, I'm interested in it. So it like makes it doable and sometimes enjoyable.

Interviewer $(\underline{01: 29})$ :

Oh, cool. Yeah. Um, so what about the lab portion specifically?

Margo (ㅁ1:33):

Um, the lab, I feel like it definitely helps, like being able to solidify what I learned in class or sometimes if we learn in lab before we learn in class, it'll like switch. So like when I'm in class, like, Oh, I just learned that in lab last week, which sometimes that could be frustrating... Like when I'm in lab learning it for the first time because I'm like, I haven't even learned this yet. And like this is my first time. But then like in the long run, I'm happy for it both ways. Like either learning it first in lab or in class, but both ways helps me solidify like the content that I'm learning.

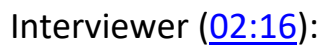

Okay. Yeah. So, um, do you think that there is like an advantage for your learning? If you have that hands on experience first and then you hear the lecture on it or vice versa like you, um, do you think you learn it better if you hear the lecture and then have hands on experience?

Margo (며:36):

So what I really like about lab is like we do a like little bit of lecture before just to kind of go over. I wish we could have more time with that because like the content and like the PowerPoints that they do are really helpful because then it helps. So in some way like a lecture based, it doesn't have to be necessarily in class, but like the lecture before, I like it when I know like what I'm actually looking at and like being 
able to piece it together. Cause sometimes when I'm just like thrown in lab and I get it, I'm like, I don't even know what this means. But so I feel like doing the lecture first, whether it be in lab or an actual lecture is more helpful than me that doing the other way first.

Interviewer $(\underline{03: 23})$ :

What is it about doing the hands on portion first that's uncomfortable? Like,

Margo (무:28):

I think because I like to know like exactly what I'm looking at and like exactly what it all means. And I think since I'm just so used to like traditional classroom settings that like doing it in like a non-traditional way like kind of makes me uncomfortable. So I'm like, wait, like I need to take notes on this first. I need to... So like it might just be from like schooling, like all these years. Like I'm not used to having labs like that first, but I definitely find it like helpful doing that after learning.

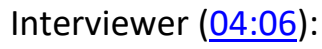

Yeah. Yeah. Despite the discomfort. Yeah.

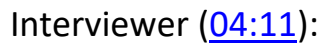

Okay. So how do you feel about your understanding of the content so far?

Margo (녀:15):

Um, I feel pretty good about it. Um, I feel like both in lecture and lab it's been helpful. Studying has been pretty straightforward. I feel like all the content is pretty straight forward.

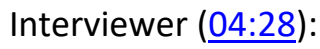

Is there, are there some areas of content that you understand better than others? 
Margo (04:34):

Yeah, and I think it's because I took like a very basic anatomy in high school. So like some things that I learned in that anatomy I have a better understanding of, but then obviously like the brand new stuff I feel a little iffy on, but it's just because of like my previous experience. Yeah.

Interviewer $(\underline{04: 53})$ :

Yeah. So what is, what are the content areas that you would have had had instruction on before?

Margo (며:59):

So, um, before like we went, we like went full in on like the skeletal system and just like straight up like naming. So like that was um, something that I felt really strong with. But then like like the muscles, like when we had to name all the muscles and like learn about like troponin and myosin complex. Like I was like... what does this even mean? But I just needed an extra at the level of like studying and looking over the content and then I felt a little better yeah after that.

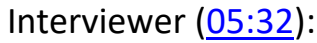

Okay. Um, so how do you feel about the amount of content in the course?

Margo (모:41):

It's a lot. It's definitely, it's doable, but I'm just lucky that like I feel confident in my other classes that I can really focus on this one because it is so much. Um, but it's doable. The next, like this upcoming week we have two lectures until our next test and then like after that we have another one. So I'm just like, Oh my gosh. And like she understands that as well. But um, it's doable. Like with my course schedule, like if I had other like really like work heavy classes, like I would be freaking out, but I'm lucky that I'm able to kind of like balance it all. 


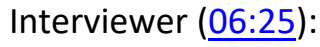

What are your other classes?

Margo (무:27):

Right now I'm taking lifespan development, fundamentals of nutrition, some kind of nutrition class, statistics just like MQM 100 and then, um, two online nursing classes. One was at the beginning of the semester and one's at the end.

Interviewer (으:47):

So not simultaneaously.

Margo (무:47):

No, yeah.

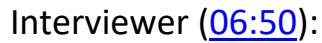

Okay. So what do you think is the relationship between how you study and the amount of information that's in this class?

Margo (ㅁ::57):

Um, so since there is so much information, I felt like for me, like normally I would wait a little bit until like, it gets closer to the test. But I've realized like, since there's so much information and since like we go through so much each lecture that like going home like that night and starting to study that and has been most helpful for me. And like, even though the test might be like two weeks away or two and a half weeks away, like it's most helpful for me, like just to start my study guide or like start like looking over things right after we'd learned that. 
Interviewer (무:37):

Yeah. So what, when you say you start studying, what do you do when you study?

Margo (무:42):

So luckily she gives us a study guide on kind of how to guide us with our studying. Its just like $20,30,40$ questions of what we should answer. So normally, um, I'll go through the PowerPoint and answer the questions that I can and then I'm really big in Quizzlet. Like I love Quizzlet. So then she says that the study guide is a nice guide, but really just you should know the PowerPoints. So I go through like each PowerPoint, like pick out, like which one... Which information from each one, like kind of stands out to me and seems like the most important to me. And then I make a Quizzlet through that and I feel like, um, even making the Quizzlet helps me study, like, not even like I'll go back and I'll actually like go through the Quizzlet like study each one and they'd show me the flash cards. But even like typing and creating it helps me study for sure. So that's like my main way of doing that.

Interviewer (요:45):

Cool. Yeah. Um, okay, so you've kind of already answered this, but I'll ask it. What is your strategy for learning the content in this course? Like, like how would you describe your strategy to someone else?

Margo (09:01):

So I would say, um, I go to class and have my PowerPoint...

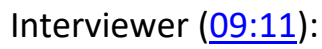

Does she make them available to you beforehand? You print them out?

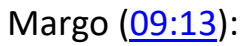


Yeah. So well, so since there's so much content and we go through it so quickly, there's actually like templates online. So like she like has like a couple of words like blocked out from them and we have to type them in. So I'll have that like downloaded on my computer and then I have like a notepad in front of me and like any, cause she does a lot of drawings as well. So I'll do like all the drawings in there. And then, um, like I was telling you after each class I'll go back and like review those drawings, make my Quizlet and like answering the study guide questions.

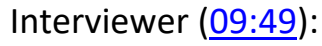

Yeah. Cool. Um, so how could all of this be facilitated? I mean it sounds like she's providing some resources for you already to facilitate how you go about learning. Um, is there anything else? Um,

\section{Margo (10:04):}

Well she also has, um, this like mastering A\&P website and it's a lot of questions. It's like 167 questions each test. But, and sometimes they're really complicated, but it does help. Like it's kind of like a self test, like being able to do like that homework each night and like challenging yourself with that. So that's definitely really helpful. And then also, um, we have to make like a mock test for each one. It's only 10 questions, but that has also been really helpful for me cause I have to go through all the PowerPoint slides and pick what I think is the most valuable for a test question and then make the test questions and stuff. So that, I'd say that besides like making my Quizzlet and stuff is probably like one of the most helpful. It can be like sometimes like... Oh my gosh, I have to make that like mock test, but then it ends up helping in the end for sure.

Interviewer (11:04):

Yeah. So is there anything that could facilitate your learning strategy that isn't happening in the course?

Margo (11:11): 
Honestly, no. I mean the only thing is like maybe more time, like for between each tests and sometimes I'm like, Oh I just wish like I could have like one more lecture, like one more, but like the amount of content that we need to cover... And like this is like A\&P one, like there's A\&P two already. So it's not like they can like split it up even more. But that's the only thing. But besides that, like all the things she has in place for us are really helpful and

Interviewer (11:43):

Um, so do you feel like this course is organized in a way that really develops your understanding material?

Margo (11:52):

Yeah, I've really liked the way that it's been organized cause like we started at the beginning like cellular level, like really small. And then we've kind of been like building up. And then once we've like built up we'll go to like each system. So we did like skeletal and muscular, now we're on like nervous. So it like makes sense in my head. Like being able to do that. And then the way it's been like built on, I'm able to draw on like, Oh, we learned that at the DNA this semester. So like that's why this works and that's why this helps that. So yeah, I definitely liked the way that it's structured.

Interviewer (12:27):

So what happens in class that allows you to call back that information you've covered before?

Margo (12:33):

Um, most of the time like she'll remind us like remember back in chapter two when we were talking about this, like this is where it ties in. And so like her giving a little bit of recall I think definitely helps.

Interviewer (12:47): 
kind of pointing out where the connections are.

Margo (12:49):

Yeah, yeah, exactly.

Interviewer (12:53):

Um, so my next question is, do you remember material from previous units?

Margo (12:57):

Yes. Yes I do. Yeah.

Interviewer (12:59):

Um, so what, besides her pointing out where the connections are, like what helps you to still remember that material?

Margo (13:08):

Um, I think just because of like how much work that we put into it, like on like the mock test and the mastering A\&P homework and then like my study guide. Like, it's almost like I have to force myself to forget if I wanted to. Like, it was just like ingrained in my brain so much through like all the things that we were doing that like I would have to be like, all right, you need to forget it. You know what I mean? Like I feel like I just worked with the content so much that it's like, it's just in my brain.

Interviewer (13:42):

Okay. So you do feel like the units build off of each other?

Margo (13:47): 
Yeah. Yeah. And like, even though like now it's like we're kinda like switching systems. Like it might not be like directly like building blocks but they all kind of relate. So like it doesn't just seem like we're just jumping from one to one. Like it all kinda connects and makes sense for me the way that it's laid out.

Interviewer (14:09):

Yeah. Cool. Good. Um, so how did you feel about the unit and bones and muscles specifically? Like you said, you had had that content before.

Margo (14:18):

Yeah. So for me, I just realized like this past test that we took was um, just on like the central nervous system and it was more about like theory instead of just like naming. So that I like theory like a lot more like, cause sometimes like memorizing for me, like it's just like difficult, like just like keep going through and going through. But like say for like the skeletal, I was like, Oh like I remember learning this and like it was at a lot slower pace when I was in high school. So like I remember a lot of it... But like the muscles, I was like, I don't even know. Like this is so tough. So it's not really much that like, like my professor like either of the lab instructors could have done cause it's really like at that point it's like you just need to memorize it. But that was just like different for me. Like just going through and memorizing all of that.

Interviewer (15:18):

So you feel like with the bones and muscles in particular, that particular content memorization is like what you got to do?

Margo (15:25): 
Yeah. Like, I mean, there might be ways, like sometimes there's like little like nuances that you could get from the words to like piece together, like what they all mean. But I feel like at that end of the day it's like you just need to sit down and like really study them and like see where they all are. Yeah.

Interviewer (15:45):

Okay. So what do you think is most important for you as a future nurse? Right, to understand about bones and muscles?

Margo (15:54):

Um, for me I think it's it was really interesting for me when we would learn about like the different diseases that were caused for bones and muscles. And I know I won't always be working with people who have diseases.

Margo (16:13):

They might just be perfectly healthy humans, but it's nice to know like that what causes what and what a different disease looks like in bones and muscles. So I felt like that was pretty helpful. Like when that would be thrown in there like, Oh, this is like what this looks like and all that. So I felt like that was pretty important for myself.

Interviewer (16:34):

So do you feel like this unit kind of developed that understanding that you will need regarding bones and muscles?

Margo (16:41):

Yeah, definitely develop it. I still feel like I need more building on it just because like it was so much content, but it definitely like laid down a good foundation. 
Interviewer (16:52):

Okay. Yeah. Um, so for this particular unit, did you feel like it was organized in such a way that developed your understanding? The understanding that you mean?

Margo (17:04):

Yeah, it was just a lot of information in a short amount of time, but it was like, it wasn't like it was super disorganized where I was like, I don't even know like where to start.

Margo (17:17):

It was just a lot of information.

Interviewer (17:18):

Okay. So how do you feel about your ability to communicate about bones and muscles?

Margo (17:25):

Um, I feel like I'm gonna need to look over it a little more and like kinda just study it a little more. Like I feel like to maybe like my mom or like my dad I would be able to like give information that like they wouldn't know. But like maybe talking to you or my professor you'd be like you need a little more help on that. So like maybe to like someone who's never learned this information I would be able to, but like someone who was knowledgeable in it, I would need a little better.

Interviewer (17:59):

Interesting because usually when someone's knowledgeable then it's like the conversation flows more freely.

Margo (18:04): 
Yeah. Well I would just think like you would just be like, you don't really know... And like in a nice way, you know what I mean?

Margo (18:14):

But like I feel like I'm at the level where like for lack of a better word, I could like dumb it down where it's like I could talk about it and like very general terms and then like say like my parents... they'd be like, Oh, okay. Like that makes sense. But like if they asked me a bunch of questions I'd be like, Oh, I don't really know. So I wouldn't be able to like teach them what I learned. But like very general terms, I feel like I could talk about it.

Interviewer (18:41):

So do you feel like it's important for you to be able to communicate this information?

Margo (18:46):

Oh yeah, for sure. I definitely think like, um, being able to talk about all this is important.

Interviewer (18:53):

Why?

Margo (18:53):

So just like, once I get into like deeper into my profession, like I want to be able to be knowledgeable and not be like uhhh that muscle on your back. It's it's kind of stretched out of place. Like I would just like to be able to talk knowledgeably about it.

Interviewer (19:17):

So what is the teaching styles that you feel like you've experienced? 
Margo (19:22):

I would say it's very much... She definitely has a plan of like how the lecture will go and she'll just go through it. But what I like about it is she will make it interactive if she needs it to be. So like if I raise my hand right away, she'll answer my question. So at least for me it feels very interactive. Like I don't know how other students will feel about it. I just know, like if I have a question, I'm like, I don't care. I'm just going to raise my hand. So for me it's very interactive and interactive also in the way that like you better be like on your A game when you're doing your PowerPoints cause... It is like she's doing a lot of content so like you can't be like shopping online or like going anything like that.

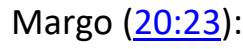

Like even if I wanted to I couldn't because I've missed like three or four slides. So it's definitely like you're locked in the whole time.

Interviewer (20:31):

What about lab?

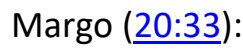

Lab... it's kind of the same way as sometimes with um, lecture just because of like the time that we have like the lecture portion at the beginning of lab. Um, it feels like a little rushed... Just because it isn't a lecture, it's lab, like we're trying to get to the part, which makes sense. But for me like I want to like be able to like take more notes and understand it. So like sometimes I wish the that could be more available or even like the slideshows that we do at the beginning of lab. Like, I wish we could have those as well because those aren't available to us. But, um, it's very interactive as well. Like I feel like if I ever had a question, I would get an answered right away with like, no, like sass or push-back. Like they're both happy to do so. Yeah. 
Interviewer (21:26):

Yeah. All right. Um, so my next question is does this teaching style help or hinder your learning? It sounds like you're happy with how it supports your learning. Can you just kind of summarize why that is?

Margo (21:39):

Um, for me, I'm very much someone who's like, I'm into the traditional, um, school way of learning. So I've just been used to lecture and taking notes and answering questions and the pace is a little bit different for me. But besides that, everything, um, really works to my liking, thankfully.

Interviewer (22:03):

Is there anything that could better support your learning that isn't happening?

Margo (22:08):

Um, just like the pace sometimes, but that's hard to ask for. It's not like a horrible, like, it's not like I wish I had like three more weeks for each one. Like, sometimes I'm just like, I just wish I have one more day to study or, and that might just be me as well.

Margo (22:26):

But um, besides that, not really. Yeah.

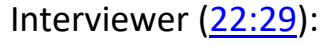

So I already know the answer to this, but, so do you think that anatomical and physiological knowledge is important?

Margo (22:39): 
Yes, for sure. Yeah. Um, for me specifically that's just like will be the foundation for like my whole profession, but just in general, I feel like it's just good to know like your own body and like what's going on and like how it all works and how to how everything is supposed to work and how you should like be taking care of everything. So I definitely think it's really important.

Interviewer (23:05):

Okay. Yeah. So, um, do you feel like this course is structured in a way that enabled you to develop, um, understanding of those important aspects?

Margo (23:16):

Yes, for sure. Um, and it's definitely a lot of the courses, like the effort that you want to put in is what you're going to get out of it. That's like with any course. But this one like for sure like its not just going to be handed to you... both in lab and in lecture there's a lot of support for you. But like if you don't take that support then like nothing's going to happen. There's no free handouts here.

Interviewer (23:49):

Yeah. All right. I have one more question that's not on my list poor Eric. He's like, Interviewer, what are you doing?

Margo (23:57):

Yeah,

Interviewer (23:58):

it's funny, throughout this whole interview you've kind of described several times of how you really enjoy lecture and enjoy traditional instruction. I'm curious how you think your transition to nursing is going to be because in nursing, you know, nothing is a lecture. It's all hands on, all like on the fly while 
you're trying to do stuff, you're talking about the content of whatever it is, you know. So how's it going to go?

Margo (24:30):

Um, I don't know. Definitely be different, but labs like this and further clinical experience and SIM labs will hopefully help me break that. But yeah, we have a SIM lab. It's right behind the Bone.

Interviewer (24:45):

Oh yeah I forget about that.

Margo (24:47):

Yeah, it's pretty new I think like within the past couple of years. So hopefully with that I'll be more comfortable with it. I think just like one of my flaws as well. It's just like perfectionism is like in my blood. So if I'm like, if I don't know the right exact answer, like from the textbook, from the PowerPoint, like it's hard for me, but obviously like I won't have my textbook out. Like when someone's like coding and I'm like, wait one second. I'm like, so it'll definitely just be a learning process. And breaking that habit of liking the traditional setting.

Interviewer (25:21):

Do you feel like there's always a right answer? Like especially in the clinical setting?

Margo (르:26):

Um, I feel like there's definitely like, I don't know, it's because I had like our nclex... It's like a multiple choice A through E. all of them could be correct. But which one is the most correct? So I feel like, yes, there's a most correct answer, but it's not like you'll be wrong if you pick another way to do something. And that's also, that could go with other things as like bedside manner or like even small things like that. 
Like some people just have different styles of teaching nursing, like anything. Like there's no like right or wrong way, but sometimes there is like better ways.

Interviewer (26:21):

Well yeah. Well it sounds like you have an exciting career.

Margo (ㄹ:25):

Yeah, I'm excited. This has been like this semester it's just been like, feels like a kickstart almost. And like I'm not being like thrown to the wall of Seattle, which I know will definitely happen. We'll be prepared for it. Yeah, exactly. Yeah, exactly. Cause everyone's like, just wait til your junior year. Like you'll have no life. Like I've God.

Interviewer (26:48):

Okay. Yeah. Do you have any questions for me?

Margo (26:53):

No, I'm not. How is this? Um, so like how is this working? Like what has, yeah, I'm just curious like what he's up to and yeah, basically

Interviewer (27:03):

he, so he and I have been really trying to him more than me. Um, cause his expertise is anatomy and physiology. Like that's what his, um, well his bachelor's is in kinesiology but then, uh, you know, he has been teaching anatomy and physiology since he started as a graduate student and um, maybe it was exercise science, I can't even remember now. Um, he's, it's been a couple of years but the point is is that um, he is really trying to like structure, um, anatomy instruction so that it helps students to think about function along with form at the same time. And when he can get students to do that, does that help 
them deal with all of the, of the amount of information? I mean we know that anatomy, physiology has a ton of information, but it's kind of like, um, you can think of it as like a whole bunch of marbles or you can think of it as like kind of nodes in a network.

Interviewer (28:13):

And if you know where to put the marble in the network, then if you can attach it to something, then it's like, it's more likely to stick. It's more like you're more likely to understand it from different perspectives. And so he's trying to structure it instruction so that it really, um, students don't just think of the memorization of all the marbles, but instead they like kind of build a mental model for how things fit in and, and doing that by linking structure, structure and function. Um, so, Mmm. He is looking specifically at the bones and muscles unit just because there's so much content. So that's why I asked about that one specifically.

Margo (28:59):

Yeah. Yeah. Interesting. Yeah. That's cool. I like that. He's so passionate about that. Yeah. That's really cool. Yeah. Cool.

Interviewer (29:07):

Any other questions for me?

Margo (29:09):

No. Yeah. Yeah. Alright. Well thank you very much. Thank you. Yeah. Sorry about that. Mix up. Oh, no, that's okay.

Interviewer (ㅁ:05):

Right. 
Interviewer (ㅁ00:06):

So my name Interviewer darner, um, I am faculty member in biology. I'm also the director of CeMaST, which is why we're here. And, um, firstly I just want to thank you for being willing to do this. Um, you know, you're, you're helping Eric get his degree, which is awesome. Um, but you're also really giving us feedback that will help us to improve the quality of an instruction. So that's really awesome too. So thank you. Um, I'm going to ask some questions and I just want to remind you that this isn't a test. We really just want your honest feedback.

Simone (00:44):

Okay.

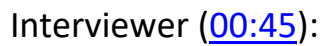

Um, so there are no right or wrong answers or anything. And, um, do you have any questions for me before we get started?

Simone (00:54):

Nope. Nope.

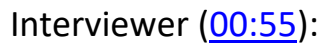

Okay. So generally speaking, how's the course going?

Simone (00:57):

Um. pretty well. Yeah.

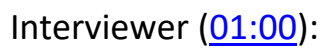

Yeah? Can you say more? 
Simone (미:00):

Um, like with the last couple of tests I did well. The last test we took, I did not do so hot, but that was kind of my own fault. I wasn't ready, I just had like some stuff going on, so like it wasn't really, um, cause of the instruction or anything. But like personally I've been doing pretty well.

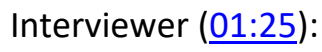

Okay.

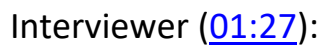

Um, so what about the lab course in particular?

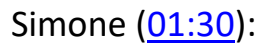

Um, I am like... Okay, in the lab and I've gotten like D's or C's lab quizzes, which isn't bad, but usually I do better.

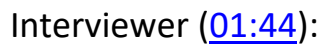

Yeah. So how do you feel about your understanding of the course? Like you've talked about grades a little bit. What about your learning of the material?

Simone (미:52):

Um, yeah, I think it, it's like set up in a way that kinda like builds on to what you learned at the beginning, like kind of all like builds onto it. So I think that's really good. Like I feel like I can tell that I'm connecting things that I already knew and learning new things. So I think it's set up really well in that way.

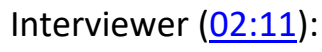


Okay, cool. Um, so do you understand some areas of amp more than others?

Simone (미:19):

Mmm, yeah, I guess I kind of like have like a photographic memory, I feel like. So I'm like, okay with learning like diagrams and stuff, but like if you asked me like a more physiology based question, it might be a little harder for me.

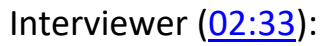

Okay.

Simone (미:34):

Just personally I'm better with anatomy than physiology.

Interviewer (으:37):

All right. So it's like learning the diagrams and having a visual is easier for you?

Simone $(\underline{02: 43})$ :

Yeah.

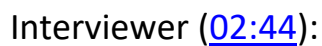

Okay. Um, so you're saying that that kind of means that you end up knowing anatomy more than physiology?

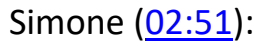

Yeah. Unless like the physiology comes with... well I guess like Betsy will draw out diagrams and stuff. So I think that really helps understand that, and helps me understand at least. 


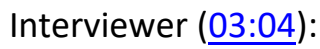

So she draws the diagrams for like physiological processing, you'd see?

Simone (무:08):

Yeah.

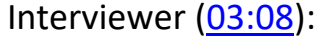

So it's like, just trying to understand the diagrams that she draws? Are they like flow chart type thing? Or like?

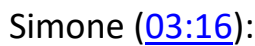

Just for like right now we're talking about the nerves. So like just kind of, instead of being like, Oh, this is what happens. And then they synapser over here and whatever, like she kinda draws it out, she'll draw like a neuron and then shows like where things are happening.

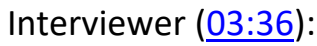

Okay. Um, so how do you feel about the amount of content in this course?

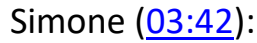

I think it's like average, like it's what you'd expect for a college level over course.

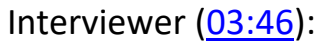

Okay. Um, so what is the relationship do you think between the amount of content in the course and how you study?

Simone (무:56): 
I don't know. Um, I tried to study like as I learned new material, like after class and stuff instead of like... It's definitely enough material that you cannot cram, which you shouldn't, but it's like definitely enough material that you need to be like studying throughout. You can't just like learn it right before a test.

Interviewer (며:28):

Yeah.

Simone (며:28):

But the tests are like, well enough spaced out. I think that there's time to learn and process them.

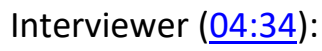

Okay. Um, and so generally, what is your strategy for learning the content? What do you do?

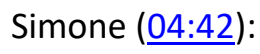

Um, for me personally, I will go through the the PowerPoints a lot and I'll use the lab manual as well that we have, cause there's like diagrams and additional questions in there. A lot of times I'll make like a Quizzlet or flash cards or whatever. Um, and then, uh, she also provides like review sheets. So those really help.

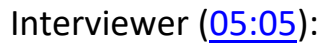

What did you do with the review sheets?

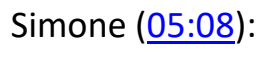

Um, typically I try to like fill them out just as much as I can and then like I'll go back and just like pretty much add as much as I can to like one simple topic. So even if it's just...

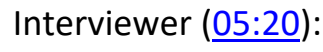


Based off your memory?

Simone (무:22):

Mhmm, and then I'll go back and like add in stuff from the slides and whatnot. Yeah.

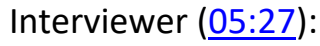

Okay.

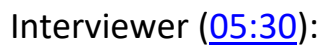

Um, so do you feel like this course is organized in a way that develops your understanding of the material?

Simone (모:35):

Yeah, definitely.

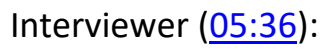

Okay. Why?

Simone (05:37):

Um, like I was saying earlier, like I feel like it kind of builds onto it. Um, I think it's good that she has a, um, like an assignment due that we kind of make our own questions. I think that's kind of cool, um, that we do that. And so we have to like go through and kind of find things that we think she might ask us questions on. And um, and then there's like using the mastering A\&P site that we have to buy for the course. I think that that really helps as well. You can kind of practice with that. And then we have homework on that as well. So I think it's like enough assignments.

Interviewer (ㅁ:13): 
What do you do in mastering A\&P, to practice like aside from the homework?

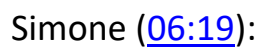

Um, aside from the homework, it helps that, well I guess just like the textbook in general, it helps that I read that. And then you can also do, um, there's like dynamic learning modules, I think it's called. And I usually do those, um, that just goes through with like each chapter and then kind of ask questions and they're usually way more like in depth than she even goes. Cause it's like you've got 50 questions on one chapter, so it kind of goes through a lot. But then I think it kind of builds on my understanding. So I like having that available.

Interviewer (으:50):

Yeah. So I'm curious, I've never seen these dynamic learning modules, but do they, um, what is dynamic about them Do you know?

Simone (ㅁ::01):

Um, it's just kinda like that they will, so it asks a question and then it has you like click once if you are sure and twice if you're not sure or, or sorry once if you're not sure twice if you're sure. And so then if you click it once and you get it right but you're like not sure about it, it'll ask you it again later on. And if you get it, like if you get it right then and you put that you were sure, then it doesn't ask again. And if you get it wrong then it asks again. So it like brings back up things that you miss.

Interviewer (무:37):

Cool.

Simone (무:38): 
And then it also has you do some things that are more than just like answering questions, like you'll fill in diagrams or whatever.

Interviewer (무:44):

Yeah. That's awesome. Um, okay, so do you remember material from previous units in this course?

Simone (무:53):

Yeah, I would say so.

Interviewer (무:54):

Yeah. Um, is there, so what is it about the course that helps you remember stuff from previous students?

Simone (요:04):

Um, like I said, I'm kind of like a very visual learner, so I think I can remember stuff that she's like explicitly like drawn out or um, like questions that have been asked in the past. Um, like on tests or on a lab quiz. Like I feel like I'm more likely to remember those things then or like something that showed up on homework, then something maybe that didn't. So I feel like if I have to like put it to use, then I'm more likely to do it, to remember it. And I think that helps. As it goes on, I'll remember the things that were asked and that she doesn't only do like a couple of tests or a couple quizzes, like there's like six tests. So I think that's like six different opportunities to test my knowledge and then like I'm more likely to remember those I think.

Interviewer (묘:56):

$\mathrm{Hmm}$. Cool. So do you think that the units build off of each other? Like you've mentioned that they do. How so? 
Simone (무:04):

Um, like we started at the beginning with like, just really like kind of like basic anatomy and the general terms you need to know.

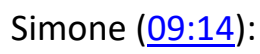

And then those like keep coming back up or different like parts of the body that you learn about in general or like, for instance, like you learn the different kinds of muscles and you learn like where they are and then now we're learning about like the nerves and how they work with those different kinds of muscles. But like if we hadn't learned about the muscles or where they were, we wouldn't really understand. Like, oh this nerve, it like goes to a skeletal muscle. Like you wouldn't really understand that. So like I think it just kind of all, it's like set up in a way that you'll learn, like kind of basic stuff first and then it kind of builds on.

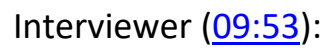

Cool. So how do you feel about the unit on bones and muscles specifically? How does that go for you?

Interviewer (10:00):

Well.

Interviewer (10:00):

Yeah. Yeah. Why?

Interviewer (10:03):

Um, cause I kinda just like memorized all those structures. And just spent a lot of time with those. Um, so I did pretty well on that portion of it. Okay. I was really nervous at first. It's very overwhelming. And I 
know talking to a lot of my classmates, they were very overwhelmed cause it's just like so much in one unit. And then you might learn, you know, 10 different diagrams.

Interviewer (ㅁ00:00):

Interviewer (00:06):

So you were talking about how bones and muscles unit was a lot. It was really overwhelming at first, but then in the end you felt like it went well.

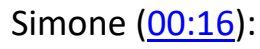

Yeah.

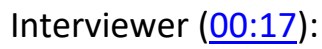

How, how did you get through it? Like how did it end up going?

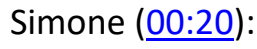

Well, um, honestly I did better on like the tests and stuff than I thought I did, which kind of was just more like... Not really guessing, but like there were a lot of questions that I was like, I'm not totally sure about that. But then seeing that like I got them right proves that I kind of knew more than I thought I did. Um, but just, it was just kind of a lot, like I just spent a whole lot of time with the diagrams and the terms and stuff like that.

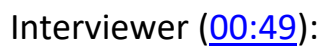

So whst did you do with the diagrams that when you're studying? 
Simone (00:51):

Um, I kind of like, I do them in the lab manual and then like, she provides them on a review sheet too. So I usually print those out and label them. And then I'Il kind of, um, one thing I did was like, I would go through and like highlight them on different diagrams, excuse me, or I would, um, like go through and like, if they were different diagrams, like I would go through on like, uh, like in the lab manual and with the ones I printed out and be like, Oh, here's this bone here and here's it from a different angle and like kind of like match them up.

Simone (미:29):

Like I would compare them.

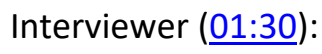

Interesting.

Simone (미:30):

So I think that kinda like helped me. So I wasn't just like, then if that exact diagram wasn't the one on the test, like I'd still kind of know what I was talking about.

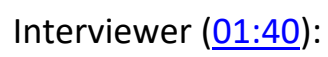

Right. So basically having different perspectives on the same structure in different angles helps you to figure it out, okay. So I never asked, what is your major?

Simone (미:54):

Nursing.

Interviewer (ㅁ1:54): 
Okay. So what do you think is the most important for you as a future nurse to know about bones and muscles?

Simone (미:02):

Um, I mean, I think as I just said, that I'm worse at the physiology part, but like I think that's the more important part. Like, um, just knowing like what the body is supposed to be doing. Cause a lot of people go to nurses if their body's not doing what it's supposed to be doing. So I think just kind of knowing that'Il help me to understand like what's going on with them, why they might be having pain or why they might be uncomfortable and just like overall like how things were supposed to work so that I can try to like provide that for them.

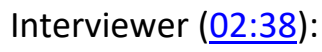

Okay. So do you feel like this unit developed that understanding that you find most important regarding the of bones and muscles?

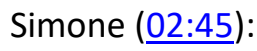

Yeah. Like, um, how, just like in general, I guess learning how, um, like different muscles well knowing like where they are is important in general, but then like just, I guess I like, it's one of those things like, you know, but I didn't take anatomy in high school so this was all kind of like a new thing to me. Like I knew generally, but, um, just like kind of learning just how they worked and I even found myself using it. Um, cause I work at a nursing home. So I think kind of saw myself, like a resident asked me something, I was like, Oh yeah, no that's, that's like a reflex as you know, this is why that happens.

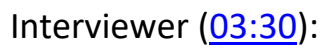

Cool. 


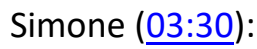

Like without even really realizing it, I've already kind of like learned, I've been able to use it.

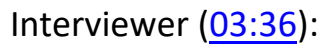

Cool. So you've kind of touched on this already with your, your example, but how do you feel about your ability to communicate this information about bones and muscles?

Simone $(\underline{03: 45)})$

Yeah, I think like it's kind of one of those things like I'm kind of able to do it without even like trying I guess. And then like we learned something the other day about, um, referred pain. Like how like you have a heart attack, you might feel it in your arm. And I thought that was just like the coolest thing. So I like texted my mom to tell her about it cause I'm like, Hey, I bet you didn't know this is why that happened. And so like I feel like I'm able to like communicate it well with, with things that I learned.

Interviewer (며:14):

Yeah. Cool. Um, so do you feel like it's important to be able to communicate this information?

Simone (며:21):

I mean, yeah, definitely.

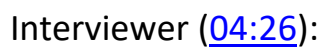

Okay, why?

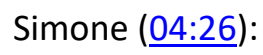

Um, well as a nursing major for sure. Like it's important to be able to explain to people what's going on with them. Like why they might be feeling the way they're feeling or you know, having the symptoms 
they're having. Like the doctor might tell them what's going on but like they are going to need a nurse to like explain why or like what, what might help. Yeah.

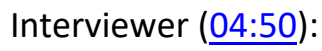

Yeah. A lot of times nurses are the more approachable ones, they get the questions. So how would you describe the teaching style that you've experienced? In A\&P?

Simone (모:02):

Um, in a lecture or lab?

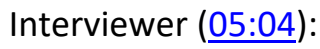

Lab actually, but both, lab is what we're most interested in. But if you could comment about, that'd be awesome.

Simone $(\underline{05: 11})$ :

Okay. Um, so in lecture I think it's really like, just overall, like this kind of straight forward she gives us the PowerPoints and we fill them out and that's, yeah, that's how we learn. That's whatever.

Simone (모:24):

Um, with the lab, I'm not quite as crazy about cause they do a PowerPoint and like kinda teach us some stuff, but we don't have access to the PowerPoints, which I know a lot of other people in the class have been kinda like...

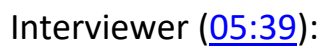

I've had heard that a lot.

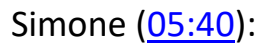


We need to have this because it's like, it's great and it's very in depth kind of even sometimes more in depth than she goes in class or just like, just different cause it's like, okay, here's this exact thing you're going to be looking at or testing and here's like, why, but we don't have access to that. So like I guess that's the frustration. But like just I guess what you asked teaching style... Its like good. Like I like that they go through and teach you, um, kinda like before you do. Um, like right now we're doing like cranial nerve so she'll teach about the cranial nerves and what they do and like the different pathways or whatever.

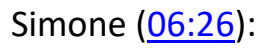

And then you kind of test like, Oh, here, now we'll look at your pupils dilate, now look at, you know, this reflex or whatever.

Interviewer (으:32):

So, yeah. So you kind of have this mini lecture and then like a more practical hands on.

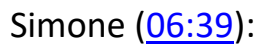

Yeah.

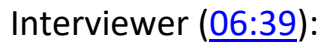

Okay. And you like that and you would, you would prefer that order over the other order?

Simone (ㅁ:6):

Oh yeah, definitely. Yeah.

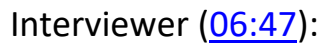

Why is that do you think? 
Simone (ㅁ:8):

Um, I think it's just like important to know what you're doing before you do it rather than like, I mean maybe, maybe other people would like it better, I don't know. But for me personally, like I like learning about it first and then kind of putting a more practical, um, application to it, cause then I think it helps build onto it.

Interviewer (무:14):

Um, so do you, is there a teaching style that would better support your learning in either lab or lecture or do you feel well supported?

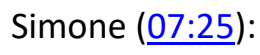

Mmm, not necessarily that I can think of. Sorry, this not much help, but I mean it's, we're on the right track.

Interviewer (무:36):

Um, okay. So, um, I already know the answer to this, but I'm going to ask. Is anatomical and physiological knowledge important?

Simone $(\underline{07: 43})$ :

Yeah, my, um, I think as like, as a nursing major, it's important. Like it's like the foundation of all the things that we're gonna learn in nursing school. Like it's really important to know about the body and what it does. And like, I think doing like, um, like in lab, um, how we get like hands on experience with like bone models or like we get to look at things on the microscope, like stuff like that. Its I think really like beneficial and I think it'll help once I get to my nursing courses as well. Um, but then also just in 
general, just like knowing like what's going on with your body and why something might be happening or not happening or, you know, whatever.

Simone (요:24):

I think just like baseline, it's just something that people should know.

Interviewer (요:30):

Like awareness of their own body?

New Speaker (요:32):

Yeah.

Interviewer (요:32):

Okay. So do you feel that this course is structured in a way that enabled you to develop understanding of those important aspects?

Simone $(\underline{08: 43})$ :

Yes. Yeah. Um, I feel like I'm repeating myself.

Interviewer (요:47):

That's okay.

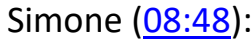

Um, but just like, I guess, um, it like kind of the way that we start with the most basic and then build on and, uh, just like able to connect those to things I already know, like, my body does this and then here's 
why. Or like, I have this reflex, here's why, here's how that works. Like, just build onto stuff you either already knew but you might not know why or like just.

New Speaker (며:20):

Other stuff that you learned in the class perhaps?

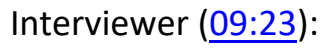

Yeah. Yeah. Cool. Do you have any, um, questions or any more comments About the course that you mean?

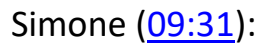

Sure. Um, I guess just overall, like I think the lab is like really beneficial. Um, one thing I would say, I think it's not really anything they can do about it. Um, like we kind of do stuff in lab before we learn it in lecture. And like I kinda said, I like to learn it first and then have that practical application of it. So like they might do this little mini lecture and then even like the last one, they did the little mini lecture. Um, and then we did the labs and whatever and it was good. And I had like basic understanding of it, but then we took a lab quiz and then literally the next week we learned about it in lecture. So it was like good, but like I kind of wish I had that before I took the lab quiz and like before I did the labs, so I knew more of like what I was actually doing.

Simone (10:20):

Like I wish it lined up with the lecture a little better.

Interviewer (10:22):

So, um, so you're saying it's like a week off, it's not just like you have lab on Monday but then lecture on Tuesday. 
Simone (10:30):

Yeah, no, it's like, it's kind of, there's, there's a big gap. It wasn't so much at the beginning of the year, but then there was a bigger, which also is just, cause you only have lab once a week and there's more lecture and then there's, you know, but it's just like, it's just kind of, because you learn things late. Like you might learn the basics in lab and then learn it more in depth than lecture, or even the opposite. Like you learned something really in depth in lab and like you test it and then she just briefly goes over it in the lecture. So it's just doesn't seem like it lines up very well.

Interviewer (11:05):

Cool. Alright. Anything else?

New Speaker (11:08):

No, that's all. Okay. All right. Well thank you. Um, let me turn this off. Okay.

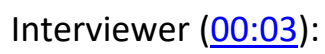

Okay. So first I just want to thank you for being willing to do this. Um, you are helping Eric get his master's degree, which is awesome. Um, but you're also really, um, helping us to figure out like what might improve anatomy and physiology education, so it's really informative as well, so, okay. You're really helping. Um, I have a whole bunch of questions to ask you, but I just want to remind you, it's not a test. There are no right or wrong answers. We really just want your honest, like, you know, opinions and thoughts on the course and your learning and how the course supports your learning.

Sandra (무:38):

Okay.

Interviewer (ㅁ00:40): 
Um, so do you have any questions for me before we get started?

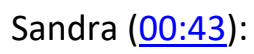

I don't think so. No. Okay. Yeah. Okay.

Interviewer (ㅁ00:46):

So generally speaking, how is the course going for you?

Sandra (무:49):

Um, it's going OK. It's, um, I've learning a lot.

Sandra (00:55):

It's very, it's very, um, I would say a little too fast paced, but it's, it's a lot... It's a lot of good information for, I'm a nursing major, so it's a lot of a base for our critical thinking. So it's going okay. And my grades are fine and everything, but yeah.

Interviewer (01:12):

So you're a nursing major, what year are you?

Sandra (ㅁ1:14):

A sophomore.

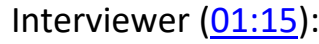

Okay. Um, all right. So what about the lab portion, specifically lab.

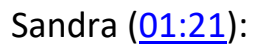


Oh, that's going well. Um, it especially helps with the visuals, the hands on the dissecting and stuff. It's going really well. We just did a, I think a cow eye. It's just, it's really good because we get to see the visual of what we're discussing in lab, which is really helps. It really helped with the bones too, especially. Cool. Yeah.

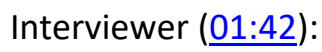

Why did it help with the bones?

Sandra (ㅁ1:45):

Especially it helps because, um, sometimes when you're, you know, if you look at something that's, that's posterior, you know, if it's on the back, you're looking at it from an anterior view, it's flipped. So it looks different, like the scapula was kinda hard and seeing things different from the interior view, like the core, you know, process, coracoid process and stuff. So you get to turn it yourself, you get to see the different stuff and it just, you're able to connect all the different, um, views. So you look at it and then you rotate it and it just makes sense. And so for bones, that was especially helpful because otherwise you're just looking at like a flat diagram. Yeah, yeah. And you can see it and it really helps because you can see the different, the fossas and different things within the bones that you know, is just kind of shaded differently on a piece of paper.

Sandra (02:32):

So it, yeah, it really helps.

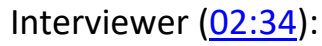


Cool. Yeah. Um, okay, so how do you feel about your understanding of the content? Like, um, we've kind of talked about aspects of the course already that help, but what about your understanding? Like how do you feel about that? Is it strong?

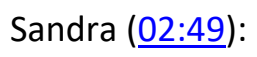

Um, yeah, I am a type of learner that, um, I cannot memorize well... So I can memorize, but I learned best by just deeply understanding what I'm learning about and being able to apply it to different things. So what was really hard for me was memorizing all the muscles because the way the courses ran, our lab doesn't really match up with our class unfortunately. And I think it's just cause it's a once a week type of thing, so it's, it's kinda hard to match up.

Sandra (03:19):

But the understanding for me, I would, I would say it's like a 70\%... because my teacher's really smart, but we move at a pace where... In all my classes it's been like this, you know, you're going at a pace and it's good to go at a good pace and a quick pace to be studying outside of class and be reading your notes... But there becomes a pace where it becomes so fast that you are memorizing and you were just shallow learning.

Sandra (03:48):

So I can remember what an oligodendrocyte is or you know, whatever for the test. But then two weeks later I forget it. And that's where I've gotten frustrated with the class is because it's moving at such a pace that we're not really true learning it. Um, for example, we just had a test over the nervous system, but we did not cover the spinal cord in class. We taught that to our own self on the spinal cord. You know, this class is the base of critical thinking for nursing. So it's really important that we cover all 
aspects or if we are to read outside of class, you give us a time where our brain has time to not only read it and comprehend it, but to absorb it.

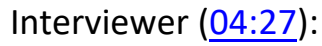

Yeah. So, okay. So, um, are there certain areas of your anatomy and physiology knowledge that are stronger than others?

Sandra (수:39):

Um, yeah, I would say my, I would say physiology. I'm definitely more apt to understand. I usually I like to learn the physiology first just focus on the physiology and then you could go like quickly go back to the anatomy and it just all comes together. Um, but yeah, I would say the functions and how they all overlap and all work together.

Sandra (05:07):

Um, and then the anatomy... If you understand the physiology... the anatomy just kind of makes sense because it just, yeah. So.

Interviewer $\underline{\underline{05: 15}})$ :

Why do you think that is?

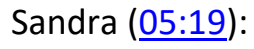

For me? Or just like for the class?

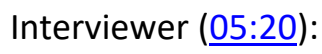

Like why is it that when you understand the functioning of everything, learning the parts, learning the form just kind of comes naturally? 
Sandra (05:29):

I think. Cause you, you know how it works. So you know what's needed. You know, it's like you're making a cookie recipe, you know, you've eaten cookies enough to know, okay, you need sugar, you need butter. So when you go to make it and you see, you know, they have a sticker, Prairie farms, but you're like, okay, that makes sense that's what goes in it. And I think it's the same for, for any type of system really. You know, you know, you need homeostasis regulation with different things. So, you know, okay, these chemicals make sense that are in this because even my basic chemistry knowledge has helped knowing different things. Like they are looking at electronegativity of different atoms. And stuff really helps me, especially with chemicals or like that.

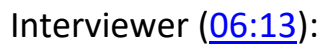

So. Okay. So, um, you've kind of already touched on this. How do you feel about the content, the amount of content in the course?

Sandra (06:21):

I really like the amount of detail because I think that is so important. Um, the level of detail and of course I think I, yeah, I think it's good. It's a college class. It's something you should be studying outside of, you know, you should be reading through your notes and um, yeah, I think, I think it's perfect. I think the level of detail I think is good.

Interviewer (여:44):

So what is the relationship then between the amount of content and how you study?

Sandra (06:52):

Mmm. You mean like the more, the more I study you mean? 
Interviewer (우:57):

Or like how you study? Like what do you actually do when you study?

Sandra (06:59):

So I am a total visual person, so I will actually... I'm a terrible drawer. I will draw out like let's say for my nutrition class, I just recently did this cause... somebody can say something to me and I receive it but I'm like a five year old, I have to see it.

Sandra (무:23):

Um, but I will draw the steps of glycolysis. I have, um, like color coordinated for different things like acetyl coA is orange. And so I have where I can see, um, how things different, how different things come together. Um, the different pyruvates. Um, yeah, I draw things out. And then my teacher, she does a really good job of also providing visual aids that you can print off.

Sandra (07:48):

So I'll print off those and then label everything, color, coordinate everything. Um, and then I'll just talk to myself and talk through it. And I don't know... that works wonders. That's usually what I do and I'll read through my notes. But actually I'Il visualize sometimes when I'm on a test, I will actually remember where it was on the page. So I can remember the top left. It was on my top left slide.

Interviewer (요:12):

Yeah. So, yeah. Cool. All right. So in courses where you don't have as much information to learn, like do you have, do you approach things differently? Do you still stick with this visualization? Like creating visuals or...

Sandra (08:24): 
Like if it's like an easier class you mean?

Interviewer (요:30):

Yeah. Or just less information. Less detail.

Sandra (08:34):

Less detail. Yeah. Also draw out a visual sometimes. I'll usually if it's not... I'm a big fan of history. I never do visuals for history cause well I'm interested in it.

New Speaker (묘:49):

Actually I'll do it in classes if it's less information, if it's not something I'm interested in. Like for example, I'm in a statistics class and I don't like it, but I will tie in if he's mentioned something political, say, well this is used in this type of polling. I'll pay attention and just remind myself, this is the type of polling I like to read. And, um, it's important to kind of connect things to like real life scenarios or examples that already have meaning to you or somebody, you know. Like I've heard of a Gallup poll and then I'll be like, this is the type that's used for, you know, different, something something.

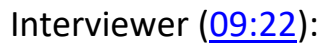

Yeah. So cool. Okay. Um, so generally what do you think, what is your strategy for learning the content in this course? You've already talked about how you create visuals. Is there more?

Sandra (09:33):

Um talking to myself. I'm in the the honors program, so we have to do like an honors project. So during class I will... my project is that I have to create an essay of 50 questions and it's her honors project. Her honors project is really good because they actually like correlate with the class and they actually help you, you know, it's not like a waste of time or something you have to do. Um, so I create an exam of 50 
questions. And so when she's lecturing, a skill I've tried to really get good at is what's the important information that she's talking about here.

Sandra (10:12):

So then out of those four sides, I'll pull a question out. You know, it'd be like, what is this, you know, or this is what a patient has, what might be wrong. And then something like that.

Interviewer (10:23):

So. Cool. So are there other ways, it sounds like your honors project is really facilitating that. Are there other ways that this strategy can be facilitated by the course?

Sandra (10:39):

I would say I think I'm a better pairing of the lab with the class would be good and maybe not being once a week for one hour and 50, maybe have two labs a week. ause I logistically like labs usually shouldn't be short, but for what we do in that class, it really could be two days a week for 50 minutes. Just so it better correlates with the lecture.

Sandra (11:07):

Yeah. Because we're doing the eye right now and we haven't even gotten to that. And so it's just like, I would love to remember that for my exam. I would love for them to, they should be working together. My microbiology that works together well, but the anatomy, I think if that class was built so that the lab and the lecture are literally holding hand in hand because are they like a week apart now or honestly taught two weeks apart usually. So like when we, we covered, we had to memorize what was hard for me was memorizing muscles when I didn't know what they were used for. And that was really hard for 
me because once I learned, you know, the quadriceps femoris is like extensions and functions and stuff like that, I was like, Oh, okay. There was no connection...

Interviewer (12:03):

No way to reason through what it looks like. Yeah.

Sandra (12:05):

Yeah. And yeah, and just the names and stuff. Like I said, I'm like a third grader when it comes to studying cause I, I have to have visuals but, yeah. Just I think if the class was structured that they were paired together, that that would really help.

Interviewer (12:19):

So it sounds to me like, um, well it's interesting... Because in a lot of ways learning is concrete first and then it becomes abstract. So sometimes we might think that like that hands on experience with something would really support the more abstract learning about the theory and everything. But what I hear from you is that understanding the functions is what enables you to really identify the, the structure and the hands on setting. Would you say that's true?

Sandra (12:56):

Yeah. Because if we have a lab where we're just kind of thrown in and you're expected to find things, okay, so I'm going to be able to find him for the activity, fine. But the second I walk out of that classroom, I forget it. And it's, it's that, that's the one sheet. And I think that's so important for nurses not to remember everything, but to just have a deep understanding of what you're looking at and not just trying to pass an exam instead of it just being an A. So like, yeah, I have an A in the class right now, 
but the important thing is that you, that we remember a lot of this stuff for the long term and right now the class is just kind of structured to where it's go, go, go.

Sandra (13:44):

So the amount of detail is fine, but the pace we're going at and the fact that we're going at such a fast pace that you're skipping over the spinal cord for the nervous system. So I went through and did my notes on my own, but I'm not going to be able to tell you two months from now, not the exact way... You know, but you should have a good general idea, you should know that they (nerves) cross the spine, you know? And that's really important. So I think there's a big lack in that part of the classroom.

Interviewer (14:13):

All right. So, um, so you've kind of touched on this, but I'll just make sure that I got all your thoughts. So do you feel like the course is organized in a way that develops your understanding of material?

Sandra (14:32):

Uh, yeah. Overall, yes. The structure of it is fine. Um, well, no, the organization is okay, but the structure of it isn't, if that makes sense. So the organization she has, you know, our teacher has it planned where, Mmm. How do I say this? Um, we only had half the material on Thursday. Basically, by the time we got to Thursday, Thursday night, it was supposed to be the night that our homework was due.

Sandra (15:38):

That homework takes like two and a half hours to do, which totally fine. But we, that we have less than a period of 24 hours to do a two and a half hour homework because we didn't get the rest of the material. First of all, we have lives, but I'm like, that sounds, you know, a catty. But you know I have, um, circus practice and so I had other things going on that were legitimate. I wasn't trying to skip, you know, and 
um, and it was just frustrating because that homework is such a good tool. It really makes you think, but when you're in put in a position where you have a time crunch, you have 24 hours to turn it in. So then she made the due date on Friday. But the thing was, you're skimming through. You're not having time to actually go through it.

Sandra (16:21):

And you know, my friends and I, we can get through it, but you're not getting out of it what you could, what you could. And also what we paid for, we paid $\$ 100$ for, you know... I think the organization of that isn't good, I think it should be due on the day of the exam because, you know, if kids aren't going to do it, they're not going to do it.

Interviewer (16:44):

Yeah. So, so what about the organization as far as like how units are put together? Like it sounds like units are kind of by system. Um, does that organization work for you or is there another organization that would better support your learning?

Sandra (17:03):

Yeah, no, I, I think, um, the classes ran very... I think it's really good with the systems because they all, they all connect and it's hard to choose. You know, you're going to go from different system to system. But it's really built in a way where we went from bones to muscles and you know, the muscles attached to the bone; so I think that part's really good cause that just helps connect everything. And the class started out with the basic connective tissues of the blood and stuff. You see that throughout and that's really helped I think.

Interviewer (17:38): 
Cool. Um, all right. So do you feel like you remember the material from previous units?

Sandra (17:56):

Yes and no. I mean. Not really. I mean I have also had a previous anatomy class that I really enjoyed in high school and um, so my bones from that are really good. I still remember a lot of that stuff. Um, so I would say that would affect my answer to that because, Mmm. Yeah. So it's like, it's hard to kind of decipher what you remember from previous units of this course versus what you remember from elsewhere.

Interviewer (18:27):

Yeah.

Sandra (18:27):

And just in the fact that in the small amount of time we had to memorize the muscles, it's fine that we have to memorize them cause I believe, I believe memorization to an extent is important, but to have it in such a short period of time to memorize, I, yeah, I couldn't tell you. I would, if I took that test again, I wouldn't get an A. I wouldn't be able to tell you.

Interviewer (18:49):

So do you think that the units could build off of each other?

Sandra (18:53):

Yeah, I think so.

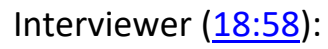

How so? 
Sandra (18:58):

I mean I think they kind of already are... Like you go from you go from bone to muscle.

Interviewer (19:05):

So like when you did that, you're learning of the muscles... How did that build off of you're learning with the bones?

Sandra (19:15):

Um, because the muscles attach at different spots on the bones. Um, so we were able to... we already knew the bones and so we were able to at that point apply, okay, this is by this bone, which would make sense because, okay. That pulls it, you know, that causes the action, you know, and yeah, I don't know. I don't really know how to...

Sandra (19:43):

Um, but even like the first thing, you know, we talked about the connective tissue. So we learned about the different adipose, the um, the blood, you learn fibers, connected tissue. So then by the time you got to, you know, the bone and the cartilage you were able to talk about okay this is the fibers tissue. We were talking about it since you've already seen the slides of what those look like, you're able to identify. Yeah, that's really, that's really important.

Sandra (20:08):

Cause the thing is they all connect and if you're, if you're in the medical field, you're going to be... Everything.... Like everything connects, you know? So yeah, that's real important and yeah.

Interviewer (20:24): 
Okay. So, um, these next few questions are about the bone and muscle unit specifically. Okay. So just generally, how'd you feel about that unit? The bone, the bone, the bone and muscles?

Sandra (20:35):

Um, I felt like I learned a lot about ossification and different stuff like that. The more the physiology aspects, the anatomy. Um, I learned a lot about, um, specific terms such as the trochanter.The parts that are lacking or the I would say just the general anatomy of this stuff.

Interviewer (21:11):

And when you say that it's lacking, do you mean your understanding of it is lacking or like the learning of the anatomy of the bones and muscles was not well supported in that unit?

Sandra (21:24):

The, I would say the time that we had to memorize the bones and muscles wasn't not long at all. Um, I don't know... I also had a parent who was in the hospital at the time, so that made it challenging. But actually I had more time to study, which is weird cause I'd be in the ICU. My dad was in the ICU, which was quiet. It was, you know, so, I actually had more time to study, but it was just, we had like a week or two week period.

Interviewer (22:05):

And can I memorize that for the test? Yes. I can absolutely memorize that for the test. And I'm not saying you should be able to recall every single one, but you know, people should know the quadriceps. We had a couple of kids in our class who forgot what the quadriceps femoris, and I was like, oh no. And I didn't do really great on the exam, I actually think I got a C and I never get C's. Which I don't care. And at that point I was like, Oh... Memorize what I can. Talking about understanding the words and the 
terminology was great but I think that forgetting the basic muscles even because we didn't spend enough time on it. It was created so that we would get an A on the test and, you know, that's fine. But when it comes to actually going into the medical field....

Interviewer (23:05):

So what do you think is most important for you as a future nurse to understand about bones and muscles?

Sandra (23:14):

I would say how bones and muscles interact, um, is really important. And yeah, I think the interaction. My dad just had, he had a stroke a month ago, so, um, I've actually been, I'm not an expert, but I've, I've been with a lot of nurses that I've just learned so much of how much they have to know about. Um, his right side got paralyzed. So, um, he's moving it now, but knowing what muscles are activated yet because of the different things he can't do, you know, he can do opposition and stuff with his fingers, but they're not the head doctor, whatever. They're the nurses and they're figuring out, um, even what nerves are fine, you know, are working for those areas. So I think just from experience of watching, I think it's really important to know how to interact and just to know the basic, the basic muscles. I think it is good that the level of what we have to learn for the class, I think to a point memorization is good. I mean, but yeah. Yeah.

Interviewer (24:24):

But it sounds like those nurses had done more than that realization, right? They're applying that knowledge.

Sandra (24:30): 
Yeah.

Interviewer (24:30):

And problem solving.

Sandra (24:30):

I hope to be like that. I really do.

Interviewer (24:32):

So. Cool. Um, so do you feel like the, this unit developed that understanding that you find most important?

Sandra (24:43):

I think there's still more. I think there could be more. I just want to say slowing down the pace of the class and I don't mean make it easy but make it absorbable, if that makes sense. There's a certain point at which you go so fast, you forget and that's just logistically that's not enough time. That's enough for you to pass the test, but it's not enough for you to remember.

Interviewer (25:32):

Yeah. Okay. So speaking to just the organization of the bones and muscles unit, do you feel like it was organized in a way that developed your understanding?

Sandra (25:42):

Yes, I would say yeah. I would say that the structure and the sequence of how it was done. Yeah. I would say the only thing is just making the lab, the lab and the lecture more in sync. But I think that's hard because another thing is how the whole lecture is set up. So where it's two days a week for an hour $15 . .$. 
I clock out at about 50 now. Am I there? Yeah. But your brain, you know, you're ready to go. So I know I'm really happy cause next semester it's three blocks of 50 minutes, which is the exact same time. But I think just spreading it out.

Sandra (26:25):

I think it's the same amount of time. It's just spatially more, you know, kids have to go to class three days a week. Yeah. It's the same amount of time.

Interviewer (26:35):

Right. Okay. So do you feel like you are able to effectively communicate this information about bones and muscles? Like, like if you were to have to have a conversation with one of those nurses, for example, Katie about this content?

Sandra (26:51):

I could pretty well, yeah. Obviously they were like way more knowledgeable but I understood what they were saying when they were telling me... You know, what was abduction with his arm, his deltoid and stuff; I was able to understand that, cause that made sense.

Sandra (27:18):

So I think if I was in their position, I think I could too. I always described myself as academically dumb. I'm not dumb, but just, I put a lot of effort into my academics and not to get the A, but so I can fully understand it. And it actually makes learning easier for me in the long run. So, yeah, I think so.

Interviewer (27:42):

Alrighty. So, um, what is, how would you describe the teaching style that you've experienced? 
Sandra (27:53):

I really like it. Um trying to think the teacher does a really good job of, um, if she's talking about something, she'll be talking about it and then she will go draw it. Granted she draws it with that like Google paint or whatever, its kinda sketchy.

Sandra (28:13):

But it totally, it totally helps with just, it's a really good balance of lecture and just showing this is what we're talking about. This is, you know, especially even something like the axon terminal, it's just nice to see the neurotransmitter, you know, it's nice to see that stuff.

Interviewer (28:31):

So you like how she's combining lecture with the drawn diagrams in real time?

Interviewer (28:38):

Yeah.

Sandra (28:38):

And it's not that often she draws them, but I don't draw out diagrams for everything, but if it's a process or something she's really pretty good at that.

Interviewer (료:50):

What about lab.

Sandra (28:57): 
Yeah, I think lab is sometimes confusing because we go through a presentation at the beginning of lab, but then though that material, we don't know if that's going to be on the exam or not because it's not in our lab book notes.

Sandra (29:15):

So I would say there's a lot of confusion there. And especially it's hard because it doesn't line up with the class now where we're learning the same things. Yes. But they're at two totally different times. So like we're covering the eye right now.

Interviewer (29:27):

What about like the teaching style that you're experiencing?

Sandra (30:14):

Um, one thing I would say we had to do this, the one for the bones where we had to draw out, um, we had to draw all the different, um, one of the different structures of the bones. Granted I'm not an artist, so it was so hard to just draw like I'm putting da Vinci shame. Like I shouldn't be drawing this, you know? But yeah. Um,

Interviewer (무:57):

Do you feel like the activity of drawing it pulls your attention to important features?

Sandra (31:09):

I think it definitely can. The group I was in, it was a great group. We were so stressed about it looking perfect, and just looking recognizable because I can't figure out all the curvature. I think if you have a picture just color coding the different sections. that to me, points out features. 
Sandra (31:56):

Yeah. So I think it just depends. So there are alternatives basically. Yeah. I think for most people, if they cannot draw, they're more stressed.

Interviewer (리:12):

So I already know the answer to this, but I'm just going to ask it anyway. So do you feel in anatomical and physiological knowledge is important?

Sandra (르:23):

Yes. Yup. This class to me is the base, the base of critical thinking and application in nursing to me.

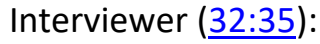

So explain more about the critical thinking part.

Sandra (32:43):

Yeah like my dad being in a hospital, it's made me realize how important critical thinking is. Um, for example, we haven't gotten to the blood system, but my dad deals with blood clots. I'm trying to think. Potassium, his potassium was low on his blood. Um, he got his blood taken a lot his potassium was low and his calcium always was low. Um, being able to recognize that.

Sandra (00:00):

Calcium is an important part in muscle and in well bone obviously, but in, in muscle production and different things like that and potassium... they knew right away, okay, here's what this affects.

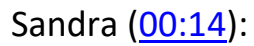


This is why this is important. You know, cause there's been times where you can have vitamin D deficiency. Right?

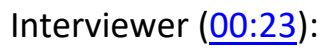

Right.

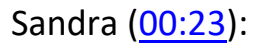

Yeah. You could have something where it's just your body's maintaining homeostasis. So it goes back and forth. Um, but you're able to apply that if maybe if they're, if their shoulders hurting. Um, actually, okay, this is weird. I work in the catering department. My manager just recently, I started getting her people to diagnose like, you want me to diagnose something?

Sandra (00:49):

Like I'm just a basic, like I haven't even touched clinicals get, you know, I don't know. So, my manager came up to me and she's like, my back really hurts and my leg. And I was like, okay, well what do you need? Like I thought she went in ice or something. I was like, I was like, ahhh... I thought she was like wanting me to do something for her. She's like, what's wrong? And I was like, okay. And so I asked you, you know where it hurt? And she's like, is it my kidney? And I said, well, no, even though I haven't the kidneys, I knew it wasn't in that region.

Sandra (01:33):

And I asked her, you know, is there anything else wrong? She's like, well, my foot's tingling. And I was like, okay.

Sandra (01:39): 
And so we've learned about the nerves and about where they're at, you know? And so it was so interesting because we had just covered like, um, lumbar, you know, nerves and, and different things like that. So I was able to tell her, I was like, I am not a doctor, I am not a nurse yet. But I was like, I think you had nerve damage and um, like a pinched nerve maybe in the vertebrae or something. And so sure enough, she went to the doctor and that's what happened. Like, you know, it's just like something like that that was to me was the first time I've really.... it was so cool, well not cool but it was interesting cause it was just happened.

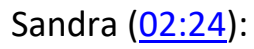

But yeah that's what nursing is all about. I mean you're, you're constantly... depending on what job you do, analyze and it's just applying what you know and apply what is so important for the body.

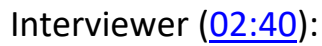

Yeah. So, so do you feel like this course has really developed that part of your understanding, that you need?

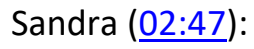

No, I would say that is no, I would say it's definitely given me the information, but the critical thinking.

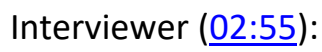

No?

Sandra (02:56):

I think the, I think that sometimes comes with self-discipline for me that came out of, as a kid not being able to memorize. So I found it once. But you know, for a lot of people it's it's easier to memorize and just forget about it. I want to say that I wasn't smart enough to do that, to just memorize. So I was kind 
of forced to go the other way of not, not understanding every little bitty aspect of it, but understanding the general and then the details. To me, I found it easier to, to know more, to remember more and different things like that.

Interviewer $(\underline{03: 35})$ :

I think that even like the biggest thing I can think of that that's happened to me and that's like learning has been easier down the road was I took chemistry in high school and then I took AP chemistry. But in junior high we had to learn all the different elements on the periodic table and memorize them. I just thought that was the dumbest thing because that's not important. I mean, you should know what elements are, but that's not important. What's important is to know the periodic trends and to know, you know, general placement of where a lot of the common ones are at on the table. So that's what we did in my chemistry classes we went through and

\section{Sandra (04:19):}

Like okay, so this the protons, yes. Yeah. And so you weren't noble gases. This, they have stable, they have met their eight electron. They, their electron shells are full. So now you know, anytime you see those, they're not really going to want to interact. So you just, you, you build, you build on that. Um, so then AP chemistry, um, we talked more about electronegativity and different stuff. But anyways, I took the AP test, I got a high enough score that I didn't have to take the lecture, but I had to take the lab. I never prepped for the lab. Um, which it was just poor choice. Like I had applied my knowledge about, um, different cat-ions and an-ions and a lot of it was honestly just electronegativity cause that just tells you the reactivity of substance. So like I ended with like a 98 or something, but just being, and I was really happy because I had remembered that up to that point and

Sandra (05:26): 
You know, I did terrible on the memorization of every single one... Nobody uses unununium you know... but carbon is, you know... I think those are important to know. But just that's something where it's been easier for me down the road where...

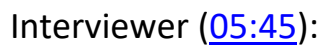

Yeah. So you're saying that like with the periodic table, memorization of all the elements didn't help you, but learning the patterns and trends allowed you to problem solved where you remembered it in here later.

Sandra (05:56):

Yeah. And when you use it, you use it so often, you know I could probably tell you where half of them were on the table, but it was because we used like the top five rows.

Sandra (06:12):

You became so accustomed to where they were at and now I, I mean, I can tell you where they're at now, I can still picture where, you know, the carbon and nitrogen.

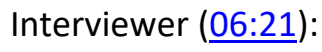

But you use the tool rather than... its like memorizing a ruler, like what's the point of that? I mean, what's the point of that is you get to know the rulers by using it over and over.

Sandra (06:31):

Yeah. And I'm not saying you know every single aspect of it but... That type of learning has had a pay off for me? Cause I like in math class, I hate math but I'm good at math. I don't like it, but I always hated learning equations until we applied them to, you know, okay, well then find this about this bridge or whatever, you know? And then we applied it to real. 
Sandra (06:58):

I really liked the application problems. That is... I Flourish on the application. I start to wilt when we learn stuff that's like, we are never going to use. But I also will when it's, yeah, it's just useless memorization. I think there's good memorization I think. Um, depending on what job you go in and if you, if you need to know the 20 amino acids, you know, you should know if the 20 amino acids, if you're a nutrition major. Yeah. I think that, I think that's real important. I don't think memorization is useless, but it's gotta be based in the fact that that's going to be used to harness and understand the concept thats there. Does that makes sense?

Interviewer (무:38):

It does, yeah. Cool. Well those are all my questions. Do you have any questions for me?

Sandra (07:46):

Are you like a teacher? 


\section{APPENDIX B: INTERVIEW PROTOCOLS}

Before we get started I would like to say thanks for being a participant, it does not go unappreciated. Also, it's very important that you know that this not a test; there are no right or wrong answers. I am simply interested in your experiences with anatomy and physiology, and our goal here today is to collectively assemble an understanding of those experiences, so that we can use them to inform A\&P learning. Specifically we'll be talking about things like the challenges of learning anatomy, the importance of anatomical knowledge, and your interactions with the course material up to this point. So again, before we get started, there are no right or wrong answers and what matters most are your thoughts and experiences. Do you have any questions before for me, before I have some for you?

1) Have you encountered any challenges or barriers to learning A\&P, and if so, can you expand on them?

\section{(follow-ups)}

1.1) What causes those challenges? What factors are at their root?

$$
\text { (follow-ups) }
$$

2) Why is anatomical \& physiological knowledge important?

(Follow up w/ personal importance vs. societal importance)

2.1) What is it specifically about anatomical \& physiological knowledge that you find important?

2.2) Why do you feel that way?

3) How well do you feel that you have understood the content thus far? 
3.1) Do you think that there is a reason as to why that is the case, and if so, please explain?

4) When you were trying to learn and understand the epithelial tissues, did you feel that:

\section{It was challenging or easy?}

Why did you feel that way?

\section{There were things that enabled your learning?}

Why did you feel that way?

\section{There was good or bad organization?}

Why did you feel that way?

\section{What did you take away from this material?}

Why was that your take-away?

Okay thanks once again for everything so far. We're heading into the final portion of this interview, which will involve some concept mapping of those epithelial tissues that we were just talking about. All of the tissues covered are here on a set of index cards, and what I would like you to do is arrange them in a way that represents your understanding of these tissues and their properties. Again it is important that you know that there are no right or wrong answers, additionally when explaining your map please try to be as thorough as possible.

5) So if you could please make a concept map of the epithelial tissues for me, this will be the last portion of the interview. (Concept Mapping)

5.1) Why did you arrange this concept map in the way that you did?

$$
\text { (Follow-ups) }
$$

6) Alright, the last question that I have for you is pertaining to this concept map. I would like you to compare and contrast this preset concept map with the one that you have just created. 
6.1) What differences do you notice, and what is the significance of those differences?

6.2) What similarities do you notice, and what is the significance of those similarities?

7) As we're wrapping this up is there anything that you would like to ask me?

Before we get started I would like to thank you once again for being a participant, it still does not go unappreciated. Also just to reiterate, this not a test, and there are no right or wrong answers. I am simply interested in your experiences with anatomy and physiology, and our goal here today is to collectively assemble an understanding of those experiences, so that we can use them to inform A\&P learning. Specifically we'll be talking about things like the challenges of learning anatomy, the importance of anatomical knowledge, and your interactions with the course material up to this point. So again, before we get started, there are no right or wrong answers and what matters most are your thoughts and experiences. Do you have any questions before for me, before I have some for you?

1) Since we've last spoke have you noticed any challenges or barriers to learning A\&P, and if so, can you expand on them?

(Follow-ups)

1.1) What causes those challenges? What factors are at their root?

$$
\text { (Follow-ups) }
$$

2) Why is anatomical \& physiological knowledge important?

(Follow up w/ personal importance vs. societal importance)

2.1) What is it specifically about anatomical \& physiological knowledge that you find important? 


\section{2) Why do you feel that way?}

3) How well do you feel that you have understood the content thus far, and why do you feel that way?

3.1) Are there certain areas of A\&P that are more understood than others, and why is that so?

4) When you were trying to learn and understand the musculoskeletal system, did you feel that:

\section{It was challenging or easy?}

Why did you feel that way?

\section{There were things that enabled your learning?}

Why did you feel that way?

\section{There was good or bad organization?}

Why did you feel that way?

\section{What did you take away from this material?}

Why was that your take-away?

Okay thanks once more for everything so far. We're heading into the final portion of this interview again, which will involve some concept mapping of the musculoskeletal system that we were just talking about. All the major bones and muscles for the upper and lower limbs or on this set of index cards, and what I would like you to do is arrange them in a way that represents your understanding of these tissues and their properties. Again it is important that you know that there are no right or wrong answers, additionally when explaining your map please try to be as thorough as possible.

5) So if you could please make a concept map of the appendicular musculoskeletal system for me, this will be the last portion of the interview. (Concept Mapping) 
5.1) Why did you arrange this concept map in the way that you did?

$$
\text { (Follow-ups) }
$$

6) Alright, the last question that I have for you is pertaining to this concept map. I would like you to compare and contrast this preset concept map with the one that you have just created.

6.1) What differences do you notice, and what is the significance of those differences?

6.2) What similarities do you notice, and what is the significance of those similarities?

7) As we're wrapping this up is there anything that you would like to ask me?

- Thank you

- Not a test, no right or wrong answers

- Interested in understanding your experiences in the course so that they can be used to inform A\&P education

- Any questions before we get started?

Can you tell me a bit about yourself, like major, future career plans...?

Generally speaking, how has the course been going for you?

How has the lab portion of the course been going?

How do you feel about your understanding of the content?

Why do you feel that way?

Do you understand some A\&P areas more than others, and why is that so?

Which areas are strongest, and why?

Which areas are weakest, and why?

How do you feel about the amount of content in this course?

What is the relationship between the amount of information \& how you study? 
What are some things that could support your learning the same amount of information, but more efficiently or effectively?

What is your strategy for learning the content in this course?

How could this be facilitated?

Do you feel that this course is organized in a way that develops your understanding of the material?

If yes... Why? If no... why not? What would you change?

Do you remember the material from previous units?

What would help you better remember the previous units?

Do you think that the units build off each other?

How could instruction help you to better build one unit off of previous units?

How did you feel about the unit on bones \& muscles?

What do you think is most important for you as a future (...) to understand about bones \& muscles?

Do you feel that this unit developed your understanding of what you find most important?

Do you feel that this unit was organized in a way that developed your understanding of the material?

If yes... Why? If no... why not? What would you change?

How do you feel about your ability to communicate this information?

Do you feel it is important to be able to communicate this information, why or why not?

How would you describe the (lab) teaching style that you've experienced in A\&P? 
Does this teaching style facilitate your learning? How so or why not?

What teaching style do you think would better support your learning?

\section{Is anatomical \& physiological knowledge important?}

Why do you feel that way?

Do you feel like A\&P knowledge will play into your career as a (...), why or why not?

Do you feel that this course was structured in a way that enabled you to develop an understanding of the important aspects of A\&P knowledge?

How could the course be better structured to help you develop this knowledge? 


\section{APPENDIX C: ACTIVITY SHEETS}

BSC 181 - Musculoskeletal System

Lab \#1 Group Activity Sheet

Identification:

- Sketch a diagram of the completed skeleton's upper limb

- Put together the disarticulated skeleton and compare (take pic if desired)

- In your lab manual identify and label the following for the upper arm, lower arm, and hand.

- Regional Name

- Bones

- Muscles

\section{Simon Says A\&P Style:}

- As a group, you must figure out what movement "Simon" is telling you to do. Once you have collectively reached a decision for all of the movements listed below please check your answers with your lab instructor. (ALL MOVEMENTS BEGIN AT ANATOMICAL POSITION)

Movement \#1:

Step 1) Contraction of the biceps brachii leading to full elbow flexion +

Step 2) Contraction of pronator muscles leading to forearm pronation +

Step 3) Contraction of the muscles of the rotator cuff and deltoids producing

$$
\text { internal and external rotation at the shoulder }
$$

Movement \#2:

Step 1) Contraction of the biceps brachii leading to half elbow flexion +

Step 2) Contraction of the pronator muscles causing half forearm pronation +

Step 3) Contraction of hand flexors leading to partial hand flexion/grasping

Movement \#3: 
Step 1) Contraction of the triceps brachii leading to full elbow extension +

Step 2) Contraction of the anterior deltoid muscles and pectoral muscles causing full shoulder flexion +

Step 3) Contraction of the hand extensors leading to full hand extension Movement \#4:

Step 1) Bi-lateral contraction of the posterior \& lateral deltoid muscles and latissimus dorsi +

Step 2) Bi-lateral contraction of pectoral and anterior deltoid muscles +

Step 3) Bi-lateral contraction of the hand flexors leading to full hand flexion Movement \#5:

Step 1) Bi-lateral contraction of the posterior deltoid muscles +

Step 2) Bi-lateral contraction of the hand flexors to full grasp/flexion +

Step 3) Bi-lateral contraction of the latissimus dorsi muscles

\section{$\underline{\text { Real-Life Scenarios: }}$}

- For the following questions you are to describe what is taking place within the musculoskeletal system during the movement listed. Consider the example below. You are encouraged to choose a movement on your own, however, there are ideas listed below as well.

Example:

What happens to the musculoskeletal system of the arms when you give a hug?

The latissimus dorsi muscles and posterior deltoids contract to pull the arms backwards, while the lateral deltoids contract to raise the arms. Additionally at this time, the triceps brachii are contracting to fully extend the arms. These muscluloskeletal movements create the 
"opening" phase of the hug. Contraction of the pectoral muscles, biceps brachii and anterior deltoids muscles elicit the "embracing" phase of the hug by causing horizontal adduction.

Questions:

- What happens to the musculoskeletal system of the arms when you...

- Throw a ball?

- Catch a ball?

- Pick up a baby?

- Brush your teeth?

BSC 181 - Musculoskeletal System

Lab \#2 Group Activity Sheet

Identification:

- Sketch a diagram of the completed skeleton's lower limb

- Put together the disarticulated skeleton and compare (take pic if desired)

- In your lab manual identify and label the following for the upper leg, lower leg, and foot.

- Regional Name

- Bones

- Muscles

Simon Says A\&P Style:

- As a group, you must figure out what movement "Simon" is telling you to do. Once you have collectively reached a decision for all of the movements listed below please check your answers with your lab instructor. (ALL MOVEMENTS BEGIN AT ANATOMICAL POSITION)

Movement \#1 (part 1):

Step 1) Contraction of the hamstrings leading to half knee flexion +

Step 2) Contraction of the hip flexors leading to half hip flexion +

Step 3) Contraction of the foot and calf muscles providing balance

Movement \# (part 2): 
Step 1) Contraction of the quadriceps full knee extension +

Step 2) Contraction of the glutes and hip extensors causing full hi extension +

Step 3) Contraction of the foot and calf muscles providing balance

Movement \#3:

Step 1) Contraction of the hip abductors +

Step 2) Stretching and relaxation of the hip adductors +

Step 3) Contraction of the foot and calf muscles providing balance

Movement \#4:

Step 1) Uni-lateral contraction of hip, knee, ankle flexors and extensors, and stabilizers causing one leg to be planted in the ground +

Step 2) Uni-lateral contraction of the opposite leg's knee flexors and hip extensors causing full knee flexion and hip extension +

Step 3) Contraction of the non-planted leg's knee extensors and hip flexors

\section{$\underline{\text { Real-Life Scenarios: }}$}

- For the following questions you are to describe what is taking place within the musculoskeletal system during the movement listed. Consider the example below. You are encouraged to choose a movement on your own, however, there are ideas listed below as well.

\section{Example:}

What happens to the musculoskeletal system of the legs when you jump?

From anatomical position, the hip and knee flexors contract leading to the

"loading" phase of the jump. This mimics the "down" phase of a squat. From this

point the hip, knee and ankle extensors synchronously contract leading the

"upward" phase of the jump.In this movement the primary hip flexors are the

iliopsoas, and the primary hip extensors are the gluteal muscles; while the primary 
knee flexors are the hamstrings and the primary knee extensors are the quadriceps.

Questions:

- What happens to the musculoskeletal system of the legs when you...

- Go for a walk/jog/run?

- Walk up the stairs?

- Put your shoes on?

BSC 181 - Musculoskeletal System Lab \#3 Group Activity Sheet

Identification:

- Sketch a diagram of the completed skeleton's head \& torso

- Put together the disarticulated skeleton and compare (take pic if desired)

- In your lab manual identify and label the following for the torso, head, and neck.

- Regional Name

- Bones

- Muscles

\section{Simon Says A\&P Style:}

- As a group, you must figure out what movement "Simon" is telling you to do. Once you have collectively reached a decision for all of the movements listed below please check your answers with your lab instructor. (ALL MOVEMENTS BEGIN AT ANATOMICAL POSITION)

Movement \#1:

Step 1) Bi-lateral contraction of the sternocleidomastoid muscle and scalene group causing neck flexion +

Step 2) Bi-lateral contraction of the splenius capitis and splenius cervicis causing neck extension

Step 3) Repeat steps $1 \& 2$ a few times

Movement \#2: 
Step 1) Uni-lateral contraction of the sternocleidomastoid and scalene group muscles causing neck rotation

Step 2) Uni-lateral contraction of the opposite sternocleidomastoid and scalene group muscles causing neck rotation

Step 3) Repeat steps $1 \& 2$ a few times

Movement \#3:

Step 1) From a seated position...

Step 2) Contraction of the iliopsoas and abdominal muscles leading to full hip

flexion

Step 3) Contraction of the erector spinae group and abdominal muscles

leading to full hip extension

Movement \#4:

Step 1) Contraction of the trapezius muscles leading to shoulder and scapula elevation

Step 2) Relaxation of the trapezius muscles leading to shoulder and scapula depression

Movement \#5:

Step 1) Contraction of the zygomaticus major and minor muscles $;$

\section{Real-Life Scenarios:}

- For the following questions you are to describe what is taking place within the musculoskeletal system during the movement listed. Consider the example below. You are encouraged to choose a movement on your own, however, there are ideas listed below as well. 
Example:

What happens to the musculoskeletal system of the torso, head, and neck when you swallow?

The digastric muscles, in concert with the mylohyoid and stylohyoid muscles, will contract forcing food towards the back of the oral cavity. The epiglottis will contract to 'cover' the trachea and stop food from entering the respiratory pathway. The thyrohyoid and sternothyroid muscles will then contract ushering food past the larynx and down the esophagus.

\section{Questions:}

- What happens to the musculoskeletal system of the torso, head, and neck when you...

- Look behind you?

- Chew your food?

- Make a surprised face?

- Touch your toes? 


\section{APPENDIX D: CODE BOOK}

\section{Code Book}

\section{- A Lot}

○ Description:

- A\&P students simply feel that there is a lot of content. There is a lot of breadth (systems) and a lot of depth (details).

○ Examples:

- 'I think it's just the amount that makes it hard, Not necessarily concept wise... It's just the amount of material that makes it hard." - Jenny

- "I think that's half the battle, is just being interested in it, because it is a lot of information." - Anna

\section{- Overwhelmed/Frustrated}

○ Description:

- Due to the intense amount of information and content, students feel overwhelmed and frustrated.

○ Examples:

- "It kind of was just overwhelming, like the amount of stuff that you need to memorize..." - Jenny

- "It was sort of frustrating to understand I thought, just like every single detail for every single tissue." - Catie

\section{- Memorization}

○ Description:

- Often as a byproduct of the amount of content and feeling overwhelmed by it, students feel the need to memorize everything. Moreover, some students feel memorization is their only option and the only way you can learn anatomy and physiology.

○ Examples:

- 'I feel like as of right now I've just been memorizing to try and get a good grade on the test, and if my teacher came in there and told me to apply all of this stuff, I would have no idea" - Catie

- "It's a lot of memorization." - Raquel

\section{- Time}

○ Description:

- Students wish they had more time to spend on/with the material. This also comes as a byproduct of the sheer amount of information in the course.

○ Examples:

- "I think we need an Anatomy 1, 2, \& 3, three courses, because if you're trying to fit all that into one... I heard it gets worse from here." - Andrea

- "It feels like a little rushed... just like the pace sometimes but that's hard to ask for." - Margo 


\section{- Career Goals}

○ Description:

- Every student interviewed, except one statistics major, readily and emphatically stated that they are taking the course because of their career goals and that is why the information is important to them. They feel that

- Examples: they must know A\&P for their careers.

- "Just me being in nursing... Like that's what kind of gets you through it. Like I have to know this. So you need to like sit down and study it." Sara

- "I'm planning on going to medical school, so I mean, I do find that it is important for that." - Juan

\section{- How}

○ Description:

- Students believe that it is most important to know how things work in the body, often because they aspire to enter healthcare, and as such, knowing how the body works is what is important.

○ Examples:

- "Well for me it's useful just because of my major in nursing. I have to know a lot of the stuff, how things work, where everything is, just how everything functions and stuff. So it's probably more important to me than any other, or like a lot of other courses." - Sara

- "So you know to be proficient and a good (health care) provider, I have to be able to understand how the body works." - Holly

\section{- Exclusion}

○ Description:

- As a result of being overwhelmed by the amount of content, students will sometimes choose to completely exclude content rather than spend time studying it. This can be seen as "content-gambling" there is simply so much information that it could never all show up on the test, so students will completely ignore certain topics and information in hopes that they won't be assessed on it.

○ Examples:

- "It was every single muscle from head to toe, like every single one. And I looked at it and was like, I'm not even going to study this because I know that $90 \%$ of this isn't going to be on the exam." - Jenny

- "I didn't feel motivated to learn every single muscle, which you know, for the last exam I felt very motivated to learn every single bone, every single bony landmark. I think it's just because in the back of my head it's like, I know we're not going to get tested on all this." - Jenny 


\section{- Misalignment}

○ Description:

- Students feel that what they view as important, and what teachers say is important, isn't represented clearly enough in class or on assessments, often leading to a significant lack of "takeaways" for students.

- Examples:

- 'I don't know, just sometimes I have a hard time seeing like, what's the point in knowing this? But I don't know up to this point." - Catie

- 'I'm mentally checked out and I'm glad the test is on Friday, that was my takeaway from it, like it's gonna end soon." - Anna

- 'Sometimes the quizzes don't necessarily match up with what everything is like" - Raquel

\section{- Resources Utilized}

○ Description:

- Students that strive to understand the content often seek outside of class learning resources, while students that strive to simply memorize the material often utilize in-class resources.

- Examples:

- "Obviously I think it's more important to understand things than just memorize them, but sometimes that's hard to do for me." - Catie

- "I like the lab manual how it's all just diagrams we have to label... just like a bunch of diagrams that I just look at over and over." Catie

- 'I watched a lot of Youtube videos... But I've looked up more stuff cause I like seeing rather than somebody telling me." - Sara

- "I have to know a lot of the stuff, how things work, where everything is, just how everything functions." - Sara

\section{- Repetition}

○ Description:

- Students, often the ones that seek to memorize as opposed to understand, feel that they simply need many repetitions of going through the material. Any prior experience also helps, repetition in high school was found to be very beneficial.

○ Examples:

- "Yeah, it just helps me like going through them over and over again to learn it." - Maddie

- "I remembered a lot from high school so it wasn't bad." - Catie 